A Research Needs Assessment

\title{
Energy Efficient Alternatives to Chlorofluorocarbons (CFCs)
}

Final Report

June 1993

Prepared for

U.S. Department of Energy Office of Energy Research Office of Program Analysis Washington, DC 20585

Under Contract No. DE-AC01-91ER30155-H1

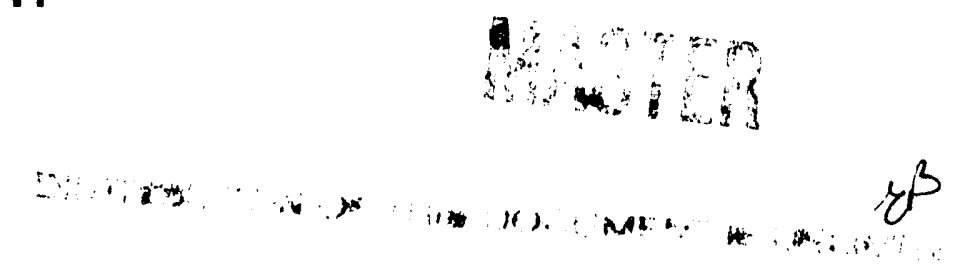




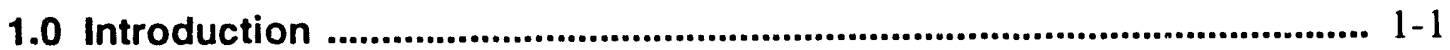

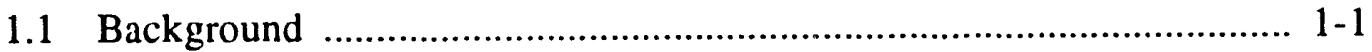

1.1.1 Impact of CFCs on the Envirc..ment ....................................... 1-1

1.1.2 Legislative Response ................................................................ 1-3

1.1.3 Effects of Legislation ....................................................... 1-4

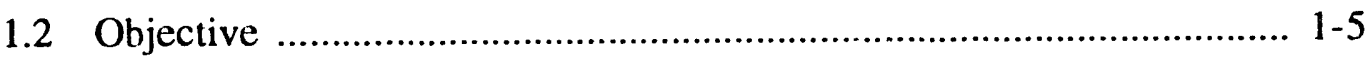

1.3 Approach ................................................................................. 1-6

1.3.1 Application Areas ............................................................ 1-6

1.3.2 Project Steps ........................................................................... 1-7

1.3.3 Data Sources ..................................................................... 1-8

1.4 Censultant Team .................................................................... 1-8

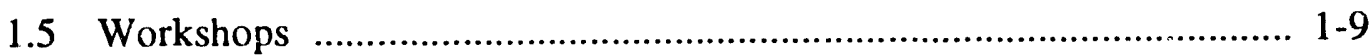

1.6 Report Organization .................................................................. 1-11

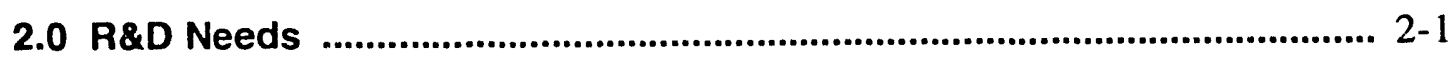

2.1 Suramary of Critical Research Areas .............................................. 2-1

2.2 Domestic Refrigeration ................................................................. 2-1

2.2.1 Critical Research Areas ......................................................... 2-1

2.2.2 Vapor Compression Cycles ...................................................... 2-4

2.2.3 Stirling Cycle Domestic Refrigeration ...................................... 2-7

2.2.4 Domestic Refrigeration Summary ......................................... 2-8

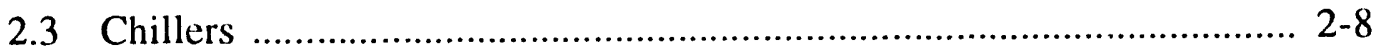

2.3.1 Critical Research Areas .......................................................... 2-8

2.3.2 Vapor Compression R\&D Needs ............................................ 2-10

2.3.3 Liquid Absorption Refrigeration Needs ..................................... 2-11

2.3.4 Solid Absorption ................................................................. 2-12

2.3.5 Stirling Cycle Research Needs ............................................... 2-12

2.3.6 Chiller System Summary ........................................................... 2-13

2.4 Commercial Refrigeration .............................................................. 2-13

2.4.1 Critical Research Areas ........................................................ 2-13

2.4.2 Commercial Refrigeration Summary ........................................ 2-13

2.5 Industrial Refrigeration ............................................................... 2-16

2.5.1 Critical Research Areas .......................................................... 2-16

2.5.2 Industrial Refrigeration Summary ............................................ 2-18

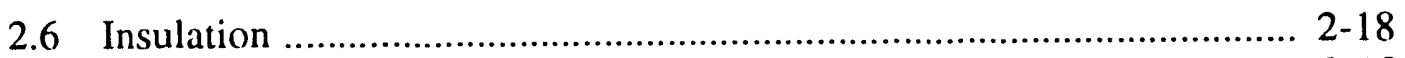

2.6.1 Critical Research Areas ....................................................... 2-18

2.6.2 Insulation Summary ................................................................. 2-23 
Table of Contents (Continued)

3.0 Long-Term R\&D Agenda .................................................................... 3-1

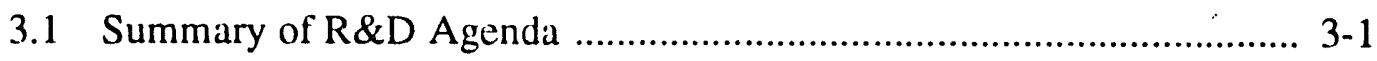

3.2 Long-Term Alternate Refrigerants ................................................... 3-3

3.3 Non-HCFC Non-Azeotropic Refrigerant Blends ................................. 3-5

3.4 Fractionation of Non-Azeotropic Refrigerant Mixtures ....................... 3-6

3.5 Flammable Fluids ......................................................................... 3-7

3.6 Efficient Low Temperature Secondary Heat Transport Loops ............. 3-8

3.7 Hydrocarbon Refrigerant/Low Temperature Secondary Loop Safety Study

3.8 Evaluation of Water Cooled Unitary Refrigerated and Frozen Displays Cases for Supermarket Refrigeration .................................... 3-10

3.9 Low Inventory Heat Exchangers ..................................................... 3-11

3.10 Improved Heat Exchangers ........................................................ 3-12

3.11 Thermal Storage Heat Exchangers …….............................................. 3-13

3.12 Alternate Concepts for Small Compressors ……............................... 3-14

3.13 Oil Free Compressor ........................................................................... 3-15

3.14 Low Expansion Materials for Compressors ........................................ 3-16

3.15 Ammonia Compatible Hermetic Compressor ……................................ 3-17

3.16 Stirling Cycle Model Enhancements ................................................. 3-18

3.17 Stirling Cycle Compact Heat Exchangers ............................................ 3-19

3.18 Stirling Cycle Regenerator Improvement ……….............................. 3-20

3.19 Stirling Cycle Drive System ........................................................ 3-21

3.20 Stiring Cycle Reliability .................................................................. 3-22

3.21 Advanced Absorption Systems ..................................................... 3-23

3.22 Adsorption Cycles .............................................................................. 3-25

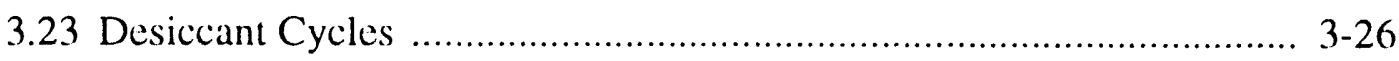

3.24 Recuperated Reverse Brayton Cycle for Industrial Blast Freezers ...... 3-27

3.25 Insulation Measurement Techniques and Equipment ........................ 3-28

3.26 Insulation Barricr Materials .......................................................... 3-29

3.27 Insulation Manufacturing \& Testing ……….................................. 3-30

3.28 Insulation Integration .................................................................... 3-31

3.29 Alternative Blowing Agents and Materials ...................................... 3-32

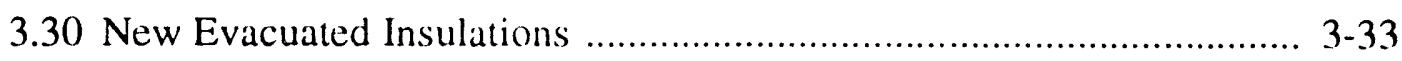

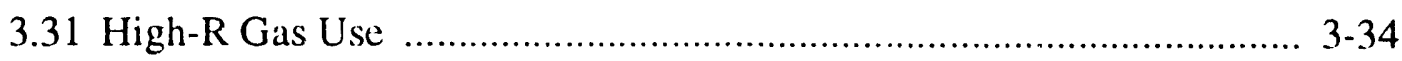

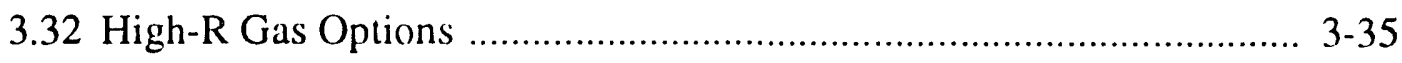

3.33 Alternative Aerogels .............................................................. 3-36 
Table of Contents (Co. rtinued)

Appendix A Overview of Technology Options ….................................. A-1

Appendix B Domestic Refrigeration ....................................................... B-1

Appendix C Chiller Systems ............................................................ C-1

Appendix D Commercial Refrigeration ................................................. D-1

Appendix E Industrial Refrigeration ................................................. E-1

Appendix F Insulation Applications …............................................... F-1

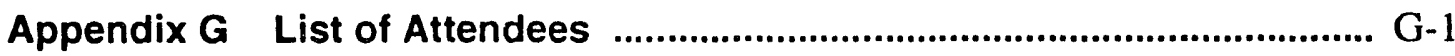




\section{List of Figures and Tables}

Figure 1-1 Accelerated CFC Phaseout ................................................... 1-5

Table 1-1 Relative ODP of Selected Fluids .............................................. 1-2

Table 1-2 GWPs of Selected Fluids ..................................................... 1-3

Table 1-3 Project Consultant Team ......................................................... 1-8

Table 1-4 First Workshop (June 1991) Attendees ..................................... 1-9

Table 1-5 Panel Presentations at Second Workshop (August 1991) .............. 1-10

Table 1-6 Second Workshop Panel Discussions ........................................ 1-10

Table 2-1 Summary of Critical Research Areas by Application ................... 2-2

Table 2-2 R\&D Summary Sheet: Domestic Refrigeration ......................... 2-9

Table 2-3 R\&D Summaryu Sheet: Chillers ............................................... 2-14

Table 2-4 R\&D Summary Sheet: Commercial Refrigeration ....................... 2-15

Table 2-5 R\&D Summary Sheet: Industrial Refrigeration ......................... 2-18

Table 2-6 Summary of Insulation Research Areas .................................... 2-25

Table 2-7 Summary Sheet of Research Areas ........................................ 2-26

Table 3-1 Summary of Recommended Long-Term R\&D Agenda ................. 3-2

Table 3-2 CFC Refrigerant Substitutes ................................................... 3-3 


\section{Acknowledgements}

This report was prepared under DOE Contract No. DE-AC01-91-ER 30155. We gratefully acknowledge the support and guidance of Mr. Larry James, the DOE project manager, and Mr. Terry Statt, of the DOE, who provided helpful technical suggestions during the course of the work.

The Arthur D. Little staff was supported by the following consultants: Kent Anderson, Dr. Wendall Biermann, Ronald Cole, Professor Roy Crawford, Dr. Richard Erth, Professor Leon Glicksmann, Dr. Ron Huffman, Professor Horst Kruse, Dr. David McElroy and Arthur Perez. Each of these experts contributed valuable insights relating to their technical fields, and played an important role during technical workshops. 


\begin{abstract}
An assessment of the state of the art in refrigeration and insulation technologies is carried out to evaluate the potential for efficient substitutes for CFCs and HCFCs to facilitate the transition to a CFC-free environment.

Opportunities for improved efficiency in domestic refrigeration, building chillers, commercial refrigeration and industrial refrigeration are evaluated. Needs for alternate refrigerants, improved components, and/or alternate cycles are identified. A summary of on-going research is presented in each area, and the potential roles of industry and government are considered.
\end{abstract}

The most promising approaches for refrigeration technology fall into these categories: 1) improved vapor compressor cycles with alternate fluids, 2) Stirling cycle development and 3 ) advances in absorption technology.

A summary of on-going research into advanced insulation, focused on vacuum - based insulation technology refrigeration is developed. Insulation applications considered include appliances, transport refrigeration, and buildings.

Specific recommendations for a long-te:m R\&D agenda are presented. The potential benefits, research, general approach, and probability of success are addressed. 


\subsection{Introduction}

\subsection{Background}

\subsubsection{Impact of CFCs on the Environment}

Chlorofluorocarbons (CFCs) have been developed and characterized since the 1890s.

They were produced from simple hydrocarbons by substituting halogen atoms. A practical method of synthesizing CFCs was introduced by Dr. F. Swarts at the University of Ghent, Belgium. However, until the end of the 1920s, CFCs were primarily of academic interest.

In 1928 CFCs were identified for use in refrigeration equipment by Thomas Midgeley. The first compound was hydrochlorofluorocarbon (HCFC)-21. Eventually CFC-12 was developed as the working fluid that most closely satisfied the requirements for an effective refrigerant.

CFCs were first produced commercially in 1931. Development followed which resulted in the commercial production of CFC-11, CFC-114, and CFC-113, and HCFC-22 by the end of the 1930s. With these working fluids, there was rapid growth in the sales of vapor compression refrigeration and air conditioning products.

During the 1950s, there was a large increase in the production of CFCs. In addition to being used as refrigeration working tluids, the advantages of CFCs made them attractive as aerosol propellants and foam blowing (expansion) agents for thermal insulation. These advantages included: non-flammability; non-toxicity; compatibility with refrigerator materials of construction; excellent thermodynamic properties for refrigeration; good stability; and, for foam-type insulation, low vapor thermal conductivity and low price.

There were practically no known disadvantages to CFCs until 1974, when Rowland and Molina published the ozone depletion theory. This theory hypothesized that CFCs would diffuse into the stratosphere because of their extremely long lifetime (20) to over 100 years). Once in the stratosphere, CFCs would be broken down by solar ultraviolet radiation photolysis and release chlorine atoms. These chlorine atoms would then catalytically destroy ozone in the stratosphere.

The ozone depletion potential (ODP) varies with various fluids depending on the compound's atmospheric lifetime and on the number of chlorine or bromine atoms in the molecule. Some fluids with shorter lifetimes (e.g., HCFC-22) break down in the lower atmosphere and are much less harmful to the stratospheric ozone layer. The actual ODP is based on a complex calculation. However, it is convenient to use a relative ozone potential for various fluids where the hasis of ODP $=1$ is assigned to CFC-11. The ODPs of various chemicals are provided in Table 1-1. 
Table 1-1: Relative ODP of Selected Fluids

\begin{tabular}{|l|c|}
\hline \multicolumn{1}{|c|}{ Compound } & ODP \\
\hline CFC-11 & 1.0 \\
\hline CFC-12 & $\sim 1.0$ \\
\hline CFC-113 & 1.07 \\
\hline CFC-114 & 0.8 \\
\hline CFC-115 & 0.5 \\
\hline HCFC-22 & 0.055 \\
\hline Halon 1211 & $\sim 4.0$ \\
\hline Halon 1301 & -16.0 \\
\hline Methyl Chloroform & 0.12 \\
\hline
\end{tabular}

(Because of the complexity of the chemistry involved, values assigned to the ODP are subject to change. However, the values given in the table are indicative of the range of actual depletion potential.)

While the ODP is characteristic of the most damaging near-term influence of selected compounds, the Global Warming Potential (GWP) is also cause for eliminating their use. Certain gases in the upper atmosphere pass solar radiation to the Earth, but they absorb radiation from the Earth, thereby preventing its escape. The result is that CFCs and other compounds cause an increase in the Earth's temperature because of the heat retention. These increases in the temperature of the surface of the Earth may cause undesirable changes in climatic conditions. Three factors determine a GWP for a particular gas:

- Its ability to absorb infrared radiation;

- Its atmospheric lifetime; and

- The time period over which the gas is compared with carbon dioxide $\left(\mathrm{CO}_{2}\right)$.

GWPs, by definition, represent the time-integrated commitment to global warming of the instantaneous release of $1 \mathrm{~kg}$ of a gas relative to $\mathrm{CO}_{2}$. Therefore, the timeframe chosen affects the relative contribution to GWP. For example, a shorter timeframe emphasizes the climate forcing potential of shorter lived gases and is useful for developing short-term delay-oriented policies. The longer timeframe is more representative of the cumulative effect of a gas on climate change over its entire lifetime. Therefore, it is more useful for developing long-term strategies and targets to limit global warming.

Table 1-2 shows the GWPs for various CFC substitutes of interest. The significant differences in GWPs for these CFC substitutes are primarily due to the widely varying lifetimes of the gases. For instance, both HCFC-152a and HCFC-123 have lifetimes under two years, while HFC-134a and HFC-125 have lifetimes of 16 years and 28 years, respectively.

It should be noted that though a gas may have a low GWP, the actual warming affect of any gas is the product of its GWP and the amount of gas emitted. Carbon dioxide, although it has the lowest GWP, has the highest emission level of any greenhouse gas (estimated at $26,000 \mathrm{Tg}$ in 1990). 
Table 1-2: GWPs of Selected Fluids

\begin{tabular}{|c|c|c|c|c|}
\hline \multirow{3}{*}{ Compound } & \multirow{3}{*}{$\begin{array}{c}\text { Estimated } \\
\text { Lifetime, years }\end{array}$} & \multicolumn{3}{|c|}{ Global Warming Potential } \\
\hline & & \multicolumn{3}{|c|}{ Integration Time Horizon, Year } \\
\hline & & 20 & 100 & 500 \\
\hline $\begin{array}{l}\text { Carbon Dioxide } \\
\text { Methane - includes indirect } \\
\text { Nitrous Oxide } \\
\text { CFC-11 } \\
\text { CFC-12 }\end{array}$ & $\begin{array}{r}10 \\
150 \\
60 \\
130\end{array}$ & $\begin{array}{r}1 \\
63 \\
270 \\
4500 \\
7100\end{array}$ & $\begin{array}{r}1 \\
21 \\
290 \\
3500 \\
7300\end{array}$ & $\begin{array}{r}1 \\
9 \\
190 \\
1500 \\
4500\end{array}$ \\
\hline $\begin{array}{l}\text { HCFC-22 } \\
\text { CFC-113 } \\
\text { CFC-114 } \\
\text { CFC-115 } \\
\text { HCFC-123 }\end{array}$ & $\begin{array}{r}15 \\
90 \\
200 \\
400 \\
1.6\end{array}$ & $\begin{array}{r}4100 \\
4500 \\
6000 \\
5500 \\
310\end{array}$ & $\begin{array}{r}1500 \\
4200 \\
6900 \\
6900 \\
85\end{array}$ & $\begin{array}{r}510 \\
2100 \\
5500 \\
7400 \\
29\end{array}$ \\
\hline $\begin{array}{l}\text { HCFC-124 } \\
\text { HFC-125 } \\
\text { HCFC-134a } \\
\text { HCFC-141b } \\
\text { HCFC-142b } \\
\text { HFC-143a } \\
\text { HFC-152a }\end{array}$ & $\begin{array}{r}6.6 \\
28 \\
16 \\
8 \\
19 \\
41 \\
1.7\end{array}$ & $\begin{array}{r}1500 \\
4700 \\
3200 \\
1500 \\
3700 \\
4500 \\
510 \\
\end{array}$ & $\begin{array}{r}430 \\
2500 \\
1200 \\
440 \\
1600 \\
2900 \\
140\end{array}$ & $\begin{array}{r}150 \\
860 \\
420 \\
150 \\
540 \\
1000 \\
47\end{array}$ \\
\hline
\end{tabular}

Indirect global warming will be far more important than direct GWP for refrigeration applications. The primary global warming gas is $\mathrm{CO}_{2}$, produced largely by the burning of fossil fuels. Therefore, the efficiency of refrigeration systems is crucial for the reduction of electricity used with its attendant generation of fossil fuel $\mathrm{CO}_{2}$ at the power plant. For the same efficiency, natural gas generates less $\mathrm{CO}_{2}$ per $\mathrm{kWh}$ than oil, which itself generates less than coal. For example, advanced direct-fired absorption systems, such as triple-effect systems, with about the same primary energy input basis coefficient of performance (COP) as vapor compression for chiller applications, would produce far less $\mathrm{CO}_{2}$ per unit of cooling by burning natural gas, an advantage for natural gas direct-fired absorption systems for chillers.

\subsubsection{Legislative Response}

In 1981 the United Nations Environmental Programme (UNEP) passed a resolution to establish a working group to draft a "Convention for the Protection of the Ozone Layer." This convention, called the Vienna Convention, was adopted by a diplomatic conference in Vienna, Austria, in 1986, and it was ratified by 20 countries.

Attempts to develop a CFC protocol to the Vienna Convention started in 1984. In 1986 and 1987, scientific reviews and economic workshops were held to resolve differences in approach to the CFC problem. The two sides were the European Economic Community and the "Toronto Group" (the U.S., Canada, and the Nordic countries). Additional negotiations were held in Brussels in June, 1987, to prepare an agreement on possible control measures. 
At a diplomatic conference in Montreal in September, 1987, a CFC protocol to the Vienna convention was formulated. The Montreal Protocol went into effect in January, 1589.

The Protocol referred to ozone-depleting CFC and halon substances. These chemicals are fully halogenated halocarbons and halons. The Protocol required that in July, 1989, a reduction in consumption of these substances to 1986 levels be instituted. In 1993 a 20 percent cut from 1986 consumption levels becomes effective. An additional cut in consumption to 50 percent of 1986 levels will be effective in July, 1998.

In June, 1990, a reassessment of the Montreal Protocol requirements resulted in an acceleration of the phase out of ozone-depleting compounds. A reduction to 50 percent of 1986 levels was advanced to 1995. A further reduction to 15 percent of 1986 levels will be required in 1997, with a total elimination required in 2000. The Montreal Protocol is being reassessed in 1992. Further acceleration of the phase-out of the ozone-depleting compounds is anticipated. Currently, the likely final phase out date is December 31, 1995.

The U.S. Clean Air Act (CAA) was signed into law in November, 1990. The section of this law entitled "Stratospheric Ozone Protection (Title VI)" contains comprehensive regulations for the production and use of CFCs, halons, methyl chloroform, carbon tetrachloride, and the HCFC and hydrofluorocarbon (HFC) substitutes. These regulations will be phased in over the next 40 years and will affect every industry that uses chlorine and bromine-containing substances that damage stratospheric ozone. Figure 1-1 shows the phase-out schedule of the revised Montreal Protocol and the CAA. As this figure shows, the CAA has accelerated the phase out in the U.S. compared to the revised Montreal Protocol.

\subsubsection{Effects of Legislation}

Initial analytical and experimental studies suggested significant economic and efficiency penalties associated with using substitute refrigerants. For example, substitution of HCFC-123 for CFC-11 in centrifugal chillers was initially considered likely to result in major reliability problems associated with a chemical attack by HCFC- 123 on electric motor windings. In this particular instance, it was believed that expensive motor replacements would be required or that open compressor systems would be required. It was also found that HCFC-123 was incompatible with nitrile rubbe: used in seals. However, recently several companies have introduced centrifugal chiller products compatible with HCFC-123, including hermetic compressor/motor components. Hence, for the near term, an acceptable substitute for CFC-11 may have been found for many centrifugal chiller applications. HFC-134a could be a long-term solution for CFC-12 in centrifugal chillers.

On the other hand, a number of materials-compatibility problems and/or toxicity questions still remain associated with the substitution of substitute of CFC-11 in foam blown insulation systems (HCFC-123 and HCFC-14lb). In addition, the 
Figure 1-1: Accelerated CFC Phaseout

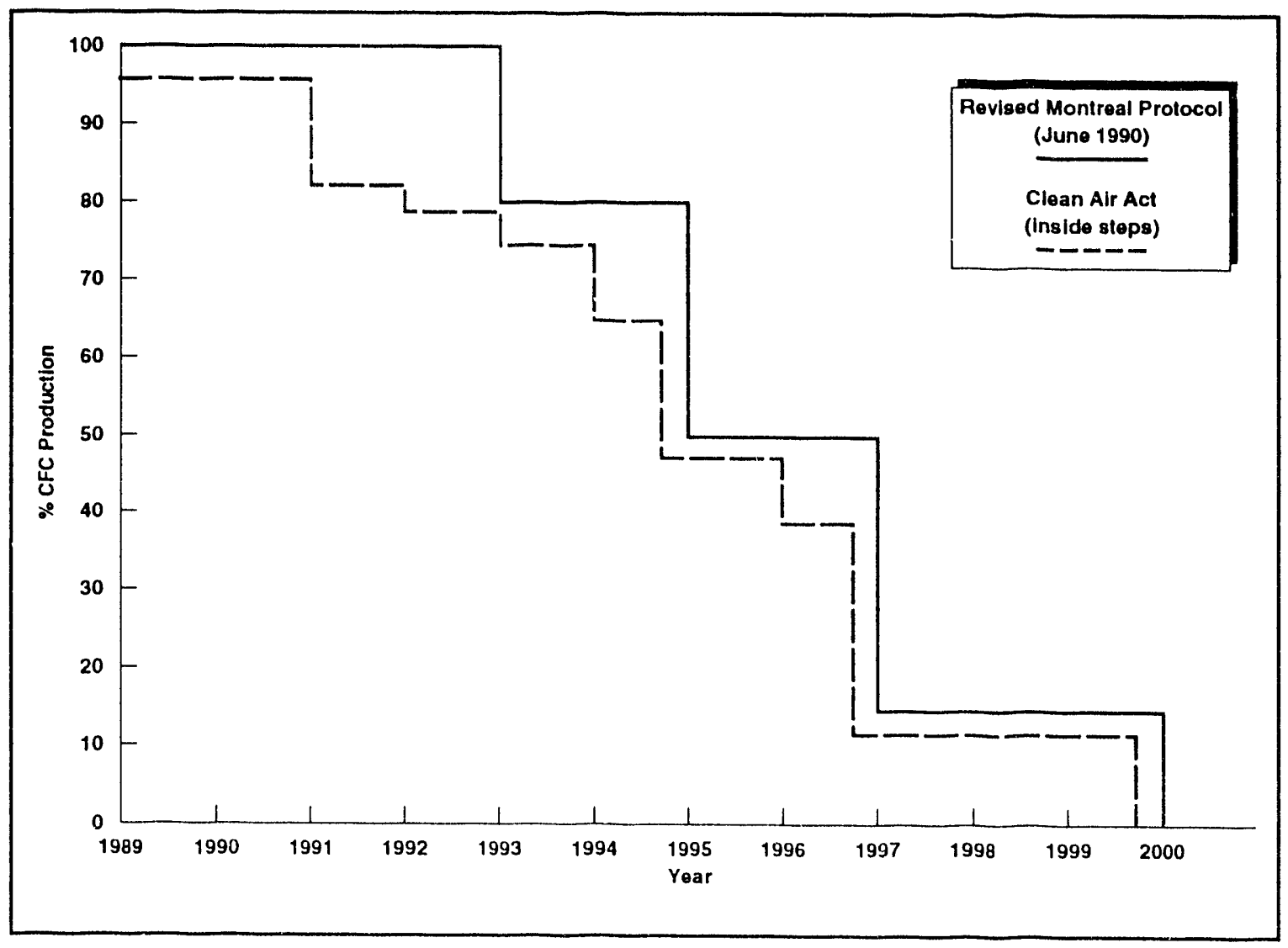

thermophysical properties of these HCFCs are inferior to those of CFC-11. Hence, an energy penalty may be inherent in these applications, leading to concerns over indirect GWP caused by additional fuel burning due to the energy penalty.

HCFC-123 and HCFC-22 have been considered as promising replacements for CFCs in other (low temperature) refrigeration applications. Recent legislation has been passed which provides for a phaseout of the use of all HCFCs (including HCFC-123), with a production freeze by the year 2()15, and a production ban by the year 2030. Hence, because of the non-zero ODP of HCFCs and a moderate GWP, they are no longer considered feasible long-term substitutes for CFCs.

In the case of insulation, HCFC-142b is being used as a substitute for CFC-12 in polystyrenes and is being offered commercially. Thus, in the near term, an acceptable substitute for CFC-12 exists for this type of closed cell plastic foam insulation.

\subsection{Objective}

This project was conducted to determine the longer term research and development needed to identify feasible substitutes for both CFCs and HCFCs. Such substitute 
technologies would enable a transition from the use of these chemicals to equipment and fluids that eliminate the contribution to ozone depletion with minimum adverse energy impacts and minimum economic disruption. The specitic objectives of the project were:

- Establish 5 to 20 year research goals to avoid the use of CFCs in stationary refrigeration equipment and the fabrication/installation of plastic foam insulations used in the appliance and building construction industries by replacing them with energy efficient chemical substitutes or alc:native refrigeration and insulating materials concepts.

- Identify a prioritized research and development agenda for obtaining these goals. The chemical and technology substitutes targeted by the R\&D agenda are limited to those options that could potentially be implemented 10 and 20 years after the initiation of the R\&D plan. The agenda excludes chemical and technology substitutes involving new applications of HCFCs.

\subsection{Approach}

\subsubsection{Application Areas}

The application focus of the work is divided into five categories: 1) domestic refrigeration, 2) chiller systems, 3 ) commercial refrigeration, 4) industrial refrigeration, and 5) insulation systems. Specific areas included in these categories are:

- Residential and light commercial refrigeration, including:

- domestic refrigerators and freezers,

- vending machines,

- residential dehumidifiers,

- drinking water fountains.

- Commercial space conditioning, including:

- chillers - reciprocating, screw, centrifugal,

- Navy chillers.

- Commercial refrigeration, including:

- refrigerated/frozen food display cases,

- upright refrigerators/freezers,

- chest freezers,

- warehouse systems,

- commercial ice machines.

- Industrial refrigeration, including:

- ice rinks,

- industrial ice machines,

- food and beverage processing,

- chemical process plants.

- Insulation technology applications, including: 
- appliances,

- foam for domestic refrigerators/freezers,

- foam for domestic water heaters,

- industrial storage tanks,

- pipelines,

- building roofs, walls, foundations, doors,

- refrigerated transport trailers,

- storage tanks.

Specifically excluded from the project were residential heat pumps and air conditioners, commercial heat pumps and air conditioners, and non-stationary equipment other than ship-board chillers and transport insulation. Automotive air conditioning was excluded. Many application areas currently use HCFCs while others will see increased near-term use of HCFCs as interim replacements for CFCs. Within the focus of the project, longer-term, non-HCFC solutions were investigated.

\subsubsection{Project Steps}

The following steps were carried out to accomplish the project objectives:

- Identify alternate refrigerants and insulation blowing agents for each application area;

- Evaluate the potential energy savings and environmental effects of the use of alternate refrigerants and insulations in each of the application areas;

- Identify alternative refrigeration technologies. These alternatives included modifications to the presently used vapor compression cycles, as well as alternate cycles;

- Evaluate the energy efficiency and competitiveness of the alternative refrigeration technologies;

- Identify alternative insulation technologies, including vacuum systems,

- Evaluate the promise in the application areas considered for insulation;

- Define research needs for each technology and each application area. Characterize the potential for significant energy efficiency improvements resulting from meeting these resesrch needs;

- Define a research agenda, with technology targets. 


\subsubsection{Data Sources}

Sources of data that were used for data collection included industry experts, research personnel, and literature. Ten representatives from industry and academia were retained as consultants on an expert team formed for the program. In addition, contacts with many refrigeration industry personnel provided necessary information and background.

Approximately 50 representatives from industry, academia, and government agencies attended a workshop held in Montreal, Canada, following an earlier planning workshop, held in Indianapolis, Indiana. These workshops were useful in providing a forum for an evaluation of technology needs by a broad cross-section of researchers and industry practitioners. One of the stated objectives of the workshops was to develop a list of R\&D goals and priorities.

An extensive literature search was also undertaken to ascertain the position and direction of each technology area. Past problems, developments, and research, and present on-going research were informative on the development of technology and on the future prospects for these technologies.

\subsection{Consultant Team}

A team of expert consultants was established for the program. The team is listed in Table 1-3.

Table 1-3: Program Consultant Team

\begin{tabular}{|l|l|}
\hline \multicolumn{1}{|c|}{ Consultant } & \multicolumn{1}{c|}{ Technical Area } \\
\hline \hline Kent Anderson & $\begin{array}{l}\text { Industry Research } \\
\text { Ammonia Research } \\
\text { R\&D Plan Development }\end{array}$ \\
\hline Wende!l Biermann & Absorption Technology \\
\hline Ronald Cole & Commercial/Industrial Refrigeration \\
\hline Roy Crawiord & Component and System Research \\
\hline Richard Erth & Chiller Technology \\
\hline Leon Glicksman & $\begin{array}{l}\text { Foam Insulation } \\
\text { Advanced Insulation }\end{array}$ \\
\hline Ron Huffman & Refrigerator/Freezers \\
\hline Horst Kruse & $\begin{array}{l}\text { R\&D in Europe } \\
\text { Refrigerants and Lubricants } \\
\text { Alternative Cycles }\end{array}$ \\
\hline Dave McElroy & Insulation Applications \\
\hline Arthur Perez & Commercial Refrigeration and Components \\
\hline
\end{tabular}

These consultants provided lists of industry/academic/government personnel, particularly those invited to workshops, and they were instrumental in identifying and characterizing and providing discussions of alternative refrigerant chemicals and technologies. The consultants participated in carrying out the workshop by leading 
small groups, participating in panel presentations, contributing to technological discussions, and providing valuable information on the status and direction of technological development.

\subsection{Workshops}

Two workshops were held during this program. The purposes of the workshops were to:

- Obtain information on current world-wide research,

- Determine critical technology needs,

- Review current positions presented by the project team, and

- Provide an opportunity to discuss R\&D needs.

The first workshop was a planning meeting held in Indianapolis in June, 1991, concurrent with the ASHRAE Summer Meeting. Attendees included the expert team, selected experts, and Arthur D. Little representatives (Table 1-4).

Table 1-4: Indianapolis Workshop (June 1991) Attendees

\begin{tabular}{|l|l|}
\hline \multicolumn{1}{|c|}{ Consultant } & \multicolumn{1}{|c|}{ Association } \\
\hline \hline Kent Anderson & Anderson Associates \\
\hline Wendell Biermann & Consultant \\
\hline Ray Bohman & Consultant \\
\hline Clark Bullard & University of Illinois \\
\hline Ronald Cole & R.A. Cole \& Associates \\
\hline Roy Crawford & University of Illinois \\
\hline John Dieckmann & Arthur D. Little \\
\hline Richard Erth & Consultant \\
\hline Ron Huffman & LDI Manufacturing \\
\hline Larry James & Department of Energy \\
\hline Horst Kruse & University of Hannover \\
\hline Arthur Perez & Consultant \\
\hline Bill Pirtle & Arthur D. Little \\
\hline Terry Statt & Departrnent of Energy \\
\hline Len Swatkowski & AHAM \\
\hline Peter Teagan & Arthur D. Little \\
\hline
\end{tabular}

Refrigeration technologies considered included domestic refrigeration/vapor compression, supermarket refrigeration, convenience store refrigeration, industrial refrigeration, industrial blast freezer refrigeration, absorption technology for commercial AC, desiccant-based commercial AC, Stirling cycle, orifice pulse tube, Vuilleumier cycle, Brayton cycle, magnetic cycle, thermoelectric refrigeration, and the vortex tube. Insulation technologies included foam systems, evacuated foam, evacuated 
powder/fiberglass panels, evacuated aerogel, aerogel, high $\mathrm{R}$ gas panels, and high vacuum insulation, with applications including domestic refrigeration/freezers, vending machines, water heaters, retail/commercial refrigeration, refrigeration transport, residential insulation, building foundations, commercial walls and foundations, and low slope roofs.

A second workshop was held in Montreal (August 12 and August 13, 1991), concurrent with the 18th International Congress of Refrigeration. There were approximately 50 attendees. (The attendance list is provided in Appendix G.)

The second workshop agenda included introductory remarks, a keynote address, panel presentations/discussion, small group discussions, and a final plenary session discussing the findings of the small groups. The keynote address, "How Should Long-Term Research Improve Today's Environment," was given by Dr. Lambert J.M. Kuijpers of Philips Research Laboratories, NJ. Panel presentations are listed in Table 1-5.

Table 1-5: Panel Presentations at Montreal Workshop (August 1991)

\begin{tabular}{|l|l|l|}
\hline \multicolumn{1}{|c|}{ Subject } & \multicolumn{1}{c|}{ Presenter } & \multicolumn{1}{c|}{ Affiliation } \\
\hline \hline Alternative Refrigerants & John Dieckmann & Arthur D. Little \\
\hline Absorption \& Desiccant Cycles & Wendell Biermann & Consultant \\
\hline Variations of Vapor Compression & Horst Kruse & University of Hannover \\
\hline Alternative Cycles & Horst Kruse & University of Hannover \\
\hline Chillers & Richard Erth & Consultant \\
\hline CommerciaVIndustrial Refrigeration & Ronald Cole & R.A. Cole \& Associates \\
\hline Alternative Blowing Agents & David McElroy & Consultant \\
\hline Alternative Insulation Technology & David McElroy & Consultant \\
\hline General Discussicn & Panel & -- \\
\hline
\end{tabular}

Small group discussions by application area are listed in Table 1-6.

Table 1-6: Second Workshop Panel Discussions

\begin{tabular}{|l|l|l|}
\hline \multicolumn{1}{|c|}{ Application Area } & \multicolumn{1}{|c|}{ Facilitator } & Arthur D. Little Assistant \\
\hline \hline Domestic Refrigeration & H. Kruse & R. Merriam \\
\hline CommerciaVIndustrial Refrigeration & R. Cole, A. Perez & J. Dieckmann \\
\hline Chillers & R. Erth, W. Biermann & B. Pirtle \\
\hline Insulation & D. McElroy & J. Aguilar \\
\hline
\end{tabular}

The afternoon of August 13 was organized into a plenary session to present the results of the small group discussions and a general discussion on a CFC alternatives research agenda. 
The results of these workshops are summarized in the following sections of this report, along with specific recommendations for long-term R\&D areas needed to achieve the desired transition into cost-effective, energy efficient, environmentally benign refrigeration and insulation technologies.

\subsection{Report Organization}

Development of a long-term R\&D agenda required consideration of the state-of-the-art of current technology in each of the five application areas and an assessment of the improvement potential for each of the technologies. Most of the technologies are utilized in more than one of the considered application areas. On the other hand, operating constraints and performance targets may differ by application area. As a consequence, the R\&D agenda considered both the attributes of a given technology and the way it can be applied to meet a refrigeration load or an insulation need.

The R\&D Needs are identified in Section 2. The Long-Term Agenda for meeting those needs is provided in Section 3. Detailed discussions supporting these sections are provided in the folowing appendixes:

\section{- Appendix A: Overview of Technology Options}

Each relevant technology is examined from the standpoint of its current use, on-going R\&D efforts, and the potential impacts of improvements in the technology. Four broad categories are considered: chemical substitutes for refrigeration cycles, alternative refrigeration technologies, chemical substitutes for insulation (foam blowing agents), and advanced insulation technology;

- Appendix B: Domestic Refrigeration This appendix provides a description of the application area and its needs. The intent is to provide a background to identification of $R \& D$ needs and for the prioritization presented in subsequent sections;

- Appendix C: Chiller Systems The special needs and requirements for chiller systems are discussed. Vapor compression and absorption chillers are included. Capacities are less than 10 tons to greater than 8000 tons.

- Appendix D: Commercial Refrigeration Supermarket and other commercial systems are complex due to their large scale, multiplicity of evaporators, and the need to continuously match the load. This appendix presents the background of the needs for commercial refrigeration.

- Appendix E: Industrial Refrigeration Institutional barriers to the use of "hazardous" working fluids such as ammonia are less in the case of industrial refrigeration. This appendix discusses the needs and requirements of industrial refrigeration.

- Appendix F: Insulation Applications The appendix discusses the insulation needs for the various insulation applications, as well as the approaches to non-ODP solutions. 


\subsection{R\&D Needs}

\subsection{Summary of Critical Research Areas}

This section provides a summary of the programs identified as candidate $R \& D$ areas. The criteria for selertion of $R \& D$ agenda areas were: 1) the technology has a reasonable chance for application in the long-term as either an improvement of current practice, or as a replacement; 2) the impact of successful $R \& D$ would be significant on improving the opportunities for efficient replacement of CFCs and HCFCs; 3 ) the research has a reasonable chance for success; and 4) an important role for government sponsored R\&D exists (that is, actions of the industry can be impacted by government R\&D). Table 2-1 summarizes the R\&D needs for energy efficient alternatives for CFCs for domestic refrigeration, chillers, commercial refrigeration, industrial refrigeration, and insulation.

\subsection{Domestic Refrigeration}

\subsubsection{Critical Research Areas}

Evaluation of the state-of-the-art of domestic refrigeration technologies leads to the following conclusions relative to the promise of future CFC-free, energy-efficient technologies:

- Vapor compression cycle-likely to be the dominant technology, based on the extensive experience with vapor compression cycle technologies and the significant opportunities for further development;

- Stirling cycle - the dominant likely alternative to vapor compression, based on the ability to use alternative chemicals, the ability to use electric drives, and the theoretical performance potential;

- Thermoacoustic - unlikely to be a feasible candidate to replace vapor compression;

- Liquid absorption systems - currently a negligible portion of the market unlikely to capture a significantly broader fraction of the domestic market than present, partly due to need for gas hookup and perceived safety issues. It is noted that the issue of residential gas hookups is the subject of significant research activity by the Gas Research Institute; and

- Solid absorption system - unlikely to significantly impact the market, due to the same constraints as for liquid absorption systems and the relatively low COPs indicated by analysis.

The assessment of critical research areas for domestic refrigeration will focus on vapor compression cycles and on the Stirling cycle. 
Table 2-1: Summary of Critical Research Areas by Application

\begin{tabular}{|c|c|}
\hline Application & Research Area(s) \\
\hline \multicolumn{2}{|l|}{ Domestic Refrigeration } \\
\hline - Vapor Compression Cycle & $\begin{array}{l}\text { - Alternate fluids to replace CFCs and HCFCs (flammability, } \\
\text { efficiency, lubrication) } \\
\text { - Improved small compressor (compatibility with ammonia, } \\
\text { lubrication, high-efficiency) } \\
\text { - Heat Exchangers (thermal storage to reduce cycle iosses } \\
\text { and optimization for new refrigerants) }\end{array}$ \\
\hline - Stirling cycle using electrical drive & $\begin{array}{l}\text { - Design (basic understanding of heat transfer and fluid flow) } \\
\text { - Heat exchangers and regenerator (minimization of } \\
\text { ineffectiveness in complicated flow regime, secondary loop } \\
\text { heat transfer losses) } \\
\text { - Drive system (efficiency and long-term reliability) }\end{array}$ \\
\hline \multicolumn{2}{|l|}{ Chiller Systems } \\
\hline - Vapor Compression Cycle & $\begin{array}{l}\text { - Alternate fluids to replace CFCs and HCFCs (flammability, } \\
\text { efficiency, lubrication) } \\
\text { - Improved small compressor (compatibility with ammonia, } \\
\text { lubrication, high-efficiency) } \\
\text { - Heat Exchangers (thermal storage to reduce cycle losses } \\
\text { and optimization for new refrigerants) } \\
\text { - Utilization of Narms - minimization of composition shifts due } \\
\text { to preferential boiling of one of the constituents and/or due to } \\
\text { leaks, refrigerant pair identification, system design, heat } \\
\text { exchanger performance, compressor performance, and } \\
\text { suitable lubricants, servicing techniques; } \\
\text { - Heat exchanger design-low inventory (e.g., spray-type) } \\
\text { evaporator to reduce refrigerant charge }\end{array}$ \\
\hline - Stirling cycle using electrical drive & $\begin{array}{l}\text { - Design (basic understanding of heat transfer and fluid flow) } \\
\text { - Heat exchangers and regenerator (minimization of } \\
\text { ineffectiveness in complicated flow regime, secondary loop } \\
\text { heat transfer losses) } \\
\text { - Drive system (efficiency and long-term reliability) }\end{array}$ \\
\hline - Advanced Absorption Cycle & $\begin{array}{l}\text { - Absorbent/refrigerant pairs for high temperature application } \\
\text { - Corrosion control and materials compatibility at high } \\
\text { temperatures }\end{array}$ \\
\hline \multicolumn{2}{|l|}{ Commercial Refrigeration } \\
\hline - Vapor Compression Cycle & $\begin{array}{l}\text { - Alternate fluids to replace CFCs and HCFCs (flammability, } \\
\text { efficiency, lubrication) } \\
\text { - Improved small compressor (compatibility with ammonia, } \\
\text { lubrication, high-efficiency) } \\
\text { - Heat Exchangers (thermal storage to reduce cycle losses } \\
\text { and optimization for new refrigerants) } \\
\text { - Secondary heat transfer loops - can be used to reduce the } \\
\text { inventory of an expensive refrigerant and/or to allow systems } \\
\text { using a hazardous working fluid (e.g., ammonia or a } \\
\text { flammable refrigerant) to be located remotely from areas } \\
\text { occupied by the general public, need improved heat transfer, } \\
\text { reduced parasitic power }\end{array}$ \\
\hline
\end{tabular}


Table 2-1: Summary of Critical Research Areas by Application (continued)

\begin{tabular}{|c|c|}
\hline Application & Research Area \\
\hline - Vapor Compression Cycle (continued) & $\begin{array}{l}\text { - Risk assessment for use of hydrocarbon refrigerants with } \\
\text { heat transfer loops-establish how flammable fluids could be } \\
\text { used in commercial refrigeration sector } \\
\text { - Low inventory heat exchanger }\end{array}$ \\
\hline - Stirling cycle using electrical drive & $\begin{array}{l}\text { - Design (basic understanding of heat transfer and fluid flow) } \\
\text { - Heat exchangers and regenerator (minimization of } \\
\text { ineffectiveness in complicated flow regime, secondary loop } \\
\text { heat transfer losses) } \\
\text { - Drive system (efficiency and long-term reliability) } \\
\text { - Efficient, cost-effective secondary heat transport loop for } \\
\text { industrial scale systems }\end{array}$ \\
\hline - Advanced Absorption/Adsorption Cycle & $\begin{array}{l}\text { - Development of cost-effective concept } \\
\text { - Materials research } \\
\text { - Modeling } \\
\text { - Efficient transport loop } \\
\text { - Additional cycle options }\end{array}$ \\
\hline \multicolumn{2}{|l|}{ industrial Refrigeration } \\
\hline - Vapor Compression Cycle & $\begin{array}{l}\text { - Alternate fluids to replace CFCs and HCFCs (flammability, } \\
\text { efficiency, lubrication) } \\
\text { - Improved small compressor (compatibility with ammonia, } \\
\text { lubrication, high-efficiency) } \\
\text { - Heat Exchangers (thermal storage to reduce cycle losses } \\
\text { and optimization for new refrigerants) } \\
\text { - Reduced inventory designs for ammonia refrigerant } \\
\text { - Optimization of the Brayton cycle for application to blast } \\
\text { freezers }\end{array}$ \\
\hline - Stirling cycle using electrical drive & $\begin{array}{l}\text { - Design (basic understanding of heat transfer and fluid flow) } \\
\text { ineat exchangers and regenerator (minimization of } \\
\text { heat transfer losses) } \\
\text { - Drive system (efficiency and long-term reliability) } \\
\text { - Efficient, cost-effective secondary heat transport loop for } \\
\text { industrial scale systems } \\
\text { - Additional cycle options }\end{array}$ \\
\hline - Advanced Absorption/Adsorption Cycle & $\begin{array}{l}\text { - Development of cost-effective concept } \\
\text { - Materials research } \\
\text { - Modeling } \\
\text { - Efficient transport loop }\end{array}$ \\
\hline Insulation Systems & $\begin{array}{l}\text { - Alternate blowing agents for foams (issues of thermal } \\
\text { conductivity, long-life, strength) } \\
\text { - Aerogels (concern over effects of moisture, manufacturing } \\
\text { limitations, lower costs) } \\
\text { - High-R gas panel (design of baffles to reduce convection, } \\
\text { enclosure materials, selection of gases) } \\
\text { - Evacuated panels (long.life, cost, weight, barrier heat } \\
\text { conduction) } \\
\text { - Whole-panel thermal measurement methods } \\
\text { - Methods for assembly of panels into appliance envelope } \\
\text { - Barrier methods for protecting the insulation } \\
\text { - Plastic formulation }\end{array}$ \\
\hline
\end{tabular}




\subsubsection{Vapor Compression Cycles}

A very wide variety of vapor compression cycles are applicable to domestic refrigeration: standard single evaporator cycle, multiple evaporators with one compressor, multiple evaporators with two compressors, and multiple pressure level systems. Options for multiple pressure level systems include: a two-stage integral compressor [1], the LaBrecque cycle, and hybrid two evaporator cycles using an ejector. Common to all of these cycles are needs for new refrigerants, improved heat exchangers, improved small compressors, and lower cost electronics.

- New fluids will be needed which provide good compatibility with lubricants, good thermodynamic efficiency and safety (low toxicity and flammability), and low ODP and GWP. Present candidates for replacing CFC-12 are HFC-134a, HFC-152a, cyclopropane, propane, refrigerant blends and $\mathrm{NH}_{3}$. HFC-134a is considered the most-likely near-term replacement candidate, but additional lubricants and refrigerant drying and filtering methods are needed to ensure reliable long-term efficient behavior in a refrigerator. Work in this area is currently underway by industry and should be completed within the next several years.

Additional "new fluids" could involve new pure refrigerants or refrigerant blends. Blends have the opportunities for improved efficiency along with tlammability suppression. Current "new" lluids include the fluoroethers and 3 and 4 carbon atom fluids. Other tluids may he defined and synthesized that have the desired thermodynamic and thermophysical properties and are non-toxic and non-flammable. Such new fluids must also be available at a moderately low cost.

Much, if not most, of the refrigerant development work will take place in industry. The search for new refigerants, significantly different in chemistry from the current fluorocarbons, is a longer-term effort which might not be undertaken by industry, other than in instances where niche markets already use chemicals developed for other applications that have promise for domestic refrigerators.

HFC-152a, cyclopropane, propane, and $\mathrm{NH}_{3}$ are flammable refrigerants. Refrigerator designs and components need to be developed that will reduce or eliminate the probability for ignition of the working fluids. The work would entail establishing conditions required to achieve ignition and methods to prevent it or to safely accommodate the occurrence.

- Considerable uncertainty in the industry exists concerning the suitability of the use of flammable fluids such as HFC-152a and $\mathrm{NH}_{3}$. Some tests designed to achieve a high probability of ignition in domestic refrigerators indicate potential problems. Some industry representatives have expressed great reluctance to utilize potentially flammable fluids, or mixtures, under current circumstances. Research relating to flammability must address the effects of external ignition sources, as well as the probability of ignition during manufacturing, transportation, service, or disposal. 
- Additional development work is needed to determine the promise of multi-pressure cycles, such as the LaBrecque cycle, hybrid cycles using ejectors, and multiple stage compressors. The promise of these cycles is improved refrigerant compression characteristics because of lower pressure ratios. Development of multiple-stage compressors will likely be carried out by industry. However, DOE may have an important role in the further development and assessment of the more complex LaBrecque and ejector cycles (see Section A2.1 for cycle descriptions). What needs to be determined, by test and experiment analysis, are the available energy savings, complexity of control, the ability to integrate the technologies into a practical overall design, and cos'. The domestic refrigerator market is highly competitive with many design constraints relating to reliability, cost, and customer features. Technologies that cannot be applied within these constraints will not be adopted.

- Compressors are at the heart of the domestic refrigeration systems. All of the advanced cabinet designs and multiple evaporator designs lead to the requirement for high efficiency small compressors.

Further development of small reciprocating and rotary compressors will be undertaken by industry in response to markel demand. Long-term DOE R\&D goals could include: (1) examination of alternate means of compression, (2) materials research into ultra-low expansion materials for use in compressors, (3) oil-free/self-lubricating or gas bearing compressors, and (4) ammonia-compatible highly efficient small hermetic compressors.

Examination of alternate means of compression is a high technical risk undertaking, since currently used compressors are the result of years of development and experience on a world-wide basis. The goal of the effort would be to identify technical approaches that would offer a significantly higher approach to Carnot efficiency than the current designs. Analysis at Arthur D. Little suggests that the ultimate practical efficiency levels of small (less than $2(0) \mathrm{Btu} / \mathrm{hr}$ ) reciprocating compressors are about $47 \%$ of Carnot for rotary designs and about $57 \%$ of Carnot for reciprocating designs [2]. A recommended goal is the identification and development of design concepts that have the possibility of achieving similar or higher efficiencies with the constraints of electric drive, size comparable to current designs, long-term reliability, acceptable cost, and tolerance to a wide range of working fluids. Alternatively, the compressor can be optimized for a selected working lluid. An example of an alternate compression technique might be one that provides more nearly isothermal compression.

Improved low-expansion materials could be valuable in maintaining tight tolerances in small compressors. For example, the gas blow-by losses in small rotaries can represent a 5-10\% loss [2]. Need for dimensionally stable materials will increase as tighter tolerances are used in future compressors as a means of reducing these kinds of losses. Basic metallurgy work would be undertaken to identify and develop new materials. 
The availability of low cost, low capacity and reliable oil-free compressors would broaden the range of acceptable refrigerants by eliminating lubrication effects on compressor behavior and on the heat transfer and thermodynamic properties. Efficiency improvements would result from improved heat exchange in the evaporator and condenser, possibly reduced pressure drop, potential design improvements for minimizing refrigerant superheat in the compressor, and elimination of some materials compatibility issues.

Domestic refrigeration systems now rely on the availability of small, efficient hermetic compressors. An advantage is the elimination of seal leakage problems and the ability to integrate the compressor/motor as a simple package into the refrigeration loop. A potential long-term substitute refrigerant for domestic refrigeration is $\mathrm{NH}_{3}$. Requirements include the availability of small efficient compressors that are compatible with this thuid and which offer long-term reliable operation.

Long-term reliability is a requirement for aceptable compressors for domestic refrigerators. Refrigerator manufacturers require that compressors run at least 100,000 hours for approval.

There is a need for ammonia resistant, efficient, motors for use in hermetic systems. For example, aluminium windings are compatible with $\mathrm{NH}_{3}$, but result in significant motor inefficiencies, which will directly impact the overall refrigeration system efficiency. Hence, there is a need for alternate electric motor designs that are compatible with ammonia to make this fluid a viable long-term option for domestic refrigeration application.

Another issue that needs to be addressed is the efficiency of the small compressors used with ammonia. Because of the properties of ammonia, smaller displacements will be needed than with today's CFC- 12 compressors. Hence, all the efficiency issues associated with scaling down in compressor size will need to be addressed as well.

It is noted that some manufacturers may be reluctant to use ammonia in domestic refrigerator applications due to concerns over toxicity and flammability.

- Cycling losses can reduce the net efficiency by 2-5\%. Approaches to reducing those losses include: use of a refrigerant shut-off valve to isolate the high and low pressure sides during off-cycle, variable speed electronics to reduce off-cycle duration, and thermal storage heat exchangers. Some manufacturers presently use the shut-off valve option. Wide spread use of variable speed electronics will await significant reductions in the costs of the electronic controls and the highly efficient DC motors. Work in this area is currently being pursued by industry, and probably should not be part of DOE's long-term R\&D agenda. However, only very little experience in the utilization of thermally massive heat exchangers has been reported. Development of 
thermal storage heat exchangers should be undertaken as part of a long-term R\&D effort related to heat exchanger development. The potential efficiency improvement with thermal storage heat exchangers is in the range of $5-10 \%$.

Requirements for practical thermal storage heat exchangers are compactness, high efficiency heat transfer, low heat transfer losses associated with the thermal storage, acceptable cost, and long-term reliability. The latter issue is of extreme ir portance if phase change materials are used as part of the design.

\subsubsection{Stirling Cycle Domestic Refrigeration}

Other than gas-fired liquid absorption systems, the Stirling cycle appears to be the most viable alternative to the vapor compression cycle. Although widely studied, for low temperature applications, and in applications with a high temperature lift, only relatively limited R\&D has been carried out to date for domestic refrigerator applications. This work has consisted of some preliminary feasibility laboratory tests, and analytical projections of potential improvements.

Based on this work, long-term improvements in Stirling cycles are needed in the following areas: (1) effective heat exchanger (with thermal storage) to couple the working fluid to a secondary heat transfer loop which is part of the evaporator system,

(2) improved drive system (linear electric motor driven and gas bearings),

(3) demonstration of potential for long-term reliability, and (4) integration into a practical domestic refrigerator.

Effective heat exchangers are required with Stirling cycles to minimize the heat transfer irreversibilities. The compactness of the hardware makes this a particular challenge. Cycling losses need to be minimized by use of thermal storage heat exchangers. A working cycle will require some sort of secondary heat transfer loop to provide high rates of heat exchange with the Stirling cycle working fluid and to facilitate an interface to the cabinet air. Since the working gas of Stirling equipment must be contained in compact volumes, the interface heat exchanger must itself be compact, with low pressure drops.

Very efficient, long-life, drive mechanisms must be developed. Additional R\&D is required to develop low-friction bearing and seal systems that have long life. This will involve extensive design analysis and experimental verification.

Free piston configurations utilizing gas bearings and clearance seals to avoid sliding contact have been used in "one-of-a-kind" spaceborne cryogenic applications. This drive configuration requires very tightly controlled machining tolerances and a sophisticated control system.

Successful application to domestic refrigerators will require that a number of practical interface issues be solved. The first step is to solve the problems limiting Stirling application to domestic refrigeration - cycling heat exchanger life, bearing life, seal life. These problems should be addressed by DOE. Then practical prototype designs should be developed, perhaps by industry, with attention paid to a consumer-acceptable 
design. The design concepts should also take materials and manufacturing costs into consideration. Experimental verification of the solutions to problem areas and the practical systems should be completed.

\subsubsection{Domestic Refrigeration Summary}

Table 2-2 summarizes the critical $R \& D$ needs in the domestic refrigeration area. The table lists the technology and application area, provides a brief description of the R\&D program, and summarizes estimates of the potential energy savings while successfully meeting the R\&D goals. Estimates of the probability of success of the program, a rating of the priority for R\&D, and the likely industry involvement are also listed.

Programs that have a high probability of success and a high R\&D priority are those most likely to impact future domestic refrigeration technology. The role of government in stimulating this research will be highest in those areas where industry involvement is likely to be low. For example, development of low cost variable-speed electronics is judged to provide a very substantial potential for reducing energy consumption; however, this is very likely to oceur naturally within the competitive environment of industry, with little need for government sponsored R\&D. On the other hand, industry is probably not likely to place a significant fraction of its $R \& D$ resources in oil-free compressor technology. Hence, in this technology/application area, an important role can be played by the government.

In all instances, the usefulness of data acquired in government research projects for CFC-replacement technologies will be cnhanced if the manufacturability aspects, and reliability of the different technologies, are taken into account.

The ratings listed in the summary table provide a basis for the recommended R\&D agenda given in Section 3.().

\subsection{Chillers}

\subsubsection{Critical Research Areas}

There are several areas where research is needed in order to address the combined objectives of this program.

The technologies offering the highest efliciency potential for chillers are:

- Vapor compression with alternative refrigerants,

- Absorption (liquid ahsorption), and

- Stirling cycle.

Vapor compression as applied to commercial space conditioning applications (chillers) will be the major, and probably dominant, lechnology into the foresecable future. The reasons are excellent efficiency, prover reliahility, and potential efficiency improvements of $10 \%$ to $15 \%$. 
Table 2-2: R\&D Summary Sheet: Domestic Refrigeration

Ratings: $1=$ Low, $5=$ High

\begin{tabular}{|c|c|c|c|c|c|}
\hline $\begin{array}{c}\text { Technology/ } \\
\text { Aipplication Category }\end{array}$ & $\begin{array}{c}\text { Description of R\&D } \\
\text { Program }\end{array}$ & $\begin{array}{c}\text { Probability } \\
\text { of Success } \\
(1-5)\end{array}$ & $\begin{array}{l}\text { Priority for } \\
\text { R\&D } \\
(1-5)\end{array}$ & $\begin{array}{c}\text { Industry } \\
\text { Involvement } \\
(1-5)\end{array}$ & \begin{tabular}{|c|}
$\begin{array}{c}\text { Potential for } \\
\text { Energy } \\
\text { Savings } \\
(\%)\end{array}$ \\
\end{tabular} \\
\hline \multirow{2}{*}{$\begin{array}{l}\text { New Fluids/Vapor } \\
\text { Compression Cycle }\end{array}$} & Synthesize New Fluids & 3 & 5 & 3 & $?$ \\
\hline & $\begin{array}{l}\text { Blends, with non-HCFC } \\
\text { Fluids }\end{array}$ & 4 & 4 & 3 & $0-10$ \\
\hline Flammable Fluids & Ignition Suppression & 5 & 5 & 4 & $0-10$ \\
\hline \multirow[t]{4}{*}{ Alternate Cycles } & $\begin{array}{l}\text { LaBrecque Cycle/lce } \\
\text { Bank Heat Exshanger }\end{array}$ & 3 & 2 & 2 & $5-20$ \\
\hline & Hybrid Ejector & 3 & 2 & 2 & $5-10$ \\
\hline & Multistage Compressor & 4 & 4 & 5 & $10-20$ \\
\hline & Thermal Acoustic & 1 & 1 & 1 & none \\
\hline \multirow[t]{5}{*}{ Small Compressors } & Improved Efficiencies & 5 & 5 & 5 & $10-30$ \\
\hline & Alternate Concepts & 2 & 4 & 1 & $?$ \\
\hline & Oil Free & 2 & 5 & 2 & $5-15$ \\
\hline & Low Expansion Materials & 4 & 4 & 3 & $10-25$ \\
\hline & $\begin{array}{l}\text { Ammonia Compatible } \\
\text { Hermetic Design }\end{array}$ & 5 & 3 & 1 & $?$ \\
\hline $\begin{array}{l}\text { Variable-Speed } \\
\text { Electronics }\end{array}$ & Low Cost Hardware & 5 & 5 & 5 & $10-30$ \\
\hline \multirow[t]{2}{*}{ Heat Exchangers } & Thr rmal Storage & 4 & 4 & 3 & $5-20$ \\
\hline & $\begin{array}{l}\text { Enhanced reat Transfer } \\
\text { with New' Fluids }\end{array}$ & 4 & 5 & 4 & $5-10$ \\
\hline \multirow[t]{5}{*}{ Stirling Cycie } & Improved Analysis Tools & 4 & 4 & 3 & N/A \\
\hline & i_inear Drive Sys $\$ m$ & 4 & 5 & 3 & Required \\
\hline & $\begin{array}{l}\text { Compact Effective Heat } \\
\text { Exchangers }\end{array}$ & 3 & 5 & 3 & Raquired \\
\hline & $\begin{array}{l}\text { Demonstrate Long-Term } \\
\text { Reliability }\end{array}$ & 3 & 5 & 3 & Required \\
\hline & $\begin{array}{l}\text { Prototype Design with } \\
\text { Market Potential }\end{array}$ & 4 & 5 & 4 & Required \\
\hline
\end{tabular}

The Stirling cycle offers the best alternative shaft-power-driven cycle to vapor compression for chillers. In the event no acceptable alternative working fluids are found for vapor compression, the Stirling cycle using helium or other inert gas offers a reasonabie potential to achieve acceptable energy efficiencies.

Liquid absorption chillers, after the development of the triple effect system, offer the potential of efficiencies comparable with vapor compression, while generating less $\mathrm{CO}_{2}$ by burning natural gas. Absorption chillers can also use central plant steam as the heating media. 


\subsubsection{Vapor Compression R\&D Needs}

R\&D needs for vapor compression are given in the following discussion:

2.3.2.1 Alternative Kefrigerants. New alternative chlorine-free refrigerants are the highest priority need. The development time needs to be shortened by quickly identifying candidates and screening them for thermodynamic performance and flammability. Testing for toxicity has been a time consuming task. This may not be an area for DOE; however, it would be very beneficial if the time required for toxicity testing can be shortened.

Many fluids noy: in use need long-term replacement. Besides CFC-11, CFC-12, HCFC-22, CFC-114, and CFC-502 used in chillers, HCFC- 123 will probably need replacement. HFC-32 and HFC-32 mixtures offer potential for replacement of HCFC-22 if investigations verify current indications. The design of systems using mixtures needs to be optimized.

If issues of flammability and toxicity can be resolved, ammonia becomes a viable alternative either for screw chillers or for centrifugal chillers through development and R\&D.

HCFC-152a and the lower boiling hydrocarbons, HC-290 (propane), HC-1270 (Propylene), HC-270 (cyclopropane), are candidates to replace chlorine-containing fluids if the flammability issues can be solved. A program on flammability risk assessment, as well as a study to design equipment for risk minimization is needed.

The alternative refrigerant study should also include HFE-134 (Navy applications) HFE-143, hydrofluoropropanes, and hydrofluorobutanes property and material compatibility data investigations.

2.3.2.2 Components. The major components of a vapor compression system are the compressor, heat exchargers (condenser and evaporator), and the expansion valve. The compressor and heat exchangers are candidates for improvement. The expansion valve could be replaced by a work-extracting expander to improve the cycle, but this is not likely because of the expense.

Compressor types are centrifugal, screw, and reciprocating or scroll. Centrifugal compressors already operate with efficiency levels in the low $80 \%$ region (at design conditions) and are driven by motors with 90 to $95 \%$ efficiency. This is to say that the system efficiency is already !igh. Possible centrifugal compressor improvements include designs to increase the overall aerodynamic efficiency and still further lowering the mechanical friction by the use of refrigerant lubricated bearings. It appears that the improvement over $83 \%$ would be incremental.

Screw compressors have the potential for improvement in the areas of lubrication and sealing. Single screw compressors are in their infancy; therefore, there is potential for development. 
Oil-free or reduced oil screw compressors need to be developed. Oil contaminates heat exchange surfaces and decreases heat transfer. Recapture and recirculation of oil will at least reduce the impairment of heat exchangers.

The use of tighter tolerances in machining the screw geometry can help to replace the sealing function of oil. The amount of tolerance tightening that is useful is limited, however, by the need to account for thermal expansion. Matching of materials or the use of low thermal expansion materials is necessary if tighter dry sealing (clearance seals) is to be achieved.

The lubricating and sealing functions of oil can potentially be replaced by liquid refrigerant injection to achieve oil-free operation. The effective lubricity of liquid refrigerant and the durability of the bearings under this condition need to be investigated. Sealing of screw compressor tips by liquid injection can also potentially replace oil. The method, location and amount of injection would have to be investigated for each refrigerant being considered.

Reciprocating compressors are fairly mature. Friction, valve, and thermal losses are a problem; however, much effort has been directed at these issues over the years. Scroll compressors have been developed for smaller sizes. They can potentially be expanded to 40 or 50 horsepower sizes with their attendant simplicity and lower noise. Both reciprocating and scroll compressors need to be re-optimized for the new alternative refrigerants.

Heat exchanger needs include optimization for new refrigerants, enhanced surfaces, and investigation of spray evaporators to improve heat transfer and reduce refrigerant inventory. Optimization to match new refrigerants with regard to performance and material compatibility can be considered as a part of normal heat exchanger design; however, it is a valuable aspect of maintaining efficiency using the new refrigerants. Enhanced surfaces can also potentially improve operation with the new refrigerants. Spray evaporators should be traded off against the improved nucleate boiling evaporators to obtain the best efficiency with the new refrigerants.

\subsubsection{Liquid Absorption Refrigeration Needs}

R\&D needs for liquid absorption include the following:

- A commercially viable triple effect absorption system with a COP of 1.8 should be developed for applications where low cost heat is available. It will also find success where vibration-free performance is required such as the upper stories of high rise buildings. The first costs will be higher than vapor compression, but running costs (including demand charges) may be less in many parts of the world depending on gas (or steam) versus electric costs.

- Research on corrosion control, chemical instabilities and incompatibilities at higher generator temperatures and modified materials of construction is needed. 
Work on triple effect systems has been on-going in two fronts. Trane bought dual loop triple effect technology from DOE. They are currently in a cost-sharing program with Gas Research Institute. The second triple effect program is with Battelle Columbus Laboratories to solve the problems of material compatibility in operating a high temperature generator. Both of these programs are principally aimed at the primary technical limitation--materials compatibility in operation of a high temperature generator for triple effect systems.

Development of high efficiency ammonia-water absorption heat pumps has been going on by Phillips Engineering Company for residential applications. This technology could be extended to water-cooled refrigeration applications with improvements in generator and absorber components, and/or, by variants to the GAX cycle.

\subsubsection{Solid Absorption}

R\&D needs for solid absorption include:

- Selection of sorbent materials for greater flexibility of design,

- A program to investigate life expectancy of the refrigeran/sorbent pair. What is the fatigue or loss of chemical after many absorption/desorption cycles?

- Heat exchanger optimization - minimize the cost of heat exchangers. Investigate minimization of metal used and minimization of fabrication costs.

- Process control/material specification - specily the quality of the absorbents. What are the critical steps in preparation of the bed? These areas are incomplete with present technology.

\subsubsection{Stirling Cycle Research Needs}

Areas needed additional research connected with the Stirling cycle are:

- A program of modeling the Stirling cycle is needed to assess the real potential at the low temperature lifts characteristic of chiller applications. The model should include basic phenomena such as heat transfer in the oscillating flow regimes in heat exchangers.

- A program of improving regenerator perlormance with regard to achieving higher effectiveness, lower pressure drop, lower void volume, lower cost, and less susceptibility to contaminant plugging.

- A program to reduce the LMTD in the cold and hot heat exchangers where high density heat transfer is required. This serves to reduce some of the temperature drops associated with secondary loop heat transter in Stirling cycles.

- Secondary heat transfer loop improvement to reduce the associated temperature drop. For example, can a heat pipe be used to reduce the temperature drop? 
- A program to improve the reliability of hardware and make the hardware cost effective. This program would include an investigation of seals and sealed bearings. In both cases, an improvement or substitute function would be objective. An objective can be to replace sliding seals with clearance seals or long lasting diaphragm seals. Clearance seals have their own set of design problems that the program would address. Sealed bearings can be replaced with long lasting, low friction gas bearings either hydrostatic or hydrodynamic. Non-contacting seals and bearings will significantly advance the reliability of Stirling systems.

\subsubsection{Chiller System Summary}

Table 2-3 summarizes the critical R\&D needs for chiller systems. The ratings listed for priority of R\&D and for industry involvement are the primary basis for definitions of specific R\&D agenda given in Section 3.0.

\subsection{Commercial Refrigeration}

\subsubsection{Critical Research Areas}

Evaluation of the state of the art of commercial refrigeration technology indicates the following conclusions relative to the promise of future CFC-free, energy efficient technologies:

- Vapor compression cycle-likely to continue as the dominant technology, given the inherent advantages of the cycle. All currently identified non-CFC/HCFC working fluids have some significant undesirable features, so a major thrust of R\&D activities needs to address the development either of new fluids, or of techniques to minimize the impact of undesirable characteristics.

- The Stirling cycle - feasible in low temperature applications, where it has a potentially, but yet to be demonstrated, higher COP than vapor cycle equipment.

- Liquid absorption cycles - multiple effect cycles for medium temperature applications, potentially with a higher primary fuel source COP than vapor cycle.

- Solid adsorbent cycle-multiple effect cycles using solid sorbent and ammonia, potentially with a higher primary fuel source energy efficiency than vapor cycle

Other cycle alternatives are generally much too low in potential efficiency to be applicable to commercial refrigeration.

2.4.2 Commercial Refrigeration Summary

Table 2-4 summarizes the critical $R \& D$ needs in the commercial refrigeration area. The table lists the technology and application area, provides a brief description of the R\&D program, and summarizes estimates of the potential energy savings while successfully meeting the R\&D goals. Estimates of the probability of success of the program, a rating of the priority for R\&D, and the likely level of industry involvement are also listed. 
Programs that have a high probability of success and a high priority are those most likely to impact future commercial refrigeration technology. The role of government in stimulating this research will be highest in those areas where initial industry involvement is likely to be low. For example, industry is probably not likely to place a significant fraction of the $R \& D$ resources in the application of hydrocarbon refrigerants (because of flammability), despite the potential advantages. Hence, in this technoiogy/application area, an important role can be played by government long-term R\&D.

The ratings listed in the summary table provide a basis for the recommended R\&D agenda given in Section 3.0.

Table 2-3: R\&D Summary Sheet: Chillers

Ratings: $1=$ Low, $5=$ High

\begin{tabular}{|c|c|c|c|c|c|}
\hline $\begin{array}{c}\text { Technology' } \\
\text { Application Category }\end{array}$ & $\begin{array}{c}\text { Description of R\&D } \\
\text { Program }\end{array}$ & $\begin{array}{c}\text { Probability } \\
\text { of Success } \\
(1-5)\end{array}$ & $\begin{array}{l}\text { Priority for } \\
\text { R\&D } \\
(1-5)\end{array}$ & $\begin{array}{c}\text { Industry } \\
\text { Involvement } \\
(1-5)\end{array}$ & $\begin{array}{c}\text { Potential for } \\
\text { Energy } \\
\text { Savings } \\
(\%)\end{array}$ \\
\hline \multirow{2}{*}{$\begin{array}{l}\text { New Refrigerants for } \\
\text { Vapor Compression } \\
\text { Cycle }\end{array}$} & Synthesize New Fluids & 3 & 5 & 5 & $?$ \\
\hline & $\begin{array}{l}\text { Blends, with non-HCFC } \\
\text { Fluids }\end{array}$ & 4 & 4 & 5 & $?$ \\
\hline $\begin{array}{l}\text { Fractionation of } \\
\text { NARMS }\end{array}$ & $\begin{array}{l}\text { Investigate composition } \\
\text { shift due to high/low side } \\
\text { fractionation, leakage }\end{array}$ & 5 & 5 & 3 & N/A \\
\hline Flammability & $\begin{array}{l}\text { Risk assessment, design } \\
\text { for reduced risks }\end{array}$ & 4 & 4 & 2 & $5-10$ \\
\hline \multirow[t]{2}{*}{ Compressors } & $\begin{array}{l}\text { Improved efficiency } \\
\text { through lubrication and } \\
\text { oil sealing }\end{array}$ & 4 & 4 & 5 & $5-10$ \\
\hline & Oil free design & 2 & 4 & 2 & $5-10$ \\
\hline Heat Exchangers & $\begin{array}{l}\text { Low fluid inventory, spray } \\
\text { evaporators }\end{array}$ & 4 & 4 & 4 & $0-10$ \\
\hline \multirow[t]{2}{*}{$\begin{array}{l}\text { Advanced Absorption } \\
\text { Systems }\end{array}$} & $\begin{array}{l}\text { Commercially viable triple } \\
\text { effect design }\end{array}$ & 4 & 4 & 4 & * \\
\hline & $\begin{array}{l}\text { Solid Absorption, } \\
\text { selection of materials }\end{array}$ & 3 & 3 & 2 & $?$ \\
\hline \multirow[t]{4}{*}{ Stirling Cycle } & improved analysis tools & 4 & 4 & 3 & N/A \\
\hline & Regenerator design & 3 & 5 & 3 & Required \\
\hline & Heat exchangers & 3 & 5 & 3 & Required \\
\hline & Long-term reliability & 3 & 5 & 3 & Required \\
\hline
\end{tabular}

" Potential improvement in thermal COP from 1.1 to 1.8 
Table 2-4: R\&D Summary Sheet: Commercial Refrigeration

Ratings: $1=$ Low, 5 = High

\begin{tabular}{|c|c|c|c|c|c|}
\hline $\begin{array}{c}\text { Technology/ } \\
\text { Application Category }\end{array}$ & $\begin{array}{c}\text { Description of R\&D } \\
\text { Program }\end{array}$ & $\begin{array}{c}\text { Probability } \\
\text { of Success } \\
(1-5)\end{array}$ & $\begin{array}{l}\text { Priority for } \\
\text { R\&D } \\
(1-5)\end{array}$ & $\begin{array}{c}\text { Industry } \\
\text { Involvement } \\
(1-5)\end{array}$ & $\begin{array}{c}\text { Potential for } \\
\text { Energy } \\
\text { Savings } \\
(\%) \\
\end{array}$ \\
\hline $\begin{array}{l}\text { New Refrigerants for } \\
\text { Vapor Compression } \\
\text { Cycle }\end{array}$ & $\begin{array}{l}\text { Synthesize/characterize } \\
\text { new, low boiling point } \\
\text { fluids and mixtures with } \\
\text { non-HCFC components }\end{array}$ & 3 & 5 & 3 & $\bar{*}$ \\
\hline $\begin{array}{l}\text { Application of } \\
\text { Ammonia }\end{array}$ & $\begin{array}{l}\text { Define alternate } \\
\text { configurations, estimate } \\
\text { performance }\end{array}$ & 4 & 2 & 5 & $5-10 \%$ \\
\hline $\begin{array}{l}\text { Application of } \\
\text { Hydrocarbons }\end{array}$ & $\begin{array}{l}\text { Define alternative } \\
\text { configurations, estimate } \\
\text { performance }\end{array}$ & 3 & 4 & 1 & $5-10 \%$ \\
\hline $\begin{array}{l}\text { Fractionation of } \\
\text { NARMs }\end{array}$ & $\begin{array}{l}\text { Investigate composition } \\
\text { shift due to high/low side } \\
\text { fractionation, leakage }\end{array}$ & 5 & 5 & 3 & N/A \\
\hline $\begin{array}{l}\text { Efficient Secondary } \\
\text { Loops }\end{array}$ & $\begin{array}{l}\text { Develop low } \Delta \mathrm{T} \text {, low } \\
\text { parasitic, }-30^{\circ} \mathrm{F} \\
\text { secondary loop }\end{array}$ & 4 & 5 & 3 & ** \\
\hline \multirow{2}{*}{$\begin{array}{l}\text { HFCs for Low and } \\
\text { Medium Temperature } \\
\text { Refrigeration }\end{array}$} & $\begin{array}{l}\text { Develop suitable } \\
\text { lubricants }\end{array}$ & 5 & 5 & 5 & $2-5 \%$ \\
\hline & $\begin{array}{l}32 / 125 \text { equipment } \\
\text { optimization }\end{array}$ & 5 & 4 & 5 & $2-5 \%$ \\
\hline $\begin{array}{l}\text { Low Refrigerant } \\
\text { Inventory System } \\
\text { Designs }\end{array}$ & $\begin{array}{l}\text { Reduced inventory heat } \\
\text { exchangers }\end{array}$ & 5 & 3 & 4 & N/A \\
\hline Refrigerant Leakage & $\begin{array}{l}\text { Develop techniques to } \\
\text { reduce leakage }\end{array}$ & 4 & 3 & 5 & N/A \\
\hline $\begin{array}{l}\text { Microprocessor } \\
\text { Controls }\end{array}$ & $\begin{array}{l}\text { Detect leaks, optimize } \\
\text { operation, detect faults }\end{array}$ & 4 & 3 & 5 & \\
\hline \multirow[t]{4}{*}{ Stirling Cycle } & Improved analysis tools & 4 & 4 & 3 & N/A \\
\hline & Regenerator design & 3 & 5 & 3 & Required \\
\hline & Heat exchangers & 3 & 5 & 3 & Required \\
\hline & Long-term reliability & 3 & 5 & 3 & Required \\
\hline $\begin{array}{l}\text { Advanced Absorption } \\
\text { Adsorption Cycle }\end{array}$ & $\begin{array}{l}\text { Design configuration, } \\
\text { modeling, COP estimate }\end{array}$ & 3 & 4 & 1 & $0-25 \%$ \\
\hline \multirow{5}{*}{$\begin{array}{l}\text { Compressor } \\
\text { Technology }\end{array}$} & Small screw & 4 & 4 & 5 & $10 \%$ \\
\hline & Scroll & 4 & 4 & 5 & $20 \%$ \\
\hline & Improved reciprocating & 4 & 4 & 5 & $5-10 \%$ \\
\hline & Variable speed & 4 & 4 & 5 & $5-10 \%$ \\
\hline & Oil-free & 2 & 4 & 2 & $?$ \\
\hline
\end{tabular}


Table 2-4: R\&D Summary Sheet: Commercial Refrigeration (continued)

Ratings: $1=$ Low, $5=$ High

\begin{tabular}{|l|c|c|c|c|c|}
\hline $\begin{array}{c}\text { Technology/ } \\
\text { Application Category }\end{array}$ & $\begin{array}{c}\text { Description of R\&D } \\
\text { Program }\end{array}$ & $\begin{array}{c}\text { Probability } \\
\text { of Success } \\
(1-5)\end{array}$ & $\begin{array}{c}\text { Priority for } \\
\text { R\&D } \\
(1-5)\end{array}$ & $\begin{array}{c}\text { Industry } \\
\text { Involvement } \\
(\mathbf{1 - 5})\end{array}$ & $\begin{array}{c}\text { Potential for } \\
\text { Energy } \\
\text { Savings } \\
\text { (\%) }\end{array}$ \\
\hline \hline Simulation Model & $\begin{array}{l}\text { Develop computer model } \\
\text { of refrigeration systems } \\
\text { to allow comparison of } \\
\text { alternatives }\end{array}$ & 5 & 5 & 1 & $\mathrm{~N} / \mathrm{A}$ \\
\hline
\end{tabular}

- New fluids may offer advantages other than improved efficiency, e.g., low GWP

** This technology is needed to facilitate use of ammonia, hydrocarbons, Stirling cycle, advanced absorption cycle

\subsection{Industrial Refrigeration}

\subsubsection{Critical Research Areas}

Evaluation of the state of the art of industrial refrigeration technology indicates the following conclusions relative to the promise of future $\mathrm{CFC}$-free, energy efficient technologies:

- Vapor compression cycle-likely to continue as the dominant technology, given the current widespread use of ammonia as the refrigerant instead of CFCs, and the relative ease of utilizing other working fluids

- The Stirling cycle is potentially applicable to low temperature applications, although the flexibility of working fluid selection for vapor cycle that is available for this application area probably reduces the incentives for pursuing this technology

- Liquid absorption cycles - for medium temperature applications, given the availability of low cost process steam

- Solid adsorbent cycle-multiple effect cycles using solid sorbent and ammonia may be usable for direct expansion, with potentially higher primary fuel source energy efficiency than with vapor cycle

- Reverse Brayton cycle-a recuperated reverse Brayton cycle, with heat rejection to ambient, is potentially competitive in efficiency with vapor cycle for blast freezers, when parasitics, defrosting, etc. are taken into account

- Other cycle alternatives are generally much too low in potential efficiency to be applicable to industrial refrigeration

In addition to the specific, ammonia system oriented areas described below, much of the technology associated with commercial refrigeration is applicable to industrial refrigeration systems that currently use CFCs. 
2.5.1.1 Vapor Cycle. Research in several areas would facilitate wider use of ammonia in industrial refrigeration and contribute to the extension of ammonia based vapor cycles to applications such as commercial refrigeration and HVAC chillers. Precise heat transfer data on ammonia in forced convection evaporation and condensation inside plain or enhanced surface tubes or in pool boiling with plain tubes is not available in the open literature. Moreover, interest in spray chillers for improved heat transfer, low operating temperature differences and reduced refrigerant inventory has been high, but no definitive data on such applications exists in the open literature. The availability of this data would facilitate the design and selection of economical, high performance, condensers and evaporators for industrial refrigeration.

When converting HCFC-22 systems to ammonia under drop-in or near drop-in circumstances, residual HCFC-22 in the system can react with the ammonia and will form ammonium fluoride. Ammonium fluoride is a solid that forms as a crystal or a thread, depending on the degree of refinement. It is probable that the formation actually occurs in the compressor due to the imposition of pressure/temperature on the mixture. Once formed it carries through the system where it settles in the receiver. It then circulates through the system with the liquid where it gets trapped in orifices and strainers and eventually plugs the system. It is soluble only in cold water and alcohol.

An understanding of the chemistry of formation, the effect of temperature and pressure on the chemistry and mass/volume relationships and levels of toleration would aid in the evaluation of potential problems in HCFC-22 to ammonia conversions. Moreover, as more chlorine-based solvents are eliminated, effective removal of residual oil from the systems will become more difficult (it is the refrigerant dissolved in the oil, as well as any residual vapor, that is the suspected source of the HCFC-22 in converted systems). Development of recommended techniques for cleaning the systems and removing all residual refrigerant and oil will aid in the successful conversion of these systems in the future.

Systems cannot be cor verted from HCFC-22 to ammonia under drop-in circumstances unless the materials of construction are fully compatible with ammonia, i.e., no copper in contact with the ammonia. Present semihermetic compressor motors are also incompatible with ammonia.

2.5.1.2 Reverse Brayton Cycle. A major subcategory within industrial refrigeration is blast freezers, where cold, high velocity air flows over a product, usually food, to be frozen. From an overall system point of view, the refrigerator system efficiency is severely compromised by high power consumption of the cold air blast blowers and the low evaporation temperature that is required. Preliminary analyses indicate that recuperated reverse Brayton cycle equipment could be comparable in efficiency to the vapor cycle, a premise that could be investigated by undertaking a detailed design study, and, if justified, engineering model development.

2.5.1.3 Reverse Stirling Cycle, Absorption Cycle, Adsorption Cycle. These three cycles are potentially applicable to industrial refrigeration for the same reasons that they are potentially applicable for commercial refrigeration. 


\subsubsection{Industrial Refrigeration Summary}

Table 2-5 summarizes the critical $R \& D$ needs in the industrial refrigeration area. The table lists the technology and application area, provides a brief description of the R\&D program, and summarizes estimates of the potential energy savings while successfully meeting the R\&D goals. Estimates of the probability of success of the program, a rating of the priority for $\mathrm{R} \& \mathrm{D}$, and the likely industry involvement are also listed.

Table 2-5: R\&D Summary Sheet: Industrial Refrigeration

Ratings: $1=$ Low, $5=$ High

\begin{tabular}{|c|c|c|c|c|c|}
\hline $\begin{array}{c}\text { Technologyl } \\
\text { Application Category }\end{array}$ & $\begin{array}{c}\text { Description of R\&D } \\
\text { Program }\end{array}$ & $\begin{array}{c}\text { Probability } \\
\text { of Success } \\
(1-5)\end{array}$ & $\begin{array}{l}\text { Priority for } \\
\text { R\&D } \\
(1-5)\end{array}$ & $\begin{array}{c}\text { Industry } \\
\text { Involvement } \\
(1-5)\end{array}$ & $\begin{array}{c}\text { Potential for } \\
\text { Energy } \\
\text { Savings } \\
(\%)\end{array}$ \\
\hline $\begin{array}{l}\text { HCFC-22 to ammonia } \\
\text { conversion (including } \\
\text { equipment changes) }\end{array}$ & $\begin{array}{l}\text { Develop techniques to } \\
\text { thoroughly clean R22 } \\
\text { from systems that are } \\
\text { otherwise compatible } \\
\text { with ammonia }\end{array}$ & 5 & 3 & 5 & $5.10 \%$ \\
\hline Heat Exchangers & $\begin{array}{l}\text { Extend the available heat } \\
\text { transfer data for } \\
\text { ammonia boiling and } \\
\text { condensation }\end{array}$ & 5 & 5 & 5 & $0-10 \%$ \\
\hline $\begin{array}{l}\text { Ammonia vapor cycle } \\
\text { w/reduced refrigerant } \\
\text { charge }\end{array}$ & $\begin{array}{l}\text { Investigate component } \\
\text { and system designs to } \\
\text { minimize charge }\end{array}$ & 4 & 4 & 4 & • \\
\hline $\begin{array}{l}\text { Efficient Secondary } \\
\text { Loops }\end{array}$ & $\begin{array}{l}\text { Develop Low } \Delta T \text {, Low } \\
\text { Parasitic, }-30^{\circ} \mathrm{F} \\
\text { Secondary Loop }\end{array}$ & 4 & 5 & 3 & "* \\
\hline $\begin{array}{l}\text { Reverse Brayton } \\
\text { Cycle }\end{array}$ & $\begin{array}{l}\text { Investigate application to } \\
\text { various configurations of } \\
\text { blast freezers }\end{array}$ & 3 & 4 & 2 & Small \\
\hline $\begin{array}{l}\text { Screw Compressors } \\
\text { for Ammonia }\end{array}$ & $\begin{array}{l}\text { Develop efficient, lower } \\
\text { capacity, air cooled }\end{array}$ & 5 & 4 & 5 & $5 \%$ \\
\hline
\end{tabular}

- Could improve safety, extend applicability of ammonia

** Technology is needed to facilitate use of ammonia, hydrocarbons, Stirling cycle, advanced absorption cycle

The ratings listed in the summary table provide a basis for the recommended $R \& D$ agenda given in Section 3.0.

\subsection{Insulation}

\subsubsection{Critical Research Areas}

2.6.1.1 Foam. Since no viable alternative foam blowing agent which has the required thermal characteristics (low k) and acceptable environmental compatibility (low ODP and GWP) exists, the development of a new blowing agent is required. Work is currently being conducted by most of the chemical companies as well as University of Tennessee and Clemson University. Those chemicals which have been developed must 
be characterized, initially by analysis and then by testing. This would include ODP/GWP, thermal conductivity, boiling point, heat of vaporization, flammability and toxicity.

The development of new blowing agents should aim to produce foams with higher resistivities and equivalent or lower cost of currently available CFC-11 blown foams. Table A-19 lists the alternatives which are currently under consideration and should be fully characterized.

The use of alternative plastic structures should also be investigated. The common polymers used for insulation are polyurethanes, polystyrenes, and phenolics. Most of the insulations center around polyurethanes and polystyrenes. The use of phenolics has specific advantages over the other two polymers, specifically, better aging

characteristics. Research in developing new blowing agents or methods of manufacture for phenolics should be continued.

New methods of fabrication, other than traditional blowing or extruding, are possible research areas. This should include looking at alternative polymers and reactions. Primarily this would open up different ranges of chemical properties, some of which may already exist.

The resulting foams, regardless of the polymer, should aim to develop the smallest cells possible. The use of opacification should be included into the development of foams. One opacification method already under investigation is the use of aluminum flakes. Researchers at MIT are working with new opacifiers, low conductivity polymeric powders with an opaque coating. The overall thermal conductivity which is a volumetric property remains low. An opacifier which is not as thermally conductive as aluminum would be preferred.

If the foams are to be used in evacuated systems, additional attention must be given to outgassing, cell size, and percent of closed cells (should be very low). If the cell size can be reduced then the required pressure will be higher.

The foams would be further enhanced if they could provide sufficient strength to be used as a structural component. This would require that the foam act as an adhesive with the liners to stiffen the shells.

The development of foam barriers for use in construction is also required. The currently available barriers are not ideal and could be improved. The characteristics which are desired include low permeability to air, blowing agents, and to water vapor, good adhesion between foam and barrier, low emissivity, and low thermal conductivity. These barriers would also slow the aging process of foams by adding additional shields to diffusion of foam gases out and air in.

The aging of foams can be reduced substantially or eliminated by the use of impermeable barriers and good foam to barrier adhesion to prevent lateral gas migration under the interface. A rapid test means to measure the performance of the barrier/foam interface is also needed. 
2.6.1.2 Aerogels. The aerogels provide a lightweight, high $\mathrm{R}$-value per inch insulation which could be used in the unevacuated form. The options of silica or organic provide some tailoring. Additional materials have been used to make aerogels in the past (including "Jello"). The different options must be examined and characterized for their thermal and mechanical properties. Originally the aerogels were aimed at window applications. This required longer drying processes to provide the highest light transmission possible. Further work in techniques to reduce the manufacturing time is required. Options to use different materials should also to be examined.

One potential problem of the current silica aerogels is the effects of moisture. If this continues to be a problem then an enclosure system must be developed which can prevent the introduction of water vapor. Development of barriers could be applicable to this technology.

Some opacification for aerogels has been developed, primarily using titanium oxide, but other systems may prove to be better. Again, the use of low thermal conductivity opacifiers is desired. The introduction of high thermal conductivity low emissivity particles has both positive and negative effects. The low emissivity reduces the radiation heat transfer while the high thermal conductivity increases the solid conduction. The decrease in the radiation heat transfer is typically greater than the increase in solid conduction at low opacifier concentration because the opacifiers are very thin and not in contact with other near-by llakes.

Another advantage of aerogels is that much of the chemicals used in the production can be recycled thereby decreasing the cost and the effects to the environment. By using the system which Thermalux has developed, the safety to workers has been improved. This primarily requires substituting one fluid for another in order to reduce the required temperature and pressure for drying. Similar types of tluid substitutions should be investigated for other aerogel materials. The safety and recycling potential are important issues in the cost and manufacturing process.

2.6.1.3 High-R Gas Panels. The primary research needs for high-R gas panels are:

- Use of different gases should be investigated. Appendix A describes some of the gases which are currently used and Table A-20 lists the thermal conductivity of various gases. These are ideal thermal conductivities which provide the minimum thermal conductivity of the panels which could be formed. It should be noted that for krypton and argon the theoretical performance of the panels and the measured performance of the panels differed by approximately $19 \%$ and $11 \%$ respectively. This was due to dilution of the inert gases by air.

- Development and characterization of enclosure materials which limit the degradation of the insulation is required for all applications and insulation systems. The diffusion rate of the high- $R$ gas out and air in must be decreased. As with the previous insulation systems, a good barrier is essential. 
- The design of the baffles must be improved. The requirements for baffles are to eliminate/reduce the convective heat transfer and to reduce the radiative heat transfer. Convection is affected primarily by decreasing the gaps so that natural convection is not allowed. The radiative heat transfer is affected by two means: using low emissivity coatings and using a sufficient number of baffles. Both of these require some additional work. The number of baffles is more of a design issue while the low emissivity coatings are more of a materials and processing issue. If these panels are to be used at higher temperatures then the radiative component becomes more important. Additionally, the requirement for higher temperature plastics is imposed.

2.6.1.4 Evacuated Panels. The evacuated panels discussed here include loose fills (silica powders, fiberglass, etc.), solid panels (foam, aerogel, liberboard), and single enclosure designs (i.e. the MBB concept). The R\&D needs for these include:

- Development and measurement of polymers which can be used for enclosures to maintain low internal pressures in the panels. Since the main issue with these panels is the aging process which is dependent on the internal pressure, the enclosure is very critical. The enclosures must be able to withstand different operating temperatures and maintain the vacuum. The permeability of different materials to the gases of interest must be measured and new materials developed. These gases would include blowing agents (current and alternatives), nitrogen, oxygen, carbon dioxide, carbon monoxide, water vapor, and other atmospheric gases. It is possible to use metal enclosures, but for small panels the edge losses would be prohibitive. In the case of very large panels, metal can be used.

- The use of glass enclosures has been investigated at MIT and shows some promise. The applications for these enclosures would have to be non-vibratory (no transportation). These types of enclosures provide low thermal conductivity systems using known technologies. The means of forming these enclosures must still be developed.

- The manufacturing process for the enclesures is a difficult problem and will require development. The issue with a metal enclosure is welding very thin panels together so that a reliable weld is formed. No leaks can be present in the weld area. Metal enclosures can be used for large panels where the edge effects are a small portion of the heat leak. For polymers, a similar situation exists in which the edges must be sealed to provide a vacuum tight enclosure.

- The types and mixtures of till materials should be investigated to locate an inexpensive and efficient material. The fills must be optimized by using mixes of different constituents to provide the smallest interstitial spacing possible. Different processing methods could produce a fill which is better as an opacifier while still meeting the other requirements. Availability of enclosures must also be incorporated into the optimization, e.g., metal or glass should be able to maintain a higher vacuum allowing the use of less expensive fills. 
- The development of aerogels, foams, and fiberglass materials was mentioned earlier. These are valid materials for use in evacuated systems.

2.6.1.5 Compact Vacuum Insulation. Compact Vacuurn Insulation (CVI) requires thorough investigation of the actual $\mathrm{R}$-value of a panel. The measurements initially conducted demonstrated the center of panel R-value and ignored the edge effects. ORNL has completed further analysis and testing of these panels and will publish the results in a report. This type of insulation must be tailored to a specific application. If space is a major criteria and large panels are required then this type of insulation may be applicable. If space is not an issue then forming panels which are thicker is possible. Thicker panels have several advantages such as:

- Edge losses are reduced since the conduction length is increased. Also, the effective length can be increased by forming a different profile (wavy).

- Heat conduction through the spacers is reduced due to the increased conduction length.

- The heat conduction along the enclosure can be decreased by making them thinner. In the cases where thin panels are required the deflection of the plates must be controlled so that no contact is made from side to side. This requires more spacers or thicker plates or both. With thicker panels, the number of spacers and the plate thickness can be reduced.

The other major hurdle to overcome is the manufacturing process. The welding of two thin plates while holding the spacers in place is a formidable task. NERL has been looking at different ways to generate these panels. The weld areas should be small to avoid increasing the edge losses.

2.6.1.6 General. A number of additional issues, which cover a broad range of insulation systems, need to be addressed:

- Equipment and proper procedures are required which will allow for the accurate measurement of the resistivity of panels. These measurements should include the effects of edges.

- Numerical simulation is needed to determine the three dimensional geometrical heat transfer effects in different applications to determine the influence of edge effects, corners in the actual geometry with realistic thermal boundary conditions.

- The testing of insulation systems in the specific applications is required to verify assembly and performance. For the more developed concepts, significant testing of panels in end use equipment is required. This would provide verification of any analysis. This type of research has been conducted on a limited basis for certain applications, such as refrigerator/treezer with CVI, powder filled evacuated panels, and evacuated aerogel panels. 
- Standardized tests and procedures are required for the advanced insulations (should include edge effects). With standardized testing, the different panels can be compared on in equal basis. Currently, the panels are tested to determine center of panel resistivities. Due to the different enclosure systems and vacuum levels, edge losses vary from one panel to the next. Also, the size of panels, equipment used, and reference inaterials are different. The use of low resistivity reference material leads to erroneous measurements when testing panels which are well out of the range of the equipment.

- An accelerated ter: iechnique is needed to determine the long-term behavior of evaluated systems. This includes permeability measurements of possible gases, outgassing from interior components, and long-term degradation of the envelope or interior material.

- Assembly methods for appliances using alternative insulation systems should be examined to support the eventual manufacturing of end-use equipment. The use of adhesives, foaras, or mechanical "fasteners" to locate and hold the panels needs to be investigated. The panel support system must, for evacuated panels, attach to the enclosure. This then implies that the enclosures must be able to support the weight of the panels during manufacturing. These assembly issues must be examined to determine where any major problem areas exist.

- Development of innovative integrated wall systems for appliances and buildings is needed. These would combine the best features of the insulation. supports and surface layers to assure good thermal and mechanical performanc:.

- Structural supports for the end-use equipment could be provided by foam or other mechanical systems. The use of materials which will nct produce short-circuiting of heat through the insulation is required. For example, polymeric or composite structural members/ribs might be used to support the liners and the insulation panels. A foam may be used if available, possibly water blown, which can provide the required support structure in the available space.

\section{E.2 Insulation Summary}

Nine research areas have been summarized arid coissolidated into various areas. These are listed in Table 2-6. Table 2-7 includes assessments of the impacts on technologies, risks, industry response, cost impacts, and time estimates. The R\&D efforts which are listed were selected because interest was demonstrated at the Montreal conference. Historically, insulation development has been handled by industry with the various government agencies providing guidelines and regulations. As required, the industry has modified the required technologies cr developed new technologies to meet the new regulations.

The definitiuns of the columns in Table 2-6 are:

- The impact on technology is defined as the benefits which will be realized if this task is s'iccessful. The impact is typically on a variety of insulations. 
- The risk is defined as the potential for the program not to succeed based on the potential payoff.

- Industry response was tyr ically based on the reactions of the participants at the Montreal Conference or on Arthur D. Little experience.

- Cost Impacts on the end use items were related. These were based on projected insulation cost multipliers.

- Time estimates are the time frame in which the technology is required and the estimate of the length of time required to develop the technology. All estimates would assume an aggressive schedule and the availability of the associated funding. 
Table 2-6: Summary of Insulation Research Areas

\begin{tabular}{|c|c|c|c|}
\hline $\begin{array}{l}\text { Research } \\
\text { Area No. }\end{array}$ & R\&D Area Summary & Impact on Technology & Technological Rlsk \\
\hline 1 & $\begin{array}{l}\text { Develop measurement } \\
\text { techniques and equipment. }\end{array}$ & $\begin{array}{l}\text { Will provide for accurate } \\
\text { measurement of new/advanced } \\
\text { insulation panels. }\end{array}$ & $\begin{array}{l}\text { No risk in developing new } \\
\text { technology. Requires } \\
\text { government coordination. }\end{array}$ \\
\hline 2 & $\begin{array}{l}\text { Investigate and/or develop } \\
\text { barrier options. }\end{array}$ & $\begin{array}{l}\text { Will provide for longer life } \\
\text { insulations and will impact all } \\
\text { insulation types. }\end{array}$ & $\begin{array}{l}\text { Without proper barriers all of } \\
\text { the insulations will have shorter } \\
\text { lives. Requires funding to } \\
\text { develop and test new } \\
\text { materials. }\end{array}$ \\
\hline 3 & $\begin{array}{l}\text { Conduct siudies in the } \\
\text { manufacture of end use } \\
\text { products with advanced } \\
\text { insulations. }\end{array}$ & $\begin{array}{l}\text { Will demonstrate the feasibility } \\
\text { of using the various types of } \\
\text { insulations. }\end{array}$ & $\begin{array}{l}\text { Without these types of studies } \\
\text { manufacturers will not have a } \\
\text { clear understanding of which } \\
\text { insulation systems are } \\
\text { practical. }\end{array}$ \\
\hline 4 & $\begin{array}{l}\text { Support the development of } \\
\text { methods of manufacturing, } \\
\text { fabrication, and integration of } \\
\text { insulations. }\end{array}$ & $\begin{array}{l}\text { Will demonstrate the feasibility } \\
\text { of making the various types of } \\
\text { insulation. }\end{array}$ & $\begin{array}{l}\text { Without these studies end } \\
\text { users will not have a clear } \\
\text { indication of the costs } \\
\text { associated with each type of } \\
\text { insulation. }\end{array}$ \\
\hline 5 & $\begin{array}{l}\text { Develop new blowing agents } \\
\text { for foams. }\end{array}$ & $\begin{array}{l}\text { Will provide economical foams } \\
\text { which can be used past the } \\
\text { expected elimination of } \\
\text { HCFCs. }\end{array}$ & $\begin{array}{l}\text { Requires significant expense in } \\
\text { developing and testing } \\
\text { compounds for use as blowing } \\
\text { agents. Any compound could } \\
\text { be eliminated for a variety of } \\
\text { reasons. }\end{array}$ \\
\hline 6 & $\begin{array}{l}\text { Determine alternative filler } \\
\text { materials for vacuum panels. }\end{array}$ & $\begin{array}{l}\text { Could provide for a lower cost } \\
\text { insulation panel or one which } \\
\text { has better thermal properties. } \\
\text { Optimize filler barrier } \\
\text { combinations. }\end{array}$ & $\begin{array}{l}\text { Could require investigation } \\
\text { over an extremely wide range } \\
\text { of materials to locate a fill } \\
\text { which could be used. Fills } \\
\text { which would have improved } \\
\text { characteristics may not be } \\
\text { found. }\end{array}$ \\
\hline 7 & $\begin{array}{l}\text { Investigate the use of high-R } \\
\text { gases as back fills } \\
\text { (displacement of air) into other } \\
\text { applications. }\end{array}$ & $\begin{array}{l}\text { Could allow for a specific type } \\
\text { of insulation to be used in more } \\
\text { applications or a higher } \\
\text { R-value/inch insulation. }\end{array}$ & $\begin{array}{l}\text { New characteristics may be } \\
\text { minimally improved. Requires } \\
\text { the development of barriers, } \\
\text { see Research Area } 2 \text {. }\end{array}$ \\
\hline 8 & $\begin{array}{l}\text { Investigate the options to } \\
\text { perfluoroalkanes, krypton, and } \\
\text { argon as high-R gases. }\end{array}$ & $\begin{array}{l}\text { Related to No. } 7 \text {, would } \\
\text { potentially provide a lower cost } \\
\text { and environmentally friendly } \\
\text { gas which could be used in } \\
\text { high-R gas panels. }\end{array}$ & $\begin{array}{l}\text { Unlikely that alternative gases } \\
\text { will not be found. May not } \\
\text { locate a gas which significantly } \\
\text { improves the performance per } \\
\text { dollar ratio. }\end{array}$ \\
\hline 9 & $\begin{array}{l}\text { investigate the use of organic } \\
\text { aerogels as insulation panels. }\end{array}$ & $\begin{array}{l}\text { Could provide an aerogel which } \\
\text { is lower in cost with better } \\
\text { thermal properties. }\end{array}$ & $\begin{array}{l}\text { Early research has indicated } \\
\text { that these will be very } \\
\text { competitive insulation systems } \\
\text { but must still be characterized } \\
\text { further. Should also look for } \\
\text { other aerogel alternatives. }\end{array}$ \\
\hline
\end{tabular}


Table 2-7: Impact of Insulation Research Areas

\begin{tabular}{|c|c|c|c|}
\hline $\begin{array}{l}\text { Research } \\
\text { Area No. }\end{array}$ & Response of Industry & Cost Impacts & Time Requirements \\
\hline 1 & $\begin{array}{l}\text { Based on the Montreal } \\
\text { meeting, industry is looking for } \\
\text { government to provide } \\
\text { coordination in standardization. }\end{array}$ & $\begin{array}{l}\text { Will have no impact on cost of } \\
\text { insulation option. }\end{array}$ & $\begin{array}{l}\text { Would expect that techniques } \\
\text { and equipment could be } \\
\text { developed in approximately } 5 \\
\text { years. }\end{array}$ \\
\hline 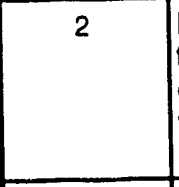 & $\begin{array}{l}\text { Industry is very interested in } \\
\text { this R\&D effort but some } \\
\text { groups may consider this to be } \\
\text { within the realm of industry } \\
\text { R\&D. }\end{array}$ & $\begin{array}{l}\text { Having an improved barrier } \\
\text { system would improve the life } \\
\text { and therefore the cost of the } \\
\text { various insulation systems. }\end{array}$ & $\begin{array}{l}\text { Would expect that the evolution } \\
\text { of barriers will continue well } \\
\text { into the next decade. }\end{array}$ \\
\hline 3 & $\begin{array}{l}\text { Industry and insulation } \\
\text { suppliers would tend to agree } \\
\text { that with government funding } \\
\text { these types of studies could be } \\
\text { carried out. }\end{array}$ & $\begin{array}{l}\text { These types of studies would } \\
\text { improve the confidence in new } \\
\text { insulation systems and would } \\
\text { provide a basis for industry to } \\
\text { develop their own } \\
\text { manufacturing techniques. }\end{array}$ & $\begin{array}{l}\text { Some insulation systems can } \\
\text { be tested now while others } \\
\text { must wait until the systems are } \\
\text { further developed. }\end{array}$ \\
\hline 4 & Similar to No. 3. & Similar to No. 3. & $\begin{array}{l}\text { Similar to No. } 3 \text {. Manufacturing } \\
\text { process of the insulations } \\
\text { themselves can be started } \\
\text { now. }\end{array}$ \\
\hline 5 & $\begin{array}{l}\text { This has typically been an area } \\
\text { which is developed by industry. } \\
\text { There are some universities } \\
\text { which have R\&D efforts in this } \\
\text { area. }\end{array}$ & $\begin{array}{l}\text { Developing the right blowing } \\
\text { agent could potentially } \\
\text { decrease the overall cost of the } \\
\text { insulation. }\end{array}$ & $\begin{array}{l}\text { Development of new blowing } \\
\text { agents will be a continuing } \\
\text { evolution. As new chemicals } \\
\text { are formed, better ones will be } \\
\text { sought. }\end{array}$ \\
\hline 6 & $\begin{array}{l}\text { Industry has typically } \\
\text { investigated new fill materials. } \\
\text { A new thorough search for } \\
\text { alternatives may require } \\
\text { government support. }\end{array}$ & $\begin{array}{l}\text { A new fill which is less } \\
\text { expensive than current options } \\
\text { could reduce the net cost of the } \\
\text { insulation, assuming that the } \\
\text { vacuum requirements are not } \\
\text { greater. }\end{array}$ & $\begin{array}{l}\text { Would expect that the search } \\
\text { for alternative fills will continue } \\
\text { as new processes are formed } \\
\text { and by-products disposal is } \\
\text { reviewed. Many of the } \\
\text { insulations use common } \\
\text { materials but by-products are } \\
\text { options in some instances. }\end{array}$ \\
\hline 7 & Similar to No. 5. & $\begin{array}{l}\text { With a low cost fill gas, an } \\
\text { insulation which has very good } \\
\text { performance characteristics } \\
\text { could be developed. Most of } \\
\text { the current suggested fills are } \\
\text { relatively expensive which } \\
\text { makes them undesirable. }\end{array}$ & $\begin{array}{l}\text { Minimal risk exists, since as } \\
\text { new blowing agents are } \\
\text { developed these are likely } \\
\text { candidates for high- } \mathrm{R} \text { gases. }\end{array}$ \\
\hline 8 & $\begin{array}{l}\text { Although similar to No. } 5 \text {, this } \\
\text { R\&D effort has not typically } \\
\text { been funded by industry. The } \\
\text { first patent was from industry } \\
\text { but more recent work has been } \\
\text { government funded. }\end{array}$ & Similar to No. 7. & Similar to No. 7. \\
\hline 9 & $\begin{array}{l}\text { Currently the R\&D effort is led } \\
\text { by LLNL and therefore funded } \\
\text { by government. }\end{array}$ & $\begin{array}{l}\text { It is expected that the organic } \\
\text { aerogels will be less expensive } \\
\text { than silica aerogels. Also, } \\
\text { other materials can be } \\
\text { investigated for use as } \\
\text { aerogels. }\end{array}$ & $\begin{array}{l}\text { Organic aerogels have been } \\
\text { developed, manufactured, and } \\
\text { tested for mechanical } \\
\text { properties. The testing for } \\
\text { thermal properties is currently } \\
\text { under way. Any future testing } \\
\text { would be on verification or } \\
\text { slightly different formulations. }\end{array}$ \\
\hline
\end{tabular}




\section{References}

[1] H. Jaster, "Refrigerator System with Dual Evaporators for Household Refrigerators," U.S. Patent 4,910,972, March 27, 1990.

[2] "State of the Art Survey of Hermetic Compressor Technology Applicable to Domestic Refrigerator/Freezers," draft report prepared for the U.S. Environmental Protection Agency, by Arthur D. Little, Inc. August, 1991. 


\subsection{Long-Term R\&D Agenda}

\subsection{Summary of R\&D Agenda}

Specific recommendations are presented for each of the five technology areas: domestic refrigeration, chillers, commercial refrigeration, industrial refrigeration and insulation. The background for these recommendations is presented in the individual state-of-the-art assessments in the appendices and the R\&D needs assessment (Section 2).

Considerable commonality of $\mathrm{R} \& \mathrm{D}$ needs exists across the application areas. To eliminate repetition, they are consolidated here into a technology-specific R\&D agenda. Twenty-nine (29) R\&D agenda are recommended, as summarized in Table 3-1. Each $\mathrm{R} \& D$ area is outlined beginning with a new page for clarity. Insulation is listed as a separate area in Table 3-1. However, insulation is key to success in all areas of providing efficient refrigerators with no CFCs.

Criteria for selecting the research topics were:

- The priority for R\&D, listed in Tables 2-2 through 2-6, has the value 3 or greater. As discussed in Section 2, a high priority rating is assigned where a significant need for R\&D exists.

- The level of industry involvement, listed in Tables 2-2 through 2-6, has a rating of 4 or lower. Research that is likely to be done, or is currently being carried out, by industry with little input from government is given the rating 5. An example is development of low cost variable speed drive electronics.

- A significant benefit will be realized from successful development of the technology. 
Table 3-1: Summary of Recommended Long-Term R\&D Agenda

\begin{tabular}{|c|c|c|c|c|c|}
\hline & \multicolumn{5}{|c|}{ Application Areas } \\
\hline & $\begin{array}{c}\text { Domestic } \\
\text { Refrigeration }\end{array}$ & Chillers & $\begin{array}{l}\text { Commercial } \\
\text { Refrigeration }\end{array}$ & $\begin{array}{c}\text { Industrial } \\
\text { Refrigeration }\end{array}$ & Insulation \\
\hline Alternate Refrigerants & - & - & $\bullet$ & $\cdot$ & \\
\hline Non-HCFC Refrigerant Blends & - & - & - & $\cdot$ & \\
\hline Flammable Fluids & - & - & $\cdot$ & & \\
\hline Alternate Small Compressors & - & & & & \\
\hline Oil Free Compressors & - & - & & & \\
\hline Low Expansion Materials & - & - & & & \\
\hline $\begin{array}{l}\text { Ammonia Compatible Hermetic } \\
\text { Compressors }\end{array}$ & • & $\bullet$ & & & \\
\hline Improved Heat Exchangers & - & $\bullet$ & & & \\
\hline Low Inventory System Design & & $\bullet$ & - & $\cdot$ & \\
\hline Thermal Storage Heat Exchangers & - & & & & \\
\hline Stirling Cycle Drive System & - & & & & \\
\hline Stirling Cycle Heat Exchangers & $\cdot$ & & & & \\
\hline Stirling Cycle Model Enhancements & • & - & - & & \\
\hline Stirling Cycle Reliability & $\cdot$ & - & & & \\
\hline Advanced Absorption Systems & & $\cdot$ & & & \\
\hline Reverse Brayton Cycle & & & & - & \\
\hline Secondary Heat Transfer Loops & & & $\bullet$ & & \\
\hline Unitary/Cooling Water Loop & & & $\cdot$ & & \\
\hline Fractionation of NARMS & & $\cdot$ & $\cdot$ & $\cdot$ & \\
\hline Hydrocarbon/Low Temperature Loop & & & $\cdot$ & $\cdot$ & \\
\hline Insulation Measurement Methods & & & & & - \\
\hline Insulation Barrier Materials & & & & & $\cdot$ \\
\hline Insulation Manufacturing & & & & & $\bullet$ \\
\hline Insulation Integration & & & & & $\bullet$ \\
\hline Alternate Blowing Agents & & & & & - \\
\hline Evacuated Insulation Technology & & & & & $\cdot$ \\
\hline High-R Gas use & & & & & $\bullet$ \\
\hline High R-gas Options & & & & & $\bullet$ \\
\hline Allernative Aerogels & & & & & - \\
\hline
\end{tabular}




\subsection{Long-Term Alternative Refrigerants}

\subsubsection{Research Need}

CFCs, or azeotropes containing CFCs, are currently used in all refrigerant application areas. Many near-term substitutes have been investigated, and are now appearing in redesigned products, or are expected to appear within the next four years. Most of these substitutes are halocarbons containing chlorine (HCFCs), which are likely to be phased out within 10 to 20 years. As such, they can only be considered as interim solutions. Table 3-2 below summarizes the new pure refrigerani needs and alternatives. These pure refrigerants can be used as blend ingredients.

Table 3-2: CFC Refrigerant Substitutes

\begin{tabular}{|c|c|c|}
\hline Current Refrigerant & Near-Term Substitute & Long-Term Substitute \\
\hline CFC-12 & HFC-134a & $\begin{array}{c}\text { HFC-134a } \\
\text { HFC-152a } \\
\text { Hydrocarbons } \\
\text { Fluoroethers } \\
\text { Ammonia } \\
\text { unknown } \\
\end{array}$ \\
\hline CFC-11 & $\begin{array}{l}\text { HCFC-123 } \\
\text { HCFC-141b }\end{array}$ & $\begin{array}{c}\text { Fluoroethers } \\
\text { Fluoroalkanes } \\
\text { unknown }\end{array}$ \\
\hline HCFC-22 & $\begin{array}{c}\text { HFC-32 } \\
\text { HFC-125 } \\
\text { HFC-143a } \\
\text { Ammonia }\end{array}$ & $\begin{array}{l}\text { HFC-32 } \\
\text { HFC-125 } \\
\text { HFC-143a } \\
\text { Ammonia } \\
\text { unknown } \\
\end{array}$ \\
\hline$R-502$ & $\begin{array}{c}\text { HCFC-22 } \\
\text { Ammonia } \\
\text { HFC-32 } \\
\text { HFC-125 } \\
\text { HFC-143a } \\
\end{array}$ & $\begin{array}{c}\text { HFC-32 } \\
\text { Ammonia } \\
\text { HFC-143a } \\
\text { Fluoroethers } \\
\text { unknown } \\
\end{array}$ \\
\hline HCFC-114 & $\begin{array}{l}\text { HCFC-124 } \\
\text { HFE-134 } \\
\text { FC-C } 318\end{array}$ & $\begin{array}{l}\text { Fluorethers } \\
\text { Fluoroalkanes } \\
\text { unknown }\end{array}$ \\
\hline
\end{tabular}

Desired attributes of the refrigerant include non-toxicity, non-flammability, zero ODP and low GWP, chemical stability, compatibility with commonly used organic-based and metallic materials in refrigeration systems, good thermodynamic and thermophysical properties, compatibility with common lubricants, and potential for low cost production. Identified refrigerants would be candidates to provide both safety and high efficiency in vanor compression refrigeration systems. The long-term research goal would be to develop fluids that are not compromise replacements to current refrigerants.

\subsubsection{Approach}

Identifying ideal long-term alternative fluids will probably require efforts in a number of fronts, including a methodical search along the lines adopted by vlidgely using properties associated with the position of the elements in the periodic table, application of "designer molecule" computer programs that utilize chemical group contribution analysis, and a screening of chemicals used or developed for use in other technical areas. The search should be guided to the extent possible by theoretical considerations of desirable properties, such as offered by generalized equation of state property relationships. 
Where thermodynamic and thermophysical property relationships are available, analyses of refrigeration cycle perlormance should be carried out for interesting refrigerant candidates. Approximation methods can be utilized to estimate properties where they are unavailable. Based on this initial assessment of cycle performanee, the most promising candidates would be selected for additional characterization.

Those selected would be tested to develop more precise data relating to their thermodynamic and thermophysical properties. In addition, materials compatibility testing would he undertaken to establish their suitability for use in current refrigeration equipment and/or to identify changes required in the equipment to ensure long-term reliable operation. In addition, compatibility with various lubricants would be established. An ideal lluid might be one that is "self lubricating," requiring little or no additives.

Fluid substitutes candidates would include both pure refrigerants and azeotropes. Ideal substitutes would have similar boiling points and densities to reduce the requirements for hardware modification. Where chemically complex candidates are identified, alternate methods of manufacturing should be explored to identify the least-cost approach. Fluid candidates that appear most promising would also undergo toxicity and flammability tests to ensure safety. Bench test laboratory experiments would determine the heat transfer properties and compressor calorimetric tests would be undertaken.

\subsubsection{Estimate of Success}

The most promising candidates for replacement of CFC-11, CFC-114, and maybe CFC-12 are ethers and 3 carbon or 4 carbon fluoroalkanes. This program will likely identify acceptable replacements from these groups.

On the other hand, it is quite probable that all possible replacements for the lower boiling point fluids HCFC-22 and CFC-5()2 are known. The lower boiling point fluids have fewer choices since the trend for replacement would tend toward molecules with fewer carbon atoms. The problem is with the shortcomings of the presently known candidates. The probability of finding suceessful replacements for CFC-22 and CFC-502 during this program is not as good as it is for CFC-11, CFC-114, and CFC-12.

The search for "ideal" alternative refrigerants will probably be an on-going activity with industry involvement at all stages. It is important that the search be guided by a strong theoretical underpinning, such as offered by chemical group contribution theory. It is estimated that the potential for success is intermediate. However, the payoff for success could be enormous in terms of improved efficiency (lower fuel usage) and reduced environmental problems. 


\subsection{Non-HCFC Non-Azeotropic Refrigerant Blends}

\subsubsection{Research Need}

In principle, refrigerant blends offer the opportunity to approximate attributes of "ideal" refrigerants by mixtures of pure components. For example, it might be feasible to achieve properties to optimize the performance of a certain hardware component such as a compressor, while compensating for undesirable features of one or more ot the chemical constituents, such as mild flammability. A number of blends for interim application have heen identified. These contain HCFCs which will be phased out over time.

\subsubsection{Approach}

Refrigerant blend R\&D would be an on-going activity that would be applied to "new" refrigerants as deemed desirable. Components in the R\&D would include:

determination of toxicity and flammability (i.e., establish composition limits of flammable constituent); estimates of thermophysical and thermodynamic properties for application to cycle analyses; determination of compatibility with lubricants, establishment of hardware requirements (i.e., is a counter-flow evaporator needed, is the temperature glide sufficiently small that standard cross-llow designs are satisfactory); establish the heat transfer behavior of the hlends in the evaporator and/or condenser; determine the consequences of preferential leaks and identify methods to compensate for leaks.

Those blends that appear to offer benefits in terms of safety, energy efficiency, and environmental impact (low ODP and GWP) would thus be further characterized by calorimeter tests and breadhoard or prototype refrigeration cycle tests. Requirements for hardware modification specilic to the application (e.g., compressor redesign) would be defined.

\subsubsection{Estimate of Success}

The use of non-HCFC blends to approximate desired refrigerant properties has a high likelihood of suceess if the target is to obtain similar performance as currently used refrigerants, with zero ODP and low GWP and with good safety characteristics. The probability of success will be substantially lower if the objective is to obtain a refrigerant that has a significant energy efficiency improvement.

The application of hlends will continue to be an altractive concept for use with newer (possibly synthesized) refrigerants. That is, it is a tool that has long-term potential application. 


\subsection{Fractionation of Non-Azeotropic Refrigerant Mixtures}

\subsubsection{Research Needs}

One of the options for developing new refrigerants with highly optimized properties or as a drop-in replacement, is to formulate mixtures of two or more components, none of which by itself is ideal. Many of the resulting mixtures, both those that have been investigated experimentally and those that could be identified and investigated in the future, are non-azeotropic. The possibility of the mixture composition shifting through fractionation, given the differing equilibrium vapor and liquid compositions of non-azeotropic mixtures, is the most frequently cited uncertainty and obstacle to practical use of NARMS. Composition shifting due to two causes are at issue. When leakage is primarily liquid or vapor, the resulting refrigerant loss will be at other than the average composition. In addition, within the system, there could be a tendency for more volatile components of the blend to accumulate in the high side of the system due to their more rapid boil off from the low side. Also, there is an issue of cross-flow versus counterflow heat transfer in a fractionating mixture. The result of these effects would be an increase in the pressure ratio between the high and low sides of the system and a corresponding decrease in the COP.

Research is needed to develop a more comprehensive understanding of these two aspects of the behavior of NARMS in systems. The key questions are the extent to which composition shifts occur, the impact of these shifts on the performance, and measures that can be implemented to maintain system, and high and low side compositions with an acceptable range.

\subsubsection{Approach}

A combined analytical and experimental investigation is needed, addressing both "near" azeotropic mixtures (small) dewpoint - bubble point temperature difference and mixtures exhibiting large temperature glides and large differences in equilibrium liquid vapor concentration. Experimental measurements of mixture composition throughout a representative system - key locations are the expansion device inlet and compressor inlet and progressive positions along the refrigerant path length of the evaporator and condenser - would provide a quantitative basis for assessing the extent to which fractionation will occur within systems. Analytical work would consist primarily of reviewing the refrigerant blend technical literature, making use of previously reported measurements of composition vs. location in the system and leakage effects on blend composition.

\subsubsection{Estimate of Success}

The technical issues associated with blend fractionation are amenable to systematic investigation; the likelihood is high that broadly applicable principles that can be used to minimize composition shift related performance degradation can be developed. 


\subsection{Flammable Fluids}

\subsubsection{Research Needs}

There are a number of either mildly flammable or highly flammable fluids that appear to offer excellent refrigerant properties. Currently, manufacturers are extremely reluctant to utilize such fluids as pure components, or even as a component of a blend, because of safety considerations in the building or in the manufacturing facility. As an example, a major concern often expressed is that a refrigerator manufacturer could incur a legal liability from a house fire even were the refrigerator not directly involved.

The objectives of the R\&D effort would be to develop guidelines relating to the safe use of flammable refrigerants, including establishing levels of risk and design methods for mitigating such risks.

\subsubsection{Approach}

All refrigerants of potential interest in the refrigeration system should be well characterized in terms of their flammability. Factors to be established include quantifiable parameters such as the lower flammable limit, ignition energy, and maximum explosion over-pressure. Conditions required to create an ignition potential should be determined by tests.

Based on these results, a formal risk assessment should be undertaken. The risk assessment would follow a standard methodology with established event probabilities. Development of the risk methodology should be completed so that a standard methodology is used for all flammable refrigerants or refrigerant blends.

Conditions under which refrigerant blends release tlammable constituents should be established and documented as part of the formal risk assessment.

Design approaches should be developed that minimize risks associated with leakage or sudden release of flammable constituents. For example, potential ignition sources could be encapsulated in a way to reduce or eliminate the possibility that the component acts as an ignition source; inother approach would be use of a secondary heat transfer loop to separate the flammable fluid from the cooling coil.

The result of this research would be the development of approved guidelines for acceptable refrigeration system practice for use with flammable fluids. Those guidelines would be developed and/or approved by industry associations, such as ASHRAE, ARI, AHAM, ANSI, NFPA, UL, ETL, and state and local building codes.

\subsubsection{Estimate of Success}

The R\&D should provide definitive guidelines and definitions of acceptable practice. A formal risk assessment methodology should be defined which the manufacturer can utilize.

The interests of this research are to ensure safe design, to provide confidence in the use of certain flammable refrigerants or mixtures that have other potential benefits such as improved energy efficiency, and to provide a technical basis for possible legal protection to manufacturers from litigation based solely on the use of flammable fluids. 


\subsection{Efficient Low Temperature Secondary Heat Transport Loops}

\subsubsection{Research Needs}

The objective is to develop a design approach for low temperature (for temperatures down to $-40^{\prime \prime} F$ ) heat transfier loops that can be used to connect either frozen food or refrigerated display cases to a remote central refrigeration unit. As discussed in early parts of the report, secondary loops are needed to allow use of ammonia within the safety ground rules of ASHRAE Std 15, and would be needed to allow the use of flammable refrigerants. Alternate technologies -- reverse Stirling and advanced absorption/adsorption cycles need a secondary heat transport loop as well. To be viable, the secondary loop design needs to provide the following characteristics: low parasitic power, minimal increase in the heat transfer temperature differentials between the evaporator (saturated suction temperature at the compressor) and the air temperature in the display case (compared to direct expansion evaporators), low heat gain from ambient, and acceptable cost.

\subsubsection{Approach}

A phased approach should be followed. The phases which are described briefly below are:

- Phase 1 - conceptual design and technical evaluation study

- Phase 2 - Proof of concept level laboratory testing

- Phase 3 - Application specilic, full scale prototype development

- Phase 4 - Field test

At the end of each phase a go/no go decision would be made on the basis of two key criteria, both of which must be satislied: a viable, low $\Delta \mathrm{T}$, low parasitic design must be established, and there must continue to be a need for high performance secondary loops, with the ultimate selection of a low temperature refrigeration working fluid that is suitable for use in direct expansion systems continuing to have uncertainties.

In the Phase I conceptual design and evaluation both liquid only and two phase (liquid-vapor and, perhaps, liquid-solid slurry) concept would be defined. Fluid candidates would be identified and characterized with respect to transport properties and safety attributes. Estimates of heat transter temperature differentials, pressure losses, and pumping power would be prepared, for a range of heat exchanger configurations, store and piping system layouts, and pipe diameters. Follow on phases would provide verification of the performance of selected low temperature loop configurations, tailored for the most promising refrigeration cycle and working fluids.

\subsubsection{Estimate of Success}

The additional $\Delta T$ 's of a secondary loop will penalize system performance. There is a reasonable probability, however, that the increased efficiency of one or more of the alternatives whose use is dependent on a low temperature secondary loop will offset these penalties. 


\subsection{Hydrocarbon Refrigerant/Low Temperature Secondary Loop Safety Study}

\subsubsection{Research Needs}

Hydrocarbons such as propane and propylene have some significant potential advantages as refrigerants -- indeed, they satisfy all of the traditional criteria for "good" refrigerants except for obvious problems of tlammability. Of particular interest, is the low environmental impacts (zero ODP, negligible GWP) and high efficiency characteristics of these fluids. Commercial refrigeration, especially low temperature commercial refrigeration, is one area where these potential advantages are very significant. A detailed study of the conditions under which fluids like propane could be used safely for low temperature commercial refrigeration is needed. A secondary loop coupled system would be a particularly germane focus of this investigation, because use of hydrocarbon refrigerants in this system configuration is only an incremental step beyond the use, which is already consistent with ASHRAE Standard 15, of ammonia in the same configuration.

\subsubsection{Approach}

Established methodologies for quantitatively evaluating risks, such as fault tree analysis and consequence modeling would be applied to the conceptual design of a low temperature, propane based, refrigerant system. The conceptual design would incorporate system design features (e.g., minimum relrigerant inventory, minimum use of non-welded/brazed tubing points) and installation requirements (e.g., roof top location, remote or explosion proof electricals.

\subsubsection{Estimate of Success}

Vast quantities of pressurized, liquified gaseous fuels, e.g., propane, are routinely handled safely and economically throughout the U.S. and world industrial, commercial, residential, and transportation sectors. In view of this experience, the probability is high that a safe, economical design of a commercial low temperature refrigeration system can be defined and analytically viewed. The eventual adoption of hydrocarbon working fluids will depend on differences is the cost and performance of other post HCFC alternatives, coupled with perceptions of liability exposure. 


\subsection{Evaluation of Water Cooled Unitary Refrigerated and Frozen Displays Cases for Supermarket Refrigeration}

\subsection{Research Needs}

Tiue direct expansion evaporator for cold case, remote condensing unit configuration of supermarket central ref rigeration systems has become broadly accepted because this arrangement minimize; noise in the retail area, maximizes display volume, and provides for heat rejection to s.mbient, so that the refrigeration capacity also acts as air conditioning capacity, rather than adding to air conditioning load. In the current environment of ozone depletion, global warming, the associated CFC phare out, and the general increase in the cost of refrigerants, major disadvantages of this arrangement include the large refrigerant inventory and the tendency of these systems to be leaky. The pressure drop in long suction lines both reduces efficiency and places practical restrictions on the candidate refrigerants to be utilized. An alternative which maintains the same thermal balance on the store environment is to use water cooled unit coolers, with the cooling water locp serving to remove heat rejected by the refrigeration system from the store interior. A factory sealed, welded hermetic refrigeration system, having a very modest "afrigerant charge, can be utilized. The reduced, hermetically contained refriger $n t$ inventory, and the short suction line between the evaporator and condenser, potentially broadens the choice of refrigerant. The overall feasibility, efficiency impact, and integration with the complete store thermal system of this design approach needs to be investigated.

\subsubsection{Approach}

Initially a system design, performance, and feasibility study is needed. The factors that need to be addressed include:

- Refrigerant options

- Hermetic compressor performance when optimized for efficiency, at design conditiolis

- Conceptual design of several representative unitary cases, considering the current design of case for use with current central refrigeration systems, the current design of unit coolers, the feasible levels of compressor eificiency, and the viable refrigerant alternatives. Address space coristraints and noise control.

- Integration of the water cooling loop with the cases and the store systems ' ambient heat rejection, ventilation, make up air heating/cooling, and recirculated ir. rrior air cooling/reheating/heating. Definition of both evaporative and non-evaporatıve cooming for heat rejection. Definition of piping sizes, materials, ans costs.

- Efficiency and performance evaluation, comparison with current ceniral refrigeration systems.

\subsubsection{Estimate of Success}

The approach described above wou d provide an accurate basis for evaluating the potential advantages and disadvantages, in the CFC/HCFC phase out environment, of this approach vis a vis the conventional arrangement of supermarkei refrigeration systems. 


\subsection{Low Inventory Heat Exchangers}

\subsubsection{Research Needs}

As the CFCs and HCFCs are phased out, the remaining refrigerant alternatives tend to be higher in cost, and/or have associated safety issues of flammability and/or toxicity. In view of this, it would be generally beneficial to reduce the refrigerant charge needed for a variety of systems. In most system configurations, the operating refrigerant inventory in the condenser and evaporator accounts for a large portion of the total system refrigerant charge, so that development of heat exchanger designs that operate with reduced refrigerant inventory, at comparable cost, pressure drop, and heat transfer coefficients offers the potential for significantly reduced system refrigerant inventory as well.

\subsubsection{Approach}

An initial design study should examine alternative configurations for refrigerant to air evaporators and condensers and refrigerant to water evaporators and condensers. Options to be considered that are applicable to one or more of these are enhanced refrigerant side heat transfer surfaces, reduced dimensions of existing geometries (e.g., roduced tube diameters), new reírigerant side geometries, plate heat exchangers, and spray evaporators. For each, the effect on working refrigerant needs to be estimated, along with heat transfer coefficient, refrigerant side pressure drop and circuiting modifications needed to minimize pressure drop and achieve good refrigerant distribution to parallel flow heat transfer channels, and a qualitative assessment of manufacturability and cost impact.

\subsubsection{Estimate of Success}

There is a high probability of successfully defining heat exchanger configurations requiring significantly less refrigerant inventory than typical current practice. 


\subsection{Improved Heat Exchangers}

\subsubsection{Research Needs}

Reduction of temperature differences between the refrigerant and the heat source (evaporator) or the heat sink (condenser) can have a significant impact on the overall cycle efficiency, particularly in low-lift applications such as with building chillers or dual evaporator domestic refrigeration. Trade-offs normally made consider the relationship between the convective heat transfer coefficient and the refrigerant or free-stream pressure drop. Reduction in air-side pressure drops can lead to immediate savings in fan power, reduction in refrigerant side pressure drop will improve the compressor performance.

Optimum heat exchanger design will be dependent on the refrigerant fluid properties. For example, the condensation coefficient of a blend of two components with widely separated boiling points is often lower than the coefficient with either pure constituent.

\subsubsection{Approach}

Several logical steps should be carried out:

1) Improve analytical methods for heat transfer and pressure drop analysis. The focus of this work would be on improving understanding of the blends in evaporation and condensation inside and outside of tubes. A goal of the analyses would be to develop easily applied rules for heat exchanger design involving complex geomeiries that promote turbulence over the entire surface.

2) Laboratory analyses in support of the analytical work. Both basic R\&D and specific geometry-fluid combination evaluations would he carried out.

Solicitation for novel heat exchanger concepts could be prepared.

\subsubsection{Estimate of Success}

This is likely to be a fruitful research area. Incremental improvements in heat exchanger design could have broad applications across all of the refrigeration sector. 


\subsection{Thermal Storage Heat Exchangers}

\subsubsection{Research Needs}

Domestic refrigeration cycling losses can, in principle, be reduced by use of thermally massive heat exchangers. The requirements include good heat transfer from the refrigerant to the internal surface and good thermal diffusivity within the thermal storage medium.

\subsubsection{Approach}

Approaches for thermal storage include additional metal structure or incorporation of a high thermal mass heat storage medium, such as a eutectic sulfur or phase change medium. Candidate designs should retain high efficiency heat exchange with both the refrigerant, including refrigerant blends, and the cabinet air. The heat exchanger should be compact to retain maximum food storage volume. Long-term reliability should be a part of the design criteria, particularly where phase change materials are employed.

Candidate designs should he reviewed in terms of methods of integration with a working domestic refrigeration unit. Laboratory and prototype testing of the heat exchanger design should be undertaken to establish the heat transfer effectiveness. The affect on refrigeration cycle losses should he quantified hy test. Impacts on the cabinet design and methods of air circulation within the cabinets would be assessed as part of the research. For example, a heat storage natural convection evaporator may not prove desirable in a two evaporator direct cooling design where the fresh food evaporator is expected to provide a natural defrost function during the off-cycle.

\subsubsection{Estimate of Success}

A high level of technical suceess is estimated. Determining factors in the application of heat storage heat exchanger technology will include cost and the reduction of cycling losses. 


\subsection{Alternate Concepts for Small Compressors}

\subsubsection{Research Needs}

Domestic refrigeration currently utilizes reciprocating or rotary compressors. Scroll technology appears limited to the higher capacity applications, such as with heat pumps or air conditioners. With reduced refrigerator cabinet losses and/or alternate cycle concepts, the need for efficient small compressors will grow.

Analysis of loss mechanisms in compressors indicates maximum efficiency opportunities in the range of 50-60\% of Carnot, the major losses being associated with the electric motor, suction gas heating, and friction. The objective of the long-term $\mathrm{R} \& \mathrm{D}$ effort is to identify alternate compressor concepts and to develop and test prototype units.

\subsubsection{Approach}

Requirements for alternate small compressors for domestic refrigerator application include small physical size for integration into the refrigerator envelop, electric drive, high efficiency (potential for greater than $60 \%$ of Carnot), reliability, and potential for low-cost production. Steps in the research include:

1) Identification of new concepts -- a review of the literature relating to compressor technologies would be carried out. Research organizations would be invited to submit proposals for specific concepts.

2) Analysis -- develop estimates of the pump efficiency and compare with current compressor technology

3) Potential for application -- describe hardware requirements, and the method for integrating the compressor into working hardware. Identify important interface issues, such as lubrication requirements, pump cooling requirements, controls

4) Test -- for promising concepts develop benchtop, or breadboard, apparatus and carry out laboratory tests. Assess promise of the technology, and determine where further development is required.

5) Cost -- assess potential costs for mass production. Compare with current technology. Establish targets for cost-effective technology that is competitive with the current highly engineered domestic refrigeration compressors.

\subsubsection{Estimate of Success}

This is a very high technical risk research area. Probability for replacement of current technology compressors is low. 


\subsection{Oil Free Compressor}

\subsubsection{Research Needs}

The efficiency of refrigeration equipment can be highly dependent on the choice of lubricant. One of the major challenges associated with the potential use of HFC-134a has been selection or development of a compatible lubricant that enables the refrigeration cycle to achieve its thermodynamic potential. As new refrigerants are developed, compatible lubricants must also be identified for this use.

Current hardware design must also accommodate the presence of oils, to ensure that it remains within the compressor unit and does not contribute to the fouling of heat transfer surfaces. For example, oil traps, filters, and other devices are used to trap oil and return it to the compressor. The existence of an efficient oil free compressor could eliminate some of this equipment, thereby providing a potential cost savings and allowing a wider choice of refrigerants.

\subsubsection{Approach}

Technologies used in other fields that employ oil-firee compressors would be reviewed to determine what is applicable to the small compressors used for refrigeration equipment. Necessary design changes in compressors would be identified, including use of special materials. Technologies of possible applications include new ceramic materials, impregnated surfaces, low friction alloys, and gas bearings, such as used in special cryogenic cooling devices on surveillance satellites. A prototype design would be developed and tested for efficiency, wear and reliability. Designs that appear attractive would under go accelerated life testing to determine the potential for reaching the $20,000-40,000$ hour operation of current oil lubricated compressors.

\subsubsection{Estimate of Success}

Development of an oil-free compressor will probably be difficult. The technical risk associated with development is high. Success may require identification of a new compressor technology. Reliability, long-life, and cost are paramount issues in the highly competitive refrigeration market. The technical risks and costs associated with the technology would have to be compared with more conventional refrigerant equipment utilizing standard compressors. 


\subsection{Low Expansion Materials for Compressors}

\subsubsection{Research Needs}

The efficiency of compressors is affected by the ability to maintain mechanical tolerances, particularly with small compressors where mechanical losses reach $8-12 \%$ and where piston blowby losses can reach another $10 \%$ in rotary designs. Internal heat dissipation from the electric motor, and from the compression process itself, could contribute to changes in internal dimensions that could affect these losses.

\subsubsection{Approach}

Several approaches to reduced dimensional changes are possible. New materials, suitable for use in the compressor would be investigated. This would involve basic metallurgy considerations. The use of ceramics in compressor design would also be explored. A recent example of suceess in this area is the development of ceramic rotors for screw compressors.

Opportunities for similar advances in small compressors should be examined, for example in the design of the piston or the cylinder of a small reciprocating unit.

Design concepts would be developed and prototype units built and tested. Long-term reliability and accelerated life testing would be undertaken.

\subsubsection{Estimate of Success}

The probability of technical suceess is moderate. Practicality of the technology will be determined by cost versus performance issues and the ability to achieve long life. 


\subsection{Ammonia Compatible Hermetic Compressor}

\subsubsection{Research Needs}

One of the major alternative refrigerants to the fluorocarbons is ammonia. Although widely used in industrial refrigeration, it has essentially no current use in domestic refrigeration. Ammonia has several problems that make it difficult to use in a hermetic system: high hygroscopy, high electrical conductivity, and high corrosivity relative to copper and iron. Hermetic compressors are desirable in domestic refrigeration hecause seal leakage problems are eliminated and the compressor pump and electric motor can be installed as a single compact unit.

\subsubsection{Approach}

Design approaches to avoiding contact between ammonia gas and the electric motor should be developed. Two methods currently conceived are the use of aluminum motor windings and the use of a hermetic can between the motor rotor and stator with the stator core located outside the can which eontains the ammonia refrigerant. Both methods suffer from significant elificiency lossc::

Alternate methods of isolation or mattrials replacement would be investigated. Consideration would include the resultant motor efficiency, compressor motor cooling methods, internal heat transter paths (suction gats heating) and life time.

\subsubsection{Estimate of Success}

Development of small hermetic aramonia compatible compressor refrigerants represents a medium technical risk. The objective should be to develop, lest, and demonstrate design concepts which could be part of an overall compressor design effort since use of ammonia as a refrigerant in domestic refrigeration would require additional changes to the system, including heal exchanger design and use of alternate materials. 


\subsection{Stirling Cycle Model Enhancements}

\subsubsection{Research Needs}

The research needs include an improvement in knowledge of fluid friction and heat transfer during oscillating flow in heat exchangers, and a more clearly defined physical model. Optimization of the heat exchanger design is critical towards approaching Carnot cycle operation. Specifically, temperature drops across the heat exchangers must be as small as possible while maintaining high rates of heat transfer and low pressure drop. Standard heat exchanger design tools are not capable of adequately describing the consequences of oscillatory flow.

\subsubsection{Approach}

1) Assess the state of the art of analysis of oscillating flow heat transfer as applied to the heat exchangers of the Stirling cycle. The exchangers include the regenerator and cold and hot heat exchangers. Assess the potential for improved regenerator performance.

2) Construct a model (or revise a state of the art model) to investigate basic phenomena of flow friction and heat transfer in Stirling heat exchangers. Include oscillating flow in the heat exchangers and basic phenomena sufficient to assess the real potential. This procedural step is difficult - to make an accurate model of the Stirling heat exchangers.

3) Operate the model, varying parameters, to define the performance of the Stirling heat exchanger system.

4) Develop design approaches to improved heat exchangers.

\subsubsection{Estimate of Success}

This program is difficult. It requires increasing the knowledge of basic fluid flow and heat transfer phenomena in order to fully evaluate Stirling cycle performance. The estimate of success is moderate that a satisfactory to excellent understanding of Stirling flow and heat transfer will be achieved. 


\subsection{Stirling Cycle Compact Heat Exchangers}

\subsubsection{Research Needs}

The working gas cannot be coupled directly to the domestic refrigerator cabinet because of physical constraints and the expected small size of the heat exchanger. Hence, an intermediate heat transfer mechanism is required to couple the unit to the refrigerator evaporator and condenser. In addition, the heat transfer effects within the heat exchanger are complicated by the oscillatory flow nature of in the working gas. Development of very effective compact heat exchangers is required to achieve performance potential of the Stirling cycle to enable it to compete with vapor compression devices, in domestic refrigerator applications.

\subsubsection{Approach}

A first step is to develop a thorough understanding of the time dependent heat transfer and fluid flow processes occurring within the heat exchangers. Tradeoffs between the rates of internal heat exchange and pressure drops will affect the cycle performance.

A low temperature drop means of secondary heat transfer to couple the Stirling unit to the cabinet space and to the heat rejection space must be developed. Possible approaches include a heat pipe or a refrigerant loop with a phase change fluid. The secondary heat exchange system would be coupled to an effective evaporator and condensing heat exchanger. Initial concept evaluations would focus on the heat exchanger and secondary heat transfer loop as a component.

Integration of the Stirling cycle into the domestic refrigeration system must ensure a minimum of parasitic losses, maximization of fond storage volume, and long-term reliable operation.

\subsubsection{Estimate of Success}

The technical challenge of an efficient heat transtier system, to couple the working fluid to the cabinet space, is substantial. However, successful completion of the research goal is essential to the development of a viable Stirling cycle based alternative to the vapor compression cycle. 


\subsection{Stirling Cycle Regenerator Improvement}

Regenerator performance and cost are one of the primary problem areas with Stirling refrigeration. Regenerator heat transfer ineffectiveness is an essential factor in causing lower COPs/performance. The following program focuses on improving regenerator performance, while keeping it cost effective, so that Stirling refigerator COPs can more nearly approach their potential.

\subsubsection{Research Need}

The research need is to improve Stirling regenerator performance - increase effectiveness, lower the pressure drop, lower void volume, lower cost, and reduce contaminant plugging.

\subsubsection{Approach}

The approach is a program to improve regenerator performance as given by the following procedure:

1) Assess the state-of-the-art with regard to regenerator fill characteristics effectiveness, pressure drop, void volume, cost, plugging susceptibility.

2) Generate concepts to improve the eflectiveness while reducing pressure drop and cost. Contamination susceptibility must be no worse than present designs.

3) Model the most promising concepts using an existing state-of-the-art model/computer program. Run the model with parameter studies to show parametric effects on regenerator performance.

4) Construct a prototype test system and prototype(s) of the hest regenerator candidate(s).

5) Conduct a program of lesting the candidate regencrator(s).

6) Perform an analysis of the test results and make conclusions about the improvement in regenerator performance.

\subsubsection{Estimate of Success}

The estimate of success is moderate. Much regenerator research has been done with marginal improvements in regenerator performance. The generation of concepts in step 2 above is a very important, difficult step. Program success is dependent on proper concepts. 


\subsection{Stirling Cycle Drive System}

\subsubsection{Research Needs}

Successful application of Stirling technology to refrigeration requires very careful attention to minimization of all losses with the system. Current efforts include a form of a linear drive mechanism, with a low friction bearing mechanism. One approach is the use of gas hearings. The need exists to develop and engineer long-life, low friction drive mechanisms for the cycle.

\subsubsection{Approach}

Continuing development of free-piston drive systems for domestic refrigeration study cycles should be undertaken. The steps include: 1) comprehensive analysis of fluid mechanics within the unit; 2) review and selection of materials, for use in the drive system, that provide long-life and low wear; 3) design optimization analysis including calculation of energy loss mechanisms; 4) incorporation of the analysis results into improved prototype mechanisms; 5) tests of the prototypes to estahlish performance; and 6) utilization of performance results to reline the analysis and to establish new approaches to optimum design.

The design concepts should emphasize long-term reliahility, and should detail the conditions that could limit reliability. Each design concept should include consideration of how the design would ultimately be integrated into a working appliance. Design experience in acrospace applications should be utilized to the degree possible. Attention must be paid to dimensional stability of all materials and to leakage of the working gas.

\subsubsection{Estimate of Success}

Development of a cost-effective, long-term reliable ellicient drive mechanism represents a significant technicial challenge. For example, it is likely that very tight mechanical tolerances will be required and that avoidance of contamination within the working volume will be of paramount importance. Costs of such a sophisticated drive mechanism may be high. 


\subsection{Stirling Cycle Reliability}

While Stirling cycle refrigeration offers the potential of high COP, system designs need improvement in reliability and cost effectiveness. The following program addresses the need for higher reliability.

\subsubsection{Research Needs}

To effectively compete with vapor compression, the reliability of the Stirling cycle needs to be increased. Components specifically needing reliability improvement include durable seals and bearings. Operating these components in a high frequency environment with dry or no lubrication requires careful consideration of design trade-offs and testing sufficient to prove the resulting design. While executing a durable Stirling cycle, the design must either not generate contaminants, e.g., wear debris from bearings and seals, or else it must successfully handle the contaminants without system degradation. The system must have a demonstratable potential for ultimate long-term use.

\subsubsection{Approach}

The approach includes the following steps:

1) Assess the state-of-the-art of Stirling refrigerators. Sources must include refrigerators made by British Aerospace, Philips, and Hughes Aircraft Corp. Identify the major bearing and seal forces in the designs. Also identify material needs for seals and bearings to function satisfactorily while eliminating or reducing contamination due to wear debris.

2) Perform wear studies on the seal/bearing materials identified in step 1 above. Include contacting and clearance seals operating under momentary contact conditions associated with kinematic Stirling cycle operation. Also consider the same seal/bearings on free piston Stirling cycles.

The initial phase of this step should be analytical studies. Following this, the most promising system(s) should be subjected to experimental testing to determine wear rate and expected lifetime.

3) Consider the effects of stopping and starting on the systems of step 2 above. If hydrodynamic bearings are used on the free piston system, what are the effects of lift off (starting) and set down (stopping)? How many start/stop cycles can the system endure? How can the endurance be improved? Consider the same questions with hydrostatic gas bearings and clearance seals.

4) Design/build a prototype(s) Stirling system using the optimal bearings/seals identified above from durability considerations.

5) Perform a long-term run of the prototype with an objective of determining seal/bearing wear/endurance. Determine the amount and size distribution of wear particulates. Determine system reliability in terms of Mean Time Between Failures or Mean Time to Failure.

6) Modify/retest as necessary to obtain a design approach to ensure bearing and seal reliability.

\subsubsection{Estimate of Success}

Success is expected in this program. The wear studies of step 2 leading to more durable seals and bearings is the most important and most difficult step of the program. 


\subsection{Advanced Absorption Systems}

\subsubsection{Research Needs}

To achieve an equivalent primary energy efficiency as electrically driven chiller systems, an absorption system must achieve a COP of 1.6 or higher. The objective is to develop a triple effect absorption system with a COP of 1.8 or higher. (Research to improve the cost effectiveness of lower COP absorption systems are not included here since the emphasis is on long-term R\&D for energy-efficient equipment.)

\subsubsection{Approach}

There are two developments underway that can serve as starting points and to define problem areas. One is the Trane dual loop triple effect system. A new chemical system is needed; therefore, a search for alternative sorbent/refrigerant pairs is needed. Also, a corrosion inhibitor and heat transfer enhancing additive that will endure at the $425^{\circ} \mathrm{F}$ to $500^{\circ} \mathrm{F}$ generator temperature of the triple effect system is needed. This is primarily a materials investigation. One primary thrust of the Trane program is to investigate material compatibility in the high temperature generator of the triple effect system. Trane is building a system with the goal of having it operational in about two years.

The other system currently under development is the lithium bromide double condenser coupled machine being developed by York together with Battelle Columbus Laboratory. The issue here is also materials - the stability of materials at the high temperatures. The general problem area is material compatibility at the $50(0) \mathrm{F}$ generator temperature necessary for triple effect systems. Corrosion additives are a concern. Stable heat transfer additives are needed to get the absorber to equilibrium more quickly.

The steps to develop high temperature materials are:

1) Explore candidate absorbent/refirigerant pairs possible and characterize them in high temperature generator operation.

2) Select the most promising absorbent/refrigerant pair

3) Develop compatible heat transfer additives and corrosion inhibitors. Be sure the heat transfer additive will not decompose at the high temperature or interact with the corrosion inhibitor or materials of construction. This may indicate a system design to get the additive out of the generator quickly.

4) Prove the chemistry of the system by life testing of a prototype chiller under controlled condition.

\subsubsection{Solid Absorbent Research Needs}

1) Complete the cataloging of available absorption/refrigerant pairs.

2) Investigate the life expectancy of absorbent/refrigerant pairs - what is the chemical fatigue after many cycles through high temperature regeneration. This step includes an investigation of the interaction of materials of construction with the absorption chemical system.

3) Develop a prototype design. Included is a heat exchanger optimization to minimize cost by minimizing metal used and fabrication cost.

4) A critical area for these systems is the heat exchange between the sorbent, sorbent support structure, barrier and heat exchange fluid. Heat transfer coefficients must be large to minimize surface area. The sorbent and the support/barrier system must maintain structural integrity through hundreds of thousands of cycles such that the heat transfer or mass transfer rates are not degraded.

5) Develop a process control/materials specification. Identify the critical steps in preparation of the bed.

6) Design, build, and test a prototype; with experience gained, improve the design. 
3.21.2.2 Liquid Absorbent Research Needs Water-cooled liquid absorption systems hi ve a potential for high COP refrigeration applications. Steps recommended for this application are:

1) Evaluate alternate refrigerant-absorber pairs, for example, HCFCs or HFCs with organic absorbents, or ammonia with water-salt absorbent;

2) investigate cycle improvements over the single-effect GAX cycle, which allow use of high temperature heat input;

3) Generator and absorber component enhancements; and

4) Develop and test prototype.

\subsubsection{Estimate of Success}

Success is $6 x$ :cted in this program. Finding fluids/inhibitors and a flow schematic to successfully uperate a triple effect system should be realized in this effort.

Similarly, enough is known about the chemistry and durability of the solid absorption systems to anticipate a variety of refigeration/chiller products emerging as well as very high efficiency hybrid solid/liquid absorption chillers. 


\subsection{Adsorption Cycles}

\subsubsection{Research Need}

The technical feasibility of adsorption heat pumping, with a COP in excess of unity for cooling has been demonstrated. Present reservations about practicality are addressed only to cost and size. The present program addresses these issues. From Section 3.2.2.4, a three ton unit, using Zeolite vould require 540 lbs. of Zeolite and appreciable copper in the heat exchanger. Material and assembled components will cost around $\$ 2500$. The cost must be reduced to be competitive with vapor compression.

\subsubsection{Approach}

The approach is given in the following list of steps:

1) Assess the state-of-the-art of adsorption refrigeration with regard to COP, cost, and size compared to vapor compression for commercial/industrial refrigeration.

2) Generate concepts for a reduced cos/size system. The COP must be increased. Particular attention must be addressed to adsorbent selection, heat exchanger design, oil heater, fan coils, pumps, and auxiliaries - reducing costsize in each case.

3) Simulate the selected concept(s) on a state-of-the-art model/computer code to determine expected performance. Make a detailed estimate of the expected cost. Evaluate the concept(s) for further action at this stage.

4) Design and construct a prototype of the most promising concept. Monitor construction costs.

5) Test the prototype under different seasonal climatic conditions to determine the seasonal COP.

6) Modify/retest as necessary.

\subsubsection{Estimate of Success}

The estimate of success is moderate. Success depends on identification of adsorbents and a design to reduce cost and size for a given seasonal COP. 


\subsection{Desiccant Cycles}

The purpose of desiccant cooling is to enhance evaporative cooling by preceeding the evaporator with a solid or liquid dehumidification system to increase the temperature lowering which takes place in the evaporator. While the COP of desiccant cooling is on the order of 0.5 (Section 3.2.3.12), the COP can be increased to an attractive level by proper use of evaporative-only cooling. Most of the seasonal cooling in many climates can be satisfied by evaporative cooling (Section 3.2.3.4). Operation of the desiccant cooler with the evaporate cooler (Figure 3-7) would only be used for the relatively small part of the time when evaporative cooling alone does not place the air in the comfort zone. The "smart" controls for proper operation of the desiccant cycle are an important part of this recommended program.

\subsubsection{Research Need}

The research need is to develop and demonstrate a combined desiccant/evaporative cooling system with a $40^{\circ} \mathrm{F} \mathrm{COP}$ of greater than 1.6 using a smart control system.

\subsubsection{Approach}

The approach is given by the following steps:

1) Develop a control system that senses the comfort condition of the air and operates the desiccant system only when evaporative cooling alone will not cool the air into the comfort zone.

2) Develop a prototype evaporative/desiccant system. Install the smart control system.

3) Test the prototype under a varicty of seasonal climatic conditions. This may involve operating the prototype at several locations.

4) Modify/retest as necessary and prepare comparisons with vapor compression and conclusions.

\subsubsection{Estimate of Success}

Success in operation of the system with smart controls is expected. The real objective of the program was to achieve a seasonal COP of 1.6 or greater under a variety of climatic conditions. Success under some climatic conditions is expected. 


\subsection{Recuperated Reverse Brayton Cycle for Industrial Blast Freezers}

\subsubsection{Research Needs}

As described in preceding sections, an open recuperated, reverse Brayton Cycle is potentially comparable in efficiency to vapor cycle for blast freezers. While the vapor cycle is inherently higher in efficiency than reverse Brayton, the power consumption of the air blast blowers is a significant parasitic in vapor cycle based systems that would be largely absent from a reverse Brayton cycle system. Air is the working fluid, so safety and ozone depletion potential are not issues.

\subsubsection{Approach}

An initial feasibility study is needed, to define, for typical blast freezers, the range of capacity needed and cold air supply and return temperatures and flow rates. The key Brayton Cycle components -- the compressor/expander/drive motor, the recuperator, and the heat rejection heat exchanger -- would be defined with respect to basic technology, performance, size, and cost. The range of cycle COP would be determined analytically, given a range of pressure ratios and component technologies (e.g. compressor/expander based on automotive turbo charger or air craft air cycle cooling technology). The results would be compared with the conventional ammonia and CFC-502 vapor cycle including parasitics.

\subsubsection{Estimate of Success}

Modest probability of defining a system design having environmental, cost, and operational advantages over vapor cycle, at comparable efficiency. 


\subsection{Insulation Measurement Techniques and Equipment}

\subsubsection{Research Needs}

Measurement techniques and equipment for testing advanced insulations must be developed. Primarily this requires the standardization of the methods used in determining the thermal properties of insulation panels both new and aged. Since the current systems were developed to measure insulations which are relatively amorphous with resistivities below 10 , the application of this equipment to most of the advanced insulations is inappropriate. Therefore, the government agencies should he active in specifying and designing the equipment which will provide accurate results for insulations with resistivities approaching 100. This equipment should be able to assess the impact of edges on the overall insulation package. This type of development is primarily to provide potential users with a proper basis for comparison between the different insulation options. Currently the thermal properties of insulations must be examined carefully along with the methods used and then adjusted for discrepancies between methodologies and equipment. Also, a means for accelerated life testing is required. This will provide life predictions and costs.

\subsubsection{Approach}

A review of all current technologies and the projected maximum resistivities must be determined. This will provide the range of thermal conductivities which must be included. Developing an appropriate approach, based on the requirements, is the next step in designing the required equipment. This would include test apparatus, procedures, and a means of calibration.

The effects of the edges should be accounted for in the measurements. This will require that an insulation be characterized hased on the edge to area ratio. This is required for the evacuated systems or those which require some type of harrier. Currently the center of panel thermal conductivity is measured, but for those insulations with enclosures or barriers this will vary depending on the panel size, enclosure/barrier material and thickness, as well as the center of panel properties. What is required is a ratio of heat leak through the edge based on the total heat leak. This measurement is complicated by the fact that the enclosure actually acts as a fin. The use of plastics or other low conductivity materials for enclosures can reduce the edge effects and, therefore, simplify the measurement. The measurement of the overall resistivity of a panel will be very difficult and will require a specific methodology.

The situation may be further complicated if large single enclosure type systems are made. This measurement could be simplified if tests similar to those currently made on refrigerator/freezers (internal heating) could be used.

The insulation boards and batts used in building construction will likely be similar to those currently used. The new measurement equipment should not affect these industries unless some of the advanced (higher resistivity) systems are used.

\subsubsection{Estimate of Success}

The development of an instrument which can accurately determine the distribution of heat leak from the edges will be difficult. It should, however, be possible to develop an instrument which can measure the overall resistivity of a panel. 


\subsection{Insulation Barrier Materials}

\subsubsection{Research Needs}

Barrier materials and encapsulations which can meet the requirements of the new insulation technologies must be developed. These requirements include the ability to hold vacuum, act as barriers, prevent water moisture transfer, and protect the insulations. In some cases this material must also act as a thermal radiation barrier. Since barrier materials are applicable to nearly every application and technology, this is an especially attractive area for government involvement. There are many technologies which will not be feasible without a good encapsulation/barrier. These typically are the evacuated and High-R gas insulations.

\subsubsection{Approach}

Coordination of efforts and a means to disseminate the information is extremely important. Definition of a standard operating environment should also be completed. This would allow definition of which materials are suited for specific applications. Specifying the requirements for the barriers and specific test requirements is an initial step in the process. The allowable permeation to specific gases should be determined and an accurate means of testing should be specified. These two items together would allow many of the materials engineering companies to begin developing materials for specific types of applications. Although much of this information exists, it needs to be collected and standardized. Some materials are available which could potentially be used as effective barriers, for these the next phase would be testing. Determining the effects of the permeation rates as the materials are cycled through temperature ranges, exposed to the potential environments (moisture, blowing agents, weather conditions, etc.), and pressure requirements (i.e. determine outgassing).

For some applications (construction industry) the main issue is the adhesion between the insulation panels and the barriers. As the temperature changes the physical dimensions vary which fatigues the interface between barrier and insulation. After a time the two hegin to separate.

The use of metal barriers would be effective but would potentially increase the cost of the insulation while decreasing its thermal performance. The main issues here are: how thin a metal is required to provide the barrier characteristics, how thick a sheevfoil is required to provide the handling and forming characteristics, and what are the effects of the environment on the metal. Cost would have to be considered when evaluating the first two issues. Although a thin metal foil uses less malerial and limits the edge losses, it is potentially more expensive to manufacture. The reverse is true for thicker sheets.

\subsubsection{Estimate of Success}

The estimate of suceess will depend on the application and the technology. To develop barrier materials for the construction industry appears to be less difficult. These would typically be used to retard the water vapor mass transfer, provide a radiation harrier, and protect the insulation. Once put in place, this type of insulation is usually sandwiched within a wall. The separation of the barrier and the insulation is hampered in this case. For these applications the adhesion issue is apparent during storage and prior to installation. For those cases where the insulation is in a cavity, the separation may be possible throughout the lifie of the insulation.

In the cases where evacuated insulations are being used, the primary issue is permeation over the life. This will be a more difticult problem to solve. The complications include: must have low/no outgassing, be sealable (heat sealable or other means), have a low thermal conduction (be thin and low thermal conductivity), and be compatible with the environment in which it is used. The enclosure may also have to support the weight of the insulation if an adhesive is used during installation. Depending on the specific application the estimate of success is moderate to good. 


\subsection{Insulation Manufacturing \& Testing}

\subsubsection{Research Needs}

An opportunity to demonstrate the manufacture of insulation systems, test insulations, and examine the feasibility of using alternative insulation systems in specific applications is required. Depending on the insulation types, industry will cover most if not all of the manufacturing issues of the insulations. In some instances where the insulation is promising, some additional support may be required to provide advancement of the technology. Some of the insulations which may benefit from manufacturing technology would be aerogels and high-R gas panels. Additionally, studies of the true environmental impacts of using a specific insulation technology will depend on the energy and waste products generated during manufacture.

A more thorough review of the applicability of various technologies to the different applications is required. Previous studies, primarily at ORNL, have evaluated the cost impacts for short term solutions typically using low resistivity (10 and lower) insulations. These types of analysis must also be conducted for potential long term solutions which may have much higher resistivities (15 to 5()). In order to verify these analysis, as the insulations are sufficiently developed they should be installed into specific applications and the actual performance measured.

\subsubsection{Approach}

The insulation systems which are nearly fully developed should be examined to determine the energy requirements and the waste products generated during manufacture. This will require that independent groups be provided with the complete manufacturing procedure and be allowed to evaluate the procedure. Some companies are ready to manufacture insulation systems now but the costs associated with the process need to be documented. Ideally, from a series of studies, the impacts to the environment can be evolnated. Also, the potential for recycling during manulacturing and at disposal should be evaluated.

The insulations must be tested to determine the performance in final form. These should be tested in as close to a mass manufactured form as possible. Additionally, models should be developed which could predict the insulation performance based on the materials of construction and the configuration. The results of the two should be compared and the models corrected as required. The use of models will provide a quick means of estimating future designs. The models and the testing should aim to provide estimates of life, thermal performance, and compatibility to different environments.

\subsubsection{Estimate of Success}

Without this type of program the insulations of the future will have to be selected based on incomplete data. There are no risks associated with this task, only benefits. 


\subsection{Insulation Integration}

\subsubsection{Research Needs}

Support in the development of methods of manufacturing, fabrication, and integration of insulations is required. For the evacuated insulation systems, integration into the various applications will necessitate different integration procedures. For boards and blown foams the insulation installation is relatively straight forward. With boards mechanical fasteners or adhesives can be used. The use of mechanical fasteners may prove to be unworkable with evacuated insulations, especially in appliances. For some applications different methods of integration have been used in preliminary testing (e.g., blowing foam to hold the insulation panel), but no optimization has been performed. In other applications, no attempts have been made to integrate the advanced insulations. The performance of the insulation as a structural component should also be examined.

\subsubsection{Approach}

End use items should be built with the new insulation systems, or near mock-ups to demonstrate the feasibility of integrating the insulation panels. This would include the methods of locating and fixing the insulation. Possibilities include using adhesives, mechanical fasteners, or foam to hold and locate the insulations. When available the end products should be tested to determine the actual performance of the insulation. The current practices for testing products (i.e. R/F, homes, etc.) can be used to verify the performance.

\subsubsection{Estimate of Success}

Methods of integration should not be major hurdles to the introduction of insulations to the markets. Therefore, the estimate of success is good. 


\subsection{Alternative Blowing Agents and Materials}

\subsubsection{Research Needs}

The development of low cost, environmentally friendly, and effective blowing agents for foams is required. With the elimination of $\mathrm{CFCs}$ and the predicted elimination of the HCFCs, a lack of available blowing agents will become evident. There will be some which will continue to be available such as water and perfluoroalkanes, but these have inherent problems which make them unattractive. Water blown foam has a lower resistivity than $\mathrm{CFC}$ blown foams as well as a higher diffusion rate for the $\mathrm{CO}_{2}$. The structural characteristics are very good and this type of foam could very likely be used as part of the structure. Perlluoroalkanes can be used to produce foams with similar resistivities as CFC blown foams but the GWP and cost are high. This effort should not be limited to blowing agents but should be expanded to blown insulation systems. This would comprise a blowing agent and the associated chemicals required to form the polymers and the interstitial gas. Also, systems which are formed by different means, other than blowing should be examined.

\subsubsection{Approach}

Industry will typically complete the required research but government should coordinate efforts and provide forums for distributing information. Initial studies at universities could be co-funded by industry and government. In this area, being extremely competitive, much of the industry considers the technology proprietary and this will make the dissemination of information more difficult. The use of universities and consortiums would allow for transfer of technology and information.

Initially, literature searches and modeling of potential systems would be required. The modeling should be able to predict the end product and some of the mechanical and thermal characteristics.

Extensive work would he required when developing new methods of foam production. When looking for new blowing agents for the current systems the required parameters are known. The need is to develop a new chemical which meets these parameters. For an all new system, the types of chemicals which are required can vary widely.

\subsubsection{Estimate of Success}

New blowing agents are likely to be available at some point, due to the industries interest in producing foum products. The development of new systems is less likely unless an acceptahle alternative hlowing agents is not developed. 


\subsection{New Evacuated Insulations}

\subsubsection{Research Needs}

Identifying new fill materials for evacuated panels with the specific aim of reducing the cost which could improve their acceptance is required. The search for alternatives should be very wide and cover many industries. The current evacuated insulations are more expensive than the foams which they would replace. In some cases this cost is prohibitive while in others the required pressure leve! is unacceptable. Optimizing either of these two parameters would promote a better insulation system.

\subsubsection{Approach}

A very diversified group of technical experts should examine products and materials generated and used in a variety of industries to determine if there exists a low cost fill which could be used as a fill material for evacuated panels. In some cases the fills currently proposed are by-products of other processes. If these are available in large quantities then the cost could be relatively low. Investigation into other processes to determine if different types of fills are available should be conducted.

The use of mixes of different fills can also improve the performance of the insulation. It may be possible to identily a mix of fills which could reduce the vacuum requirement and therefore simplify the enclosure requirements. There have been some mixes tested but these have been very limited. Optimization of the fills would also include selection of enclosure, since the enclosure will affect the internal pressure capability.

\subsubsection{Estimate of Success}

The estimate of success is moderate. It is unclear if there actually exists a lower cost and efficient fill material. 


\subsection{High-R Gas Use}

\subsubsection{Research Needs}

Investigation of high-R gases as back fills into other applications could provide attractive insulations systems. It may be advantageous to model and test the use of high-R gases as the interstitial gas in already existing insulations which may lead to better cost performance ratios. Since some of the insulations can be used without vacuum, such as aerogels and open cell toams, the substitution of a gas with lower thermal conductivity would decrease the overall thermal conductivity. The insulations would then be able to combine the low thermal conductivity gas, small cell sizes, and the opacification systems which are being developed.

\subsubsection{Approach}

A program should be set up to fabricate and test various combinations of gases and insulation structures (i.e. aerogels, fiberboard, open cell foam, etc.). The cost effectiveness of these insulation systems would have to be estimated to compare with existing and future alternatives.

The issues of proper encapsulation would have to be addressed and further tests on projected lifetimes would be needed. The effects of adding short-circuits around the insulation with the encapsulation will of fset some of the benefits of using a high- $\mathrm{R}$ gas. The reliability of this type of systems would be lower than a non-filled panel of the same material, since, with a puncture or improper sealing the high-R gas would leak out.

The cost of the panels should take into account not only the higher cost of the gas but also the cost to evacuate the panel and backfill. The use of an air-high- $R$ gas mixture may provide attractive combinations which would reduce the cost.

\subsubsection{Estimate of Success}

It will likely prove that backfilling with high-R gases will produce higher performance panels but the cost may be prohibitive. 


\subsection{High-R Gas Options}

\subsubsection{Research Needs}

Identification of new fill gases for high-R gas panels could reduce insulation costs and should be investigated. The focus should be on maintaining the performance while reducing the cost of the gas. When possible, performance improvements should also be investigated.

\subsubsection{Approach}

As new chemicals (blowing agents) are developed they should be examined for their application as fill gases. The primary criteria should be thermal conductivity, materials compatibility, cost, and resistance to permeation.

LBL is currently investigating options for high-R gas panels and Enhanced Insulations, Inc. is looking at variations of this type of insulation. These types of systems should be built and tested. The tests should include performance and life testing.

\subsubsection{Estimate of Success}

It is likely that alternative gases will be found which will be less expensive than some of the current options. Argon will tend to set the cost and performance goal. 


\subsection{Alternative Aerogils}

\subsubsection{Research Needs}

Characterization of the organic aerogels, and other aerogels which could be formed is required. In the past, Kistler and others formed aerogels from different materials. Originally these were interesting oddities which had no application. More recently these have been recognized as potentially good bases for insulation. If aerogels of different materials can be formed then the performance may be improved. This may include being able to relax the vacuum requirements.

\subsubsection{Approach}

Set up a program which will test the different organic aerogel formations for the mechanical and thermal properties. The first step would be to review literature for the aerogels which have already been developed and determine if the characteristics are suitable for insulation panels. The important characteristics would be thermal conductivity of the base material, cell size, potential for opacification, compatibility with a vacuum (for evacuated panels), and strength.

After the literature search, the next step would be to fabricate and test those panels which are good candidates. The testing should include evacuated, non-evacuated, and backfilled. The cost and performance need to be examined as well. For the evacuated panels the resistivity versus pressure should also be tested. This will allow for the tailoring of different panels for different applications.

\subsubsection{Estimate of Success}

There will be alternative aerogel materials but none may have better performance to cost ratios than the organic and silica. However, the wide range of materials which can be used to form aerogels may yield another alternative. 
Appendix A

Overview of Technology Options 
A-1 Chemical Substitutes for Refrigeration Cycles A-1

A-1.1 Summary of Substitute Fluids That Have Been Identified ............. A-4

A-1.2 Long-Term Potential Substitutes ............................................... A-10

A-1.3 Recent and Current R\&D .................................................. A-13

A-2 Alternative Refriy $=$ ration Technologies ............................................. A-14

A-2.1 Alternative Vapor Compression Cycles …................................. A-15

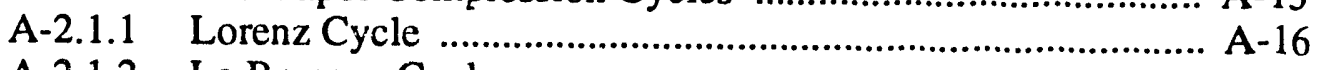

A-2.1.2 La Brecque Cycle ................................................................ A-18

A-2.1.3 Hybrid Vapor Compression'Injection Cycle ......................... A-19

A-2.1.4 Multiple Evaporator/Compressor Cycles .............................. A-20

A-2.2 Absorption and Adsorption Refrigeration ................................... A-20

A-2.2.1 Current Status of Absorption Space Conditioning .................. A-21

A-2.2.2 Anticipated Developments, Liquid Absorbent Systems ....... A-22

A-2.2.3 Heat Pumps Using Solid Sorbents .................................... A-24

A-2.2.4 Adsorption Heat Pumping .................................................. A-24

A-2.2.5 Solid Absorption Heat Pumping: Solid
H; $;$ ute/Ammoniate Heat Pumping for CFC Replacement

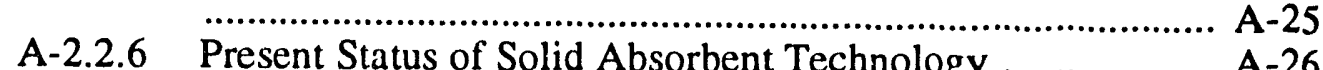

A-2.3 Humidification/Dehumidification in Space Cooling ..................... A-27

A-2.3.1 Overview .................................................................... A-27

A-2.3.2 The Principle ................................................................. A-28

A-2.3.3 Some Operational Considerations of the Evaporative

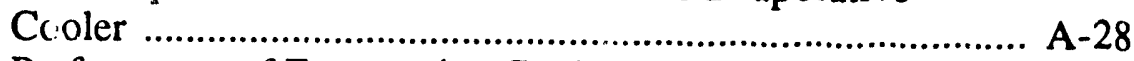

A-2.3.4 Performance of Evaporative Coolers ................................... A-29

A-2.3.5 As Assessment of Evaporative Cooling as CFC

A-2.3.6 Indirect Evaporative Cooling ……...................................... A A-32

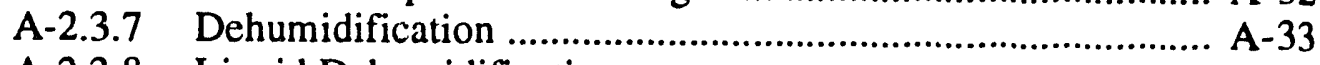

A-2.3.8 Liquid Dehumidification .................................................... A-33

A-2.3.9 Solid Dehumidification System …….............................. A- A .35

A-2.3.10 Desiccant Cooling Systems .............................................. A-31

A-2.3.11 Liquid Desiccant Cooling ................................................. A-37

A-2.3.12 Solid Desiccant Cooling …............................................ A-38

A-2.4 Stirling Cycle ................................................................... A-40

A-2.4.1 Status of Ttirling Development …................................... A-41

A-2.4.2 Technical Issues ......................................................... A-42

A-2.4.3 Life and Reliability ......................................................... A-43

A-2.4.4 System Configurations ..................................................... A-43

A-2.5 Vuilleumier Cycle ............................................................ A-46

A-2.6 Reverse Brayton Cycie ........................................................ A-46 
Table of Contents (Continued)

A-2.7 Magnetic Refrigeration ..................................................... A-48

A-2.8 Ejector Heat Pump ............................................................... A-51

A-2.9 Thermoacoustic Refrigerator ............................................... A-53

A-2.10 Vortex Tube ..................................................................... A-56

A-2.11 Pulse Tube .................................................................... A-57

A-2.12 Malone Refrigeration .......................................................... A-59

A-2.13 Thermoelectric Refrigeration .............................................. A-61

A-2.13.1 Background ............................................................. A-61

A-2.13.2 Some Scientific Background ......................................... A-62

A-2.13.3 A Commercial Claim .................................................. A-65

A-2.13.4 An Example .......................................................... A A-65

A-3 Alternative Blowing Agents for Foams ...................................... A-66

A-3.1 Requirements for Blowing Agents ......................................... A-68

A-3.2 Potential Alternatives ..................................................... A-70

A-4 Advanced Insulation Technologies ............................................... A-72

A-4.1 Non-Evacuated Fiberglass and Loose Fill Insulation ..................... A-74

A-4.2 Non-Evacuated Aerogel ....................................................... A-75

A-4.3 High-R Gas Panels ............................................................ A-77

A-4.4 Evacuated Systems .......................................................... A-79

A-4.4.1 Evacuated Foam ...................................................... A-8

A-4.4.2 Evacuated Powder/Fiberglass Panels ................................. A-83

A-4.4.3 Evacuated Aerogel ................................................... A-84

A-4.5 High Vacuum Insulation .................................................. A-85 


\section{A-1 Chemical Substitutes for Refrigeration Cycles}

One basic approach to meeting the cooling requirements traditionally met by vapor compression cycle cooling equipment using one of the CFCs as the refrigerant is to use a non-ozone depleting refrigerant in the same, or, if necessary, modified or redesigned vapor compression cycle based equipment. The CFCs that are covered by the Montreal Protocol are CFCs 11,12,13,13B1,113,114, and 115. All of these, except CFC-113, are commonly used as a refrigerant in one or more of the refrigeration and cooling applications that fall within the scope of this project. Table A-1 and Figure A-1 summarize the vapor cycle working fluid applications of CFCs $11,12,114$, and 115 (CFC-502 is $48 \%$ HCFC-22 and $51 \%$ CFC-115). Table A-2 summarizes the basic properties of the CFCs.

Table A-1: Current CFC Refrigerants Used in Applications within the Scope of this Study

\begin{tabular}{|c|c|c|c|c|c|}
\hline Refrigerant & E.P., 'F & Applications & $\begin{array}{c}\text { Capacity Range } \\
\text { tons }\end{array}$ & & \multicolumn{2}{|c|}{ Typical Temperature Lift } \\
\cline { 4 - 6 } & & & & Evaporator, ${ }^{\circ} \mathrm{F}$ & Condenser, $^{\circ} \mathrm{F}$ \\
\hline CFC-11 & 75 & HVAC chiller & $80-2000$ & 40 & 100 \\
\hline CFC-114 & 39 & Navy chiller & $100-250$ & 40 & 110 \\
\hline CFC-12 & -22 & HVAC chiller & $100-+2,500$ & 40 & 100 \\
& & Domes.ic refrigeration & 0.1 & -20 & 130 \\
& & Commercial refrigeration & $0.5-50$ & $-40 / 10$ & 130 \\
& Industrial refrigeration & $2-1000$ & $-40 / 10$ & 130 \\
\hline CFC-502 & -50 & Commercial refrigeration & $0.5-50$ & -40 & 130 \\
& & Industrial refrigeration & $2-1000$ & -40 & 130 \\
\hline
\end{tabular}

Tuble A-2: Selected Property Values for the CFCs that are Commonly Used as Refrigerants

\begin{tabular}{|c|c|c|c|c|c|}
\hline Property & inits & CFC-11 & CFC-12 & CFC-114 & CFC-502 \\
\hline Normal Boiling Temperc ture & $\cdot F$ & 74.9 & -21.6 & 38.8 & -50.1 \\
\hline Critical Temperature & ' $F$ & 388.4 & 233.6 & 294.3 & 194 \\
\hline Critical Pressure & psia & 640 & 597 & 473 & 619 \\
\hline Flammability & $\cdots$ & $N$ & $N$ & $N$ & $N$ \\
\hline $\begin{array}{l}\text { Toxicity: } \\
\text { TLV-TWA } \\
\text { STEL } \\
\text { UL Classification }\end{array}$ & $\begin{array}{l}\text { ppm } \\
\text { ppm }\end{array}$ & $\begin{array}{r}1000 \\
-- \\
5 a\end{array}$ & $\begin{array}{r}1000 \\
\cdots \\
6\end{array}$ & $\begin{array}{r}1000 \\
- \\
6\end{array}$ & $\begin{array}{r}1000 \\
2500 \\
5 a \\
(115=6)\end{array}$ \\
\hline
\end{tabular}

TLV $=$ Threshold Limit Value, TWA $=$ Time Weighted Average, STEL $=$ Short Term Exposure Limit. These values indicate safe, long-erm exposure limits relative to known chronic (long-term) toxic effects, as established by the American Conference of Governmental and Industrial Hygienists (ACGIH).

A "good" refrigerant will have most of the following characteristics, listed in the rough order of priority (all of these characteristics are important; the exact order of priority, and the degree to which compromises can be accepted depends on the application): 
Figure A-1: CFC Refrigerants: Temperature Lift Ranges for Current Applications

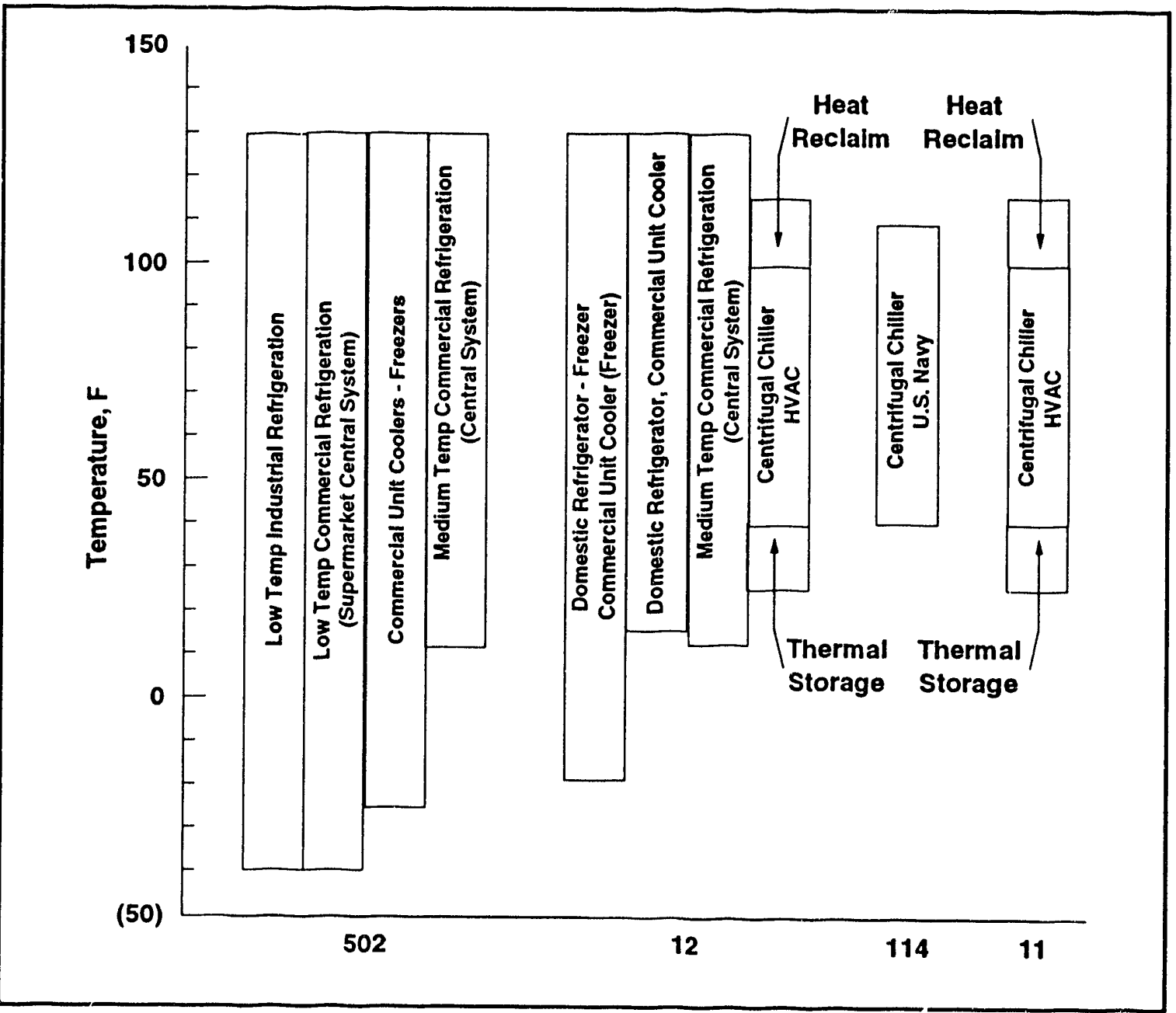

1) Environmentally benign, as mandated by the Clean Air Act Amendments of 1990

- zero ODP (<< 0.05 required)

- low GWP (desirable)

- short atmospheric lifetime (a major factor in determining the ODP and GWP)

2) Thermodynamic properties

- high theoretical COP (cooling effect/input power)

- vapor pressure-temperature curve suitable for the operating temperature range and the type of compressor

3) Chemical stability in a closed system

- temperature

- lubricant

- materials of construction 
4) Chemical compatibility

- does not attack materials of construction

5) Lubricant solubility

- preferably mineral oil, an effective, low cost lubricant with excellent performance as a lubricant

- others also acceptable, e.g., alkylbenzenes, polyolesters

6) Safe

- non-toxic

- non-flammable

7) Transport properties

- high heat transfer coefficients

- low pressure drops

8) Easily produced and low cost

The currently used CFCs meet all of these criteria with the exception of the first. None of the environmentally acceptable substitute fluids that have been considered combine all other desirable characteristics to the extent of the CFCs; as a result, compromises are now being accepted that were unthinkable a few years ago.

After the environmental characteristics, which are mandated by the Montreal Protocol and U.S. Clean Air Act, the next four attributes (thermodynamic properties, chemical stability, chemical compatibility, and lubricant solubility) can be viewed as the core requirements the refrigerant must satisfy to serve as the basis of practical, reliable, efficient cooling equipment.

The remaining characteristics are important attributes, but there is much more room for compromise than there is in the core attributes, because reasonable design measures and/or operating procedures can limit any resulting disadvantages.

Safety, of course, is of paramount importance. During the 60 years of the CFC era, safety requirements were viewed in terms of the fluid, i.e., the fluid should be sufficiently benign that large quantities could be released, either by accident or sloppy handling, with no safety consequences. In practice, this requires non-flammability and very low toxicity, two basic attributes of the CFCs. As the CFC phase out begins to take effect, the traditional view of safety is shifting toward one of considering the total sircumstances of the application, the nature of the equipment design, the placement of the equipment, and the procedures that could be followed in the event of an accident. For example, recent HCFC-123 toxicity test results have resulted in the reduction of the allowable exposure limit (AEL) to $10 \mathrm{ppm}$ (compared to $1000 \mathrm{ppm}$ for all of the common refrigerants). In reference [1], the Trane Company presents a strong argument in favor of accepting this (comparatively) toxic refrigerant, for use in HVAC chillers, on the basis of the much lower concentrations of refrigerant vapor (compared to the AEL) that is typically found in chiller rooms and the ability of operating procedures to adequately limit the risks associated with accidental releases. 
Similar rationakes can be developed to demonstrate the feasibility of using flammable refrigerants safeiy in various applications, given an appropriate combination of equipment location, high reliability leak-tight system design, limited quantity of refrigerant charge, absence of potential ignition sources, ventilation, vapor sensors, etc.

Favorable transport properties are an attribute that facilitates efficient equipment design. Less favorable transport properties can be offset through design, basically larger refrigerant side heat transfer surfaces. Thus, efficiency can be maintained, but at a higher equipment cost.

Low fluid cost is desirable--the CFCs typically were on the order of $\$ 1.00$ per pound (1986 price). Much higher costs are now being accepted for the current substitutes. For example, the price of HFC-134a in bulk quantities will be nearly $\$ 10.00$ per pound during the first several years of production.

In view of the overall importance of the preceding attributes, the first phase in the evaluation of an alternative is to characterize the fluid in terms of these attributes. The next phase in the evaluation of the alternative is to design, fabricate, and test prototype cooling equipment, first for performance evaluation. When satisfactory performance has been demonstrated, testing for durability is initiated.

\section{A-1.1 Summary of Substitute Fluids That Have Been Identified}

In the material that follows, the discussion of alternative refrigerants is organized in terms of potential substitutes for each of these four CFC refrigerants (CFC-11, CFC-12, CFC-114, CFC-502). Although this treatment is somewhat arbitrary, the equipment that has been found to be most economical for most cooling applications generally has tended been designed around the characteristics of one of these fluids. Where an alternative fluid might be a reasonable substitute for more than one CFC, it is so noted.

In the material that follows, the substitutes for each CFC are grouped into "current," "near to medium term," or "long term" substitute categories. Table A-3 summarizes the categories.

- "Current substitutes" are currently available and will be in widespread use within the next 2-3 years:

- Not a CFC (may or may not be an HCFC);

- Currently (as of late 1991) in either initial commercial production or large scale production;

- Cooling equipment that uses the current substitute, generically similar to equipment using the CFC w be replaced, either is being produced, or equipment manufacturer(s) have puiblicly committed to be producing such equipment;

- Not necessarily a "drop-in" or a "near drop-in" fluid for existing CFC based equipment.

- "Near to medium term substitutes" satisfy criteria similar to the above, but with a longer lead time required to sll scale commercial use as a refrigerant. The basic criteria are: 
Table A-3: Summary of Current and Longer Term CFC Substitute Fluids (pure fluids also can be used in blends)

\begin{tabular}{|c|c|c|c|c|c|}
\cline { 2 - 6 } & \multicolumn{2}{c|}{ Current Substitutes } & \multicolumn{2}{c|}{$\begin{array}{c}\text { Near to Medium Term } \\
\text { Substitutes }\end{array}$} & $\begin{array}{c}\text { Long Term } \\
\text { Substitutes }\end{array}$ \\
\hline $\begin{array}{c}\text { CFC } \\
\text { Refrigerant }\end{array}$ & HCFC & Non-Chlorine & HCFC & Non-Chlorine & Non-Chlorine \\
\hline $\begin{array}{c}\text { CFC-11 } \\
\text { (refrigerant) }\end{array}$ & 123 & $\cdots$ & $141 \mathrm{~b}$ & $\cdots-$ & $\begin{array}{c}\text { E-143 } \\
\text { E-152 } \\
\text { HFC-216 } \\
\text { Fluorobutanes }\end{array}$ \\
\hline CFC-114 & $\cdots$ & $\cdots$ & 124 & $\begin{array}{c}\text { E-134 } \\
\text { C318 }\end{array}$ & $\begin{array}{c}\text { Fluoropropanes } \\
\text { Other } \\
\text { Fluoroethers }\end{array}$ \\
\hline CFC-12 & $\begin{array}{c}\text { Ternary } \\
(22 / 114 / 124) \\
142 b\end{array}$ & Ammonia & $\begin{array}{c}\text { Ternary } \\
(22 / 152 a / 124)\end{array}$ & $\begin{array}{c}134 a \\
152 a \\
\text { Ammonia } \\
\text { Propane } \\
\text { Cyclopropane }\end{array}$ & $\begin{array}{c}\text { E-125 } \\
\text { HFC-227ea,ca } \\
\text { Ammonia } \\
\text { Propane } \\
\text { Cyclopropane }\end{array}$ \\
\hline CFC-502 & 22 & Ammonia & 22 based blends & $\begin{array}{c}\text { HFC-125 } \\
\text { HFC-143a } \\
\text { HFC-32 } \\
32 / 125 \\
\text { Ammonia }\end{array}$ & $\begin{array}{c}\text { E-125 } \\
\text { E-116 } \\
\text { Ammonia } \\
\text { Propane } \\
\text { Propylene }\end{array}$ \\
\hline (also HCFC-22) & & & & & \\
\hline & & & & & \\
\hline
\end{tabular}

- Not a CFC;

- The fluid is either commercially produced or under active commercial development for refrigerant application;

- Cooling equipment to use the fluid may or may not be available or under active development;

- Not necessarily a "drop-in".

- "Long term substitutes" have potential advantages, but are not under active commercial development as refrigerants. The time to bring one of these fluids to commercial acceptance as a refrigerant would be on the order of ten years. Fluids in this category are the primary focus of the $R \& D$ recommendations of this project. The basic attributes are:

- Non-chlorinated;

- Normal boiling point close to ore of the CFCs;

- Thermodynamic and transport properties, if known, result in high cycle efficiency;

- Other known characteristics do not disqualify for refrigerant application.

Tables A-4 through A-7 summarize the characteristics of each of these potential substitutes, for CFC-11, CFC-12, CFC-114 and CFC-502, respectively with the substitutes grouped as described above. 
Table A-4: Alternative Refrigerants for CFC-11 (Chiller Working Fluid)

\begin{tabular}{|c|c|c|c|c|c|c|c|}
\hline Refrigerant & $\begin{array}{l}\text { Bolling } \\
\text { Point, } F\end{array}$ & $\begin{array}{c}\text { Flammability } \\
\text { Troxiclty }\end{array}$ & ODP/GWP & $\begin{array}{l}\text { Probable } \\
\text { Availabillty }\end{array}$ & $\begin{array}{c}\text { Theoretical } \\
\Delta \\
\text { Efticlencies }\end{array}$ & $\begin{array}{c}\text { Problem } \\
\text { Areas/ } \\
\text { R\&D Needs } \\
\end{array}$ & $\begin{array}{c}\text { Description, Status, } \\
\text { Comment }\end{array}$ \\
\hline CFC-11 & 75 & $N / N$ & $1.00 / 3,500$ & Current & 0 & & Will be phased out. \\
\hline \multicolumn{8}{|l|}{$\begin{array}{c}\text { Current } \\
\text { Substitutes }\end{array}$} \\
\hline HCFC-123 & 82 & $N / T$ & $0.016 / 85$ & Current & $-2 \%$ & $\begin{array}{l}\text { Toxicity, } \\
\text { materials }\end{array}$ & $\begin{array}{l}\text { Toxicity testing underway, } \\
\text { needs to be completed. } \\
\text { Based on recent results, } \\
\text { exposure limits < } 10 \mathrm{ppm} \text {. } \\
\text { Aggressive solvent, } \\
\text { potential materials } \\
\text { problems with motor } \\
\text { insulation and elastomers. }\end{array}$ \\
\hline \multicolumn{8}{|l|}{$\begin{array}{c}\text { Near/Medium } \\
\text { Term } \\
\text { Substitutes }\end{array}$} \\
\hline HCFC-141b & 90 & $M F / N$ & $0.15 / 440$ & Current & $-2 \%$ & Materials & $\begin{array}{l}\text { Co-product of HCFC-142b } \\
\text { production. Commercial } \\
\text { production began in July } \\
\text { 1988. Toxicity testing } \\
\text { underway. Aggressive } \\
\text { solvent, potential materials } \\
\text { problems ". ith motor } \\
\text { insulatir . and elastomers. }\end{array}$ \\
\hline \multicolumn{8}{|l|}{$\begin{array}{l}\text { Long Term } \\
\text { Substitutes }\end{array}$} \\
\hline Fluoroalkanes & & $N / ?$ & O/low? & Long Terrn & $?$ & & $\begin{array}{l}\text { Initial characterization - } \\
\text { much work remains to } \\
\text { establish characteristics, } \\
\text { potential advantages, } \\
\text { disadvantages. }\end{array}$ \\
\hline $\mathrm{HFC}-245 \mathrm{ca}$ & 77 & & & & & & \\
\hline HFC-236ea & 60 & & & & & & \\
\hline HFC-235ca & 83 & & & & & & \\
\hline HFC-338eea & 78 & & & & & & \\
\hline Fluoroethers & & $N / ?$ & O/low? & Long Term & $?$ & & $\begin{array}{l}\text { Initial characterization - } \\
\text { much work remains to } \\
\text { establish characteristics, } \\
\text { potential advantages, } \\
\text { disadvantages. } \\
\end{array}$ \\
\hline HFE-143 & 86 & & & & & & \\
\hline HFE-152 & 91 & & & & & & \\
\hline HFE-245cb & 93 & & & & & & \\
\hline HFE-245fa & 85 & & & & & & \\
\hline
\end{tabular}

Flammability: $\mathrm{N}=$ nonflammable, $\mathrm{MF}=$ moderately flammable, $\mathrm{F}=$ flammable

Toxicity: $N=$ nontoxic, $T=$ toxic. No chemical can be proven to be totally non-toxic; the $N / T$ designation indicates whether or not the particular fluid generially would-be considered to be problematic in this regard, resulting in special application requirements and prohibition in many applications.

Probable Availability: Availability of the fluid in commercial quantities; timing of suitable technology to use the fluid for particular applications not addressed by this column.

GWP: $\mathrm{CO}_{2}$ equivalent, 100 year integration time horizon.

ODP: $\mathrm{CFC}-12=1.0$

Theoretical $\Delta$ efficiencies: Thermodynamic cycle. HVAC chiller conditions. Differences in transport properties not accounted for. 
Table A-5: Alternative Refrigerants for CFC-12

\begin{tabular}{|c|c|c|c|c|c|c|c|}
\hline Rofrigerant & $\begin{array}{l}\text { Boiling } \\
\text { Point, } F\end{array}$ & $\begin{array}{c}\text { Flammability } \\
\text { /Toxicity }\end{array}$ & ODP/GWP & \begin{tabular}{|} 
Probable \\
Availability
\end{tabular} & $\begin{array}{c}\text { Theoretical } \\
\Delta \\
\text { Efficlencles }\end{array}$ & $\begin{array}{c}\text { Problem } \\
\text { Areas/ } \\
\text { R\&D Needs }\end{array}$ & $\begin{array}{c}\text { Description, Status, } \\
\text { Comment }\end{array}$ \\
\hline CFC-12 & -22 & $N / N$ & $\begin{array}{l}1.00 / \\
7,300 \\
\end{array}$ & Current & 0 & & Will be phased out. \\
\hline \multicolumn{8}{|l|}{$\begin{array}{c}\text { Current } \\
\text { Substitutes }\end{array}$} \\
\hline HFC-134a & -16 & $N / N$ & $0 / 1,200$ & $1992-1993$ & $-\%$ & Lubricants & $\begin{array}{l}\text { Toxicity testing underway, } \\
\text { needs to be completed, no } \\
\text { problems expected. }\end{array}$ \\
\hline Ternary Blend & --20 & $N / N ?$ & $0.03 / 740$ & Current & 0 & $\begin{array}{l}\text { "Blend" issues; } \\
\text { material } \\
\text { compatibility; } \\
\text { toxicity }\end{array}$ & Available \\
\hline HCFC-22 & -41 & $N / N$ & $\begin{array}{l}0.05 / \\
1.500\end{array}$ & Current & 0 & $\begin{array}{l}\text { High } \\
\text { compressor } \\
\text { discharge } \\
\text { temp at high } \\
\text { lifts }\end{array}$ & $\begin{array}{l}\text { Higher pressure and } \\
\text { capacity, higher discharge } \\
\text { temperature. } 1990 \text { Clean } \\
\text { Air Act phase out schedule } \\
\text { is likely to be accelerated. }\end{array}$ \\
\hline $\begin{array}{l}\text { HCFC-142b } \\
22-142 b\end{array}$ & 14 & $M F / N$ & $\begin{array}{l}0.06 / \\
1,600\end{array}$ & Current & N/A & "Blend issues" & $\begin{array}{l}\text { Used in R22/R142b blends } \\
\text { - aerosol propellant, } \\
\text { NARM; } 142 \mathrm{~b} \text { is moderately } \\
\text { flammable. }\end{array}$ \\
\hline $\mathrm{NH}_{3}$ & -28 & $\mathrm{MF} / \mathrm{T}$ & $0 / 0$ & Current & 0 to +5 & $\begin{array}{l}\text { Safety issues, } \\
\text { materials for } \\
\text { application to } \\
\text { hermetic } \\
\text { compressor }\end{array}$ & $\begin{array}{l}\text { Commercially available. } \\
\text { Widely used in industrial } \\
\text { refrigeration sector. Toxic } \\
\text { with low flammability. } \\
\text { Excellent transport } \\
\text { properties. }\end{array}$ \\
\hline \multicolumn{8}{|l|}{$\begin{array}{c}\text { Near Torm } \\
\text { Substitutes }\end{array}$} \\
\hline HCFC-124 & 10 & $N / N$ & $0.02 / 430$ & $1993-95$ & $N / A$ & $\begin{array}{l}\text { Toxicity, } \\
\text { material } \\
\text { compatibility }\end{array}$ & $\begin{array}{l}\text { Co-product of HCFC-123 } \\
\text { production. Long term } \\
\text { toxicity testing startorl. } \\
\text { "Ternary blend" } \\
\text { component. } \\
\end{array}$ \\
\hline HFC-134a & -16 & $N / N$ & $0 / 1,200$ & $1992-1993$ & $-3 \%$ & Lubricant & $\begin{array}{l}\text { Toxicity testing underway, } \\
\text { needs to be completed, no } \\
\text { problems expected. }\end{array}$ \\
\hline HFC-152a & -13 & $F / N$ & $0 / 140$ & Current & $+2 \%$ & Safety issues & $\begin{array}{l}\text { Commercially produced } \\
\text { and sold in moderate } \\
\text { quantities, used primarily } \\
\text { as a component in } \\
\text { CFC-500 (26\%) and as a } \\
\text { component in aerosol } \\
\text { propellant blends. } \\
\text { Flammable. }\end{array}$ \\
\hline
\end{tabular}


Table A-5: Alternative Refrigerants for CFC-12 (continued)

\begin{tabular}{|c|c|c|c|c|c|c|c|}
\hline Rofrigerant & $\begin{array}{l}\text { Boiling } \\
\text { Point, } F\end{array}$ & $\begin{array}{c}\text { Flammability } \\
\text { Troxicity }\end{array}$ & ODP/GWP & $\begin{array}{c}\text { Probable } \\
\text { Avallability }\end{array}$ & $\begin{array}{c}\text { Theoretical } \\
\Delta \\
\text { Efflclencles } \\
\end{array}$ & $\begin{array}{c}\text { Problem } \\
\text { Areas/ } \\
\text { R\&D Noods } \\
\end{array}$ & $\begin{array}{c}\text { Description, Status, } \\
\text { Comment }\end{array}$ \\
\hline \multicolumn{8}{|l|}{$\begin{array}{l}\text { Long Term } \\
\text { Substitutes }\end{array}$} \\
\hline $\begin{array}{l}\text { HC-290 } \\
\text { (propane) }\end{array}$ & -44 & $F / N$ & $0 / 8$ & Current & $-5 \%$ & $\begin{array}{l}\text { Flammability } \\
\text { related safety } \\
\text { issues }\end{array}$ & $\begin{array}{l}\text { Widely available fluid, } \\
\text { favorable transport } \\
\text { properties. }\end{array}$ \\
\hline $\begin{array}{c}\mathrm{HC}-270 \\
\text { (cyclopropane) }\end{array}$ & -26 & $F / N$ & $0 / 8$ & $\begin{array}{l}\text { Specialty } \\
\text { chemical }\end{array}$ & $+5 \%$ & \begin{tabular}{|l|} 
Fire safety; full \\
characterizatio \\
$n$ as a \\
refrigerant
\end{tabular} & $\begin{array}{l}\text { Favorable transport } \\
\text { properties }\end{array}$ \\
\hline $\begin{array}{l}\mathrm{HFC}-215 \mathrm{aa} \\
\left(\mathrm{CH}_{3} \mathrm{CF}_{2} \mathrm{CF}_{3}\right)\end{array}$ & 0 & $N / ?$ & $0 /$ low? & Long term & $?$ & \begin{tabular}{|l|}
$\begin{array}{l}\text { Sufficient char } \\
\text { acterization to } \\
\text { evaluate vs. } \\
\text { other options }\end{array}$ \\
\end{tabular} & $\begin{array}{l}\text { Initial characterization - } \\
\text { much work remains to } \\
\text { establish characteristics, } \\
\text { potential advantages, } \\
\text { disadvantages. }\end{array}$ \\
\hline HFE-143a & -9 & $N / ?$ & $0 /$ low? & Long term & $?$ & $\begin{array}{l}\text { Sufficient char } \\
\text { acterization to } \\
\text { evaluate vs. } \\
\text { other options }\end{array}$ & $\begin{array}{l}\text { Initial characterization - } \\
\text { much work remains to } \\
\text { establish characteristics, } \\
\text { potential advantages, } \\
\text { disadvantages. }\end{array}$ \\
\hline HFE-125 & -31 & $N / ?$ & $0 /$ low? & & & & \\
\hline CE-216 & -21 & $N / ?$ & $0 /$ low? & & & & \\
\hline CEE-216 & -8 & $N / ?$ & $0 /$ low? & & & & \\
\hline
\end{tabular}

Flammability: $N=$ nonflammable, $M F=$ moderately flammable, $F=$ flammable

Toxicity: $N=$ nontoxic, $T=$ toxic. No chemical can be proven to be totally non-toxic; the $N / T$ designation indicates whether or not the particular fluid generally would-be considered to be problematic in this regard, resulting in special application requirements and prohibition in many applications.

Probable Availability: Availability of the fluid in commercial quantities; timing of suitable technology to use the fluid for particular applications not addressed by this column.

GWP: $\mathrm{CO}_{2}$ equivalent, 100 year integration time herizon (IPCC values)

ODP: $C F C-12=1.0$

Theoretical $\Delta$ Efficiencies: Thermodynamic cycle, Domestic R/F conditions. Differences in transport properties not accounted for. 
Table A-6: Altenative Refrigerants for CFC-502 (and HCFC-22)

\begin{tabular}{|c|c|c|c|c|c|c|c|}
\hline Refrigerant & $\begin{array}{l}\text { Normal } \\
\text { Bolling } \\
\text { Point } \\
{ }_{F} \mathrm{~F} \\
\end{array}$ & $\begin{array}{l}\text { Flammability } \\
\text { /Toxicity }\end{array}$ & $\begin{array}{l}\text { ODP } \\
\text { IGWP }\end{array}$ & $\begin{array}{l}\text { Probable } \\
\text { Avallability }\end{array}$ & $\begin{array}{c}\text { Theoretical } \\
\Delta \\
\text { Efficlency }\end{array}$ & $\begin{array}{c}\text { Problem } \\
\text { Areas } \\
\text { R\&D Noeds }\end{array}$ & $\begin{array}{c}\text { Description, Status, } \\
\text { Comment }\end{array}$ \\
\hline CFC-502 & -50 & $N / N$ & $.31 / 4,200$ & Current & 0 & & Will be phased out. \\
\hline \multicolumn{8}{|l|}{$\begin{array}{c}\text { Current } \\
\text { Substitutes }\end{array}$} \\
\hline HCFC.-22 & -41 & $N / N$ & $.05 / 1,500$ & Current & +15 & $\begin{array}{l}\text { High discharge } \\
\text { temperature at } \\
\text { large lifts. }\end{array}$ & $\begin{array}{l}\text { System design to limit } \\
\text { discharge temperature is } \\
\text { needed. Accoleration of } \\
\text { Clean Air Act phase out is } \\
\text { likely. }\end{array}$ \\
\hline \multicolumn{8}{|l|}{$\begin{array}{l}\text { Near Term } \\
\text { Substitutes }\end{array}$} \\
\hline $\mathrm{NH}_{3}$ & -28 & $\mathrm{MF} / \mathrm{T}$ & $0 / 0$ & Current & +16 & $\begin{array}{l}\text { Safety issues, } \\
\text { secondary } \\
\text { loops. Very } \\
\text { high discharge } \\
\text { temperatures. }\end{array}$ & $\begin{array}{l}\text { Commercially available, } \\
\text { Widely used in industrial } \\
\text { refrigeration sector. Toxic } \\
\text { with low flammability. }\end{array}$ \\
\hline HFC-125 & -54 & $N / N ?$ & $0 / 2,500$ & $\begin{array}{c}\text { Uncertain, } \\
\text { probably no } \\
\text { earlier than } \\
1994\end{array}$ & -6 & $\begin{array}{l}\text { Lubricants; } \\
\text { Low efficiency } \\
\text { - cycle mods to } \\
\text { offset. }\end{array}$ & $\begin{array}{l}\text { DuPont program has been } \\
\text { initiated only recenty } \\
\text { (January, 1989), lower } \\
\text { priority than CFC-11, } \\
\text { CFC-12 substitute } \\
\text { programs. High GWP. }\end{array}$ \\
\hline HCF-143a & -53 & $M F / N ?$ & $0 / 2,900$ & $"$ & 0 & Lubricants & $"$ \\
\hline HFC-32 & -60 & MF / N? & $0 / \sim 600$ & $"$ & +12 & $\begin{array}{l}\text { Lubricants; } \\
\text { high discharge } \\
\text { temperature; } \\
\text { fire safety. }\end{array}$ & $\begin{array}{l}\text { High theoretical efficiency, } \\
\text { high compressor discharge } \\
\text { temperature, moderately } \\
\text { flammable }\end{array}$ \\
\hline HFC-32/125 & --60 & $N / N ?$ & $0 /-1,700$ & Post 1995 & +8 & $\begin{array}{l}\text { Preliminary } \\
\text { equipment } \\
\text { design } \\
\text { investigation; } \\
\text { lubricants. } \\
\end{array}$ & $\begin{array}{l}\text { Azeotropic mixture with } \\
\text { promising properties - high } \\
\text { efficiency, moderate } \\
\text { discharge temperature, } \\
\text { non-flammable. }\end{array}$ \\
\hline $\begin{array}{l}\text { HP-62 blend } \\
\text { (HFC) }\end{array}$ & & $N / N$ & $\mathrm{O} / \mathrm{N}$ & Late 1993 & & & $\begin{array}{l}\text { Near azeotropic HFC; } \\
\text { Copeland has endorsed } \\
\text { and committed to } \\
\text { develc pment. }\end{array}$ \\
\hline
\end{tabular}


Table A-6: Alternative Refrigerants for CFC-502 (and HCFC-22) (continued)

\begin{tabular}{|c|c|c|c|c|c|c|c|}
\hline Pefrigerant & $\begin{array}{l}\text { Normal } \\
\text { Bolling } \\
\text { Polnt } \\
\text { F }\end{array}$ & $\begin{array}{l}\text { Flammability } \\
\text { Toxlcity }\end{array}$ & $\begin{array}{l}\text { ODP } \\
\text { IGWP }\end{array}$ & $\begin{array}{l}\text { Probable } \\
\text { Avallability }\end{array}$ & $\begin{array}{c}\text { Theoretical } \\
\Delta \\
\text { Efflelency }\end{array}$ & $\begin{array}{l}\text { Problem } \\
\text { Areas } \\
\text { R\&D Needs }\end{array}$ & $\begin{array}{c}\text { Descrlption, Status, } \\
\text { Comment }\end{array}$ \\
\hline \multicolumn{8}{|l|}{$\begin{array}{l}\text { Long Term } \\
\text { Substitutes }\end{array}$} \\
\hline FE-116 & .74 & $N / N ?$ & O/high? & Long Term & $?$ & $\begin{array}{l}\text { Establish } \\
\text { properties; } \\
\text { cycle } \\
\text { analyses. }\end{array}$ & $\begin{array}{l}\text { Some initial } \\
\text { characterization has been } \\
\text { completed. Considerable } \\
\text { work remains to establish } \\
\text { properties, potential } \\
\text { advantages and } \\
\text { disadvantages, } \\
\text { manufacturing process. }\end{array}$ \\
\hline HFE-125 & -31 & $N / N ?$ & O/low? & Long Term & $?$ & $"$ & \\
\hline Propane & -44 & $F / N$ & $0 / 8$ & Current & $+7 \%$ & Safety issues & $\begin{array}{l}\text { Low cost, readily available } \\
\text { material. Excollent } \\
\text { transport properties. }\end{array}$ \\
\hline Propylene & -54 & $F / N$ & $0 / 8$ & Current & $+20 \%$ & Safety issues & $\begin{array}{l}\text { Low cost, readily available } \\
\text { material. Excellent } \\
\text { transport properties. }\end{array}$ \\
\hline $\begin{array}{c}\text { CFC-12 } \\
\text { Substitutes }\end{array}$ & & & & & & & $\begin{array}{l}\text { Lower capacity, see } \\
\text { CFC- } 12 \text { alternatives. } \\
\text { Possible use as blend } \\
\text { components with any of the } \\
\text { substitutes listed above. }\end{array}$ \\
\hline
\end{tabular}

Flammability: $\mathrm{N}=$ nonflammable, $M F=$ moderately flammable, $F=$ flammable

Toxicity: $\mathrm{N}=$ nontoxic, $\mathrm{T}=$ toxic. No chemical can be proven to be totally non-toxic; the $\mathrm{N} / \mathrm{T}$ designation indicates whether or not the particular fluid generally would-be considered to be problematic in this regard, resulting in special application requirements and prohibition in many applications.

Probable Availability: Availability of the fluid in commercial quantities; timing of suitable technology to use the fluid for particular applications not addressed by this column.

GWP: $\mathrm{CO}_{2}$ equivalent, 100 year integration time horizon. (IPCC values)

ODP: CFC. $12=1.0$

Theoretical $\triangle$ Efficiencies: Thermodynamic cycle, low temperature commercial refrigeration conditions. Differences in transport properties not accounted for. 
Table A-7: Alternative Refrigerants for CFC-114

\begin{tabular}{|c|c|c|c|c|c|c|c|}
\hline Refrigerant & $\begin{array}{l}\text { Boiling } \\
\text { Point, }{ }^{\circ} \mathrm{F}\end{array}$ & $\begin{array}{c}\text { Flammability } \\
\text { Troxicity }\end{array}$ & ODP/GWP & $\begin{array}{c}\text { Probable } \\
\text { Avallability }\end{array}$ & $\begin{array}{c}\text { Theoretical } \\
\Delta \\
\text { Efflclencles }\end{array}$ & $\begin{array}{c}\text { Problem } \\
\text { Areas/ } \\
\text { R\&D Needs }\end{array}$ & $\begin{array}{c}\text { Description, Status, } \\
\text { Comment }\end{array}$ \\
\hline CFC-114 & 39 & $N / N$ & $0.80 / 6,900$ & Current & 0 & & Will be phased out. \\
\hline $\begin{array}{c}\text { Current } \\
\text { Substitutes }\end{array}$ & & & & & & & None \\
\hline \multicolumn{8}{|l|}{$\begin{array}{c}\text { Near Term } \\
\text { Substitutes }\end{array}$} \\
\hline HCFC-124 & 14 & $N / ?$ & $0.02 / 430$ & 1993-95 & $+1 \%$ & $\begin{array}{l}\text { Higher } \\
\text { pressures are } \\
\text { a potential } \\
\text { problem for } \\
\text { drop-in to } \\
\text { existing Navy } \\
\text { chiller designs. }\end{array}$ & $\begin{array}{l}\text { Co-product of HCFC-123 } \\
\text { production. Long term } \\
\text { toxicity lesting started. } \\
\text { "Ternary blend" } \\
\text { component. }\end{array}$ \\
\hline HFE-134 & 41 & $N / N$ & O/low? & Near Term & $?$ & & $\begin{array}{l}\text { Navy is pursuing chiller } \\
\text { development based on this } \\
\text { fluid. }\end{array}$ \\
\hline FC-C318 & 21 & $N / N$ & $0 / ?$ & mid 90's? & $?$ & & $\begin{array}{l}\text { Fully fluorinated, long } \\
\text { atmospheric life? Navy is } \\
\text { investigating. }\end{array}$ \\
\hline \multicolumn{8}{|l|}{$\begin{array}{l}\text { Long Term } \\
\text { Substitutes }\end{array}$} \\
\hline Fluoroethers & & $N / ?$ & O/low? & Long Term & $?$ & $\begin{array}{l}\text { Need more } \\
\text { property data }\end{array}$ & $\begin{array}{l}\text { Initial characterization - } \\
\text { much work remains to } \\
\text { establish characteristics, } \\
\text { potential advantages, } \\
\text { disadvantages. } \\
\end{array}$ \\
\hline HFE-227ca & 25 & $N / ?$ & 0/low? & Long Term & $?$ & $\begin{array}{l}\text { Need more } \\
\text { property data }\end{array}$ & \\
\hline $\begin{array}{c}3 \mathrm{C}, 4 \mathrm{C} \\
\text { Fluoroalkanes }\end{array}$ & & $N / ?$ & O/low? & Long Term & $?$ & $"$ & $\begin{array}{l}\text { Initial characterization - } \\
\text { much work remains to } \\
\text { establish characteristics, } \\
\text { potential advantages, } \\
\text { disadvantages. }\end{array}$ \\
\hline
\end{tabular}

Flammability: $\mathrm{N}=$ nonflammable, $\mathrm{MF}=$ moderately flammable, $\mathrm{F}=$ flammable

Toxicity: $N=$ nontoxic, $T=$ toxic. No chemical can be proven to be totally non-toxic; the $N / T$ designation indicates whether or not the particular fluid generally would-be considered to be problematic in this regard, resulting in special application requirements and prohibition in many applications.

Probable Availability: Availability of the fluid in commercial quantities; timing of suitable technology to use the fluid for particular applications not addressed by this column.

GWP: $\mathrm{CO}_{2}$ equivalent, 100 year integration time horizon. (IPCC values)

ODP: $C F C-12=1.0$

Theoretical $\Delta$ efficiencies: Thermodynamic cycle, HVAC chiller conditions. Differences in transport properties not accouniot ? . 
Table A-3 summarizes the substitute refrigerants for each of the CFCs, indicating which are current, near/medium-term, or long-term substitutes for current and near/medium-term substitutes, whether or not the fluid contains chlorine.

The striking feature of this table is the scarcity of current- and near-term substitutes, especially of zero ODP, non-chlorinated substitutes.

The need for interim (post CFC/pre HCFC phase out) substitutes will most likely be met by HCFC-123 (for CFC-11), HFC-134a (for most CFC-12 applications), and HCFC-22 (for some CFC- 12 applications and most CFC-502 applications). A definite replacement has yet to be selected for CFC-114, either for centrifugal chillers, or high condenser temperature applications. Each of these interim fluids has some important disadvantages:

- Based on the PAFT study toxicity testing results, an allowable exposure limit of 10 ppm has been set for HCFC-123, one to two orders of magnitude less than the 100 ppm limit associated with CFC-11 and most other commonly used refrigerants. Preliminary studies indicate this lower limit may not be a problem. While the ODP is very low, the fluid is an HCFC and could be subject to the group II substances (HCFC) phase out.

- HFC-134a has a fairly high GWP.

- HCFC-22 will be subject to the group II substance phase out.

Given these limitations, examination of the longer-term possibilities would appear to be merited, as discussed below.

The theoretical efficiency changes listed in Tables A-3 through A-7 do not consider the effects of lubricant changes, or in component improvements. For example, testing recently completed by the U.S. DOE, for refrigerator applications, has shown little difference in energy performance between CFC-12, HFC-134a, and HFC-152a. Hence, the choice between these fluids for specific applications will probably be driven by other factors.

\section{A-1.2 Long-Term Potential Substitutes}

The long-term substitutes listed in Table A-3 fall into a few basic categories:

- Ammonia, which is also a current substitute for CFC-12 and CFC-502 in industrial refrigeration applications. Safety related institutional restrictions (e.g., building codes and ASHRAE Std. 15, "Safety Code for Mechanical Refrigeration," which is incorporated into many building codes) limit the use of ammonia for other applications. It is well understood as a refrigerant, and could potentially be used in other applications. 
- Hydrocarbons, many of which have been investigated and are reasonably well understood as refrigerants. As refrigerants, they have zero ODP and GWP. Many have thermodynamic and heat transfer characteristics that should result in improved efficiency.

- Partially fluorinated ethers, have been investigated as refrigerants only for the past several years. Table A-8 lists, in ascending order of boiling point, a number of fluorinated ethers for which basic thermophysical property data is available. While many compounds have been synthesized, and boiling temperatures established, with the relative exception of a few specific compounds, they have not been well characterized as refrigerants. There is little basis for expecting energy efficiencies to be inherently higher, lower, or generally similar to conventional refrigerants having similar boiling temperatures. These are most promising as replacements for higher boiling refrigerants - CFC-11 and CFC-114. They could also be used as blend components to replace any of the current CFCs.

- Partially fluorinated propane and butane. Table A-9 lists a number of these compounds in ascending order of boiling point. As with the fluoroethers, many compounds have been synthesized, with normal boiling points determined, but few have been thoroughly characterized. They are nost promising as replacements for higher boiling refrigerants - CFC-11 and CFC-114. They could also serve as blend components to replace any of the current CFCs.

Table A-10 summarizes the rationale for consideration of these fluid categories, the remaining problem areas, and the nature of the $R \& D$ activities needed to address these problems.

With ammonia and the hydrocarbons and flammable HCFCs, one approach to addressing the safety issue is to locate the refrigeration system outdoors, usually on a rooftop, and to transport the cooling capacity to the cooling load via a secondary coolant loop, in similar fashion to a chilled water loop in building HVAC system. 
Table A-8: Fluoroethers

\begin{tabular}{|c|c|c|c|}
\hline Category & Number Designation & Chemical Formula & Boiling Point, ' $F$ \\
\hline \multirow[t]{10}{*}{ Dimethyl Ether based } & HE-170 & $\mathrm{CH}_{3}-\mathrm{O}-\mathrm{CH}_{3}$ & -11 \\
\hline & FE-116 & $\mathrm{CF}_{3}-\mathrm{O}-\mathrm{CF}_{3}$ & -74 \\
\hline & HFE-125 & $\mathrm{CF}_{3} \cdot \mathrm{O}-\mathrm{CHF}_{2}$ & -31 \\
\hline & HFE-143a & $\mathrm{CH}_{3}-\mathrm{O}-\mathrm{CF}_{3}$ & -9 \\
\hline & HFE-134a & $\mathrm{CH}_{2} \mathrm{~F}-\mathrm{O}-\mathrm{CF}_{3}$ & -4 \\
\hline & HFE-152a & $\mathrm{CH}_{3}-\mathrm{O}-\mathrm{CHF}_{2}$ & 23 \\
\hline & HFE-134 & $\mathrm{CHF}_{2}-\mathrm{O}-\mathrm{CHF}_{2}$ & 41 \\
\hline & HFE-161 & $\mathrm{CH}_{3}-\mathrm{O}-\mathrm{CH}_{2} \mathrm{~F}$ & 50 \\
\hline & HFE-143 & $\mathrm{CH}_{2} \mathrm{~F}-\mathrm{O}-\mathrm{CHF}_{2}$ & 86 \\
\hline & HFE-152 & $\mathrm{CH}_{2} \mathrm{~F}-\mathrm{O}-\mathrm{CH}_{2} \mathrm{~F}$ & 91 \\
\hline \multirow[t]{7}{*}{ Other Fluoroethers } & EE-218 & $\mathrm{CF}_{3}-\mathrm{O}-\mathrm{CF}_{2}-\mathrm{O}-\mathrm{CF}_{3}$ & 14 \\
\hline & $\mathrm{E}-227 \mathrm{ca}$ & $\mathrm{CF}_{3}-\mathrm{O}-\mathrm{CF}_{2}-\mathrm{CF}_{2} \mathrm{H}$ & 25 \\
\hline & CE-216 & $c-C F_{2}-C F_{2}-C F_{2}-O$ & $-21-20.5$ \\
\hline & $E-? 54 \mathrm{cb}$ & $\mathrm{CHF}_{2}-\mathrm{O}-\mathrm{CF}_{2}-\mathrm{CH}_{3}$ & 97.6 \\
\hline & $E-245 c b$ & $\mathrm{CF}_{3}-\mathrm{O}-\mathrm{CF}_{2}-\mathrm{CH}_{3}$ & 93.3 \\
\hline & E-245fa & $\mathrm{CF}_{3}-\mathrm{CH}_{2}-\mathrm{O}-\mathrm{CF}_{2} \mathrm{H}$ & 84.6 \\
\hline & CEE-216 & $-\mathrm{CF}_{2}-\mathrm{O}-\mathrm{CF}_{2}-\mathrm{O}-\mathrm{CF}_{2^{-}}$ & -7.8 \\
\hline
\end{tabular}

Table A-9: Fluorinated Propanes and Butanes

\begin{tabular}{|c|c|c|c|}
\hline Category & Number Designation & Chemical Formula & Boiling Point, ${ }^{\circ} \mathrm{F}$ \\
\hline \multirow[t]{11}{*}{ Propane based ( $3 C)$} & HFC-245cb & $\mathrm{CF}_{3}-\mathrm{CF}_{2}-\mathrm{CF}_{3}$ & -0.9 \\
\hline & HFC-227ca & $\mathrm{CF}_{3}-\mathrm{CF}_{2}-\mathrm{CF}_{2} \mathrm{H}$ & 2.7 \\
\hline & HFC-227ea & $\mathrm{CF}_{3} \cdot \mathrm{CHF}-\mathrm{CF}_{3}$ & 4.6 \\
\hline & HFC-236cb & $\mathrm{CF}_{3}-\mathrm{CF}_{2}-\mathrm{CFH}_{2}$ & 29.4 \\
\hline & HFC-236fa & $\mathrm{CF}_{3} \cdot \mathrm{CH}_{2}-\mathrm{CF}_{3}$ & 30.0 \\
\hline & HFC-254cb & $\mathrm{CH}_{3}-\mathrm{CF}_{2}-\mathrm{CF}_{2} \mathrm{H}$ & 30.6 \\
\hline & HFC-236ca & $\mathrm{CF}_{2} \mathrm{H}-\mathrm{CF}_{2}-\mathrm{CF}_{2} \mathrm{H}$ & 41.0 \\
\hline & HFC-236ea & $\mathrm{CF}_{3}-\mathrm{CFH}-\mathrm{CF}_{2} \mathrm{H}$ & 43.7 \\
\hline & HFC-347ccd & & 59.2 \\
\hline & HFC-245fa & $\mathrm{CF}_{3}-\mathrm{CH}_{2}-\mathrm{CF}_{2} \mathrm{H}$ & 59.5 \\
\hline & HFC-245ca & $\mathrm{CF}_{2} \mathrm{H}-\mathrm{CF}_{2}-\mathrm{CFH}_{2}$ & 76.9 \\
\hline \multirow[t]{2}{*}{ Butane based (4C) } & HFC-338eea & & 77.7 \\
\hline & C-326d & & 100.6 \\
\hline
\end{tabular}


Table A-10: Summary of R\&D Needed for Long-Term Substitute Refrigerants

\begin{tabular}{|c|c|c|c|c|}
\hline $\begin{array}{l}\text { Fluld Type and } \\
\text { Examples }\end{array}$ & $\begin{array}{c}\text { Estimated } \\
\Delta \text { Efficlency } \\
\end{array}$ & $\begin{array}{l}\text { Rationale for } \\
\text { Consideration }\end{array}$ & $\begin{array}{c}\text { Remalning Problem } \\
\text { Areas }\end{array}$ & Needed R\&D \\
\hline Ammonia & +5 to $10 \%$ & $\begin{array}{l}\text { Potential efficiency } \\
\text { improvement; zero } \\
\text { ODP and GWP, } \\
\text { inexpensive fluid }\end{array}$ & $\begin{array}{c}\text { Toxicity } \\
\text { Mild flammability } \\
\text { Need hermetic } \\
\text { compressors }\end{array}$ & $\begin{array}{l}\text { - Secondary loop } \\
\text { technology } \\
\text { - Application specific risk } \\
\text { analysis } \\
\text { - Application specific } \\
\text { hermetic designs } \\
\text { - Ammonia compatible } \\
\text { hermetic compressor } \\
\text { prototype development }\end{array}$ \\
\hline $\begin{array}{l}\text { Hydrocarbons \& } \\
\text { lammable HFCs, e.g. } \\
\text { Propane } \\
\text { Propylene } \\
\text { Cyclopropane } \\
\text { HFC-152a } \\
\text { HFC-32 }\end{array}$ & 0 to $+10 \%$ & $\begin{array}{l}\text { Potential efficiency } \\
\text { impro sement, zero } \\
\text { ODP, negl. GWP, } \\
\text { inexpensive fluid, } \\
\text { toxicity is already } \\
\text { characterized, so no } \\
\text { costly PAFT type } \\
\text { evaluation is needed. } \\
\text { (exception: HFC-32). }\end{array}$ & Flammability & $\begin{array}{l}\text { - Some further property } \\
\text { characteristics } \\
\text { - Application specific risk } \\
\text { analysis } \\
\text { - Secondary loop } \\
\text { technology }\end{array}$ \\
\hline Fluoroethers & $\begin{array}{l}\text { Unknown, probably } \\
\text { reduced a small } \\
\text { amount? }\end{array}$ & $\begin{array}{l}\text { Absence of } \\
\text { satisfactory long-term } \\
\text { substitutes for } \\
\text { CFC-11, R-502, and } \\
\text { CFC-114. Zero ODP, } \\
\text { low cost, } \\
\text { non-flammable }\end{array}$ & $\begin{array}{l}\text { Need to characterize: } \\
\text { - Thermodynamic } \\
\text { properties } \\
\text { - Transport } \\
\text { properties } \\
\text { - Stability } \\
\text { - Rationale } \\
\text { compatibility } \\
\text { - Lubricant } \\
\text { compatibility } \\
\text { - Toxicity } \\
\text { Need to evaluate } \\
\text { production feasibility }\end{array}$ & $\begin{array}{l}\text { - Characterize koy } \\
\text { properties of most promising } \\
\text { fluids }\end{array}$ \\
\hline $\begin{array}{l}\text { Fluoropropanes and } \\
\text { lluorobutanes }\end{array}$ & $\begin{array}{l}\text { Unknown, probably } \\
\text { reduced a small } \\
\text { amount? }\end{array}$ & $\begin{array}{l}\text { Absence of } \\
\text { satisfactory long-term } \\
\text { substitutes for } \\
\text { CFC-11, R-502 and } \\
\text { CFC-114. Zero ODP. } \\
\text { low cost, } \\
\text { non-flammable }\end{array}$ & $\begin{array}{l}\text { Need to characterize: } \\
\text { - Thermodynamic } \\
\text { properties } \\
\text { - Transport } \\
\text { properties } \\
\text { - Stability } \\
\text { - Rationale } \\
\text { compatibility } \\
\text { - Lubricant } \\
\text { compatibility } \\
\text { Toxicity } \\
\text { Need to evaluate } \\
\text { production feasibility }\end{array}$ & $\begin{array}{l}\text { Characterize key } \\
\text { properties of most promising } \\
\text { fluids }\end{array}$ \\
\hline Mixtures & Comparable efficiency & $\begin{array}{l}\text { Absence of the } \\
\text { satisfactory long-term } \\
\text { substitutes for CFCs. } \\
\text { Additional flexibility in } \\
\text { choosing fluid. }\end{array}$ & $\begin{array}{l}\text { HCFC phaseout. } \\
\text { Flammability of some } \\
\text { HFC constiusents }\end{array}$ & $\begin{array}{l}\text { Characterize thermophysical } \\
\text { properties Laboratory research } \\
\text { Consider new fluids }\end{array}$ \\
\hline
\end{tabular}

\section{A-1.3 Recent and Current R\&D}

Table A-11 is a brief summary of R\&D activities that are either on-going or recently completed, specifically focussed on developing and characterizing new refrigerants. The emphasis is on programs involving fluids that will be used in the longer term. 
Table A-11: Recent and Current R\&D: Chemical Substitutes for Refrigerant Application

\begin{tabular}{|c|c|c|c|c|}
\hline $\begin{array}{c}\text { R\&D Organization } \\
\text { Address } \\
\text { Names } \\
\text { Phone \# } \\
\end{array}$ & Sponsor & Technology & $\begin{array}{l}\text { Research } \\
\text { Description }\end{array}$ & Potential Impact \\
\hline $\begin{array}{l}\text { PAFT Studies } \\
\text { (Program for } \\
\text { Alternative } \\
\text { Flourocarbon Toxicity } \\
\text { Testing) } \\
\end{array}$ & $\begin{array}{c}\text { Major } \\
\text { producers of } \\
\text { fluorochemic } \\
\text { als }\end{array}$ & $\begin{array}{l}\text { HCFC \& HFC } \\
\text { Substitutes }\end{array}$ & $\begin{array}{l}\text { Detailed evaluation of } \\
\text { chronic toxicity of } \\
\text { these fluids }\end{array}$ & $\begin{array}{l}\text { Determine allowable } \\
\text { exposure limits, } \\
\text { provida data for TSCA } \\
\text { (Toxic Substance } \\
\text { Control Act) approval }\end{array}$ \\
\hline $\begin{array}{l}\text { Lak Ridge National } \\
\text { Laboratory }\end{array}$ & DOE & $\begin{array}{l}\text { CEC Alternatives } \\
\text { Scriening }\end{array}$ & $\begin{array}{l}\text { Characterize fluids } \\
\text { applicable to } \\
\text { refrigeration, } \\
\text { commercial } \\
\text { refrigeration, chillers, } \\
\text { heat pump }\end{array}$ & $\begin{array}{l}\text { Identify available } \\
\text { fluids } \\
\text { Define attributes }\end{array}$ \\
\hline $\begin{array}{l}\text { Oak Ridige National } \\
\text { Laboratory }\end{array}$ & ARI & $\begin{array}{l}\text { Materials } \\
\text { Compatibility }\end{array}$ & $\begin{array}{l}\text { Test materials and } \\
\text { lubricant } \\
\text { compatibilities with } \\
\text { new refrigerants }\end{array}$ & $\begin{array}{l}\text { Database on practical } \\
\text { design } \\
\text { Issues associated } \\
\text { with alternative } \\
\text { refrigerants }\end{array}$ \\
\hline UL/Arthur D. Litile & & $\begin{array}{l}\text { Use of flammable } \\
\text { refrigerant }\end{array}$ & $\begin{array}{l}\text { Risk assessment of } \\
\text { HFC-152a, tests }\end{array}$ & $\begin{array}{l}\text { Allow use of } \\
\text { flammable refrigerant }\end{array}$ \\
\hline $\begin{array}{l}\text { University of } \\
\text { Tennesse日 }\end{array}$ & EPRI/EPA & $\begin{array}{l}\text { Fluorinated ethers } \\
\text { synthesis }\end{array}$ & $\begin{array}{l}\text { Synthesis of fluids } \\
\text { Thermodynamic } \\
\text { properties } \\
\text { Toxicity, flammability }\end{array}$ & Alternative refrigerant \\
\hline Clemson University & EPA & $\begin{array}{l}\text { Synthesis and } \\
\text { preliminary evaluation } \\
\text { of fluoropropanes and } \\
\text { fluorobutanes }\end{array}$ & $\begin{array}{l}\text { Synthesis of fluids } \\
\text { Thermodynamic } \\
\text { properties } \\
\text { Toxicity, flammability }\end{array}$ & Alternative refrigerant \\
\hline $\begin{array}{l}\text { National Institute of } \\
\text { Standards and } \\
\text { Technology (NIST) }\end{array}$ & & $\begin{array}{l}\text { HFC-134a } \\
\text { HCFC-123 }\end{array}$ & $\begin{array}{l}\text { Precise determination } \\
\text { of thermodynamic } \\
\text { properties of } \\
\text { HFC-134a and } \\
\text { HCFC-123 }\end{array}$ & $\begin{array}{l}\text { Accurate basis for } \\
\text { performance analysis }\end{array}$ \\
\hline $\begin{array}{l}\text { Swedish Royal } \\
\text { Institute of } \\
\text { Technology }\end{array}$ & $\begin{array}{l}\text { Swedish } \\
\text { Council for } \\
\text { Building } \\
\text { Research }\end{array}$ & $\begin{array}{l}\text { HFC-134a, } \\
\text { HFC-152a, etc., with } \\
\text { oil }\end{array}$ & $\begin{array}{l}\text { Local heat transfer } \\
\text { coefficients. Oil } \\
\text { influence. Vapor } \\
\text { pressure relationships }\end{array}$ & $\begin{array}{l}\text { Develspment of } \\
\text { relations for } \\
\text { engineering use }\end{array}$ \\
\hline $\begin{array}{l}\text { Swedish Royal } \\
\text { Insitute of Technology }\end{array}$ & $\begin{array}{c}\text { Swedish } \\
\text { Council for } \\
\text { Building } \\
\text { Research } \\
\end{array}$ & $\begin{array}{l}\text { HCFC, HFC } \\
\text { substitutes }\end{array}$ & $\begin{array}{l}\text { Enhanced boiling in } \\
\text { evaporators }\end{array}$ & $\begin{array}{l}\text { Low temperature } \\
\text { differences in } \\
\text { evaporators }\end{array}$ \\
\hline $\begin{array}{l}\text { Swedish Royal } \\
\text { Institute of } \\
\text { Technology }\end{array}$ & $\begin{array}{c}\text { Swedish } \\
\text { Council for } \\
\text { Building } \\
\text { Research }\end{array}$ & $\begin{array}{l}\text { HCFC \& HFC } \\
\text { substitutes } \\
\text { Nen-azeotropic } \\
\text { mixtures }\end{array}$ & $\begin{array}{l}\text { Evaluation of drop in } \\
\text { substitutes }\end{array}$ & $\begin{array}{l}\text { Experimental results } \\
\text { for cycles and heat } \\
\text { transfer } \\
\text { characteristics }\end{array}$ \\
\hline
\end{tabular}


It is recognized that substantial programs are on-going at the R\&D labs of the major fluorochemical producers, addressing both longer-term (post HCFC) refrigerants and current product implementation needs. Of necessity, the larger portion of resources have been allocated to the immediate, commercialization related problems of lubricants, compatible materials, and economical production processes. The R\&D staffs at the fluorochemical producers also serve as a critical resource that is accessed by developers of compressors and systems, during the process of developing modified or altogether new products to use the post HCFC refrigerants.

\section{A-2 Alternative Refrigeration Technologies}

Alternative refrigeration technologies offer a potentially attractive means of achieving the required refrigeration without any direct ODP or GWP environmental damage. The efficiency (COP) of alternatives must be carefully considered and compared to present methods to insure that alternatives do not increase the contribution to global warming.

The following subsections describe potential alternative refrigeration methods and make comparisons with vapor compression. Some of the methods are potentially applicable primarily in only one area (e.g., absorption systems are applicable primarily to chillers). In cases such as this, the cycle alternative discussion is slanted toward the specific application.

\section{A-2.1 Alternative Vapor Compression Cycles.}

The standard vapor compression cycle consists of a compressor, condenser, expansion device and a single evaporator and utilizes a pure refrigerant which condenses at a nearly constant temperature and evaporates at a lower, nearly constant temperature. With a pure refrigerant, the deviations from a constant temperature phase change are caused only by pressure changes in the heat exchangers. Sometimes an interchanger between the high pressure condenser liquid and the low pressure vapor leaving the evaporator is used as a means of lowering the liquid temperature prior to expansion. The ideal cycle is the Carnot cycle.

Introduction of a refrigerant blend, typically carrying two or three components, will normally result in some temperature deviation in heat exchangers, the degree depending on the characteristics of the blend. With an azeotrope mixture, such as R-500, the phasi change is nearly at constant temperature, whereas as with a nonazeotropic mixture, such as $\mathrm{R}-22-\mathrm{R} 142 \mathrm{~b}$, a significant temperature glide may occur during evaporation or condensation.

A number of alternatives to the standard vapor compression cycle have been proposed. These include: the Lorenz cycle, La Brecque cycle, hybrid vapor compression/injector cycle, and various options involving multiple evaporators and/or multi-stage operation.

\section{A-2.1.1 Lorenz Cycle.}

The Lorenz cycle differs from the standard vapor compression cycle in its deliberate use of non-azeotropic refrigerant blends as a means of introducing a temperature glide into the heat exchange process. For example, in the evaporation process, the more volatile 
component of the mixture will preferentially evaporate first, leaving the liquid richer in the less volatile component. To complete the evaporation, the temperature must be raised to boil off the lower volatility compound; as a consequence, the refrigerant temperature will increase along the length of the evaporator. Since the temperature of the heat source (air or water) will decrease as heat is withdrawn, an opportunity exists to more nearly match the temperature profiles in the two streams, thereby lowering the log-mean temperature differences and hence the heat exchange irreversibilities. Accomplishing this objective will require: counter-flow heat exchange, selection of a mixture that yields the desired temperature change in the heat exchanger, and minimized degradation to the heat transfer process itself. Some degradation of the refrigerant-side heat transfer is bound to occur since the vapor and liquid phase compositions are different during the phase change, a condition similar to condensation in the presence of a non-condensible gas.

Figure A-2 illustrates a typical temperature-cnthalpy cycle diagram for a binary refrigerant mixture. At any given pressure level, the refrigerant temperature in the evaporator is a (roughly linear) function of the vapor quality in a mixed-refrigerant cycle. The average evaporator temperature will be lower with increased subcooling. Hence, as opposed to conventional cycles using pure refrigerants, liquid subcooling can accomplish two functions: 1) increase the enthalpy change across the evaporator, and 2) lower the average temperature in the evaporator. A reduced evaporator temperature provides an opportunity for an increase in the evaporator pressure while maintaining the same average temperature achieved in the absence of subcooling, thereby increasing the vapor density and yielding a higher capacity.

Applications of Lorenz Cycle. The potential advantages of the Lorenz cycle (mixed refrigerants) have been explored for air conditioning or heat pump cycles $[2,3,4,5]$, industrial refrigeration $[6,7]$, chillers $[8]$, and refrigerators $[9,10]$. Table A-12 summarizes the research efforts for refrigerator and freezers. Each of these efforts aim to improve the operation of the cycle shown in Figure A-3.

The cycle analyzed shows two interchangers, HX1, and HX2. HX1 represents the interchanger found in the standard configuration, where the cap tube is bonded to the gas-phase refrigerant line from the fresh food evaporator to the compressor. HX2 is a second "interchanger" that is used to further subcool the liquid in the cap tube while raising the temperature of the 2 phase refrigerant between the freezer temperature and fresh food temperature.

In principle, the cycle will work optimally with a refrigerant that has a temperature glide over the evaporation range similar to the temperature difference between the freezer and fresh food sections. Hence, what is required to achieve high performance is the selection of a favorable blend, a counter-flow heat exchanger, and high effectiveness interchangers. 
Figure A-2: Temperature-Enthalpy Diagram for Cycle with Mixed Refrigerants

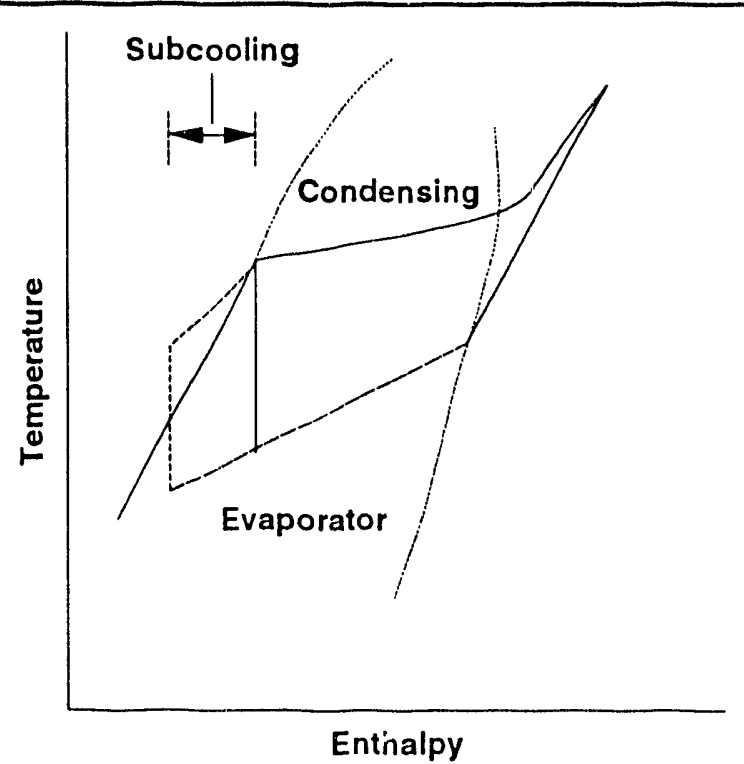

Table A-12: Lorenz Cycle Research Efforts for Refrigerator/Freezers

\begin{tabular}{|l|c|l|l|}
\hline \multicolumn{1}{|c|}{ Who } & Time Period & \multicolumn{1}{c|}{ Description } & \multicolumn{1}{c|}{ Results } \\
\hline \hline $\begin{array}{l}\text { W. Stoecker } \\
\text { University of Illinois }\end{array}$ & $\sim 1975-85$ & $\begin{array}{l}\text { R-22/R-114 mixtlires, } \\
\text { rnodel and bench tests }\end{array}$ & $\begin{array}{l}\text { Theoretically efficiency } \\
\text { increase of 6\%-12\%. } \\
\text { Small measured } \\
\text { efficiency gain. }\end{array}$ \\
\hline $\begin{array}{l}\text { H. Kruse } \\
\text { University of Hannover }\end{array}$ & $1985-1991$ & $\begin{array}{l}\text { Various mixtures, } \\
\text { prototype tests }\end{array}$ & Small savings \\
\hline $\begin{array}{l}\text { E. Vineyard } \\
\text { Oak Ridge National Labs }\end{array}$ & $1988-$ present & $\begin{array}{l}\text { Benchmark tests, } \\
\text { modified freezer }\end{array}$ & On-going \\
\hline $\begin{array}{l}\text { R. Radermacher } \\
\text { University of Maryland }\end{array}$ & 1988 -present & $\begin{array}{l}\text { Benchmark tests, various } \\
\text { refrigerants }\end{array}$ & $10-15 \%$ improvement \\
\hline $\begin{array}{l}\text { R. Crawford } \\
\text { University of Illinois }\end{array}$ & $1988-1990$ & $\begin{array}{l}\text { Evaporator module } \\
\text { optimization }\end{array}$ & \\
\hline
\end{tabular}

In addition, as in all vapor compression systems, the refrigerant must have favorable lubrication properties with the compressor.

An issue with application of the Lorenz cycle to domestic refrigeration is the method of control of the evaporator capacity. The easiest method for control is the use of evaporator fans in both cabinet sections. A drawback is the added energy use and heat load from the fans. The solution adopted by the University of Maryland is the use of an oversized freezer evaporator, with fan-forced convection, and a natural convection evaporator in the fresh food section. With this configuration, the compressor operation is controlled by the temperature in the fresh food section while the fan operation is controlled by the freezer temperature. 
Figure A-3: Lorenz Cycle for Refrigerator/Freezer Application

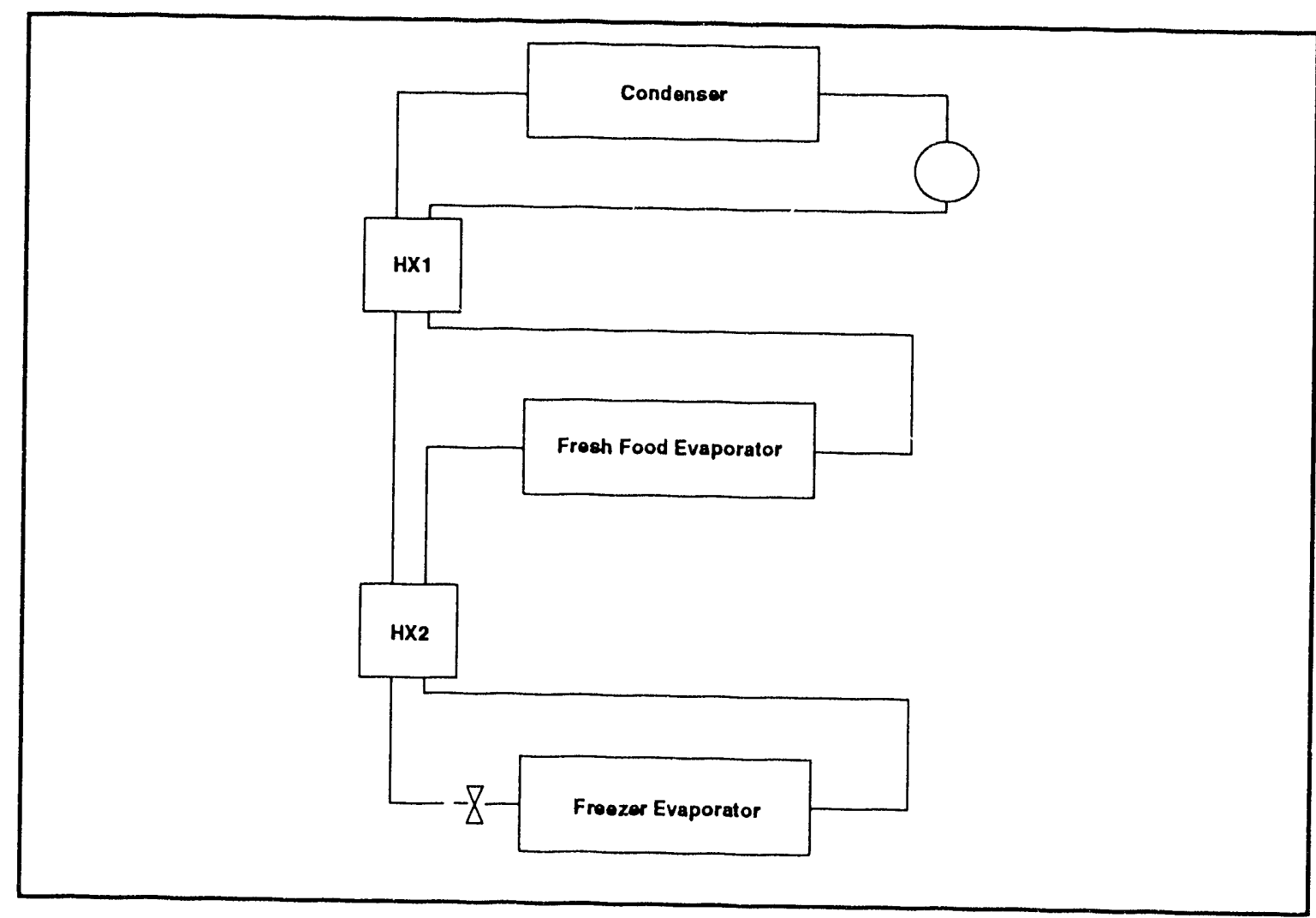

\section{A-2.1.2 La Brecque Cycle.}

The La Brecque cycle is a means of achieving two-stage refrigerators with one compressor connected alternately between the freezer loop and the fresh food loop $[11,12]$. The fresh food evaporator serves as a condenser when the compressor is in freezer operation and serves as the evaporator in the fresh food cycle. This feature reduces the pressure ratio to roughly 5 (from the normal 9-11 with the single evaporator design), thereby permitting the use of HCFC-22 as a potential replacement for CFC- 12 .

The unit under development at the University of Maine (Orono) uses natural convection heat exchangers with an ice bank as the fresh food evaporator. Design of the ice bank involves a critical balance between providing sufficient heat transfer area to minimize thermodynamic losses and retention of desired food storage volume. In principle, there is no reason fans could not be used with the cycle.

The present technical problems include:

- Complexity of control--the cabinet loads need to be balanced since, ideally, the fresh food evaporator capacity should maich the freezer condenser and the fresh food cabinet load; 
- Ice bank thermal irreversibilities associated with alternately freezing and thawing water/ice--in essence, two additional heat exchanger temperature drops are imposed, which will affect the overall energy consumption. The primary theoretical advantage derives from the use of two-stage compression to overcome the large temperature lift (pressure ratio about 10) in current refrigerator/freezers;

- Volume occupied by fresh food evaporator; and

- Need for additional components--ice bank evaporator, check valve, solenoid.

The only known research in the cycle is being carried out at the University of Maine. Although the researchers reported a theoretical average COP 1.65 , versus 1.1 to 1.2 for the standard design, early test results were disappointing. Continuation of the research is currently at a low level.

\section{A-2.1.3 Hybrid Vapor Compression/Injection Cycle}

An alternate means of reducing the pressure ratio across a domestic refrigerator/freezer compressor is offered by a theoretical cycle using a separator and ejector between the fresh food and freezer evaporator [13]. By the use of two expansion devices (cap tube) the fresh food and freezer evaporator processes occur at different pressure levels (see Figure A-4).

Figure A-4: Cycle Diagram of Hybrid Vapor Compression/njector Cycle

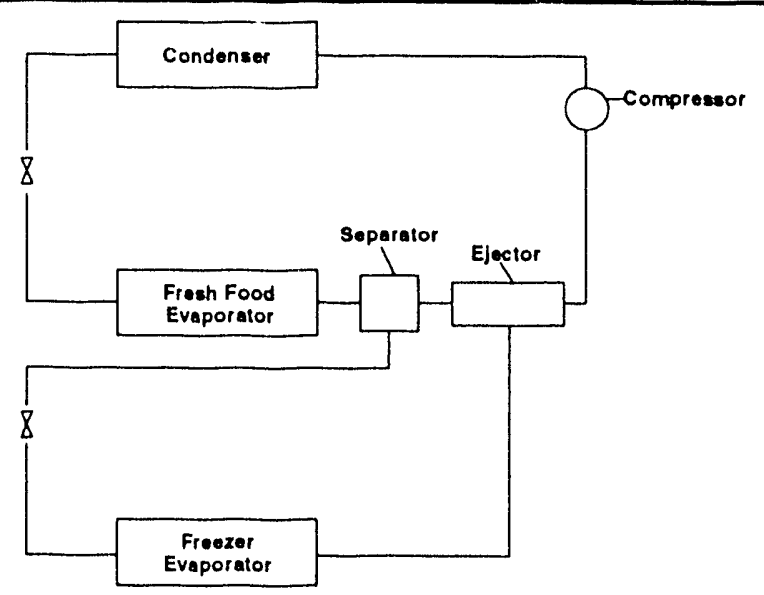

The separator allows liquid leaving the incomplete evaporator from the fresh food evaporator to enter the lower pressure capillary tube while the vapor is used with the ejector to entrain the vapor leaving the freezer evaporator and raise it to a pressure level intermediate to the two evaporator pressures.

The work is being carried out at the University of Xi' an Jiaotong (China) [13] on a theoretical basis. Idealized calculations suggest the potential for a $12 \%-16 \%$ efficiency gain. No experiments have been reported. 
The potential advantages of the cycle are: a modest efficiency gain, smaller compressor displacement requirement, simplicity of ejector design. Disadvantages include:

additional hardware requirements (separator, ejector, another capillary tube), control (both cabinets must require refrigeration), no experimental history in

refrigerator/freezers.

\section{A-2.1.4 Multiple Evaporator/Compressor Cycles.}

A number of vapor compression cycle alternatives are either currently used in European and Asian refrigerators, or are being explored. Examples include:

- Dual evaporator, single compressor cycle with the evaporator connected in series. The pressure ratio is established by the freezer sections temperature;

- Dual evaporator, single compression cycle with a valve used to alternately connect the fresh food evaporator to the compressor (freezer isolated) and then the freezer evaporator to the compressor (fresh food isolated); and

- Two-stage compression, with two evaporators and two expansion devices.

Each of these is generically a vapor-compression cycle with a minor variation designed to improve the compression process.

\section{A-2.2 Absorption and Adsorption Refrigeration.}

The application feature which characterizes (ad-or ab-) sorption space conditioning and refrigeration is that it is heat actuated rather than electrically driven.

The sorption cycle is the use of a chemical system to replace the compressor in a conventional cooling or refrigeration system. The refrigerant selected must have a corresponding ab- or adsorbent capable of sorbing the refrigerant to such a degree that the pressure of refrigerant over the sorbate, at the heat rejection temperature, is less than the pressure of the refrigerant in the evaporator. The refrigerant is recovered by desorbing in through an increase in temperature, its pressure being high enough to permit liquification in a condenser which rejects heat to the heat sink (iooling tower, ambient air, etc.) being used.

To improve efficiency, multi-effect cycles are commonly used, wherein heat of condensation and/or heat of absorption of one cycle is used to supply heat energy to the generator of a bottoming cycle.

Solid absorption conditioning and refrigeration has not previously been developed as an important commercial product. Some new developments give it great promise in the long term. At present, sorption refrigeration is virtually synonymous with liquid absorption space conditioning and our next sections will deal with this technology. 


\section{A-2.2.1 Current Status of Absorption Space Conditioning.}

Three types of absorption heat pumps have achieved commercial importance:

1. Aqua Ammonia Chillers. Ammonia refrigerant, using water as absorbent and employing chromate as a corrosion inhibitor, was the basis of an important product for space cooling of residential and small commercial sites. Because of the ASME pressure vessel code restriction, the generator could not easily be sized above 7.5 tons cooling. Whirlpool, Bryant, and Arkla manufactured many hundreds of thousands of these machines prior to the early 1970s. Whirlpool stopped manufacturing in 1970, and Bryant stopped two or three years later, perhaps 1973, each for its own reasons and only partly related to any gas utility subsidization. Arkla continued production, and remains in production today. Arkla has made no significant technical improvements since the 1970s, and sales have declined. Since 1973, Arkla (and its successor companies Preway, Dometic, and Robur) have made many tens of thousands of the old technology aqua-ammonia chillers.

The aqua ammonia chiller was characterized by high cost, (it required subsidization by gas utilities to be commercially viable), low efficiency and field maintenance problems. It has not been a commercial product for nearly twenty years, although Arkla did afterwards manufacture a few for special orders. There seems to be no Japanese interest in this machine.

The revival of aqua ammonia refrigeration will depend upon improved performance and lower costs.

2. "Servel" Gas Refrigerator. This Swedish development used ammonia and water (with chromate inhibitor) for domestic refrigeration. A circulating stream of hydrogen kept the evaporator and condenser sections at the same total pressure, so that solution circulation could be effected by a bubble lift pump. Characteristics of this product were:

- Long, service free, product life; and

- Low thermal efficiency.

The gas refrigerator has mostly been displaced by the more convenient and versatile R-12 compression cycle. A limited market exists for camping and remote site applications.

Improvements in the technology for residential absorption refrigerators have been known since the 1960s. However, due to the decrease in the market for this equipment, the decision was not made to produce more efficient equipment in the U.S. These decisions were made during the time period when CFC and HCFC issues were not a concern. However, due to the perceived market potential for residential absorption refrigerators, it would probably require a DOE research program to resurrect and update the technology. However, improved absorption domestic refrigeration systems would have to compete with vapor compression systems which will also see substantial improvements over the next 5 to 10 years. 
3. Lithium Bromide - Water Machines. The lithium bromide chiller was introduced as a product in the 1950's, and prospered when the problems of hermeticity were solved. Product success was due to vibration free performance (particularly valuable for upper stories of high rise buildings) and the general availability of excess low pressure steam generated when fuel supplies were abundant and cost was low, and air pollution concerns and conservation were not widely considered.

In the United States the version sold was a "single effect" machine with a thermal Coefficient of Performance of about 0.7 at ARI rating conditions and long life expectancy. Since it operated with 24 psia steam, it was outside the ASME direct fired pressure vessel code. Carrier Corporation, The Trane Company, the York Division of Borg Warner and, to a lesser extent, Arkla manufactured this product until the market collapsed in 1973, due to the energy crisis when both York and Carrier dropped out of the market. There has recently been a slight recovery of the American market but, because of lack of product improvement, the Amer' can manufacturers are relying on
Japanese partners to upgrade their product lines for them.

Japanese Manufacturers (Hitachi, Mitsubishi, Ebara, Kawasaki, Sanyo and Yasaki) continued the development of American technology through the seventies and eighties, primarily because of Japanese government encouragement of a natural gas based economy and the high cost of electricity. While still supplying single effect machines for special situations, the bulk of Japanese production is a direct gas fired, two effect machine with an efficiency, against the heat value of the gas consumed, of 1.1.

Market Considerations. Because this is a very low pressure machine, the vapor spaces must be large. This is reflected by a very strong dependency on cost per ton versus size. As the size increases, the cost/ton drops and levels out around 300 tons capacity. As a result it is characteristically a large tonnage machine - various attempts to market technically satisfactory machines under 100 tons have been economic failures.

Because of the limited "lift" between evaporator and absorber temperatures possible within lithium bromide (because of its solubility limits) the commercial lithium bromide machine has not been air cooled but rejects its absorber and condenser heats to a cooling tower. Small cooling towers are undesirable because of the maintenance problems, further restricting the lithium bromide machine to larger sizes.

\section{A-2.2.2 Anticipated Developments, Liquid Absorbent Systems.}

Six decades of research on new absorbent-refrigerant pairs seems to identify ammonia, water and (perhaps) methanol as the only refrigerants likely to see commercial success in absorption cycles. Furthermore, enough is known about the necessary characteristics of absorbents that we can be pretty sure that no "breakthrough" discoveries will be made - we almost certainly know of the materials which will be used in future cycles, although some adjustment of ratios of mixed absorbents will probably take place.

Corrosion control, chemical instabilities and incompatibilities at high gencrator temperatures and modified materials of construction will require additional research. 
Short Term Research Goals. Developments which may take place over the next five to ten years could include the following:

1. Attempts are being made (Phillips Engineering Company) to revive the small aqua-ammonia space conditioning system by improving the efficiency and including space heating. If design goals are met it would have about the same fossil fuel efficiency for cooling, and significally higher fossil fuel efficiency for heating, with current AC/gas furnace combinations and wol!d be free of halocarbon refrigerants. Codes would be no problem since the outdoor unil sirculates brine to the indoor furnace coil.

2. Other developments in the process include a long standing program at Lawrence Berkeley Laboratories to develop a more efficient aqua ammonia machine and Columbia Gas Systems work with ammonia and a (proprietary?) salt absorbent.

3. Current technology aqua ammonia, or variants of this using salts to enhance the solubility of ammonia in water, are unlikely to be found in larger commercial machines because of the lesser efficiency of ammonia cy.les (compared to water) and the problem of the direct fired pressure vessel code. Analyses carried out by Phillips Engineering Company (point 1 above) include a potential for achieving high COP operation with the GAX cycle when water cooled. Such systems could operate below $32^{\circ} \mathrm{F}$ evaporator temperature, thereby extending this potential application to commercial and industrial refrigeration.

Water Refrigerant Systems. Some work should be done refining the existing information about caustic alkalies, other lithium salts and mixtures of lithium salts with zinc salts and/or organic additives as water absorbents. Much of the research will revolve about controlling corrosion and minimizing thermal incompatibility among chemical species.

Specific product development may well include:

1. Higher efficiency ("triple effect") cycles. DOE developments in this area are being undertaken by Trane, Apache and a York-Battelle joint program. Higher than three effect cycles do not appear practical with liquid absorbents. The projected cooling performance of 1.6-1.8 for this machine will be more (primary) energy efficient than current R-11 machines and would avoid halocarbon use. The first costs would be higher, but running costs (including demand charges) would be very much less in most parts of the world.

2. Air cooled cycles using water, aimed at residential and roof top applications, neither of which welcome cooling towers, are underway at Tokyo Gas (Hitachi

Engineering), Battelle (Columbus) Research Laboratories and has been accomplished in the DOE Solar program. High first costs make this an area unlikely to impinge upon HCFC replacement. 
3. Since both absorption and (re) generation take place over a temperature range, they are analogous to the use of non-azeotropic refrigerant mixtures, and some work has been done using an absorption-desorption cycle, coupled to a compressor, to achieve a Lorenz cooling cycle. It is also possible to reduce the compression ratio between evaporator and condenser temperatures. As a halocarbon replacement method, this raises the familiar question - what refrigerant will be used?

\section{A-2.2.3 Heat Pumps Using Solid Sorbents.}

Over the years there have been many studies, mostly simulation but some in hardware, proposing a variety of solid adsorbents (e.g., silica gel, charcoal, molecular sieves) which have large specific surface areas or small pores upon/in which the refrigerant is held by various forces. A second class of solid adsorbents, retain the refrigerant by means of specific chemical compound formation. These may be salt ammoniates, hydrates or other coordinately bonded ligands and may include other types of chemical compounds such as calcium oxide absorbing water to form calcium hydroxide. The primary requirement is that the chemical compound be formed and, reversibly, decomposed at appropriate temperatures and pressures.

These were formerly discussed as a single group but recent advances make it desirable to discuss separately the absorbers and the adsorbers.

Solid sorbents, not being pumpable, cannot be incrementally sent to the regenerator, as with solutions, but must be cycled between absorption and regeneration temperatures as a bed, including not only the absorbent but also the containment materials and heat transfer hardware. Thus a sorption bed will supply cooling for a period (a "batch" of cooling), until it has become saturated with refrigerant, at which time cooling will interrupted until it has been through a recharging temperature cycle.

\section{A-2.2.4 Adsorption Heat Pumping.}

Background. Typical of these systems, probably the most promising and certainly the best developed, is the use of molecular sieves (Zeolites) to absorb water vapor. Much of the information here was supplied by Professor Tchnerev of MIT through his Zeopower company.

Technical Considerations. The Technical feasibility of heat pumping by adsorbing refrigerant vapor in a bed of zeolite (or other adsorbent) has been repeatedly demonstrated. No commercial space conditioning or refrigeration products have developed. Some important characteristics of adsorbent materials include:

1. The adsorptive capacity has been relatively low.

2. Heat transfer $b \geq t$ tween beds of porous, granular, solids and fluids in pipes is very slow and attempts to speed it up generally involve lavish use of tubes and fins, which add to cost. 
3. As the bed function changes between adsorption and regeneration, large amounts of sensible heat must either be wasted or transferred by clumsy and slow heat transfer loops. Loss of this sensible heat can be a large source of inefficiency.

4. The heat of desorption will always be higher than the heat of evaporation of the refrigerant because of the heat liberated when the refrigerant is bonded to the sorbent.

Zeopower claims several factors which tend to reduce the effects of these classical limitations. These are:

1. An intrinsic property of Zeolites is said to be lower sensitivity to adsorber and evaporator temperature and allows for a higher degree of desorption in the generator. This allows it to take place over a wide temperature range $\left(100^{\circ} \mathrm{F}\right.$ to $300^{\circ} \mathrm{F}$ in a good case scenario).

2. Since regeneration can begin at $100^{\circ} \mathrm{F}$, the heat of adsorption can be used to supply some of the heat of regeneration, using an external liquid heat transfer loop.

Potential of Zeolite Heat Pumping as a CFC Replacement. Technical feasibility of zeolite heat pumping, with a COP in excess of unity for cooling appears to have been demonstrated. Reservations about its practicality are addressed only to cost and size:

A three ton unit, using the published data, would require 540 pounds of Zeolite and, judging from the very little information given about the heat exchanger construction, probably at least that much copper. By the time one adds an hydraulic pump, two oil-air fan coil units and a gas fired oil heater, the unit is very large and very expensive. Materials and assembled components costs for a three ton unit are probably going to be in the ballpark of $\$ 2,500$, to which must be added labor and overhead. Even with the heat exchangers coiled, assuming this to be possible with the internal construction, it would be big.

There are other avenues for CFC replacement which will give competitive energy efficiency but more acceptable consumer costs. These are discussed in the following sections.

\section{A-2.2.5 Solid Absorption Heat Pumping: Solid Hydrate/Ammoniate Heat Pumping for CFC Replacement.}

Comparison of Solid and Liquid Absorption Systems. The well developed technology of liquid absorption systems cannot be directly applied to solid absorption systems. Among the differences which are especially important to the machine designer are the following:

- Hydrates and ammoniates do not change pressure as refrigerant is absorbed over the working range of the absorbent. This means that the use of solids will call for rethinking of machine control. 
- When a solid absorption bed is exhausted with respect to the function of the heat exchanger, the process comes to an end. Since the absorbent, and the heat exchanger are not practically separable, both the heat exchanger and the absorbent must be cooled or heated to the temperature required for the next process. If the sensible heat is not to be wasted, some cost-effective alternate to liquid-liquid heat exchange must be developed.

- Under the best conditions one can neglect the sensible heat losses in heating or cooling absorbent beds and their associated containment and heat transfer surface because 5 to 15 times the refrigerant is absorbed by solid absorbents compared to liquid absorbents.

- The heat of sorption from solid hydrates and ammoniates may be higher by a factor of two or three than the heat of vaporization of pure refrigerant. This is a serious limitation on cycle efficiency in high temperature lift situations, as when an absorber is at a much higher temperature than the desorber (evaporator).

- The absence of a liquid phase in the generator makes corrosion a much slower process than with liquids. Corrosion studies of ammoniates in aluminum have been favorable up to $400^{\circ} \mathrm{F}$.

- Unlike liquid solution which shows no deterioration of properties over numerous cycles, solids can show deteriorating performance over repeat cycles through decrepitation, surface contamination, etc. Absorbent salts processed according to the Rocky Research methods have shown no change in properties over thousands of cycles.

While the efficiency per stage tends to be low, multistaging of these systems is very attractive because of the very large numbers of useful absorbents covering a broad range of temperature applications.

\section{A-2.2.6 Present Status of Solid Absorbent Technology.}

Space Conditioning. A simulation of an ammonia solid absorbent system study projected a cooling COP of 1.03 and a heating COP of 2.07. The capacity was 3.75 tons cooling and $93,200 \mathrm{Btu} / \mathrm{hr}$ heating. The estimated fabrication cost was $\$ 905$, which is pretty close to the fabrication cost of 3.5 ton, mid-range, electric air conditioner and an $85,000 \mathrm{Btu} / \mathrm{hr}, 78 \%$ efficient, gas furnace. The volume and dimensions would be similar to that of a furnace of similar capacity but be located outdoors.

This could be scaled up to large sized equipment and additional stages added to improve efficiency without any "break through" discoveries needed.

Recent improvements in cycle times make the above estimate very conservative. The essential components of a space heating/cooling system have been reduced to practice in pilot plant sized demonstrations. 
More efficient (and somewhat more complex) cycles have been designed, based on laboratory experimental data, awaiting future development.

Mixed Space Conditioning Systems. In the longer term, one can see solid absorption systems being developed as topping cycles, perhaps retrofitable, for single and double effect lithium bromide chillers. Use with compressors as desorbers and resorbers can be considered to improve compression ratio between two temperatures.

Additional basic rezearch needs to be done to add to the selection of absorbent materials so that greater design flexibility will result. Life expectancy has been fairly well established but some additional work is desirable. A lot of work in heat exchanger optimization, process control, materials specification, etc., will be required before solid absorbent systems can be a manufactured product.

Assessment as CFC Replacement Technology. Even if the CFC problem had not arisen, solid absorption heat pumps would look like a viable product in terms of initial cost, reduced operating costs and reduced fossil fuel consumption. With the added incentive of CFC replacement, there is potential for this to become a commercial product beyond the year 2000 . Residential space conditioning will come first, with air-cooled rooftop units a close second. Large space cooling machines and refrigeration applications would follow after the technology becomes well established with the smaller units.

Ammonia cycles, at present, look more promising than water systems because the very low pressure of water machines adds too much cost to small units. Since heat exchange with the beds will most likely be done with heat transfer liquids, rather than direct air heat exchange, no code problems appear to be of consequence.

At present, several major manufacturers are looking at the technology with interest.

\section{A-2.3 Humidification/Dehumidification in Space Cooling.}

\section{A-2.3.1 Overview.}

There exist a variety of proposed space cooling methods based upon evaporation or condensation of water into an air stream, either singly or in combinations of the two. Since the technologies are overlapping, this group will be treated as a single area, divided into the following subgroups:

- Evaporative cooling, in which an air stream is cooled by adiabatic evaporation of water, increasing the saturation temperature (wet bulb temperature) and decreasing the dry bulb temperature

- Indirect evaporative cooling, in which an air stream cooled as in evaporative cooling, is used as a heat sink to cool a secondary stream of air 
- Dehumidification, in which the latent part of the cooling load is accomplished by chemical sorption of a portion of the contained water vapor. This must be accompanied by subsequent drying, usually by heating, of the sorbing material. Dehumidification both reduces the required size of the cooling machine and also improves its efficiency by allowing the evaporator to operate at temperatures above those needed for dehumidification (latent cooling). Twc dehumidification methods have been used:

- Liquid dehumidification systems, in which the air stream is contacted with a liquid which can dissolve a portion of the water vapor in the air stream. Solutions of lithium salts and various glycols have been used.

- Solid dehumidification systems, in which the air stream is contacted with solid which will remove a portion of the contained water vapor by ad- or ab-sorption. Solid, hydrate-able, salts, silica gel, and activated carbon are among materials which have been proposed.

- Desiccant cooling. Several serious attempts have been made to enhance evaporative cooling by preceding the evaporator with a solid dehumidification or a liquid dehumidification system to enhance the temperature lowering which takes place in the evaporator. Because the mechanics are very different, they will be considered under the headings of:

- Solid desiccant cooling, and

- Liquid desiccant cooling.

\section{A-2.3.2 The Principle.}

If an air stream, unsaturated with respect to water, is brought into contact with liquid water under adiabatic conditions, some of the water will evaporate and, by its latent heat of vaporization, cool both the water and the air stream. The steady state temperature which will be reached will depend upon three things:

- The area of the water surface exposed to the air stream,

- The residence time, a function of air stream velocity, and

- The amount of water carried by the airstream prior to humidification, which can be measured by either "wet bulb temperature" or by "dry bulb temperature" plus "relative humidity."

If the evaporator is very effective, the airstream will pick up as much vapor as can be carried at equilibrium (i.e., be "saturated") at which point its temperature will be the wet bulb temperature of the entering airstream and its relative humidity will be $100 \%$. The lowest temperature which can be reached by an evaporative cooler is the wet bulb temperature of the airstream entering the evaporator.

A-2.3.3 Some Operational Considerations of the Evaporative Cooler. Evaporative cooling, as a manufactured space cooling product, has been around for many decades, although it has never become an important product line for reasons 
which will be considered below. The basic technology is closely allied to several other, more widely used, products; namely, humidification devices and evaporative cooling of some industrial devices, although cooling towers are generally preferred.

Some of the factors one looks at in the design and evaluation of evaporative coolers, humidifiers and the like include:

- The presentation of a large surface between the evaporating water and the airstream:

- Poured foams of sellulose and other plastic materials are popular. They must wet easily, be cheap and easily replaced. The pressure drop must be low even when mineral build up has progressed.

- Expanded metal structures, usually aluminum, are easily wetted, have good capacity of minerals and low pressure drops. Cost is higher than plastics.

- Water sprays and ultrasonically generated fogs humidify effectively but in many areas leave objectionably large amount of water residues as dust in the conditioned stream.

- For large humidification installations it is probable that a packed tower would be the design of choice.

- Scale build up when water evaporates can be a problem in some areas, particularly in the southwestern United States where evaporative cooling is most effective, but which also has some of the worst water in the country [14]. Since only a portion of the water used is evaporated, evaporative cooling is often prohibited in water-short regions.

- Because scale build up will generally be a major maintenance item, the evaporative surface must be easily replaced, at low cost, by an unskilled user.

- The evaporative couler is known colloquially as a "swamp cooler" because of the odors often developed by microorganism growth in the sump. Biocide addition should be part of the regular maintenance program.

- Claims are made, by some vendors [15], of the air purification ability of the evaporative cooler. It will not remove radon or many other gaseous pollutants and will not be very effective in removing particulates since the velocity is too low for impact removal of particles and the evaporative meshes are far to coarse to remove suspended particulates.

\section{A-2.3.4 Performance of Evaporative Coolers.}

An alternate term for "space cooling" is "comfort air conditioning." This reminds us that any product which is to be successful must make the consumer comfortable. To predict customer comfort we turn to the ASHRAE Comfort Chart, Figure A-5, which is a good guide to the temperature and relative humidity relationships which bound the 
perception of "comfort." A reproduction of this chart is included below for reference. The most obvious generalization we can make is that as the relative humidity increases, the dry bulb temperature must decrease to maintain a feeling of comfort.

Figure A-5: Revised ASHRAE Comfort Chart

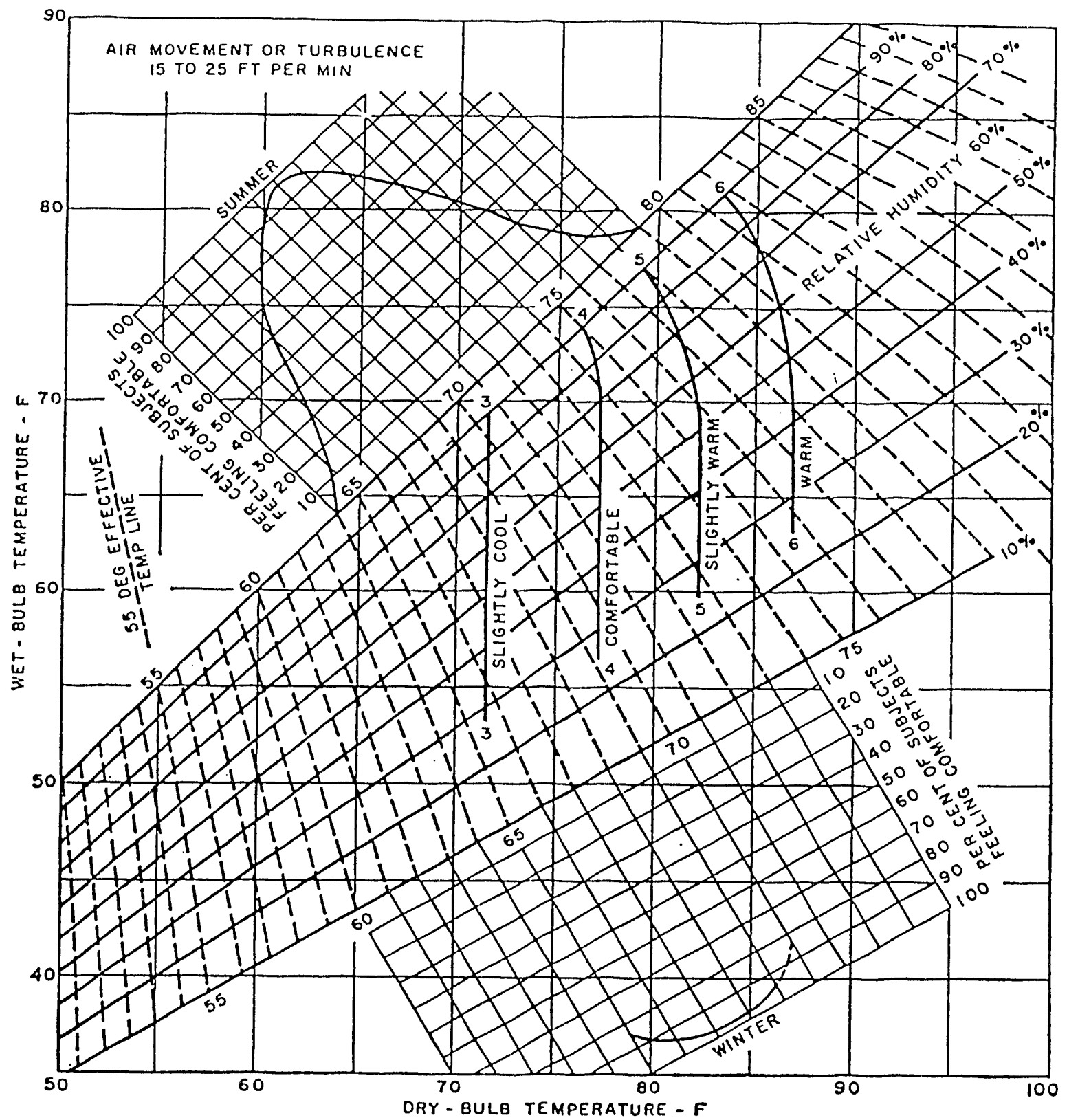


Unfortunately, in evaporative cooling the process which lowers the dry bulb temperature also increases the relative humidity, so the evaporation process in a measure works against itself. Let us consider a few examples, using the Psychometric chart of Figure A-6.

Figure A-6: Psychrometric Chart - Medium Temperature, Barometric Pressure, 29.92 in. Hg.

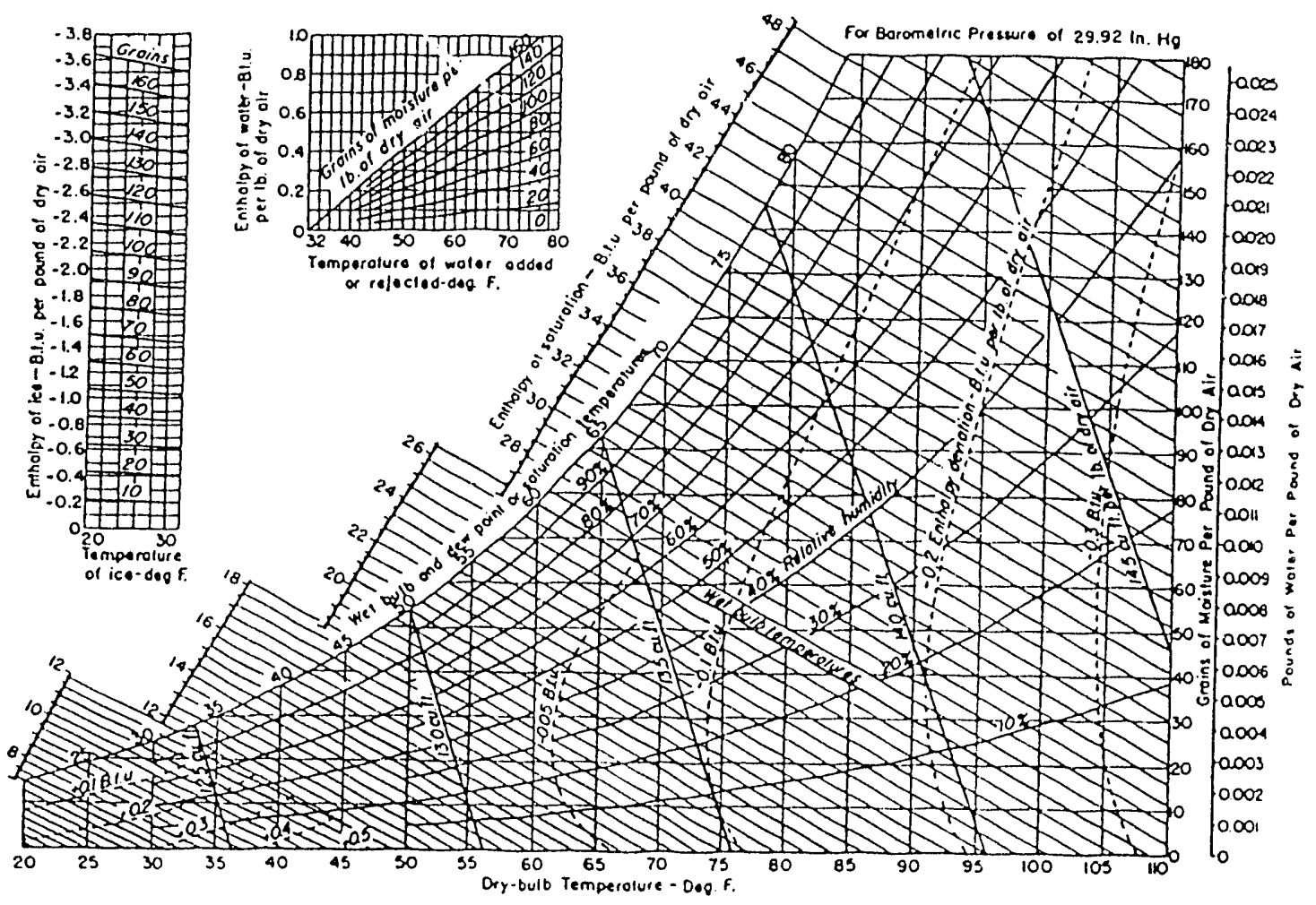

Take air at $95^{\circ} \mathrm{db}, 70^{\circ} \mathrm{wb}$ ( $\mathrm{rh}=28 \%$, a beautiful, dry day). As we add moisture we move along the diagonal constant enthalpy line of the Psychometric Chart, and when we reach $75^{\circ} \mathrm{db}$, our relative humidity is about $79 \%$, the wb remaining at $70^{\circ}$. Going to our comfort chart, we see that nobody would have been comfortable under the outdoor condition. After our dehumidification, however, about $80 \%$ of the population would be comfortable, a good application for evaporative cooling.

Consider now the wb rising to $80^{\circ}$ ( $\mathrm{rh}=53 \%$, still pretty dry). As we go along the constant enthalpy line, by evaporatively cooling the air, we find that when we reach the terminus $\left(\mathrm{Tdb}=\mathrm{Twb}=80^{\circ}\right)$ we have not yet entered the comfort zone.

We conclude, therefore, that evaporative cooling can give customer comfort only when we are dealing with very low ambient relative humidities. In most climatic conditions, it merely makes us, at best, less uncomfortable that we were before. 
A-2.3.5 As Assessment of Evaporative Cooling as CFC Replacement. Evaporative coolers are relatively inexpensive to purchase, operating costs are low, some maintenance is needed, and a fairly abundant water supply is needed for continuous operation. In very few places would the customer feel that our contemporary standards of comfort were being reliably (i.e., $100 \%$ of the year) met.

These same qualitie: have not succeeded in making this an exciting investment opportunity in the past. A few (by mass production standards) will be sold:

- In areas where the climate is pretty dependably hot but very dry, as in parts of the southwestern United States.

- To environmental enthusiasts.

- For spaces occupied for short intervals, such as warehouses and other storage areas.

- A few have always been sold to automobilists whose hot weather driving did not, in their minds, justify the cost of mechanical A/C. For short, intermittent use, one doesn't worry about scaling of the evaporator surface and neglects bleed.

In summary, there is no evidence of significant customer acceptance of simple evaporative cooling in the large American markets.

\section{A-2.3.6 Indirect Evaporative Cooling.}

When the outdoor wet bulb temperature is less than $75^{\circ} \mathrm{F}$, evaporative cooling can lower the dry bulb temperature to the comfort region but the simultaneous increase in relative humidity will usually push the air back out of the comfort region. It has been suggested [16] that the cooled, wet, air could be used to cool a secondary stream by means of a heat exchanger. Two versions of this are suggested:

1. The evaporator and air-air heat exchangers are physically distinct units.

2. The air-air heat exchanger be of a stacked flat plate construction, with alternate spaces in the stack being surfaced with an evaporative pad so that the heat exchanger also serves as evaporative cooler.

Some Operational Considerations. Item 2 above, combined heat exchanger-evaporator, appears impractical because of the difficulty of opening the heat exchanger and changing surfaces when they scale.

A typical air to surface heat transfer coefficient for HVAC type equipment is 10 $\mathrm{Btu} / \mathrm{hr}-\mathrm{ft}^{2}-{ }^{\circ} \mathrm{F}$. For two surfaces, as in a heat exchanger, the overall coefficient would be $5 \mathrm{Btu} / \mathrm{hr}-\mathrm{ft}^{2}{ }^{\circ} \mathrm{F}$. For a ton of cooling capacity, e.g, 12,000 Btu/hr, with a LMTD of $10^{\circ} \mathrm{F}$, the required area would be:

$$
\mathrm{AREA}=12000 /(5 \times 10)=240 \mathrm{ft}^{2}
$$


This might be a practical sized heat exchanger, but the approach temperature wipes out too much of the temperature drop. In the McClellan [17] analysis, an approach temperature of $3^{\circ} \mathrm{F}$ was taken, which would require a surface of $800 \mathrm{ft}^{2}$ per ton, which is getting pretty large and expensive. The favorable conclusions of McClellen are questionable.

Assessment of Indirect Evaporative Cooling as CFC Replacement. There does not appear to be any evidence of commercial use of this concept. Future use is unlikely.

\section{A-2.3.7 Dehumidification.}

In mechanical air conditioning, the air stream is generally cooled down to $65^{\circ} \mathrm{F}$ so that the relative humidity will nut be high enough to push the occupied space outside the comfort zone. This "latent load," the heat of condensation of excess moisture in the airstream, is a small part of the annual load and is necessary for comfort only a very small portion of the time. If this excess cooling were not required for dehumidification, the evaporator could be run about $10^{\circ} \mathrm{F}$ higher and reduce the annual energy usage by about $30 \%$, both for mechanical and for heat operated space conditioners.

Along with the reduction in energy consumption would be a corresponding decrease in the size of the compressor, or absorption chiller, needed to handle the load because of the lower peak load and improved COP.

Three ways of saving this energy and compressor capacity suggest themselves:

1. Accept less personal comfort during high humidity periods. This would require a major sales job to the average customer who installs a comfort conditioning system because he wants to be comfortable.

2. Design the system so that the evaporator temperature drops only in response to increasing humidity. Evidently this would not save compressor size. A competent analysis of this approach has not been found. There are some extra costs (e.g., larger coils in the airstream) in trying to do this, but it might be worth a look.

3. Effect humidity control by a second device which would be used only when needed.

Item 3 is the logic which leads to the concept of dehumidification as an adjunct to the primary cooling device.

\section{A-2.3.8 Liquid Dehumidification.}

Desiccant dehumidifiers have been traditionally used in specialty air conditioning applications. Industrial applications include battery production, food, and pharmaceutical where the need to maintain a dry air environment is critical to the manufacturing process. The efficiency and cost of this class of equipment are not the primary concern, but rather system performance as measured by the production of dry air is key to acceptance. As a result, desiccant dehumidifier equipment is an industrial product with an occasional commercial application. Current liquid desiccant designs have coefficient of performance of .5 to .6 or it requires roughly $2 \mathrm{Btu}$ of heat into the regenerator to remove $1 \mathrm{Btu}$ of water vapor from the air stream. Desiccant 
dehumidifiers range from very small units processing less than $100 \mathrm{cfm}$ of air to units that process flows in excess of $20,000 \mathrm{cfm}$. This class of product with energy performance levels of roughly a .6 COP (latent energy of water removed/primary fuel use) has a cost of about $\$ 2,000 /$ ton or $\$ 4$ to $\$ 6 / \mathrm{cfm}$. The current market (1990) size is roughly $\$ 35$ millio a of annual equipment sales with the majority of sales in the solid wheel portion of the industry.

Industrial desiccant dehumidifier technology is divided into two groups:

- Liquid desiccants, and

- Solid desiccant (honeycomb and packed wheels).

Both approaches remove moisture from an air flow by creating a vapor pressure differential between the air and desiccant material. As shown in Figure A-7, a typical liquid dehumidifier consists of two sections, a conditioner (contactor) for air drying and a regenerator to remove the water absorbed by the air drying process. A liquid desiccant drys or removes water from the return air stream by bringing it in contact with a liquid desiccant solution (e.g., water-glycol, water/lithium chloride), where the partial pressure difference between the air stream and absorbent fluid drives water vapor from the air stream to the desiccant fluid. As the absorbent fluid gains more water, its ability to remove moisture decreases and a fluid regeneration step is required. The regenerator section acts as a boiler or evaporator where the absorbent fluid is concentrated rejecting the water gained to the ambient air. Niagara Blower's current design (water-glycol) air purge to establish a low partial pressure needed for low temperature regeneration. Units using $\mathrm{LiCl}$ as the desiccant are sold commercially by the Kathabar Systems Division of Somerset Technologies, Inc., in capacities of 4 to 200 tons $[18,19]$. They also offer the ability to control humidity and temperature independently.

The ability to reach a high cooling COP is a strong function of the regenerator. The smaller the energy input for regenerating or creating a strong solution, the higher the COP. Recent work by Andrew Lowenstein and Mary Helen Dean ("The Effect of Regenerator Performance on a Liquid Desiccant Air Conditioner,"

ASHRAE-AN-92-3-2) shows that alternative regenerator configurations offer the ability to increase significantly the $\mathrm{COP}$ of $\mathrm{LiCl}$ desiccant air conditioners. Table A-13 summarizes their findings. Clearly, replacing the packed bed regenerators on today's liquid desiccant air conditioners has the potential to make these systems quite energy competitive. 
Figure A-7: General Liquid-Desiccant Air Conditioner

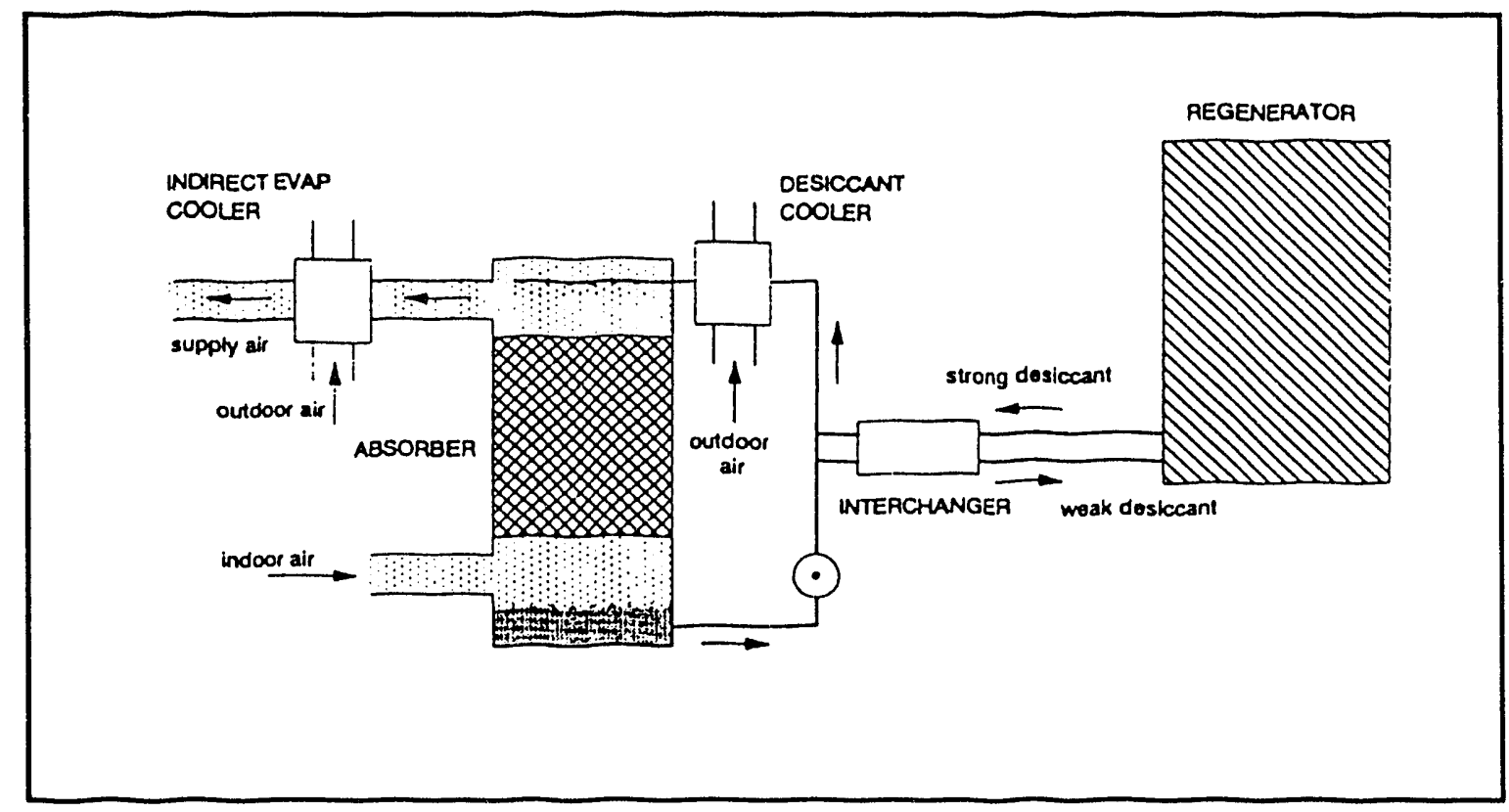

Table A-13: Effect of Regenerator Configuration on System COP

\begin{tabular}{|l|c|}
\hline \multicolumn{1}{|c|}{ Regenerator Configuration } & COP \\
\hline \hline Packed bed, $150^{\circ} \mathrm{F}$ spray temperature & 0.57 \\
\hline Packed bed, $240^{\circ} \mathrm{F}$ spray temperature & 0.69 \\
\hline Simple boiler, $212^{\circ} \mathrm{F}$ saturated steam leaving & 0.67 \\
\hline Simple boiler, $120^{\circ} \mathrm{F}$ saturated steam leaving & 0.79 \\
\hline Simple boiler, $100^{\circ} \mathrm{F}$ saturated steam leaving & 0.82 \\
\hline Double-effect boiler, $120^{\circ} \mathrm{F}$ saturated steam leaving & 1.36 \\
\hline Triple-effect boiler, $120^{\circ} \mathrm{F}$ saturated steam leaving & 1.89 \\
\hline Steam recompression & 2.40 \\
\hline
\end{tabular}

Some Design and Operational Considerations. Some of the more obvious considerations include:

- Provision must be made to minimize foreign matter brought into the system, and means of coping with any consequences of accumulated foreign matter must be included

- No materials hazardous to health, or constituting threats to property, must be allowed to escape under any conditions. Most manufacturers would be very nervous about the materials used even if containment were fairly certain.

- Corrosion problems will be vastly greater in the presence of air than under the hermetic conditions of an absorption chiller. Fortunately the low temperatures would permit free use of cheap plastics. 
Currently, Ahlstrom Rosenblad of Stockholm is using a triple effect (ADIAC unit) liquid desiccant drying system for timber drying that has COP in excess of 1.7.

Ablers Air Conditioning of Tempe, $\mathrm{AZ}$ is currently developing a $\mathrm{LiBr} /$ water liquid desiccant air conditioner with a double boiler (regenerator) with a likely COP of 1 at ARI conditions.

Given the potential of liquid desiccant systems to produce high COP systems, then their development should accelerate.

Assessment of Liquid Dehumidification Systems. Liquid dehumidification system potentially can act as CFC replacement. They are also important in two other ways:

1. By reducing the size of compressors, the amount of HCFC needed would be reduced. Similarly, the annual energy savings would translate into significant fossil fuel savings--translatable into other environmental values. The energy consumption of the liquid dehumidifier would be very small on an annual basis.

2. As a subsystem for desiccant cooling, which is treated later in this section, it is potentially useful as an alternate to compression or absorption cooling.

In spite of a few commercial systems by Kathabar, liquid dehumidification is still in early developmental stages. Some previous DOE sponsored research would supply useful, basic, design data [20,21].

\section{A-2.3.9 Solid Dehumidification System.}

There is a long history of solid adsorbents being used for dehumidification in indoor climate control. These fall into two categories:

Solid Beds. These are generally loosely packed beds of hydrated alumina, silica gel, or a zeolite. Some hydrate-able salts may also be used. In use, air is blown through the bed until it no longer removes water vapor due to saturation. At this point, the airstream is diverted to a second bed while the first is being recharged by blowing hot air through it. The "batch cycle" is then repeated.

Problems encountered with these beds have been:

- Disintegration of the adsorbent pieces (decrepitation), leading to dusting and increased pressure drop across the bed. The activity of the adsorbents also seems to decrease with time, probably due to the surface becoming contaminated.

- The equipment is bulky.

- It's a lot more convenient to dehumidify with a mechanical chiller.

The Use of "Wheels". Munters of Sweden pioneered the use of lithium salts immobilized in a porous mat (originally a corrugated asbestos, since discontinued) which was mounted on a wheel, through which the air to be dehumidified was passed. Instead of having to switch airstreams to regenerate, the wheel was turned so that one 
portion was in the working airstream while the other was in the recharging airstream. Thus, it was a continuous process, versus a batch process. Other solid desiccants could also be used but most development has been with the lithium salts.

The problems have been life of the absorbent wheel, seals between the hot and cold airstreams and general complexity since efficiency requires that there also be heat exchange wheels.

The primary use of the Munter's wheel has been as a subsystem for desiccant cooling, as will be covered in the next topic.

Assessment of Solid Dehumidification Systems. In terms of cost, maintenance, and energy efficiency, the solid dehumidification systems appear to be inferior to the liquid dehumidification systems [22].

\section{A-2.3.10 Desiccant Cooling Systems.}

Evapcrative cooling is effective in increasing comfort when the ambient wet bulb temperaiure is low. To make evaporative cooling generally useful, a number of attempts have been made to reduce the relative humidity by dehumidification prior to cooling the air in an evaporative cooler.

The principle design considerations of evaporative coolers and dehumidifiers have been covered above.

\section{A-2.3.11 Liquid Desiccant Cooling.}

A good deal of basic research on "open cycle" generators has been done in connection with solar driven absorption chillers with generators operating with atmospheric exposure to reduce the required temperature $[23,24]$.

To establish the order of magnitude of efficiency of a liquid desiccant chiller, a simple calculation was done assuming ambient air at $95^{\circ} \mathrm{F} \mathrm{db}$ and $80^{\circ} \mathrm{F}$ wb ( $\mathrm{rh}=53 \%$ ), a non atypical summer day. Using a lithium tromide absorber, the air was dried to $33^{\circ} \mathrm{F} w \mathrm{wb}$ and $100^{\circ} \mathrm{F} \mathrm{db}$. The increase in do temperature was occasioned by the need of rejecting the considerable heat of absorption to a cooling tower supplying $85^{\circ} \mathrm{F}$ coolant. This was the amount of drying required to put the air in the middle of the comfort chart when the dried stream was evaporatively cooled, as read from the Psychometric Chart.

The calculated result showed a therma! COP of 0.11 if no solution $\mathrm{HX}$ was used, increasing to 0.19 if a $75 \%$ effective solution heat exchanger was added.

This is not a final efficiency answer, however. For a large part of any cooling season in most parts of the country, the evaporative chiller would be sufficient to produce comfort. Only when the weather became excessively hot, or the humidity fairly high, would the dehumidifier portion of the unit be needed. With a "smart" control, the seasonal performance might be quite good. 


\section{A-2.3.12 Solid Desiccant Cooling.}

A decissant cooling system was developed by Institute of Gas Technology [25] which purchased the Munters' (Sweden) patents in the early 1960s. Development for direct fired gas cooling was sponsored by the American Gas Association during the 1960s, for solar cooling in the 1970s by DOE as the "Solar Mec," and by Southern California Gas in a major field test for natural gas cooling during the 1980s. A self-explanatory diagram of the Solar version follows as Figure A-8; simple deletion of the solar heating coil converts it to a natural gas fired desiccant chiller.

It is noted that the open cycle system shown in Figure A-8 is of the recirculation type where indoor air is processed and returned indoors. Another variation is ventilation mode where outdoor air is conditioned and sent indooors. The ventilation mode may be beneficial in certain applications where fresh outdoor air is required.

The electrical requirement of the solar Mec is about $30 \%$ of its design cooling capacity, giving an electrical COP of 3.3.

With suitable controls, an acceptable seasonal COP could be expected since the desiccant wheel need only be run under high humidity conditions.

Assessment of Desiccant Cooling as CFC Replacement. The lack of success after much research and promotional effort is discouraging. Nevertheless, technical feasibility has been demonstrated $[26,27]$ and seasonal COPs are encouraging.

As with any new space conditioning technology, retrofitting these devices into existing state of the art installations presents some problems. It is hard to introduce a product line for new construction only.

Further studies, stressing "smart" controls to make maximum use of evaporation alone, and simulations of a few system over a range of climatic conditions, are justified.

Long-Term Research and Development. The systems mentioned above can exhibit a COP of about 1.0. Research areas to obtain high efficiency and minimize first cost and operating cost include:

- desiccant material,

- desiccant support material,

- manufacture of low-cost wheels, and

- highly efficient, low-cost, low-pressure drop heat exchangers.

Sufficient design information is available that conceptual models of all the above applications of evaporative cooling, desiccant assisted cooling, and desiccant cooling alone can be developed and the performance reliably calculated.

This should be done and each model (sized for a few "representative" building types) should be run with weather tapes over the five or six temperature zones of the United 
States. One would look for seasonal cooling energies, compared with conventional machinery customarily used in the buildings modeled and develop some installed first cost comparisons.

Figure A-8: Solar-Mec Unit System III

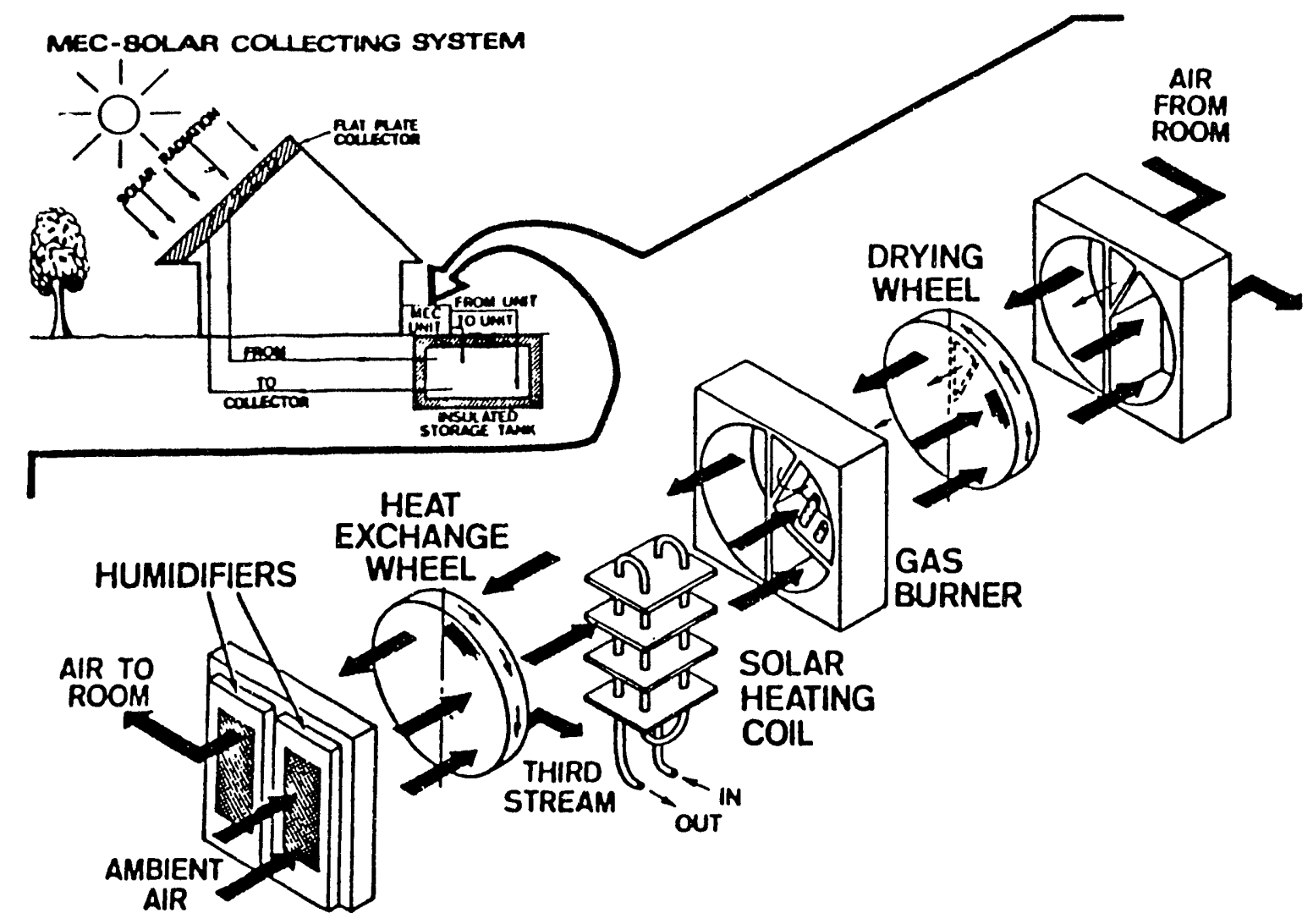

These results would determine the locations and sizes of potential markets. Scattered studies to date give a basis for the expectation that these simulations would show customer cost savings, successful replacement of HCFC based equipment and reduction in fossil fuel combustion products into the atmosphere.

The engineering problems have been pretty well outlined under the individual components; they do not appear to be particularly formidable. The biggest challenge may be to design mass producible equipment which can retrofit into existing spaces and interconnecting subsystems. 


\section{A-2.4 Stirling Cycle.}

Equipment designed using the Stirling cycle has been used for cryogenic refrigeration for a long time. The cryogenic refrigeration typically is produced at $20 \mathrm{~K}$ to $80 \mathrm{~K}$ where conventional vapor compression technology is not applicable due to basic limitations of working fluids. Cryogenic refrigeration has been used for a variety of terrestrial and spaceborne functions such as liquid nitrogen generation, infrared sensor cooling, electronic equipment cooling and liquefaction of gases. There are several companies in the cryogenic field including Phillips, Cryodynamics, Hughes Aircraft Co., Creare, CTI Cryogenics, and British Aerospace.

In principle, the same type of equipment used for cryogenic applications can be used for warmer temperature range applications. As an example, Cryodynamics, Inc., of Mountainside, N.J. has programs to modify existing cryogenic product lines for use in household refrigerators and mobile air conditioners.

During the last decade, Stirling cycle technology development has focused on engine applications. Several companies are now utilizing their Stirling engine technology base for the development of Stirling cycle heat pump and refrigeration equipment. Sunpower and MTI, funded by DOE, are two examples of companies with these types of programs.

The Stirling cycle has long been of interest in refrigeration cycles. A primary driving reason is that the theoretical coefficient of performance is equal to that of the Carnot cycle, the maximum possible. While hardware to realize the very high efficiencies has been elusive and difficult to carry out, the promise of potential maximum efficiency has spurred attempts at hardware development.

There are other reasons for considering the Stirling cycle particularly at this time of interest in the ozone layer. The working fluid used in Stirling equipment is usually helium which has an ODP and GWP of zero. Helium is an ideal fluid from an environmental standpoint. Helium is also compatible with any chosen material for construction from a corrosion or compatibility viewpoint. The only problem with helium is that it very slowly diffuses through most non-metallic materials. As an example a toy balloon with helium loses its size even with no apparent leak, since the helium diffuses through the wall of the balloon. Most equipment materials are metallic so that diffusion is so small that it isn't a problem. The inertness of helium (the most inert element) is a great advantage in refrigeration hardware. Ample supplies and recoverable resources of helium are available to meet the needs of large scale use of Stirling cycle equipment. In addition to supplies in natural gas wells that are not currently utilized, the atmosphere contains $5 \mathrm{ppm}$ of helium which could be recovered as a by-product of air separation processes.

These advantages provide sufficient reason to actively pursue Stirling cycle technology for refrigeration applications. The assessment of Stirling cycle technoiogy must, however, take into account the following factors: 
- Vapor compression equipment has very long life and high reliability due to the excellent lubrication achieved in most equipment. Vapor compression equipment lifetime is 20,000 and 50,000 hours with very low maintenance.

- There are highly favorable heat transfer regimes (condensing and boiling) in vapor compression equipment which when combined with relatively simple mechanical components, result in low cost mechanical components and heat exchangers.

The successful development of Stirling equipment will require that it compare favorably with the well developed vapor compression systems relative to reliability and cost as well as thermodynamic performance.

The efficiency (coefficient of performance) of the ideal Stirling cycle is equal to that of the Carnot cycle and is given by:

$$
C O P=\frac{Q c}{W_{\text {in }}}=\frac{T c}{T_{H}-T_{C}}=\frac{Q c}{W_{C}-W_{E}}
$$

where: $\quad Q_{c}=$ heat absorbed

$$
\begin{aligned}
& \mathrm{W}_{\mathrm{c}}=\text { compressor work } \\
& \mathrm{W}_{\mathrm{E}}=\text { expansion work } \\
& \mathrm{W}_{\mathrm{in}}=\mathrm{W}_{\mathrm{c}}-\mathrm{W}_{\mathrm{E}},=\text { net input work } \\
& \mathrm{T}_{\mathrm{c}}=\text { cold expansion gas temperature } \\
& \mathrm{T}_{\mathrm{H}}=\text { hot compression gas temperature }
\end{aligned}
$$

In practice, it is difficult to implement the Stirling cycle in its ideal form because of the following reasons:

- The gas cycle is affected by the motion of the pistons which are either controlled by slider crank mechanisms or by free piston motion. In either case the flow of the working gas only approximates the motion required to achieve the ideal cycle.

- The ideal cycle requires that all the gas be compressed and expanded isothermally. This is not possible in reality due to practical considerations in heat exchanger design and the actual flow patterns of the working gas.

- Thermodynamic, mechanical and leakage losses in the compression and expansion processes cause the cycle to deviate from the ideal cycle. Analysis of hardware to carry out the realities of the Stirling cycle is greatly complicated by the items listed above as well as other factors. There are still significant uncertainties about how to model rather basic physical phenomena such as heat transfer in the oscillating flow regimes in the heat exchangers. 


\section{A-2.4.1 Status of Stirling Development.}

There has been relatively little development effort on Stirling cycle refrigeration equipment because of the dominant position of vapor compression. The work that has been done on the Stirling cycle has included:

- Development of an experimental free piston Stirling cooling cycle unit for use in a Duplex Stirling system as part of a Gas Research Institute sponsored program with Sunpower, Inc., of Athens, Ohio. This program, undertaken in the early 1980's experimentally verified that Stirling heat pump cycles could achieve efficiencies approaching $50 \%$ of Carnot even with low temperature lifts. This would result in efficiencies comparable to that achieved with well designed vapor compression units.

- This potential was subsequently verified by Kawasaki Heavy Industries in an integrated Duplex Stirling Unit designed with the assistance of SUNPOWER. This work, done in $1986 / 87$, also pointed out the advantage of the Stirling heat pump cycle when operating with low ambient air temperatures since capacity and efficiency are relatively unaffected by the temperature lifts over the operating range of interest.

- Oak Ridge National Laboratories undertook analytical studies of Stirling heat pump technology using NASA Lewis Research Center's third order code computer based models applied to available kinematic Stirling engine configurations. These studies indicated the potential for achieving efficiency levels of interest and the potential advantages of Stirling equipment as the temperature lifts increase.

- Cryodynamics Inc., of Mountainside, N.J. has recently adapted several of their units designed for cryogenic applications for use in refrigerators and for mobile refrigeration. These units have further verified the potential applicability of the cryogenic equipment experience for more conventional refrigeration applications.

- The U.S. Department of Energy is currently (1990) sponsoring two analytical/design projects to assess the potential for Stirling heat pump technology. The industrial participates are SUNPOWER and Mechanical Technologies, Inc., (MTI) of Latham, N.Y. This program addresses both free piston and kinematic configurations over a range of application categories.

- The Swedish council for Building Research is sponsoring the Royal Institute of Technology, Dept. of Applied Thermodynamics and Refrigartion in the design, optimization, and laboratory testing of Stirling cycles. The potential impact is simplicity and a compact design for high temperature lifts.

- Work is ongoing at several R\&D centers in Europe on VM cycle heat pump equipment. The cooling side of this heat actuated cycle equipment is similar to Stirling equipment and provides additional insights into the practical issues of implementing practical systems. 
The experience to date suggests that Stirling equipment would have highly competitive efficiency characteristics. Much analytical and experimental work is required to verify this potential for commercially viable configurations.

\section{A-2.4.2 Technical Issues.}

As indicated above, the limited experience with Stirling equipment indicates good potential for achieving performance levels of practical interest. There are, however, important cost and technical performance issues which will impact on the commercial prospects for the technology. These include Stirling system life and reliability and the impacts of Stirling cycle equipment on overall system design, performance, and cost. Both of these issues are reviewed briefly below.

\section{A-2.4.3 Life and Reliability.}

Vapor compression chiller equipment typically has a useful life in excess of 50,000 hours with relatively low maintenance requirements. This long life and high reliability is due, in large part, to the excellent lubrication regimes achieved in the bearings and other moving parts. Achieving similar reliability and life with Stirling equipment is complicated by the fact that the working space must be free of all contaminants, i.e ., cannot contain lubrication fluids. Two strategies are in use to address this issue:

- The use of low friction contact bearings and seals in the working space - typical materials used are Rulon $L D \circledast$ and TORLON®. Most of the kinematic configurations will require the use of contact bearings and seals.

- Utilizing a free piston configuration using gas bearings and clearance seals to avoid sliding contact between moving parts. This approach is used on several spaceborne cryogenic configurations.

Further complicating the issue with kinematic configurations is that the "crankcase" bearings and linkages must use some form of lubrication. If normal liquid lubrication is used, some form of very effective shaft seal must be used to keep oil out of the working gas space. This can be avoided by using sealed bearings - such bearings have, however, limited load bearing capability, limited life, and large size.

There are still many outstanding issues regarding the life and reliability potential of Stirling cooling cycle technology due to the above factors. Systems using contact bearings and seals have achieved lives of about 10,000 hours in both cooling and Stirling engine configurations. The ability of contact bearing and seal arrangements to consistently achieve lifetimes in excess of 50,000 hours still must be demonstrated. Systems employing clearance seals and gas (or magnetic) bearings have demonstrated lives in excess of 20,000 hours with no degradation. These technologies are, however, are very costly in their present configurations. In short, developing economically viable technology strategies for achieving the necessary life and reliability characteristics is probably the single largest challenge facing Stirling cooling technology. 


\section{A-2.4.4 System Configurations.}

The working gas of Stirling cooling equipment must be contained in compact volumes to achieve high efficiency levels and high specific outputs. Because void volume in the working gas degrades performance, there is not the option to have working fluid lines running considerable distances to heat exchangers such as evaporator or condenser coils as in vapor compression equipment. As such, the interface between the Stirling cooling unit and the external heat exchangers will most often require liquid to working gas heat exchangers with associated secondary heat transfer loops. The void volume issue requires a high heat transfer density between the working fluid and the secondary heat transfer fluids in the hot and cold heat exchangers. This heat transfer density accentuates the temperature drop required in the heat exchangers. The parasitic power requirements, temperature drops, and costs of the associated system complexities must be realistically accounted for in assessing the merits of the Stirling option for each application category under consideration. Two example applications are presented to highlight these considerations.

The Stirling residential heat pump concept is configured externally to resemble a 3-ton split vapor cycle heat pump and it is shown schematically in Figure A-9. For this residential application the Stirling heat pump module is placed in an "outdoor unit" similar in style to the vapor cycle condenser/compressor package. The connection between the home/indoor and the outdoor unit is via a secondary loop containing a non-freezing fluid (water/glycol). In addition, a second loop connects the Stirling heat pump module to the outdoor coil. Small circulating pumps are used to pump the fluid from the heat pump to air coils. Based on the earlier work of Kawasaki [28], the Stirling heat pump was given the following characteristics.

- Effectiveness of $50 \%$ of Carnot can be achieved at the $47^{\circ} \mathrm{F}$ ARI rating point (based helium working space temperatures).

- A small increase in percent of Carnot was credited to the Stirling heat pump when operate over temperature lifts greater than $47^{\circ} \mathrm{F}$ ARI rating point. The increase in efficiency relative to Carnot of the Stirling cycle heat pump is projected by $\mathrm{N}$. Domingo [29] and is also consistent with analyses of other gas based cycles.

- A small decrease in the percent of Carnot efficiency was applied to the Stirling system when operated at lower lifts (i.e., ARI cooling point).

- The Stirling and vapor compression cycle use heat exchangers which result in the same air side approach temperatures to the working fluid (Freon or intermediate fluid for the Stirling package).

- The Stirling unit was penalized an additional $\Delta T=6 F$ in each space to account for the heat transfer between the helium and the intermediate liquid loop.

A summary of the performance characteristics of a good quality split heat pump and the Stirling concept are presented in Table A-14. 
Figure A-9: Stirling Cycle Heat Pump Unit

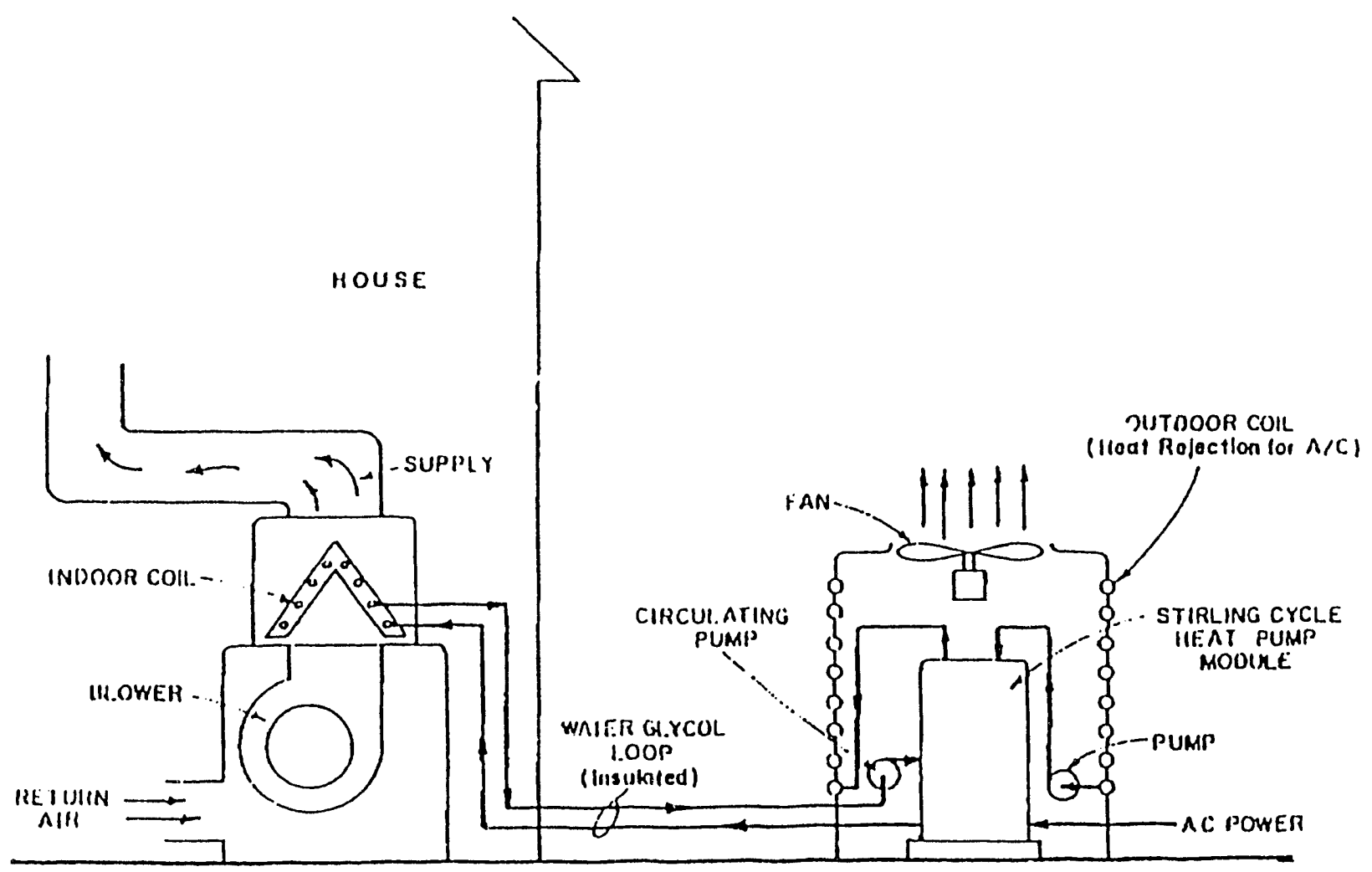

Table A-14: Three Ton Heat Pump Design Comparison

\begin{tabular}{|l|c|c|c|}
\cline { 3 - 4 } \multicolumn{2}{c|}{} & \multicolumn{2}{c|}{ Heat Pump Type } \\
\hline \hline Rating Point & System Performance & Vapor Cycle & Stirling \\
\hline $5^{\circ} \mathrm{F}$ Cooling ARI & COP (system) & 2.9 & 2.5 \\
& Capacity & 36,000 & 36,000 \\
\hline $47^{\circ} \mathrm{F}$ Heating Point & COP (system) & 3.0 & 2.6 \\
& Capacity & 37,000 & 36,000 \\
\hline $17^{\circ} \mathrm{F}$ Heating & COP (system) & 2.0 & 2.5 \\
& Capacity & 21,000 & 33,000 \\
\hline
\end{tabular}

These results were based on Stirling design parameters that reflect the limited activity in this field. The Stirling heat pump system has a reduced COP at lower overall lifts due to the additional $12^{\circ} \mathrm{F}$ in lift imposed by the need for intermediate heat exchange loops. At higher lifts it does have a superior Carnot efficiency (based on working gas 
temperatures). Both the capacities and the efficiency (relative to Carnot) of the vapor compression cycle equipment decreases with decreasing outside air temperature in the heating mode.

The results which were based on the limited work in Stirling heat pump cycles indicated that:

- In a well designed system the efficiency of a Stirling cycle heat pump may approach or be only slightly less than that of vapor compression equipment under standard A/C operating conditions.

- On a seasonal basis the efficiency of the Stirling heat pump system may be equal to or even exceed that of vapor compression cycle equipment when operating in the heat pump mode - particularly in northern areas having low ambient air temperatures.

The development of Stirling refrigeration and cooling equipment which can compete with the established and improving vapor cycle refrigeration equipment requires not only that the basic Stirling equipment be efficient and reliable but also that the Stirling machine be configured as an entire system that is reliable, efficient, cost effective, and configurable to the desired application.

Specific areas of the Stirling cycle needing development include regenerators (minimization of pressure drop and dead volume), hot and cold heat exchangers, secondary heat transfer fluid loops. A real area of needed improvement is the realization of reliable, cost effective hardware. Life limiting Stirling cycle components include seals, sealed bearings, and regenerator contaminant clogging.

\section{A-2.5 Vuilleumier Cycle.}

The Vuilleumier cycle is a Stirling cycle in which the pressure increase step is accomplished by heat input rather than a volume decrease caused by a piston. The cycle is a Stirling expansion driven by a thermal compressor.

The heat addition method of compression results in a lower efficiency when compared with the Stirling cycle. This efficiency is $10 \%$ to $15 \%$ of Carnot compared to $50 \%$ for the shaft driven Stirling cycle. Both of these efficiencies are based on the load temperature and the sink heat exchanger temperature. This low efficiency is a great impediment for the use of Vuillemier cycles. Vuilleumier cycle refrigerators are used in some military and space applications where long life (unattended) is a higher priority than input power. Hughes Aircraft Corp has completed an accelerated test to show that the VM cryogenic refrigerator will have a five year lifetime in a space application. This durability/reliability is an attribute in a small niche market; however, it is not enough to overcome the low efficiency problem and gain acceptance in the applications of this program. 
Since the VM refrigerator has been applied to spacecraft refrigeration applications, efforts have been made to satisfy the usual spacecraft requirements - one of which is high efficiency. Some evolutionary improvements in efficiency can be expected; however, improvements of the magnitude necessary for competition with vapor compression or the Stirling cycle are not very likely.

\section{A-2.6 Reverse Brayton Cycle.}

The reverse Brayton cycle uses the steps of gas compression, heat rejection, work extraction by gas expansion and heat absorption to accomplish useful refrigeration. There is no working fluid phase change. The cycle was well known and applied in the last century. Two versions are used - the open cycle and the closed cycle. The open cycle uses the fluid to be cooled, typically air, as the working fluid. The air is exhausted, after the expansion process, for direct contact cooling of the load. Aircraft cabin air conditioners are an example of application of the open Brayton cycle.

The closed cycle recirculates the working fluid without change of phase in a closed envelope. Therefore, any thermodynamically and environmentally attractive fluid can be used. Helium is often chosen as the closed cycle working fluid. It works thermodynamically well and it has zero ODP and GWP. Since it is chemically inert, there are no material compatibility problems. Note that helium will diffuse through many materials. The diffusion rate is noticeable in non metals so it appears as though a leak is present. The diffusion rate is negligible in metals; therefore, metallic construction should be used.

The service life of Brayton systems can be very long with high reliability. This has been established in aircraft air conditioning systems.

Table A-15 gives a limited listing of research efforts using the Brayton cycle.

The tabular entries indicate that there are applications where Brayton cycle refrigerators/heat pumps are sufficiently attractive to warrant developmental investigation.

Fallon [30] at Garret - Air Research has investigated Brayton cycles for ovens and heat pumps. He made a comparison with the Rankine cycle. The Brayton cycle has an attractive COP only at the elevated temperatures dryers and ovens.

Mills and Chappell [31] at the Idaho National Engineering Laboratory undertook a program to develop a Brayton cycle solvent recovery system. The system was designed for operation at $-120^{\circ} \mathrm{F}$.

Several investigators [32], [33], [34], [35] in Europe have investigated the Brayton cycle as an open air cycle for refrigeration and air conditioning applications. Kruse [36] reports that one open air cycle concern is effective water separation before expansion in the turbine. 
Table A-15: Brayton Cycle Research Efforts

\begin{tabular}{|c|c|c|c|}
\hline Who & Time Period & Description & Temperature Range \\
\hline $\begin{array}{l}\text { J. Fallon } \\
\text { Garret - Air Research } \\
\text { (DOE) }\end{array}$ & -1980 & $\begin{array}{l}\text { High temperature heat } \\
\text { pump for dryers and ovens }\end{array}$ & $200^{\circ} \mathrm{F}$ to $600^{\circ} \mathrm{F}$ \\
\hline $\begin{array}{l}\text { James I. Mills } \\
\text { Idaho National Engineering } \\
\text { Laboratory (DOE) }\end{array}$ & $1980-1985$ & $\begin{array}{l}\text { Brayton cycle solvent } \\
\text { recovery systems }\end{array}$ & $-120^{\circ} \mathrm{F}$ \\
\hline $\begin{array}{l}\text { A. J. Gigiel, AFRC } \\
\text { Inst. } \\
\text { Food Res., } \\
\text { Briston, U.K. }\end{array}$ & $1980 \mathrm{~s}$ & $\begin{array}{l}\text { Open air cycle, theoretical } \\
\text { cycle model }\end{array}$ & $-20^{\circ} \mathrm{F}$ to $40^{\circ} \mathrm{F}$ \\
\hline $\begin{array}{l}\text { E. Granryd, } \\
\text { Tekniska Hogskolan, Sweden }\end{array}$ & $1980 \mathrm{~s}$ & $\begin{array}{l}\text { Open air cycle, theoretical } \\
\text { model }\end{array}$ & $-20^{\circ} \mathrm{F}$ to $40^{\circ} \mathrm{F}$ \\
\hline $\begin{array}{l}\text { H. Kruse, Inst. Refr. Univ. } \\
\text { Hannover, Germany }\end{array}$ & 1980 s, 1990 & $\begin{array}{l}\text { Open air cycle, theoretical } \\
\text { model and experimental } \\
\text { studies }\end{array}$ & $-20^{\circ} \mathrm{F}$ to $40^{\circ} \mathrm{F}$ \\
\hline $\begin{array}{l}\text { A. Henatsch, Univ. of Dresden, } \\
\text { Germany }\end{array}$ & $1980 \mathrm{~s}$ & $\begin{array}{l}\text { Open air cycle, theoretical } \\
\text { model }\end{array}$ & $-20^{\circ}$ to $40^{\circ} \mathrm{F}$ \\
\hline
\end{tabular}

The problem with Brayton cycle is efficiency. Brayton cycle efficiencies are approximately $10 \%$ to $20 \%$ of Carnot in the range of $40^{\circ} \mathrm{F}$ temperature used in chillers. This is less than half the efficiency of the Stirling cycle and vapor compression. For reference, Brayton inefficiencies occur largely in the load and heat rejection heat exchangers and in the expander-compressor. This low efficiency of the Brayton cycle is reason to eliminate it from consideration for most of the applications of this program.

One area where the Brayton cycle may find application is in Navy chillers. Many Navy ships are gas turbine powered. Therefore the Brayton cycle refrigerator can be applied like an aircraft cabin refrigerator. The high turbine speed can lead to lighter systems, and experience in the aircraft industry indicates that a high reliability system will result. The attractiveness of the system environmentally and the compatibility with Naval applications may override the low efficiency in Naval chiller applications, especially when the system can be driven by the propulsion turbine.

The Brayton cycle has found application in industrial refrigeration in the area of blast freezers where comparison with vapor compression is more favorable at temperatures less than $-30^{\circ} \mathrm{C}$.

The potential for improving the efficiency of the Brayton cycle is limited. Evolutionary improvements of a few percent of Carnot can be expected. The main limit in efficiency improvement is the efficiency limit on compressors, expanders, and heat exchangers. These components have been under development, especially in the aircraft industry, for many years. Compressor and expander technology has reached a mature stage where only incremental improvements can be expected. 


\section{A-2.7 Magnetic Refrigeration.}

When a strong magnetic field is applied to certain paramagnetic materials at cryogenic temperatures and to ferromagnetic materials at temperatures close to their Curie point, a decrease in entropy (related to an increase in the ordering in the electron spin state) occurs. A decrease in internal energy is associated with the decreased entropy and results in heat being released to the bulk of the material. If this process occurs adiabatically, the temperature of the material will increase; for the change to occur isothermally, heat must be rejected to the surroundings, e.g., a coolant fluid. Within the range of magnetic field strengths that can be produced in the laboratory (on the order of 10 Tesla, or 100,000 Gauss, using super conducting magnets), the adiabatic temperature change is proportional to the strength of the magnetic field. Thermodynamically the process is almost reversible in that removal of the strong magnetic field will result in almost the complete reversal of the temperature rise, and in the almost complete recovery of the work that was required initially to apply the magnetic field, with only very small internal losses, at least for low cycle rates. The thermodynamic reversibility of the phenomena, with the inherent possibility of obtaining high cycle efficiencies, has lead to interest in the development of room temperature heat pump cycles, spanning the heat load and heat sink temperature ranges characteristic of conventional refrigeration applications and building and mobile space conditioning applications.

The earliest experimental work with this phenomena was at liquid helium temperatures. The magnetic refrigeration effect was used to achieve a closer approach to absolute zero temperature than could be achieved with a liquid helium based cooling cycle alone. Ferromagnetic materials have been discovered that undergo the type of state change described near room temperature. Metallic gadolinium (Gd, atomic number 64, one of the rare earths), and intermetallic compounds containing $\mathrm{Gd}$ are the best materials that have been identified for room temperature range cooling applications. The maximum temperature rise for gadolinium occurs at the Curie temperature of $293 \mathrm{~K}\left(68^{\circ} \mathrm{F}\right)$. At 7 Tesla and $68^{\circ} \mathrm{F}$, the adiabatic temperature rise is $14^{\circ} \mathrm{K}\left(25^{\circ} \mathrm{F}\right)$.

The basic closed cycle refrigeration process is as follows. First, the magnetic field is applied to the magnetic working material, which has finished absorbing heat from the cooling load. When the field is applied, internal energy released from the changed state raises the temperature of the material above the heat sink temperature. Next, heat is rejected to the heat sink, cooling the material to the heat sink temperature. Then, the magnetic field is removed, and the temperature of the material is reduced to below the cooling load temperature. Heat is absorbed from the cooling load, after which the cycle is repeated. A Carnot cycle can be carried out, in principle (practicalities aside), by modifying this process so that the adiabatic temperature changes associated with application and removal of the magnetic field are limited to that necessary to reach the temperature of the reservoir in the heat removal and absorption steps. Heat removal and absorption are then carried out isothermally, while continuing to increase or decrease, respectively, the applied field. A difficulty for practical cooling applications is that the adiabatic temperature rise, even with intense magnetic fields, is not very large, so the largest temperature lift of a Carnot type cycle with net cooling capacity is only 10 to 
$15^{\circ} \mathrm{F}$. Recognizing this limitation, several researchers have developed regenerative, Stirling/Ericsson cycle analog, thermomagnetic heat pumping cycles. The key features of the experimental systems were:

- Providing for regenerative heat transfer between working material being transferred from the cold sink to the hot with working material being transferred from the hot sink to the cold, leaving the majority of the heat of the thermal magnetic effect available for cooling and heat rejection,

- Providing close fluid coupling to the working material, and configuring the working material so that at least one dimension is small enough (e.g. thin plates, small diameter wire, or spheres) so that the internal conduction heat transfer resistance of the working material is reasonably low.

Experimental systems reported in the literature include a linear, Stirling-like, device [36] where liquid in the cylinder acted as the heat storage/regeneration medium, and concentric, thin sheets of $\mathrm{Gd}$, with gaps between formed a piston which was reciprocated in the cylinder, with the applied magnetic field cycled appropriately. With a $7 \mathrm{~T}$ field, a no heat load temperature span of $47^{\circ} \mathrm{C}$ was achieved. In a second approach, [37], a rotating $\mathrm{Gd}$ wheel was configured with appropriately located zones of applied field and heat transfer with a liquid loop. The fluid in the loop served as the heat transfer medium for both the regenerative heat transfer and the cooling load and heat rejection. The measured performance of the prototype system was $1 / 2 \mathrm{~kW}(1,700$ $\mathrm{Btu} / \mathrm{hr}$ ) of continuous cooling across a $7 \mathrm{~K}$ lift (near room temperature), at a COP of $26 \%$ of Carnot.

A number of factors severely limit the practical applicability (and potential competitiveness with vapor cycle) of the magnetic cooling cycle:

- A very strong magnetic field is required to produce a significant refrigeration effect, typically 5 Tesla or more, which far exceeds the magnetic field strength of any known permanent magnet materials. In fact, the strongest permanent magnet field strength reported in the magnetic refrigerating literature was 1.2 Tesla. Field strengths on the order of 5 to 10 Tesla are more typically associated with super conducting electromagnets.

- A very high regeneration effectiveness, with low parasitic power consumption and with temperature gradients maintained reversibly in an intermediate heat transiur fluid, is required to be able to even approach the lifts and COP level (as a traction of the Carnot COP) that is typical of vapor compression cycle equipment. To put the regenerative heat transfer requirement in perspective, a heat transfer rate approximately 10 times the net cooling capacity, driven by $1 / 2$ of the temperature difference usually employed in economically sized, water cooled vapor compression cycle equipment is required to obtain performance comparable to the vapor compression cycle (with a $7 \mathrm{~T}$ field). At lower field strengths, even higher regenerator performance levels are needed. 
As indicated by these factors, there are economic and technical difficulties for magnetic refrigeration. These include the energy needed for refrigerating superconducting magnets, the sunerconducting magnet material cost, the magnetic working material cost, the cost of the regenerator, the difficulty of reliably operating, cyclically, a system with magnetic fields greater than 7 Tesla.

The energy needed for refrigerating the superconducting magnets needed to produce the high magnetic field will be a sizable fraction of the total system energy. Magnets that are superconducting at temperatures much closer to ambient will be necessary before the technology is viable rom an energy stanapoint.

The cost of materials is a very strong issue. Kirol, et al.[38] gives cost estimates for a magnetic heat pump. Based on their figures, $25 \%$ of the cost is for superconducting magnets, $18 \%$ for the working material, and $25 \%$ for refrigeration for the

superconductung magnets. While they state that there is potential for cost reduction, a substantial reduction will be needed to bring their cost estimate of $\$ 131 / \mathrm{kW}$ down to their comparison of $\$ 85 / \mathrm{kW}$ for a Westinghouse Rankine cycle heat pump.

Even with the costs given above, another cost is very significant. This is the cost of the highly efficient regeneration necessary to carry out the regenerative cycles to produce useable temperature lifts. One of the statements made at the Montreal workshop (chillers small group) is that the cost of the regenerator to achieve the high thermal performance required will even exceed the cost of the magnets and working material. While the comment was not quantified, it does illustrate that the regenerator is another high cost component of nagnetic refrigeration.

Significant development remains to be done to produce a magnetic refrigerator capable of technicaily and economically approaching the performarce routinely obtained with the much simpler vapor compression cycle. Without significant breakthroughs in high temperature superconductor technology and in magnetic working media, the requirement for a large regenerator capacity and the extremely high magnetic fields that are only available with superconducting magnets cooled to cryogenic temperatures cristitute an essentially insurmountable barrier to the development of a low cost, technically viable magnetic refrigeration system.

\section{A-2.8 Ejector Heat Pump.}

The ejector heat pump can be eusily visıalized as a Rankine (vapor compression) cycle in which the compressor has been replaced by a pum 1 , boiler, and ejector. It therefore consists of a power cycle and a refrigeration cycle. A schematic of an ejector heat pump in its simplest form is shown in Figure A-10 from reference [39]. The driving force for the Rankine cycle is supplied by the ejector instead of a compressor. The components of the Ranki : a cycle become the ejector, condenser, expansion valve, and evaporator. The pum, boiler, ejector, and condenser constitute the power or driving cycle. The pump ey pends a relatively low power to increase the pressure of the liquid. The boiler adds he'at to vaporize the fluid. The vaporized fluid expands in the ejector and transfers momenı um to the Rankine cycle 1?uid to increase the pressure. The power sycle 
therefore performs work by absorbing heat at higher temperature in the boiler and rejecting heat at lower temperature in the condenser. The refrigeration section pumps heat by absorbing it at low temperature in the evaporator and rejecting the heat at higher temperature in the condi nser.

Figure A-10: A Simple Ejer tor Heat Pump Cycle

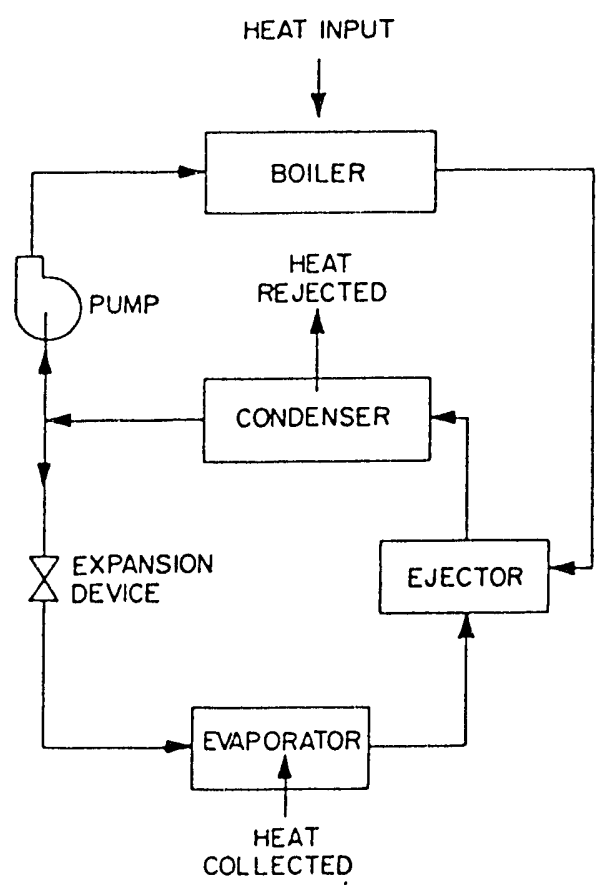

A very important feature of the ejector pump is that it can operate with relatively low boiler temperatures, on the order of $200^{\circ} \mathrm{F}$ if CFC- 11 is used as the working fluid. This feature allows the ejector heat pump to operate with low quality heat such as would be available from solar collectors or waste heat from a steam power or heating system. Therefore, in some cases, the cost of heat input to the ejector heat pump can be immaterial. Only capital/maintenance costs would need to be considered. Note that the CFC-11 used for the example will have to be changed to an alternative fluid.

Waste heat may not be available in many potential ejector heat pump applications. Primary heat sources may be necessary. It then becomes important to evaluate the thermodynamic performance of the ejector heat pump. Hamner [40] tested the performance of three ejector configurations using CFC-11 as the w/orking fluid. The boiler temperature was $93^{\circ} \mathrm{C}\left(200^{\circ} \mathrm{F}\right)$ and the condenser temperature was $29^{\circ} \mathrm{C}\left(84^{\circ} \mathrm{F}\right)$. The best COP for cooling obtained was approximately 0.28 ; however, the ejector may not have been optimized. 
As a comparison for relative performance, the Carnot or maximum possible COP for the system needs to be defined. It can be shown that the ideal COP for cooling for the ejector heat pump can be given by:

$$
\mathrm{COP}_{\mathrm{I}}=\frac{T_{b}-T_{c}}{T_{b}} \frac{T_{e}}{T_{c}-T_{e}}
$$

where:

$$
\begin{array}{ll}
T_{b} & =\text { boiler (heat addition) fluid temperature } \\
T_{c}= & \text { condenser (heat rejection) fluid temperature } \\
T_{e}= & \text { evaporator fluid temperature }
\end{array}
$$

The $\mathrm{COP}_{I}$ is composed of the efficiency of a Carnot engine operating between $T_{b}$ and $T_{c}$, times the COP of a Carnot refrigerator operating between $T_{e}$ and $T_{c}$. If $T_{b}=93^{\circ} \mathrm{C}, \mathrm{T}_{c}=$ $29^{\circ} \mathrm{C}$, and $\mathrm{T}_{e}=10^{\circ} \mathrm{C}$, then $\mathrm{COP}_{1}=2.6$. Then the $\mathrm{COP}=.28$ given above is $11 \%$ of Carnot.

Chen [40] calculates the performance of a non-ideal ejector heat pump. The calculation included an ejector diffuser efficiency of 0.5 and a nozzle efficiency of 0.97 . The temperatures were: $T_{b}=200^{\circ} \mathrm{F}, \mathrm{T}_{\mathrm{c}}=110^{\circ} \mathrm{F}, \mathrm{T}_{\mathrm{e}}=50^{\circ} \mathrm{F}$. The COP was calculated based on the cooling energy absorbed divided by the energy that costs:

$$
\mathrm{COP}=\frac{m_{e}\left(h_{e o}-h_{e i}\right)}{m_{b}\left(h_{b o}-h_{b i}\right)}
$$

For the parameters listed above, the COP $=0.3$ which is $26 \%$ of ideal.

The reasons for the relatively low performance (26\%) of the real system are inefficiencies in the ejector. The mixing of the high velocity primary gas from the nozzle with the entrained low velocity gas coming from the evaporator produces a loss of a considerable amount of kinetic energy. The gas also goes through shock waves which decrease the available energy and increase the entropy. The mixing and shock processes are highly irreversible.

Chen [40] lists regeneration and multiple staging of ejectors as possible methods to improve ejector heat pump system performance. The improvements are $17 \%$ for the heat exchangers and $6 \%$ for a two stage ejector. If the COP $=0.3$ is used as a basis, these improvements could bring it up to 0.37 or $32 \%$ of ideal.

In order to increase the COP, the boiler temperature may be extended as high as the critical temperature. In the example for CFC-11 cited above, this is $388^{\circ} \mathrm{F}$. Chen uses $\mathrm{T}_{\mathrm{b}}=180^{\circ}$ and $359^{\circ} \mathrm{F}, \mathrm{T}_{\mathrm{c}}=110^{\circ} \mathrm{F}, \mathrm{T}_{\mathrm{e}}=50^{\circ} \mathrm{F}$ to get a COP increase from 0.257 to 0.514 . The boiler pressure increases from 65 psig to $488 \mathrm{psig}$ to do this however. Also, the $359^{\circ} \mathrm{F}$ would seem to be a burden on many solar and waste heat supplies. 
The ejector heat pump appears to have potential in applications where the cost of the low quality energy is not an issue. However, the COP of the system is appreciably lower than that of the mature vapor compression technology. The relative simplicity of the ejector heat pump may have the potential for high reliability since a compressor is replaced by a pump, boiler, and ejector. The technology is not mature enough to make a solid judgement on reliability however.

\section{A-2.9 Thermoacoustic Refrigerator.}

Thermoacoustic heat pumps and refrigerators use acoustic power to pump heat from the low temperature source to a high temperature sink. The thermoacoustic refrigerator, shown in Figure A-11 from Swift [41] consists of a gas filled resonator driven by a loudspeaker and containing a "stack" of plates for heat exchange. One end of the stack is thermally anchored at the sink temperature. The stack is generally a series of surfaces arranged so that the gas flows parallel to the surfaces. This can be a series of stacked plates, or a spiral wound surface. In both geometries, a spacer separates the plates by an amount of the order of the thermal penetration depth while letting the gas flow through freely.

The loudspeaker causes pressure pulsations to occur in the gas. The gas compresses while flowing in one direction. The compression heats the gas which moves a short distance. The hot gas then exchanges heat with the stack surfaces and cools to about the stack temperature at that point. As the acoustic pulse reaches the low pressure phase, the gas expands and moves back to near its original location. Since the expansion causes the gas to cool, it can now absorb heat from this original position on the stack surface. Repeating the process causes heat to be pumped axially along the stack surface. A temperature gradient is thereby established over the length of the stack. Placement of heat exchangers at the hot and cold ends of the stack allows heat to be pumped from a colder surface to a warmer surface. This creates a refrigeration cycle. The heat transfer method described above can be pictured as two reversible adiabatic pressure change steps and two irreversible heat exchange steps - a reverse Brayton cycle. The similarity to a Brayton cycle is because of the descriptive method used. The cycle has more similarities with the Stirling cycle.

In the Stirling cycle, pistons move with correct relative timing $(\sim 9)^{\circ}$ between compressor and expander) for the working medium to execute the thermodynamic cycle. The thermoacoustic system has only the loudspeaker to move the working gas. The key to phasing (parallel to a Stirling cycle) in acoustic systems is the fluid and the interaction of the fluid with the stack. Fluid oscillation along a plate at acoustic frequency causes it to experience temperature changes as described simply above. Part of the temperature change comes from compression and expansion of the fluid and the rest occurs because of the local temperature of the plate. Fluid/plate heat flow does not produce instantaneous changes in fluid temperature. Heat flow causes a time delay or time phasing between temperature and pressure and motion. This phasing is needed to drive the fluid through the thermodynamic cycle. Simple but irreversible heat flow 
Figure A-11: Thermoacoustic Refrigerator

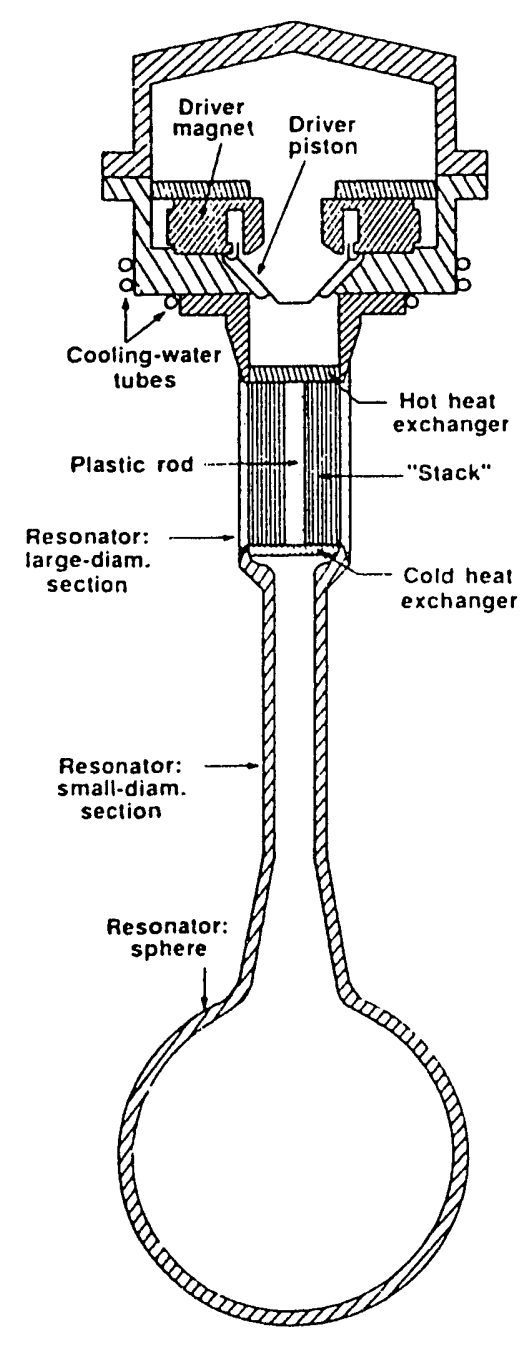

across a temperature difference is essential to the operation of thermoacoustic refrigerators. Poor thermal contact is necessary to achieve proper phasing of the temperature oscillations of the working fluid.

The resonator section serves to maintain a pressure antinode at the end of the large diameter system near the hot heat exchanger and a velocity antinode near the bottom of the small diameter section. This results in $1 / 4$ wavelength resonance, which is necessary to carry out the cycle. 
The feature of the cycle is that the only part that can be called "moving" is the loudspeaker - and this movement is small. The feature offers the potential of very high reliability for the thermoacoustic refrigerator. This can be a very desirable feature in locations like space or at the bottom of the ocean where reliability is essential.

Engineering of practical refrigeration systems can be far removed from conclusions of elementary thermodynamics. The desire to approach Carnot efficiency must compete against needs for low cost, high reliability, compactness to be practical. The thermoacoustic refrigerator makes the tradeoff toward the potential of very high reliability.

The thermoacoustic refrigerator constructed by Hofler [42], as shown schematically in Figure A-10 above achieved a measured COP of $12 \%$ of Carnot at $\mathrm{T}_{\text {COLN }} / \mathrm{T}_{1 \mathrm{HOT}}=0.82$. Part of the reason for the low COP is that the loudspeaker had an electric to acoustic power conversion efficiency of $20 \%$ [42]. A vapor compression system would be expected to get better than $40 \%$ of Carnot at this temperature ratio. The thermoacoustic refrigerator suffers an input power penalty of greater than 3 compared to vapor compression.

While the thermoacoustic refrigerator may likely have potential for high reliability requirement applications such as spacecraft, it efficiency is too low to be considered a serious candidate for replacement of vapor compression refrigeration cycles.

\section{A-2.10 Vortex Tube.}

The vortex tube was first identified by G.J. Ranque in a patent in 1934 [43]. It was also described in an article in 1947 by Rudolph Hilsch [44]. The device is therefore often identified as a Hilsch tube.

A sketch of the vortex or Hilsch tube is shown in Figure A-12. The tube consists of a pipe with a means of introducing moderately high pressure gas flow tangentially and perpendicular to the tube axis. An orifice on the pipe axis is located a short distance from the tangential gas inlet. A valve is located about 30 diameters down the pipe on the end opposite the orifice. Gas entering tangentially expands in a nozzle to nearly atmospheric pressure and thereby attains a very high velocity. This produces a very rapid motion of the gas in the tube near the nozzle. The gas is permitted to escape through the orifice on the one side and the pipe on the other. The throttling valve 30 diameters downstream in the pipe controls the flow split.

The gas which emerges through the central orifice is cold whereas the gas departing through the pipe is warm. By proper adjustment of the flow split, air temperatures can be produced which are $70^{\circ} \mathrm{F}$ less than the inlet air temperature.

The vortex tube has no moving parts itself. It relies on an air compressor such as might be central to a manufacturing plant as its air source. This allows the vortex tube to be installed for refrigeration very reliably anywhere in a compressed air distribution system. 
Figure A-12: Vortex Tube

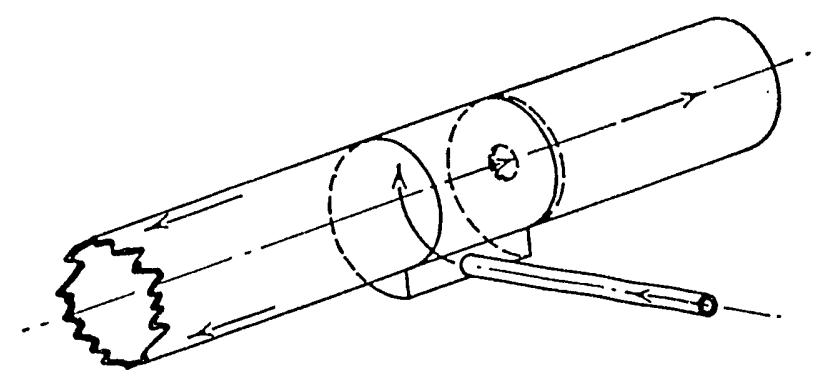

The problem with the vortex tube is efficiency. A Vortec [45] model 750 vortex tube is used as an example. This system will deliver $400 \mathrm{Btu} / \mathrm{hr}$ at about $5^{\circ} \mathrm{F}$ while consuming $8 \mathrm{scfm}$ of air at $100 \mathrm{psig}$. If isothermal (most efficient) compression is assumed, 46.87 $\mathrm{Btu} / \mathrm{min}$ is required for air compression. The resulting COP is 0.1422 . Carnot COP is 5.17 between $5^{\circ} \mathrm{F}$ and $95^{\circ} \mathrm{F}$. Then $\mathrm{COP} / \mathrm{COP}_{\mathrm{c}} \times 100 \%=2.75 \%$. This is optimistic because isothermal compression was assumed. Not that the $5^{\circ} \mathrm{F}$ is the most efficient performance point for the 750 vortex tube. The point is that vortex tubes are totally outside the efficiency range needed to compete with present technology-vapor compression. Vortex tubes have a niche market for industrial spot cooling where compressed air is available. They offer a fast, convenient cooling means where efficiency is not of concern.

\section{A-2.11 Pulse Tube.}

The pulse tube of Gifford and Longsworth [46] is shown in Figure A-13. Heat is pumped in the large open "pulse" tube whose diameter is a few thermal penetration depths. The heat pumping method is very similar to that occurring in the stack of a thermoacoustic refrigerator. A small element of gas at temperature $\mathrm{T}$, is displaced a short distance as a result of pressurizing the tube by supplying gas from a supply. The pressure increase of the gas also causes a temperature increase - say that the gas undergoes isentropic compression and moves to the new location. If the pressure in the tube is held constant for a time, heat will be transferred from the gas to the new location cooling the gas to near the wall temperature. When gas is allowed to flow out of the tube and the pressure is returned to its initial value, the gas element cools by expansion and returns to near its original position. The temperature of the gas element is now cooler than the wall so that heat is transferred from the wall to the gas.

Repeating the pressurization cycle causes heat to be pumped from the cooler to the warmer positions on the wall. This effect occurs throughout the tube wall and produces a heat pumping effect from the open (colder) end to the closed (warmer) end. If the pressure change occurs fast enough, heat transfer during the pressure change is negligible and the gas follows an isentropic path. Heat will be exchanged with the wall and pumped along the wall until such a condition is reached that the gas temperature 
Figure A-13: Pulse Tube Refrigeration Configuration

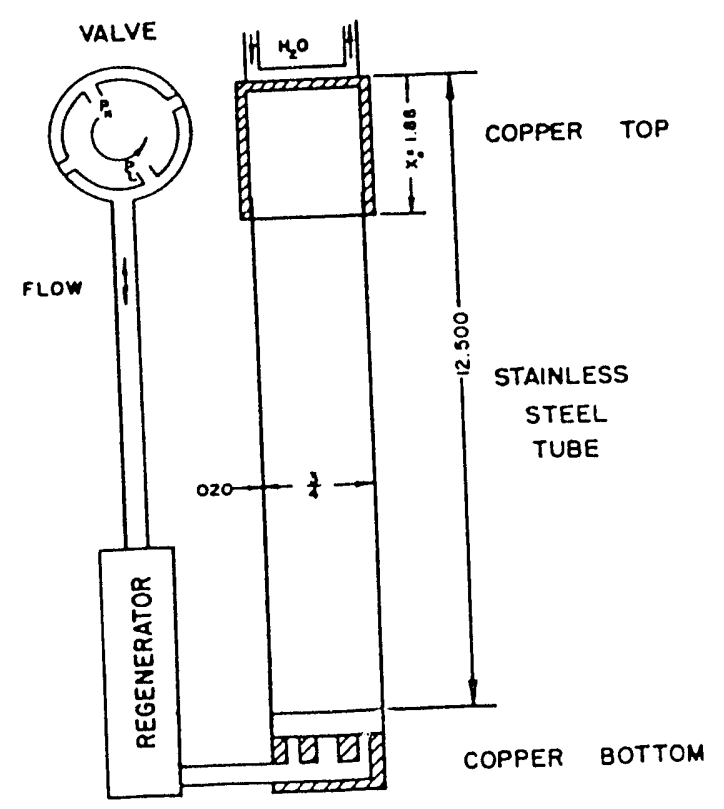

coincides with the wall temperature everywhere along the tube. If the temperature at $x=x_{0}$ is fixed to $T_{0}$ and the temperature of the rest of the tube is allowed to come to equilibrium with the gas so that no heat is being pumped, then the temperature at position $\mathrm{x}$ along the tube is given by:

$$
T_{(x)}=T_{o}\left(\frac{x_{o}}{x}\right)^{\gamma-1}
$$

where $\gamma$ is the polytropic (isentropic) exponent. The temperature difference built up over the tube depends on the tube length. The temperature difference can be very great compared to the temperature change due to isentropic compression over the pressure ratio.

The regenerator serves to thermally separate the cold region from the warm work input region. However, since there is a temperature difference across the regenerator, there is Stirling cycle heat pumping in the regenerator [42]. The regenerator pumps non-negligible heat from its cold to warm ends. The total refrigeration is partly pulse tube (or thermoacoustic) and partly Stirling. 
Mikulin [47] made an advance in the pulse tube by introducing an orifice and large volume at the warm end of the pulse tube. The orifice is adjustable. Pressure oscillations in the pulse tube cause oscillatory flow through the orifice into the large volume. This results in an increase in cooling power.

Radebaugh [48] has studied the orifice pulse tube and has made a tube that achieves $60 \mathrm{~K}$. Radebaugh's tube performs essentially as a Stirling engine with the low temperature piston replaced with a work absorber having no moving parts. Replacing the work extraction piston by a non-moving element results in lower efficiency; however, the device is significantly simpler (less cost, higher reliability).

Radebaugh [49] reports performance of an orifice pulse tube. He reports that the efficiency is less than that of a Stirling refrigerator because the reversible motion of the displacer has been replaced with irreversible expansion. The efficiency of the orifice pulse tube in the vicinity of $40^{\circ} \mathrm{F}(278 \mathrm{~K})$ is less than $20 \%$ of Carnot depending on the orifice setting.

While the relative simplicity of the (orifice) pulse tube offers potential for high reliability and low cost compared to Stirling systems, the efficiency is at least a factor of 2 , and more like a factor of 4 worse than vapor compression. Because of the high energy penalty, the pulse tube system is not competitive for the refrigeration applications of this program.

\section{A-2.12 Malone Refrigeration.}

The use of a liquid near its critical point, without change of phase, in a Stirling or Brayton cycle is called Malone refrigeration. John Malone [50, 51, 52] first investigated the use of liquids in heat engines in 1924. The use of liquids in reversed heat engines or refrigeration cycles is a direct result.

It is generally thought that liquids are essentially thermodynamically inert. In fact, in the area just below the critical point, many liquids have thermophysical properties that make them well suited in Stirling or Brayton refrigeration cycles. Swift [53] has investigated Malone refrigeration as reported in a 1989 article as far as understanding the basic principles. However, engineering development has not been undertaken; therefore, much development is required to achieve a viable Malone refrigerator.

The common assumption is that liquids are incompressible and therefore cannot be used in Stirling or Brayton cycles. In fact, liquids near the critical point can be used in these cycles with some advantages over gases.

The most important property of a single phase liquid refrigerant is thermal expansion coefficient. Heat absorbed during isothermal expansion is proportional to the thermal expansion coefficient [54]. Liquids just below the critical point have expansion coefficients comparable to ideal gases. 
A second important property is compressibility. Low compressibility of liquids has several advantages. Adiabatic losses are low and it allows large pressure changes (with the attendant temperature change) to be achieved with relatively small volume changes in the liquid. This allows cylinders to be made smaller. More fluid can be accepted in the regenerator and heat exchangers. Also, low expansion coefficient leads to less stored elastic energy thereby reducing the danger of explosions. Note that low compressibility does not reduce the useful cooling effect. This effect is proportional to thermal expansion coefficient and not to compressibility.

Another important property is volumetric specific heat - density times specific heat at constant volume. In a Stirling or Brayton cycle, the volumetric specific heat is a determining factor in how much heat can be absorbed. The volumetric specific heat of a liquid is much larger than a gas because the density is larger. The volumetric specific heat of Malone cycle liquids times only a $1^{\circ} \mathrm{F}$ temperature difference can be comparable to the latent heat per unit vapor volume of conventional refrigerants such as R-12. This results in a sizable difference between heat exchangers for liquids and gases or gas/liquid mixtures. Less volumetric displacement of the liquid through the heat exchanger is needed to transfer a given amount of heat. This results in less mechanical power.

It should be noted that the fractional temperature drop with expansion of gases is a substantial fraction of the absolute temperature for pressure changes that are a substantial fraction of the mean pressure. Liquids have such a high specific heat that only a small adiabatic temperature change occurs on expansion. It follows that a simple Malone cycle such as the Carnot cycle won't achieve a large temperature lift. Malone refrigerators always need to use a regenerator or recuperator in the cycle (i.e., Stirling or Brayton cycle) to achieve useful temperature lifts.

The thermodynamic properties of liquids make them useful Malone refrigerants in the temperature range between $70 \%$ of the critical temperature and the critical temperature [55]. Several fluids have been considered. Some are listed in the following table:

\begin{tabular}{|l|c|c|}
\hline \multicolumn{1}{|c|}{ Fluid } & P $_{\text {CAIT }}$ PSI & T $_{\text {CAIT }}$ 'F \\
\hline \hline Carbon Dioxide & 1060 & 88 \\
\hline Sulfur Hexafuoride & 540 & 114 \\
\hline Hexafluoropropylene & 420 & 201 \\
\hline Perfluorocyclobutane & 400 & 240 \\
\hline R-134a & 590 & 214 \\
\hline Propane & 610 & 206 \\
\hline Propylene & 660 & 197 \\
\hline
\end{tabular}

A problem with these fluids is that they have various greenhouse warming potential. Hexafluoropropylene is toxic. Toxicity testing on some has not been completed. Propane and propylene are flammable. The point to be made is that fluid choice is definitely not finalized at this point. There are tradeoffs to be considered - as there are in vapor compression. 
There are some indications of the efficiency which may be expected from Malone refrigeration. Swift [55] obtained $20 \%$ of Carnot using a Stirling cycle for a temperature lift of $55^{\circ} \mathrm{F}$, and a difference between high and low pressure of $1200 \mathrm{psi}$. This is $1 / 3$ to $1 / 2$ of that of current vapor compression water cooled chillers. They believe the system has the potential of reaching about $48 \%$ of Carnot by improving hardware design even though the inherent cycle COP is no greater than that of vapor compression.

High pressure operation is a problem with Malone refrigeration. The operational pressures are on the order of 400 psi to 1000 psi or higher for many of the working fluids of interest. Even though the liquid stores less elastic energy than gases, the danger of explosion is still present. Containing the fluid requires substantial walls on the compressor, heat exchangers, and components. This results in a relatively heavy construction which must be traded off against the smaller heat exchangers discussed above.

Perhaps the most difficult problem is the uncertainty in development of Malone refrigeration. Performance and reliability databases are not available. The technology is not ready for application. The efficiency potential is no greater than vapor compression.

It is difficult to recommend a new technology that does not improve the energy consumption of current technology--vapor compression, and is currently a long way from reaching efficiency levels equal to vapor compression.

\section{A-2.13 Thermoelectric Refrigeration.}

\section{A-2.13.1 Background.}

The principles involved in thermoelectric cooling were known in the nineteenth century. From about 1955 to 1965 a concerted effort was made to develop a commercial space conditioning application of these principles. Among the investigating groups were Westinghouse, Melcor, Naval Research Laboratory, and Carrier Research and Development Company. The latter carried out the technology to the point of a substantial commercial installation at the Johnson Wax Offices in Milwaukee, where certain aesthetic considerations made cost a secondary consideration.

For reasons which will be developed below, the quest was abandoned as hopeless, although thermoelectric cooling has continued to have a small market in special, low power, applications such as electronic equipment cooling.

It is now being promoted for mobile air conditioning under the name "Electron Transfer Solid State Heat Pump."

\section{A-2.13.2 Some Scientific Background.}

There are several primary properties involved in the process of thermoelectric cooling. These will be quickly identified with the aid of Figure A-14. 
Figure A-14: Thermoelectric Junction

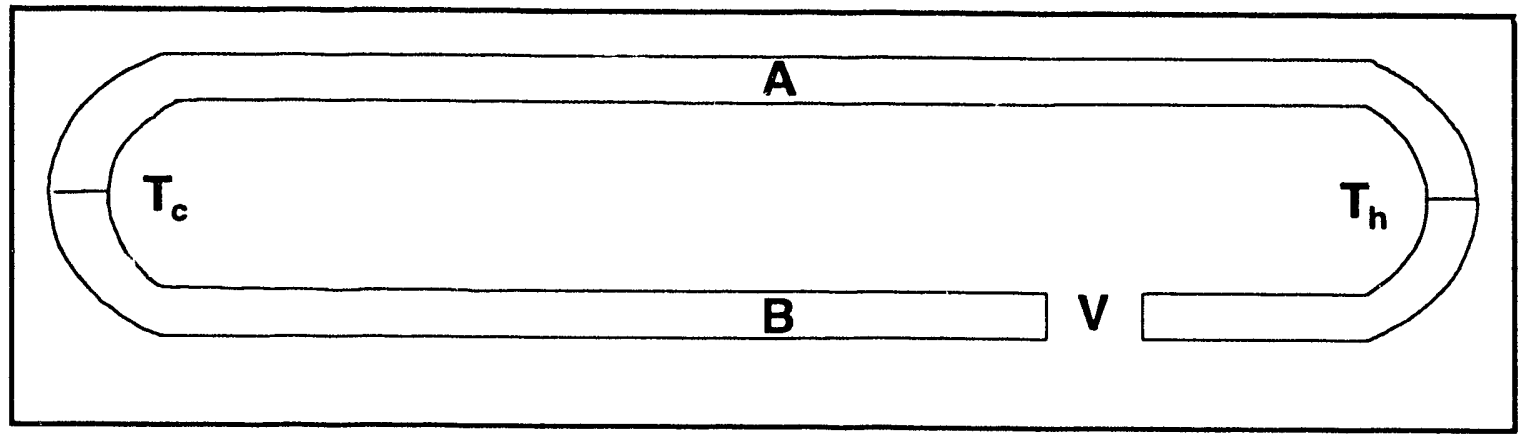

Seebeck Effect. If $\mathrm{T}_{\mathrm{h}}$ and $\mathrm{T}_{\mathrm{c}}$ are at different temperatures, then the junctions between the unlike, electrically conductive, materials $\mathrm{A}$ and $\mathrm{B}$ will create a potential difference at each junction and the algebraic sum will be read as the potential V. Should V be replaced by an appropriate machine, current would flow and work would be done. This "Seebeck Voltage" is proportional to the temperature difference, under no-load conditions, and the constant of proportionality is called the Seebeck Coefficient, $\alpha_{A B}$, measured in volts per degree. In some low power applications, such as controls, the Seebeck effect has been commercially used for power generation.

Peltier Effect. This is an effect complementary to the Seebeck effect. If $\mathrm{V}$ becomes a source of potential, such as a battery, current flows through the loop and one junction between $\mathrm{A}$ and $\mathrm{B}$ heats while the other cools. Reversing the current flow reverses the effect.

The temperature difference, under "no-load" conditions, is proportional to the current flow, the constant of proportionality being the "Peltier Coefficient," $\pi$, measured as degrees/ampere.

Joule Heating. As current is passed through a conductor, heat is liberated. The resistance to current passage is measured by the Joule Coefficient, $\rho$, measured in ohms/centimer. In both T.E. generation and refrigeration, Joule heating is lost energy.

Thermal Conductivity. Temperature differences in the loop will cause heat to flow through the conductors $A$ and $B$ by an amount measured by the thermal conductivity of the materials, measured by the conductance $\mathrm{k}$, in Watts per centimeter per degree Kelvin.

The "Figure of Merit," Z, of a thermoelectric cooling device is given by:

$$
Z=\frac{\left(\alpha_{A B}\right)}{\left(\sqrt{k_{A} \rho_{A}}+\sqrt{k_{B} \rho_{B}}\right)} \text { where the subcripts } A
$$

and B refer to materials A and B. Typical values of these quantities for the best materials known in the literature are: 


$$
\alpha_{\mathrm{AB}}=0.0002 \mathrm{~V} /{ }^{\circ} \mathrm{C} ; \rho=0.00083 \mathrm{ohms} / \mathrm{cm} ; \mathrm{k}=0.016 \mathrm{~W} / \mathrm{cm}-\mathrm{C}
$$

which lead to a value of $\mathrm{Z}=.003 /{ }^{\circ} \mathrm{C}$.

A theoretical coefficient of Performance (COP) can be derived for ideal operating conditions as:

$$
\mathrm{COP}=\frac{T_{c}}{\left(T_{h}-T_{c}\right)} \times \frac{\sqrt{(1+Z T)}-T_{h} / T_{c}}{\sqrt{(1+Z T)}+1}
$$

The first term, $T_{c} /\left(T_{h}-T_{c}\right)$, is recognized as the Carnot efficiency of a refrigeration cycle and the second is the thermoelectric circuit efficiency. For a typical operating condition of $\mathrm{T}_{\mathrm{h}}=35^{\circ} \mathrm{C}\left(308^{\circ} \mathrm{K}\right), \mathrm{T}_{\mathrm{c}}=5^{\circ} \mathrm{C}\left(278^{\circ} \mathrm{K}\right)$, with an average $\mathrm{T}=293^{\circ} \mathrm{K}$, using $\mathrm{Z}=0.003$, we get:

$\mathrm{COP}=9.3 \times 0.11=1.02$, the ratio of cooling produced to electrical energy taken in under ideal operating conditions. The reality has historically been significantly less than this value.

The key to improved T.E. efficiency is the Figure of Merit, as defined above. The development of T.E. devices was virtually abandoned because solid state theory gave no hope of significant improvement in this ratio of properties, and a massive experimental materials program supported this pessimism.

Thermoelectric Cooling Equipment. Figure A-15 shows a single cell of thermoelectric cooling device. The vertical dimension is greatly exaggerated for convenience. Typical dimension of a single cell is about 0.75 inches square and half an inch thick, not including the heat transfer means which must be on top and bottom surface. Since the semiconductors A and B must be cut from single crystals, the dimensions are necessarily small.

A T.E. "panel" will be an assembly of perhaps 20-25 of these cells, electrically insulated from one another, appropriately wired and usually bonded together by special, very low melting point, solders applied by induction heating of the assembled panel.

A couple dozen of these panels would then be mounted together to make a 'Г.E. cooler capable of cooling a small office.

Evaluation of T.E. Heat Pumps. Thermoelectric refrigeration, based on the Peltier effect, has achieved practicality in small specialty applications including recreational vehicle refrigerators, mobile home refrigerators, portable picnic coolers, cream dispensers, display case coolers, ophthalmological cornea freezers, beer keg coolers, and aquarium coolers. 
Figure A-15: Single Cell of Thermoelectric Cooling Device

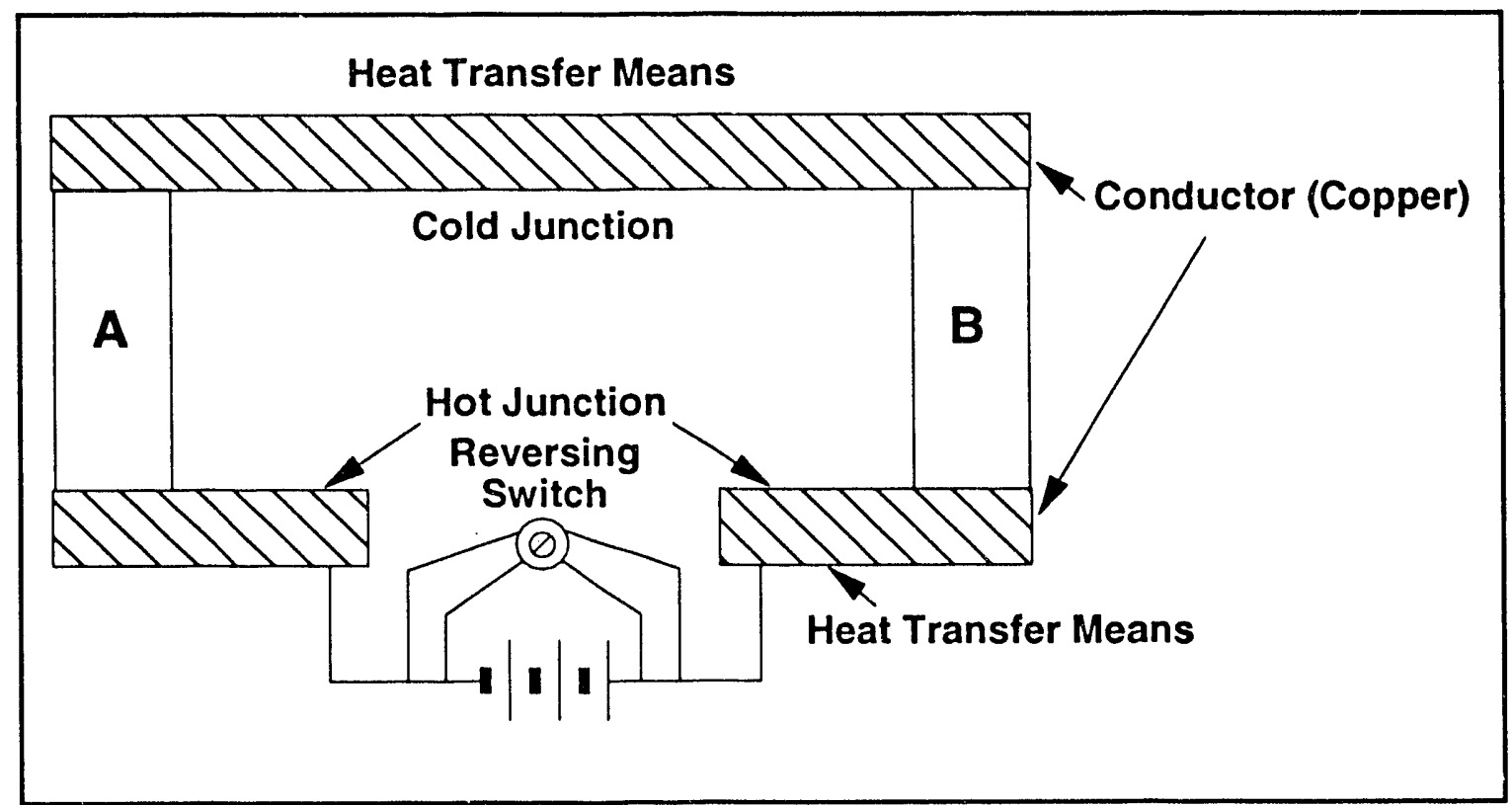

Thermoelectric heat pumps show some distinct advantages:

1. There are no internal moving parts, which give low maintenance and long life expectancy. External moving parts are usually blowers to move coolant air across an extended surface on the hot side and load air across similar extended surfaces on the cool side.

2. Modulation is effected simply by varying the voltage across the panels (as compared to changing pump speed or displacement).

3. Heating/cooling function is easily reversed by means of an electrical switch.

The primary disadvantages would include:

1. Material Costs. Bismuth tellurides and selenides, of ultra high purity, carefully "doped" and grown as single crystals from a melt were about the best materials developed. This is a very expensive.

2. Fabrication costs are intrinsically high, involving many pieces. It could probably be adopted to a very high degree of automation, but would require a very large capital investment.

3. It is a low voltage, high current, D.C. device with all the cost limitations of such power. There will also be rectification losses to be factored into the total energy consumption. 
4. It has an inherent low efficiency. An electrical efficiency less than one relates to fossil fuel efficiency no greater than 0.3 .

\section{A-2.13.3 A Commercial Claim.}

Gre $^{\circ}$.peace [55] references a product offered by Solaire of California which is reported to produce $108 \mathrm{~B}: \mathrm{u} / \mathrm{hour}$ cooling, using 1.9 amperes of current at 12 volts, and carries a price of $\$ 450$. It is said ts be designed for automotive cooling but is most likely an off-the-shelf electronic ircuit board cooler. A little quick arithmetic shows that this is 0.009 tons of coolis. 3.0 tons usually specified for automotive pulldown. Accepting this surprisin yly high efficiency ( $1.38=$ cooling outelectricity in), this scales up to 638 amperes for automotive cooling, which would require a generator, or alternator-rectifier, of very substantial size. Perhaps the price would be somewhat reduced from linear scale up by a scale factor.

\section{A-2.13.4 An Example.}

An example is a water source heat pump and compiring thermoelectrics with vapor compression. For the vapor compression system:

$$
\begin{aligned}
& \mathrm{T}_{\text {evaporator }}=45^{\circ} \mathrm{F} \\
& \mathrm{T}_{\text {condenser }}=70^{\circ} \mathrm{F} \text { (using } 55^{\circ} \mathrm{F} \text { water with a } 10^{\circ} \mathrm{F} \text { rise and a } 5^{\circ} \mathrm{F} \text { approach) }
\end{aligned}
$$

From the Bristol Inertia Data [56]:

$$
\begin{aligned}
& \mathrm{EER}=29.6 \mathrm{Btu} / \mathrm{Watt} \mathrm{hr} \\
& \mathrm{COP}=8.7
\end{aligned}
$$

For the thermoelectric system:

$$
\begin{aligned}
& \mathrm{T}_{\text {water in }}=55^{\circ} \mathrm{F} \\
& \mathrm{T}_{\text {water out }}=65^{\circ} \mathrm{F}\left(10^{\circ} \mathrm{F} \text { rise }\right) \\
& \mathrm{T}_{\text {air in }}=78^{\circ} \mathrm{r} \\
& \mathrm{T}_{\text {air out }}=57^{\circ} \mathrm{F}
\end{aligned}
$$

Then

$$
\begin{aligned}
& \mathrm{T}_{\text {effective water }}=60^{\circ} \mathrm{F} \\
& \mathrm{T}_{\text {effective air }}=65^{\circ} \mathrm{F}
\end{aligned}
$$

Assuming $10^{\circ} \mathrm{F} \Delta \mathrm{T}$ in each case, the thermoelectric temperatures are:

$$
\begin{aligned}
& \mathrm{T}_{c}=55^{\circ} \mathrm{F} \\
& \mathrm{T}_{\mathrm{b}}=70^{\circ} \mathrm{F}
\end{aligned}
$$


Using Melcor [57] data for module number CP 1.4-127-10L as an example, the COP is given in the following table:

\begin{tabular}{|c|c|c|c|c|}
\hline Amps & Volts & Btu/hr & Watts & COP \\
\hline \hline 1 & 4.6 & 38 & 4.6 & 2.42 \\
\hline 2 & 8.8 & 73 & 17.6 & 1.21 \\
\hline 3 & 12.5 & 95 & 37.5 & 0.74 \\
\hline
\end{tabular}

These COPs represent an energy penalty of 4 to 11 compared with vapor compression. This very severe energy penalty precludes thermoelectric refrigeration from being of interest for the present program.

The size of the system is also of interest. It is estimated that the COP may rise to approximately 5 if the current density is reduced by a factor of 2 . The result is a requirement of 1000 modules, each 1.5 in square for a 3 ton capacity.

Potential as Halocarbon Replacement. Low efficiency and high cost make this a very unlikely candidate for the applications of this program. There is no basis for believing that additional research would significantly improve the deficiencies.

\section{A-3 Alternative Blowing Agents for Foams}

The category of foams is very broad since there are numerous foam materials, methods of manufacturing, and types of foams (open or closed cell). The most common foam materials are polyurethane/polyisocyanurate, phenolic, and polystyrene. Several different blowing agents are currently available and several substitutes are being studied. Foams can be open cell (no gas is trapped within the foam) or closed cell (gas is trapped), and they can be blown into place, extruded, or cut into board stock.

The increase in thermal resistivity is typically accomplished by forming cells which are very small. Any cell which is smaller than $10 \mathrm{~mm}$ effectively eliminates convection [58]. By having many small cells, thereby increasing the number, the radiation heat transfer is also reduced. The plastic materials used are also of low thermal conductivity which reduces the solid conduction. Typically for a closed cell foam system filled with CFC vapor, gaseous conduction is about 50\% of the total heat transfer through the foam. The remaining 50\% is radiation and solid conduction (20\%). For open cell foams filled with air, gaseous conduction is about three times higher than closed cell foam filled with CFC-11 vapor.

Currently the common blowing agents for foam are CFC-11 and CFC-12. The use of blowing agents provides a gas which is then trapped in the foam and reduces the overall heat transfer. CFC-11 is the most common of the blowing agents, used with the polyurethanes and polyisocyanurates. CFC-12 is used with polystyrene and in some cases with laminated foam insulitions [59]. 
Insulation options are listed in Tables A-16 and A-17. Included in these tables are typical characteristics of the insulation types. The two tables are divided into baseline insulation systems, i.e. those currently used, and foam insulation systems which use alternative blowing agents.

Phenolic foams were initially used as in open cell configurations, but more recently have been used in the closed cell form. The phenolic provides a better barrier to gas diffusion and therefore reduces the aging process. The typical blowing agents are CFC-11 and CFC-113, or mixtures of the two. The alternatives which are typically considered include HCFC-141b and HCFC-123. Water as a blowing agent is not feasible for phenolics [60].

The previously mentioned foams, PU/PIR and phenolic, are thermosetting and react to form the foam. Extruded polystyrene is a thermoplastic and is formed by injecting the hlowing agent into the melted styrene and allowing it to cool. The blowing agent forms cells during the cooling process. The common blowing agent for extruded polystyrene is CFC-12. Using CFC-12 provides a $98 \%$ or better closed cell structure. Originally the blowing agent was methyl chloride. The alternatives which are under consideration as short term replacements are HCFC-22, HCFC-142b, and hydrocarbons (butanes and pentanes). The longer-term solutions cited are HFC-134a and HCFC-124. The only one of these alternatives which has possibility as a very long-term future is HFC-134a. Tht main disadvantage of HFC-134a is that the vapor thermal conductivity is approximately $40 \%$ higher than CFC- 12 .

Table A-16: Baseline Insulation Options

\begin{tabular}{|c|c|c|c|c|c|c|}
\hline $\begin{array}{l}\text { Primary } \\
\text { Insulation } \\
\text { System and } \\
\text { References }\end{array}$ & 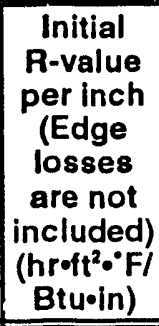 & $\begin{array}{l}\text { Density } \\
\text { in Final } \\
\text { Form } \\
\left(1 \mathrm{bm} / \mathrm{ft}^{3}\right)\end{array}$ & $\begin{array}{l}\text { Required } \\
\text { Vacuum } \\
\text { (Torr) }\end{array}$ & $\begin{array}{c}\text { Encapsulation } \\
\text { or Barrier } \\
\text { Type }\end{array}$ & $\begin{array}{c}\text { Status of } \\
\text { Technology }\end{array}$ & $\begin{array}{c}\text { Flammability/ } \\
\text { Toxicity/ } \\
\text { Safety }\end{array}$ \\
\hline $\begin{array}{l}\text { CFC-11 Blown } \\
\text { PIR/PU Foam } \\
60,61,62,65]\end{array}$ & $7-8$ & 2 & none & $\begin{array}{l}\text { metal foil; } \\
\text { polymer; } \\
\text { appliance } \\
\text { cavity }\end{array}$ & $\begin{array}{l}\text { Fully developed. } \\
\text { Testing on aging } \\
\text { and means to } \\
\text { slow process } \\
\text { down are } \\
\text { required. }\end{array}$ & $\begin{array}{l}\text { No toxicity or } \\
\text { flammability } \\
\text { issues for } \\
\text { blowing ageni. }\end{array}$ \\
\hline $\begin{array}{l}\text { Extruded } \\
\text { Polystyrene }\end{array}$ & 5 & 2 & none & $\begin{array}{l}\text { metal foil; } \\
\text { polymer; } \\
\text { appliance } \\
\text { cavity }\end{array}$ & Fully developed. & $\begin{array}{l}\text { No toxicity } \\
\text { issues. }\end{array}$ \\
\hline $\begin{array}{l}\text { Expanded } \\
\text { Polystyrene }\end{array}$ & 4 & 1.5 & none & metal foil & Fully developed. & \\
\hline Phenolic Foams & 8.8 .5 & $2-3$ & none & $\begin{array}{l}\text { metal foil; } \\
\text { polymer }\end{array}$ & $\begin{array}{l}\text { Fully developed } \\
\text { board stock }\end{array}$ & \\
\hline
\end{tabular}


Table A-17: Foams with Alternative Blowing Agents

\begin{tabular}{|c|c|c|c|c|c|c|}
\hline $\begin{array}{c}\text { Primary } \\
\text { Insulation } \\
\text { System and } \\
\text { References }\end{array}$ & $\begin{array}{c}\text { Initial } \\
\text { R-value } \\
\text { per inch } \\
\text { (Edge } \\
\text { losses } \\
\text { are not } \\
\text { included) } \\
\text { (hroft'o. F/ } \\
\text { Btuoin) } \\
\end{array}$ & $\begin{array}{c}\text { Density } \\
\text { in Final } \\
\text { Form } \\
\left(\mathrm{lbm} / \mathrm{ft}^{3}\right)\end{array}$ & $\begin{array}{c}\text { Required } \\
\text { Vacuum } \\
\text { (Torr) }\end{array}$ & $\begin{array}{c}\text { Encapsulation } \\
\text { or Barrier } \\
\text { Type }\end{array}$ & $\begin{array}{c}\text { Status of } \\
\text { Technology }\end{array}$ & $\begin{array}{c}\text { Flammability/ } \\
\text { Toxicity/ } \\
\text { Safety }\end{array}$ \\
\hline $\begin{array}{l}\text { HCFC Blown } \\
\text { PIR/PU Foam } \\
\text { (HCFC- } 123 \text { and } \\
\text { HCFC-141b) } \\
{[63,64,65]}\end{array}$ & $6-8$ & 2 & none & $\begin{array}{l}\text { metal foil; } \\
\text { polymer; } \\
\text { appliance } \\
\text { cavity }\end{array}$ & $\begin{array}{l}\text { Toxicity testing } \\
\text { ongoing; requires } \\
\text { testing on aging } \\
\text { and resistivity } \\
\text { improvements. } \\
\text { Methods of } \\
\text { sealing foam } \\
\text { surface to reduce } \\
\text { aging. }\end{array}$ & $\begin{array}{l}\text { HCFC-141b may } \\
\text { have flammability } \\
\text { concerns. }\end{array}$ \\
\hline $\begin{array}{l}\text { HCFC/Water } \\
\text { Blown PIR/PU } \\
\text { Foams }\end{array}$ & $6-8$ & 2 & none & $\begin{array}{l}\text { metal foil; } \\
\text { polymer; } \\
\text { appliance } \\
\text { cavity }\end{array}$ & $\begin{array}{l}\text { Testing for fine } \\
\text { cellular foam is } \\
\text { required. } \\
\text { Methods of } \\
\text { sealing foam } \\
\text { surface to reduce } \\
\text { aging and foam } \\
\text { shrinkage. }\end{array}$ & $\begin{array}{l}\text { HCFC-141b may } \\
\text { have flammability } \\
\text { concerns. }\end{array}$ \\
\hline $\begin{array}{l}\text { Water Blown } \\
\text { PIR/PU Foam } \\
\text { 64] }\end{array}$ & $5-6$ & 2.2 & none & $\begin{array}{c}\text { none; } \\
\text { appliance } \\
\text { cavity }\end{array}$ & $\begin{array}{l}\text { Requires } \\
\text { additional testing } \\
\text { of foam } \\
\text { properties }\end{array}$ & $\begin{array}{l}\text { No toxicity or } \\
\text { flammability } \\
\text { issues. }\end{array}$ \\
\hline $\begin{array}{l}\text { Perfluoroalkane } \\
\text { Blown PIR/PU } \\
\text { Foam [66] }\end{array}$ & 8.0 & unknown & none & $\begin{array}{l}\text { none; } \\
\text { appliance } \\
\text { cavity; } \\
\text { appliance } \\
\text { cavity }\end{array}$ & $\begin{array}{l}\text { Foams have } \\
\text { been blown, } \\
\text { requires further } \\
\text { testing on aging } \\
\text { and mechanical } \\
\text { properties }\end{array}$ & $\begin{array}{l}\text { No toxicity or } \\
\text { flammability } \\
\text { issues. }\end{array}$ \\
\hline $\begin{array}{l}\text { HFC Blown } \\
\text { PIR/PU Foam }\end{array}$ & unknown & unknown & unknown & $\begin{array}{c}\text { metal foil; } \\
\text { polymer; } \\
\text { appliance } \\
\text { cavity } \\
\end{array}$ & $\begin{array}{l}\text { Development } \\
\text { required. }\end{array}$ & \\
\hline $\begin{array}{l}\text { HCFC Blown } \\
\text { Phenolic Foam } \\
\text { 67] }\end{array}$ & unknown & unknown & unknown & $\begin{array}{c}\text { none or metal } \\
\text { barrier; } \\
\text { appliance } \\
\text { cavity }\end{array}$ & $\begin{array}{l}\text { Blowing systems } \\
\text { are under } \\
\text { development. }\end{array}$ & \\
\hline $\begin{array}{l}\text { Expanded } \\
\text { Polystyrene }\end{array}$ & 4 & 1.5 & none & $\begin{array}{l}\text { metal foil; } \\
\text { polymer; } \\
\text { appliance } \\
\text { cavity }\end{array}$ & & \\
\hline $\begin{array}{l}\text { Extruded } \\
\text { Polystyrene using } \\
\text { HCFC-142b }\end{array}$ & & & & & & \\
\hline
\end{tabular}




\section{A-3.1 Requirements for Blowing Agents}

Since the blowing agent must react with the foam constituents during the forming stage but not after the foam has set, specific criteria exist. These include, for closed cell foams [68]:

- Appropriate volatility: A critical property which has to be within a specific range. If too high then the blowing agent could force rupture of cell walls and collapse of the foam. If too low then the requirements for equipment would be complicated.

- Nonreactivity: The blowing agent should not react with the foam material over long periods of time.

- Adequate solubility: In the prefoam, a blowing agent which is completely soluble is preferred. In order to minimize the blowing agent use, most of the blowing agent should vaporize during blowing, i.e., low solubility at blowing conditions. Once the foam is formed, the remaining gas should not react with the foam or the foam could become soft.

- Effective heat of vaporization: The reaction which occurs is exothermic and requires sufficient heat to release the blowing agent out of solution.

- Low vapor thermal conductivity: Since heat transfer through the blowing agent accounts for a substantial component of the overall heat conduction, keeping this low is of great importance.

- Low diffusion rate: Since the blowing agent is a very important component of the overall thermal conductivity, it should not be allowed to diffuse out. Also, the diffusion of air in should be prevented to avoid diluting the blowing agent. The polymer blowing agent should minimize air diffusion by lower polymer permeability and a larger fraction of polymer in the cell walls to inhibit diffusion.

- Low molecular weight: Although a low molecular weight also implies a high thermal conductivity, the volumetric efficiency can be improved. This would result in a lower cost foam system.

In addition to these performance criteria, the blowing agent should be environmentally benign. This requires that the ODP and GWP be low, preferably zero. The blowing agents must also be non-toxic.

\section{A-3.2 Potential Alternatives}

Two blowing agents which are currently being investigated as substitutes for CFC-11 are HCFC-123 and HCFC-141b and for CFC-12 are HFC-134a and HCFC-124. The properties for blowing agents are shown in Tables A-18 and A-19. 
Table A-18: Baseline Blowing Agent Properties $[69,69]$

\begin{tabular}{|l|c|c|c|}
\hline \multicolumn{1}{|c|}{ Property } & CFC-11 & CFC-12 & CFC-113 \\
\hline \hline Formula & CCl3F & CCl2F & CCl $_{2} \mathrm{FCClF}_{2}$ \\
Molecular Weight & 137.4 & 120.9 & 187.4 \\
Boiling Pt. ('F) & 74.0 & -6.9 & -23.8 \\
Vapor Therm. Cond. & 0.0045 & 0.0064 & \\
(Btu/hr-ft-"F) & 43.1 & 34.4 & 47.3 \\
Heat of Vaporization at B.P. & 1.0 & 1.0 & 1.07 \\
(Cal/gm) & 0.5 & 1.0 & 0.57 \\
ODPa & & \\
GWP' & &
\end{tabular}

- Estimates based on preliminary or incomplete data except for CFC-22, which is reliable and for values quoted as zero which are non-chlorine containing molecules, based on CFC-12 $=1.0$ for 100 year time horizons.

- $\quad C D=$ Catalyst Deficiency

$\mathrm{NC}=$ Not Commercialized

Dev $=$ Developmental Only

Water blown foams leave $\mathrm{CO}_{2}$ as the interstitial gas. $\mathrm{CO}_{2}$ has a higher conductivity than CFC-11 but also tends to give smaller cells in the foam which reduces the radition heat transfer. Since the $\mathrm{CO}_{2}$ has a much higher permeability through the foam the aging process is very fast, in a matter of weeks for unfaced foam. Therefore, water blown foam requires a barrier material or limiting its use to structural member only. ICI is using an all water blown system for beverage vending machines [70]. In order to slow the aging, metal liners on both the outside and the inside are used.

Perfluoroalkanes (PFAs) are another possibility for foams but are predicted to have a high GWP and cost. PFAs can be used as an additive to HCFC blown systems, thereby increasing the thermal conductivity of the interstitial gas.

The resistivity of an all PFA blown foam is 8 . Although the thermal conductivity of the gas is higher than CFC-11, PFA generates foarns with a finer cell structure which increases the overall foam resistivity.

Foams are currently used to provide rigidity to the structures, especially in appliances. Tables A-19 and A-20 list the thermal resistivity and other characteristics of the different types of foams and blowing agents. The alternative foam systems typically would require thicker sections to maintain the same overall $R$-value. The requirement for thicker sections is driven by either a need for equivalent $\mathrm{R}$-value using a material with a higher thermal conductivity or by required lower energy consumption. In some cases both of these requirements are present.

Aging of foams may be an issue. The permeability of HCFCs out of the foam must be determined. The aged values in Table A-20 are only shown as typical values. The exact test time and thickness were not specified in the reference. Materials compatibility with refrigerator/freezer liners is not good and requires development of new liners. HCFCs will likely be phased out in the future due to ODP. 
Table A-19: Blowing Agent Alternatives $[64,65,66,67,68,69,70,71,99]$

\begin{tabular}{|c|c|c|c|c|c|c|c|c|}
\hline Number & Formula & $\begin{array}{c}\text { Molecular } \\
\text { Weight }\end{array}$ & $\begin{array}{c}\text { Boilling } \\
\text { Polnt, }{ }^{\circ} \mathrm{C}\end{array}$ & ODP & GWP" & Flammable & Toxicology & Mfg.ab \\
\hline \multicolumn{9}{|l|}{ Baselines } \\
\hline $\begin{array}{l}\text { CFC-11 } \\
\text { CFC-12 } \\
\text { CFC-113 }\end{array}$ & $\begin{array}{c}\mathrm{CC13F} \\
\mathrm{CC}_{12 F_{2}} \\
\mathrm{CC}_{12 \mathrm{FCClF}}\end{array}$ & $\begin{array}{l}137.4 \\
120.9 \\
187.4\end{array}$ & $\begin{array}{l}23.8 \\
-21.6 \\
-31.0\end{array}$ & $\begin{array}{l}1.0 \\
1.0 \\
1.07\end{array}$ & $\begin{array}{l}0.5 \\
1.0 \\
0.57\end{array}$ & No & Low & $\begin{array}{l}\text { Yes } \\
\text { Yes } \\
\text { Yes }\end{array}$ \\
\hline \multicolumn{9}{|c|}{ Existing Commercial Products } \\
\hline $\begin{array}{l}\text { HCFC-22 } \\
\text { HCFC-142B } \\
\text { HFC-152A } \\
\text { Water/CO }\end{array}$ & $\begin{array}{c}\mathrm{CHClF}_{2} \\
\mathrm{CH}_{3} \mathrm{CClF}_{2} \\
\mathrm{CH}_{3} \mathrm{CHF}_{2} \\
\mathrm{CO}_{2}\end{array}$ & $\begin{array}{c}86.5 \\
100.5 \\
66.1 \\
44.0\end{array}$ & $\begin{array}{l}-40.8 \\
-9.2 \\
-24.7 \\
-78.3\end{array}$ & $\begin{array}{c}0.055 \\
0.065 \\
0 \\
0 \\
\end{array}$ & $\begin{array}{l}0.2 \\
0.2 \\
<0.1 \\
<0.1\end{array}$ & $\begin{array}{l}\text { No } \\
\text { Yes } \\
\text { Yes } \\
\text { No }\end{array}$ & $\begin{array}{l}\text { Low } \\
\text { Low } \\
\text { Low } \\
\text { No }\end{array}$ & $\begin{array}{l}\text { Yes } \\
\text { Yes } \\
\text { Yes } \\
\text { Yes }\end{array}$ \\
\hline \multicolumn{9}{|c|}{ Under Consideration } \\
\hline $\begin{array}{l}\text { HCFC-123 } \\
\text { HCFC-124 } \\
\text { HFC-25 } \\
\text { HFC-134A } \\
\text { HCFC-141B } \\
\text { HFC-143A } \\
\text { Perfluoropentane/ } \\
\text { Perfiuorohexane }\end{array}$ & $\begin{array}{c}\mathrm{CHCl}_{2} \mathrm{CF}_{3} \\
\mathrm{CHClFCF}_{3} \\
\mathrm{CHF}_{2} \mathrm{CF}_{3} \\
\mathrm{CH}_{2} \mathrm{FCF}_{3} \\
\mathrm{CH}_{3} \mathrm{CCH}_{2} \mathrm{~F} \\
\mathrm{CH}_{3} \mathrm{CF}_{3}\end{array}$ & $\begin{array}{c}152.9 \\
136.5 \\
120.0 \\
102.0 \\
117.0 \\
84.0\end{array}$ & $\begin{array}{c}28.7 \\
-12.0 \\
-48.5 \\
-26.5 \\
32.0 \\
-47.6 \\
30.0 / 56.1\end{array}$ & $\begin{array}{c}0.02 \\
0.02 \\
0 \\
0 \\
0.11 \\
0 \\
0\end{array}$ & $\begin{array}{l}<0.1 \\
<0.1 \\
<0.2 \\
0.16 \\
<0.1 \\
<0.4 \\
\text { high }\end{array}$ & $\begin{array}{l}\text { No } \\
\text { No } \\
\text { No } \\
\text { No } \\
\text { Yes } \\
\text { Yes } \\
\text { No }\end{array}$ & $\begin{array}{c}\text { Low } \\
\text { Low } \\
\text { Unknown } \\
\text { Incomplete } \\
\text { Incomplete } \\
\text { Incomplete } \\
\text { No }\end{array}$ & $\begin{array}{l}C D \\
C D \\
C D \\
C D \\
D e V \\
N C \\
\text { Yes }\end{array}$ \\
\hline \multicolumn{9}{|c|}{ Disqualified due to Toxicity } \\
\hline $\begin{array}{l}F C-21 \\
F C-31 \\
F C-132 B \\
F C-133 A\end{array}$ & $\begin{array}{c}\mathrm{CHCl} 2 \mathrm{~F} \\
\mathrm{CH} 2 \mathrm{ClF} \\
\mathrm{CH} 2 \mathrm{ClCClF} 2 \\
\mathrm{CH} 2 \mathrm{ClCF} 3\end{array}$ & $\begin{array}{l}102.9 \\
68.5 \\
134.8 \\
118.4\end{array}$ & $\begin{array}{c}8.9 \\
-9.1 \\
46.8 \\
6.1 \\
\end{array}$ & $\begin{array}{l}<0.05 \\
<0.05 \\
<0.05 \\
<0.05\end{array}$ & $\begin{array}{l}<0.1 \\
<0.1 \\
<0.1 \\
<0.1\end{array}$ & $\begin{array}{l}\text { No } \\
\text { Yes } \\
\text { No } \\
\text { No } \\
\end{array}$ & $\begin{array}{c}\text { Toxic } \\
\text { Toxic } \\
\text { Toxic } \\
\text { Embryotoxin }\end{array}$ & $\begin{array}{c}\text { Yes } \\
\text { NC } \\
\text { No } \\
\text { NC (US) }\end{array}$ \\
\hline \multicolumn{9}{|c|}{ Possible Long Term Options } \\
\hline $\begin{array}{l}\text { E-143 } \\
\text { E-152 } \\
\text { Fluoropropane } \\
\text { Fluorobutanes }\end{array}$ & & & $\begin{array}{l}30.0 \\
32.8\end{array}$ & $\begin{array}{l}0 \\
0 \\
0 \\
0\end{array}$ & $\begin{array}{l}? \\
? \\
? \\
?\end{array}$ & $\begin{array}{l}\text { No } \\
\text { No } \\
\text { No } \\
\text { No }\end{array}$ & $\begin{array}{l}? \\
? \\
? \\
?\end{array}$ & $\begin{array}{l}\text { No } \\
\text { No } \\
\text { No } \\
\text { No }\end{array}$ \\
\hline
\end{tabular}

- Estimates based on preliminary or incomplete data except for CFC-22, which is reliable and for values quoted as zero which are non-chlorine containing molecules, based on CFC-12 $=1.0$ for 100 year time horizons.

b $\quad C D=$ Catalyst Deficiency

$\mathrm{NC}=$ Not Commercialized

Dev = Developmental Only

The increase in foam resistivity is typically achieved by forming foams which have smaller cells and including opacifiers. The smaller cell sizes are achieved by using the proper mix of chemicals and conditions (temperature, pressure, etc.). At low concentrations opacifiers reduce the R-value, while at high concentrations the benefits are reduced or eliminated. One type of opacifier which is under consideration is carbon black. Although the carbon black has a relatively high thermal conductivity, particles are small enough to provide some resistance. Also, the benefit of the lower emissivity of the flakes offsets the increase of the thermal conductivity.

The actual foam materials are typically polyurethane, polyisocyanurate, polystyrene, or phenolic. All of the options mentioned above apply to polyurethane and polyisocyanurate foams. Expanded polystyrene uses $\mathrm{CFC}-12$ as the blowing agent. Phenolics can use a variety of blowing agents, a preferred one being CFC-114. The use of water as a blowing agent for phenolics is not possible. One advantage of phenolic 
foams is the higher resistance to gas diffusion through the foam. Presently, no blown in place systems are available for phenolic systems, they are all board stock applications. Another advantage for phenolic foams is better burn resistance characteristics.

Table A-20: Specific and Projected Resistivities for Foams [64]

\begin{tabular}{|c|c|c|c|c|}
\hline Gas & 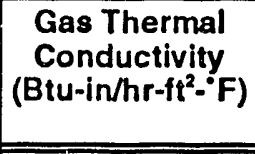 & $\begin{array}{c}\text { Fresh Foam } \\
\text { Thermal } \\
\text { Conductivity } \\
\left(\text { Btu-in/hr-ft' }{ }^{2}-\mathrm{F}\right) \\
\end{array}$ & 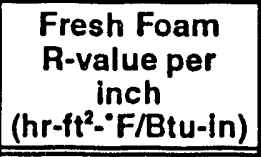 & $\begin{array}{c}\text { Aged Foam } \\
\text { R-value per } \\
\text { Inch } \\
\text { (hr-ft'- F/Btu-in) } \\
\end{array}$ \\
\hline $\begin{array}{l}\text { Air } \\
\mathrm{CO}_{2} \\
\text { CFC-11 } \\
\text { CFC-12 } \\
\text { HCFC-22 } \\
\text { HCFC-123 } \\
\text { HCFC-124 } \\
\text { HFC-134a } \\
\text { HCFC-141b } \\
\text { HCFC-142b } \\
\text { Air/CFC-11 (50/50) } \\
\text { CO /CFC-11 }(33 / 66) \\
\text { CO } / C F C-11(50 / 50) \\
\text { Butane } \\
\text { Pentane }\end{array}$ & $\begin{array}{l}0.18 \\
0.107 \\
0.057 \\
0.067 \\
0.073 \\
0.072 \\
0.075 \\
0.094 \\
0.070 \\
0.077 \\
0.118 \\
0.073 \\
0.082 \\
0.100 \\
0.089\end{array}$ & $\begin{array}{l}0.253 \\
0.180 \\
0.130 \\
0.140 \\
0.146 \\
0.145 \\
0.148 \\
0.167 \\
0.143 \\
0.150 \\
0.191 \\
0.146 \\
0.155 \\
0.173 \\
0.162\end{array}$ & $\begin{array}{l}3.95 \\
5.56 \\
7.69 \\
7.14 \\
6.85 \\
6.90 \\
6.76 \\
5.99 \\
6.99 \\
6.67 \\
5.24 \\
6.85 \\
6.45 \\
5.78 \\
6.17\end{array}$ & $\begin{array}{l}3.9 \\
3.9 \\
6.2 \\
5.0 \\
\approx 4\end{array}$ \\
\hline
\end{tabular}

Note: Fresh foam values are projected based on $\mathrm{K}($ foam $)=\mathrm{K}($ gas $)+0.073$.

\section{A-4 Advanced Insulation Technologies}

The commonly used insulations include foams (open and closed cell), fiber systems (batts, boards, loose fill), and powder filled. Of these, only foams will be affected due to the elimination of CFCs. As a near term relief, the use of HCFCs as blowing agents is practical. For a longer term solution other blowing agents, thick insulations, or new technologies will be required.

In order to develop a new insulation, the heat transfer mechanisms must be addressed. These mechanisms include solid and gaseous conduction, and convective and radiative heat transfer. Reducing the heat transfer is different for each of the four modes.

Solid Heat Conduction: Conduction through a solid material is defined by Fourier's Law

$$
\begin{aligned}
\vec{q} & =-k \vec{\nabla} T \\
Q & =-k A \frac{d T}{d \cdot x}
\end{aligned}
$$

where $q$ is the heat flux, $Q$ is the heat flow, $k$ is the thermal conductivity, $T$ is the temperature, $A$ is the heat flow area, and $x$ is the heat flow path length. Therefore, in order to reduce the thermal flow, either the thermal conductivity and/or the area must be reduced, or the flow path length increased. Two of these parameters involve the 
geometry of the system. By forming a very tortuous heat flow path, decreasing the area and increasing the length, the heat conduction can be reduced. One way of reducing conduction is to use a discontinuous solid (e.g., powders, flakes, or short fibers) and allowing only lightly compressed point contact between neighboring solids. For a foam, the struts (linear elements formed at the intersections of cells) conduct less heat per unit volume of solid than cell walls. For a homogeneous insulation, the heat flow due to solid conduction varies inversely with the solid thickness. The thermal conductivity of a continuous homogeneous material is a material property which, in general, increases with temperature. For an insulation which has inhomogeneities, voids, or multiple materials, the conductivity defined by the above equation is an effective value which includes different mechanisms of heat transfer.

Gaseous Heat Conduction: If there is negligible bulk flow on a macroscopic level the equation for heat transfer by gas conduction is identical to that for solid conduction. At low pressures the conductivity is pressure dependent. Heat is transferred through a gas by the motion of gas molecules with an exchange between molecules in the high temperature region which have a higher energy and lower energy molecules in the low temperature region. By a simple kinetic theory model, the gas conductivity is proportional to:

$$
k \sim n \lambda
$$

where $\mathrm{n}$ is the number of molecules per unit volume and $\lambda$ is the mean free path, the average distance between successive molecular collisions. At high gas pressure $(p), n$ varies with $\mathrm{p}$ and $\lambda$ is inversely proportional to $\mathrm{p}$ which indicates that $\mathrm{k}$ is independent of pressure. When the pressure is reduced so that $\lambda$ is less than the mean spacing between adjacent solid boundaries, $k$ becomes proportional to the product of $n$ and the mean spacing (1).

$$
\begin{aligned}
& k \propto n l \\
& k \propto p l
\end{aligned}
$$

Therefore, as the pressure is further decreased, $\mathrm{n}$ and $\mathrm{k}$ decrease. The transition pressure at which $\mathrm{k}$ decreases is dependent on the mean spacing, i.e., small mean spacing results in higher transition pressures. Above the transition pressure the conductivity approaches a constant value which remains the same up to and above one atmosphere
pressure.

Natural Convective Heat Transfer: Convective heat transfer occurs when bulk motion of fluid augments the conductive molecular motion. In natural convection, buoyancy forces due to temperature differences in the fluid set up the bulk motion. Natural convection occurs when the buoyancy forces overcome viscous restraining forces; this occurs at high temperature difference and large cavity spacings. The criteria for the onset of natural convection is set by the Rayleigh number. Foams and fiberous insulations typically have cavities small enough to suppress natural convection. 
Radiative Heat Transfer: Whereas in conduction the heat transfer is proportional to the temperature gradient, in thermal radiation the heat transfer is proportional to the emissive power given as $\sigma \mathrm{T}_{4}$ where $\sigma$ is the Stefan Boltzmann constant and T is the absolute temperature of the emitting bodies. For large transparent cavities made up of parallel surfaces,

$$
Q=\frac{\left(\sigma T_{1}^{4}-\sigma T_{2}^{4}\right) A_{1}}{\frac{1}{\varepsilon_{1}}+\frac{1}{\varepsilon_{2}}-1}
$$

where $\varepsilon_{1}$ and $\varepsilon_{2}$ are the emissivities of the two surfaces. For heterogeneous insulation systems with small pore sizes with respect to the insulation thickness, radiation can be represented as

$$
q=\frac{4}{3 K} \frac{d\left(\sigma T_{4}\right)}{d x}
$$

where $\mathrm{K}$ is the extinction coefficient, a property of the material size and refractive index.

Depending on the type of insulation system which is being considered, the modes of heat transfer are addressed distinctly. The following sections describe the insulation types and how they address the heat transfer through the systems.

\section{A-4.1 Non-Evacuated Fiberglass and Loose Fill Insulation}

Non-evacuated systems consist of foams, fiberglass, and other materials of construction. Within the context of this report we will not address the impacts of "materials of construction," i.e. wood, metal liners, plastic liners, etc. Fiberglass can be used in batts, boards, or loose fill foam. Each of these have specific advantages.

Table A-21 lists the fiberglass insulation characteristics. Fiberglass systems are typically bats/blankets, boards or loose fill. The resistivity of the systems varies depending on the insulation type and density. Typical resistivity range for fiberglass is 3 to 4.5. Fiberglass has been used in several applications for many years. Depending on the size of the fiberglass strands it is classified as a skin irritant or a potential carcinogen. The use of fiberglass in appliances and homes is very common. There are no issues regarding the continued use of fiberglass insulations except for the potential as a carcinogen. Fiberglass insulation has less thermal resistivity than foams and therefore requires a thicker panel to achieve an equivalent $R$-value.

The fiberglass batts or blankets are typically made of glass or rock wool fibers [74]. In the final form these are flexible and can be cut and fit into a specific area or form. The typical resistivity for batts or blankets is 2.9 to 3.4 (see Table A-22). Blankets can be made with facings which help reduce the radiative heat transfer to the exterior of the 
Table A-21: Baseline Insulation Options

\begin{tabular}{|c|c|c|c|c|c|c|}
\hline $\begin{array}{c}\text { Primary } \\
\text { Insulation } \\
\text { System and } \\
\text { References }\end{array}$ & $\begin{array}{c}\text { Initial } \\
\text { R-value } \\
\text { per inch } \\
\text { (Edge } \\
\text { losses } \\
\text { are not } \\
\text { included) } \\
\text { (hroft }{ }^{2} \cdot \mathrm{F} \text { ) } \\
\text { Btu•in) }\end{array}$ & $\begin{array}{l}\text { Density } \\
\text { in Final } \\
\text { Form } \\
\left(1 \mathrm{bm} / \mathrm{ft}^{3}\right)\end{array}$ & $\begin{array}{c}\text { Required } \\
\text { Vacuum } \\
\text { (Torr) }\end{array}$ & $\begin{array}{c}\text { Encapsulation } \\
\text { or Barrier } \\
\text { Type }\end{array}$ & $\begin{array}{l}\text { Status of } \\
\text { Technology }\end{array}$ & $\begin{array}{l}\text { Flammability/ } \\
\text { Toxicity/ } \\
\text { Safety }\end{array}$ \\
\hline $\begin{array}{l}\text { Fiberglass } \\
61,62,71,72, \\
64,73,65]\end{array}$ & $3-4.5$ & $0.8-0.9$ & none & none & $\begin{array}{l}\text { Use for various } \\
\text { application in } \\
\text { past }\end{array}$ & $\begin{array}{l}\text { Some fiberglass } \\
\text { may pose } \\
\text { respiratory } \\
\text { problems. }\end{array}$ \\
\hline
\end{tabular}

blanket as well as reduce vapor diffusion into the blanket. Primarily the fiberglass structure of small fibers produce a large drag force on the air and this yields still (non-moving) air which eliminates convective heat transfer.

Boards require a binder to hold the fibers in place into a rigid structure. Possible binders are phenol-formaldehyde and sodium silicate with mineral fiber [75]. These are most commonly used in the construction industry. In addition to thermal insulation fiberglass provides acoustic insulation. These may also be faced with a reflective foil which would reduce the radiative heat transfer to the exterior of the board.

The loose fill fiberglass insulation is used in the construction industry for hard to reach or irregularly shaped areas. Typical fills and their resistivities are shown in Table A-22. This type of insulation is either poured into place or blown. In the case of blown insulatioin, adhesives can be added to provide a more rigid system.

Table A-22: Common Loose Fill or Fiber Insulation [75]

\begin{tabular}{|l|c|c|}
\hline Insulation Type & Fiber Type & $\begin{array}{c}\text { Resistivity } \\
\text { hroft }{ }^{0^{\circ}} \text { F/Btu-in }\end{array}$ \\
\hline \hline Blanket or Batts & Mineral Fiber & 3.0 to 3.4 \\
\hline Loose or Blown Fill & Fiberglass & 2.1 to 2.7 \\
& Rock Wool & 3.1 \\
& Cellulosic Fiber & 2.9 \\
& Perlite or Vermiculite & 2.4 to 3.7 \\
\hline
\end{tabular}

\section{A-4.2 Non-Evacuated Aerogel}

Aerogel panels are made up of monolithic sections which are formed by drying a gel at supercritical temperature and pressure. By following this procedure the remaining solid structure does not contract with the receeding liquid meniscus tension. The final structure which is left has small pores and an overall shape of the mold. For ethylalcohol-silica aerogels the traditional processing pressure and temperature are $240^{\circ} \mathrm{C}$ and 81 bars $[76,77]$. These conditions are dangerous and pose a potential hazard to workers. Thermalux has developed a process in which the alcohol in the gel is removed and replaced with carbon dioxide. In this form the required temperature is 
reduced to $31^{\circ} \mathrm{C}$ but high pressures are still involved. The time required to form an aerogel panel is 8 to 12 hours. Research in reducing the processing time is under way at Thermalux.

The most common material for aerogels is silica although other substances have been used. Due to the high porosity $(98 \%)$, the density is approximately $6 \mathrm{lbm} / \mathrm{ft}^{3}$. The resistivity of non-evacuated aerogel panels is 7 to $15 \mathrm{hr}^{\circ} \mathrm{ft}^{2} \bullet^{\circ} \mathrm{F} / \mathrm{Btu} \cdot \mathrm{in}$ [78]. Battelle claims to have aerogel panels which are at the upper end of 7 to 15 range. No specific information on the procedures used to manufacture these panels was available. More typical resistivity numbers for non-evacuated aerogel panels have been in the 7 to 8 range and as high as 10.3 for aerogels with opacifiers [79]. Table A-23 lists the aerogel characteristics.

Table A-23: Summary of Aerogel Technology

\begin{tabular}{|c|c|c|c|c|c|c|}
\hline $\begin{array}{c}\text { Primary } \\
\text { Insulation } \\
\text { System and } \\
\text { References }\end{array}$ & $\begin{array}{c}\text { Initial } \\
\text { R-value } \\
\text { per inch } \\
\text { (Edge } \\
\text { losses } \\
\text { are not } \\
\text { included) } \\
\text { (hroft' }{ }^{2} \cdot \mathrm{F} / \\
\text { Btu-in) } \\
\end{array}$ & $\begin{array}{c}\text { Density } \\
\text { in Final } \\
\text { Form } \\
\left(\mathrm{lbm} / \mathrm{ft}^{3}\right)\end{array}$ & $\begin{array}{c}\text { Required } \\
\text { Vacuum } \\
\text { (Torr) }\end{array}$ & $\begin{array}{c}\text { Encapsulation } \\
\text { or Barrier } \\
\text { Type }\end{array}$ & $\begin{array}{l}\text { Status of } \\
\text { Technology }\end{array}$ & $\begin{array}{c}\text { Flammability/ } \\
\text { Toxicity/ } \\
\text { Safety }\end{array}$ \\
\hline $\begin{array}{l}\text { Aerogel, silica } \\
{[80,81,63,64]}\end{array}$ & $7-15$ & 6 & none & polymer & $\begin{array}{l}\text { Small panels } \\
\text { have been } \\
\text { formed, } \\
\text { opacifiers } \\
\text { required to get to } \\
\text { high resistivities }\end{array}$ & $\begin{array}{l}\text { No toxicity or } \\
\text { flammability } \\
\text { issues. }\end{array}$ \\
\hline $\begin{array}{l}\text { Organic Aerogels } \\
{[82,83]}\end{array}$ & unknown & $3.4-5.6$ & unknown & polymer & $\begin{array}{l}\text { Organic aerogels } \\
\text { have been made } \\
\text { but no test of } \\
\text { thermal } \\
\text { properties have } \\
\text { been made. }\end{array}$ & No known issues. \\
\hline
\end{tabular}

Organic aerogels are also proposed and have been manufactured. No thermal characteristics have been documented but research and testing is continuing. Lawrence Livermore National Laboratory is directing the research. The variation in the properties, such as density, vary drastically depending on the specific manufacturing procedure. Densities in the range of 3.4 to $5.6 \mathrm{lbm} / \mathrm{ft}^{3}$ have been measured $[81,82]$.

The primary method of reducing heat transfer through non-evacuated aerogels is by using a relatively low thermal conductivity material amorphous (silica) and providing small cells which reduce the convective heat transfer. Opacifiers will reduce the radiative heat transfer. Typical opacifiers are carbon soot or titanium oxide [80]. With a good opacification system resistivities approaching 15 may be feasible. 
The current panel sizes available from Thermalux, 14 inch by 14 inch, are limited by the size of available autoclaves. The available shapes of the aerogels are limited by the available molds. For production quantities a batch mode is likely. The size of the batch is also limited by the size of the available autoclave.

Aerogels have specific problems as insulation materials when not enclosed and evacuated, such as:

- Durability in the normal handling of panels. Aerogels are weak and can be crushed by hand. Using an encapsulation would help in protecting the panels. The encapsulation could be in the form of a foam. The encapsulation would have to be able to withstand the daily handling without forming defects. The organic aerogels compressive strength has been measured and is in the same range as silica aerogels. The aerogels made by Thermalux tend to be weak (compressive strength of 20 to 30 psi $[77,78])$. The compressive strength of aerogels in general can be as high as $10^{5}$ psi [82]. The strength varies with the densities and thereby with the thermal conductivity of the panels.

- Earlier forms of silica aerogels dissolved in water. Thermalux claims to have a process in which this is no longer the case [71]. If exposure to moisture continues to provide a problem area then moisture barriers will be required.

- Time required to produce aerogels is high, on the order of 10 hours per batch, which tends to increase the cost of manufacturing. Since the original application was for windows, obtaining a clear aerogel was the goal. For aerogels which are not required to be clear, the processing time is decreased [71].

The use of aerogels would be suitable for appliances (refrigerator/freezer, water heaters, vending machines), transportation (vibration effects must be reviewed), and retail refrigeration. Aerogels could also be used in building applications. The common factors in these applications are:

- Insulation requires high $\mathrm{R}$-value in a limited space.

- Light weight insulation is advantageous and for saving transportation costs and increase consumer ease of handling.

\section{A-4.3 High-R Gas Panels}

High-R gas panels are formed by trapping a gas which has a low thermal conductivity in an enclosure. The enclosure should be of a low thermal conductivity material and have a low permeability to air and the high- $R$ gas. In order to reduce convective and radiative heat transfer, baffles with low emissivity coatings are added inside the enclosure. Typical gases would be Krypton and Argon. Table A-24 lists the high-R gas panel characterization. Total panels should provide panels with $\mathrm{R}$-value per inch of 15.0 
(Krypton) and 7.9 (Argon) [83]. Tests on small panels have shown Krypton based panels to have R-value per inch of 12.5 and Argon panels of 7.1. Mixes of these gases and air could be used to reduce cost and tailor the pariel for specific uses.

Table A-24: Summary of High-R Gas Insulation System

\begin{tabular}{|c|c|c|c|c|c|c|}
\hline $\begin{array}{c}\text { Primary } \\
\text { Insulation } \\
\text { System and } \\
\text { References }\end{array}$ & \begin{tabular}{|c|} 
Initial \\
R-value \\
per inch \\
(Edge \\
losses \\
are not \\
included) \\
(hroft ${ }^{2} \cdot 0^{\circ}$ FI \\
Btu-in) \\
\end{tabular} & $\begin{array}{c}\text { Density } \\
\text { in Final } \\
\text { Form } \\
\left(1 \mathrm{bm} / \mathrm{ft}^{3}\right)\end{array}$ & $\begin{array}{l}\text { Required } \\
\text { Vacuum } \\
\text { (Torr) }\end{array}$ & $\begin{array}{c}\text { Encapsulation } \\
\text { or Barrier } \\
\text { Type }\end{array}$ & $\begin{array}{l}\text { Status of } \\
\text { Technology }\end{array}$ & $\begin{array}{l}\text { Flammability/ } \\
\text { Toxicity/ } \\
\text { Safety }\end{array}$ \\
\hline $\begin{array}{l}\text { High-R Gas: } \\
\text { Argon } \\
{[84,84]}\end{array}$ & $7-7.5$ & unknown & none & polymer & $\begin{array}{l}\text { Sample panels } \\
\text { have been } \\
\text { manufactured } \\
\text { and tested }\end{array}$ & $\begin{array}{l}\text { No toxicity or } \\
\text { flammability } \\
\text { issues. }\end{array}$ \\
\hline $\begin{array}{l}\text { High-R Gas: } \\
\text { Krypton } \\
84,85]\end{array}$ & $12-13$ & unknown & none & polymer & $\begin{array}{l}\text { Sample panels } \\
\text { have been } \\
\text { manufactured } \\
\text { and tested; } \\
\text { availability of } \\
\text { krypton } \\
\text { questionable }\end{array}$ & $\begin{array}{l}\text { No toxicity or } \\
\text { flammability } \\
\text { issues. }\end{array}$ \\
\hline
\end{tabular}

Life testing of the high- $\mathrm{R}$ gas panels is required. This type of insulation has no structural capabilities and would require foam or other structural support system. Substitute gases which have lower thermal conductivities could be used (e.g. perfluoroalkanes, methylchloride, dichloroldifluoromethane, and methylbromide [85]). Also, different forms for high-R gas panels could be developed. These would include using open celled foam or aerogels and back-filling with an appropriate gas. For these types of panels a barrier material would be required. Similar life/permeation issues exist.

Reference [86] poses the use of an insulation which contains a high molecular weight vapor (perfluorohexane) at a slight vacuum. Estimates of center of panel resistivity are $55 \mathrm{hr} \cdot \mathrm{ft}^{2}{ }^{\circ} \mathrm{F} / \mathrm{Btu} \cdot \mathrm{in}$. When edge losses and radiation heat transfer are accounted for the estimate is a resistivity of 24.4 to 30.5 for refrigerator sized panels.

Some of the problem areas for high-R gas insulation are:

- A reliable encapsulation is required which will maintain the composition of the internal gas for the lifetime of the insulation.

- Cost of the Krypton could be prohibitive and would require trading some of the higher R-value per inch for lower cost panels.

- Additional support is required to prevent bowing of appliance walls. These same supports could provide thermal shorts around the insulation. 
- If high-R gas panels which are at a slight vacuum are used then the issue of maintaining the required vacuum exists.

The typical application would be for appliances and transportation systems where weight would be important. The applications would benefit from the low density and intermediate $\mathrm{R}$-value per inch.

Building application would not be recommended since puncture of the enclosure would destroy the R-value for that section. If a "bubble wrap" type system were used then application to buildings could be feasible. In this fashion only a very small portion would be damaged by a nail or other puncture.

\section{A-4.4 Evac. ted Systems}

Evacuated insulation panels, as discussed in this section, are panels which are formed by placing a fill material into an enclosure, evacuating and sealing the panel. In these systeins the pressure is decreased to the level where the mean free path of the gas molecules is greater than the cell size (the t/jpical pore or spacing between filler material). Addition of opacifiers to the systems will reduce the radiation heat transfer. The convective heat transfer is essentially zero due to the small cell sizes (i.e. smaller than $10 \mathrm{~mm}$ ). The solid heat conduction is reduced by forming very tortuous paths and using materials with relatively low thermal conductivity. Table A-25 lists some of the typical fill materials and their characteristics.

Three types of insulation systems have , en proposed:

- Single panel systems: Each panel is a single board once completely fabricated. The edge to panel area is lower than the second alternative which would indicate a lower edge loss effect. These panels would be placed in the walls of the refrigerated area and foamed in place. The required foaming would provide structural support and reduce the edge losses.

- Multiple single panel system: Small panels are arranged to provide complete coverage of an area. The advantage to using this type of system is in the increased durability of the insulation. Damage to a single panel will only affect that panel and will not have as severe an impact as larger single panels. The primary disadvantage is the increased edge to area ratio. The edge losses would increase which would make the net $\mathrm{R}$-value per inch decrease.

- One enclosure systems: For this type of insulation system the entire housing is fabricated as one unit. The typical shape would be a set of concentric cylinders or one "bathtub" shape located within another, each of these two components connected by a membrane. The membrane, ideally would be of a low thermal conductivity material. 
Table A-25: Summary of Evacuated Insulation Options

\begin{tabular}{|c|c|c|c|c|c|c|}
\hline $\begin{array}{c}\text { Primary } \\
\text { Insulation } \\
\text { System and } \\
\text { References }\end{array}$ & $\begin{array}{c}\text { Initial } \\
\text { R-value } \\
\text { per inch } \\
\text { (Edge } \\
\text { losses } \\
\text { are not } \\
\text { included) } \\
\text { (hroft' } \\
\text { Btuoin) } \\
\end{array}$ & $\begin{array}{c}\text { Density } \\
\text { in Final } \\
\text { Form } \\
\left(\text { lbm/ } \mathrm{ft}^{3}\right)\end{array}$ & $\begin{array}{c}\text { Required } \\
\text { Vacuum } \\
\text { (Torr) }\end{array}$ & $\begin{array}{c}\text { Encapsulation } \\
\text { or Barrier } \\
\text { Type }\end{array}$ & $\begin{array}{c}\text { Status of } \\
\text { Technology }\end{array}$ & $\begin{array}{c}\text { Flammability/ } \\
\text { Toxicity/ } \\
\text { Safety }\end{array}$ \\
\hline $\begin{array}{l}\text { Evacuated } \\
\text { Powder, Panels } \\
\text { [87, 88, 89, 90, } \\
91]\end{array}$ & $28-22$ & $10-16$ & $0.1-10.0$ & polymer; glass & $\begin{array}{l}\text { Several suppliers } \\
\text { are prepared to } \\
\text { manufacture or } \\
\text { license panels. } \\
\text { Envelope/barriers } \\
\text { Require life test } \\
\text { and } \\
\text { improvements. }\end{array}$ & $\begin{array}{l}\text { No flammability } \\
\text { concerns. } \\
\text { Powder size may } \\
\text { lead to health } \\
\text { problems. } \\
\end{array}$ \\
\hline $\begin{array}{l}\text { Evacuated } \\
\text { Powder, Panels } \\
{[88,89,90,91 \text {, }} \\
92]\end{array}$ & $28-22$ & $10-16$ & $0.1-10.0$ & metal & $\begin{array}{l}\text { Larger panels are } \\
\text { being supplied by } \\
\text { MBB for retail } \\
\text { refrigeration. }\end{array}$ & $\begin{array}{l}\text { No flammability } \\
\text { concerns. } \\
\text { Powder size may } \\
\text { lead to health } \\
\text { problems. }\end{array}$ \\
\hline $\begin{array}{l}\text { Evacuated } \\
\text { Powder, Single } \\
\text { Enclosure (MBB } \\
\text { style full cabinet) } \\
{[91,92]}\end{array}$ & 30 & 28 & 10.0 & metal & $\begin{array}{l}\text { Concept tried in } \\
\text { insulating piping } \\
\text { for district } \\
\text { heating. }\end{array}$ & $\begin{array}{l}\text { No flammability } \\
\text { concerns. } \\
\text { Powder size may } \\
\text { lead to health } \\
\text { problems. }\end{array}$ \\
\hline $\begin{array}{l}\text { Evacuated } \\
\text { Aerogel } \\
{[81,80,63,64]}\end{array}$ & $20-36$ & 6 & 80 & polymer & $\begin{array}{l}\text { Small panels } \\
\text { have been } \\
\text { formed. } \\
\text { opacifiers } \\
\text { required to get to } \\
\text { high resistivities }\end{array}$ & $\begin{array}{l}\text { No toxicity or } \\
\text { flammability } \\
\text { issues. }\end{array}$ \\
\hline Prganic Aerogels & $?$ & $?$ & $?$ & polymer & $\begin{array}{l}\text { Panels have } \\
\text { been made but } \\
\text { not fully } \\
\text { characterized }\end{array}$ & $?$ \\
\hline $\begin{array}{l}\text { Evacuated } \\
\text { Fiberglass } \\
73,92]\end{array}$ & $10-80$ & 19 & $0.001-1.0$ & polymer & $\begin{array}{l}\text { Wide range of } \\
\text { properties, based } \\
\text { on fiberglass } \\
\text { particle } \\
\text { dimensions, } \\
\text { packed density, } \\
\text { and vacuum }\end{array}$ & $\begin{array}{l}\text { Some fiberglass } \\
\text { may pose } \\
\text { respiratory } \\
\text { problems. }\end{array}$ \\
\hline $\begin{array}{l}\text { Evacuated Small } \\
\text { Cell PIR/PU } \\
\text { Foam } \\
\text { 93] }\end{array}$ & $18-20$ & 2 & $0.1-0.001$ & polymer; glass & $\begin{array}{l}\text { Patents issued } \\
\text { and panels have } \\
\text { been made for } \\
\text { testing }\end{array}$ & $\begin{array}{l}\text { No toxicity or } \\
\text { flammability } \\
\text { issues. }\end{array}$ \\
\hline
\end{tabular}


Some of the common issues of the evacuated systems are:

- The edge effects which effectively reduce the net resistivity of the insulation. This is due to the short-circuiting around the insulation core with the enclosure. The use of polymer or glass enclosure is preferred over a metal one due to the lower thermal conductivity. Another option is to use polymer films with metal foils as the encapsulation. The metal foil acts as a barrier to vapor diffusion, but would negatively impact the edge loses. In order to reduce the edge effects the enclosure should be as thin and as long as possible, and should be made of a low thermal conductivity material. Additionally, the edge length to insulation area ratio should be as small as possible, i.e. large panels are better.

- Permeation through the enclosure. Thicker films, addition of metal foils, or the use of metal encapsulation could be used to reduce the permeation.: Each of these would, however, increase the edge losses.

- Reliable encapsulation of panels. An encansulation which has no pin holes or other defects is required. Any such defect would allow for the degradation of the vacuum. Using thicker encapsulation films improves the reliability but increases the edge effects.

- Durability in the normal handling of panels. The encapsulation would have to be able to withstand the daily handling without forming defects. This issue is similar to the previous one with the same comments applying.

- Long term tests of enclosures, especially polymers for degradation, water absorption, and other influences. This would include, in the case of a composite, the compatibility between the foam blowing agent and the encapsulation. Other criteria include compatibility with a vacuum and corrosion problems. Also, accelerated testing techniques should be developed.

- The manufacturing techniques of the enclosure system must be developed. The enclosure must be sealed with either welding (for metals) or heat sealing (for polymers). Welding of thin metal plates is difficult especially when the goal is to maintain the thinnest cross-section, i.e. butt welds are preferred over lap welds. When heat sealing a polymeric system, the heat affected area should be as small as possible. The greater the area the higher the edge losses.

In the review of evacuated insulations the edge effects have to be discussed. Typically the resistivities which are reported only address the center of the insulation panel. Figure A-16 shows the effects of metal and polymer encapsulation systems. Metal envelopes would prohibit the use of small panels, due to the high edge losses but larger panels may be possible due to the increased edge to area ratios.

In the "one enclosure" design the edge losses are reduced by eliminating all but one edge. In this systern a metal envelope could be used with a variety of fills. This type of system does reduce the reliability of the insulation. One puncture or damaged seam would effectively ruin the insulation. 
Figure A-16: Effects of Enclosures on Evacuated Panels

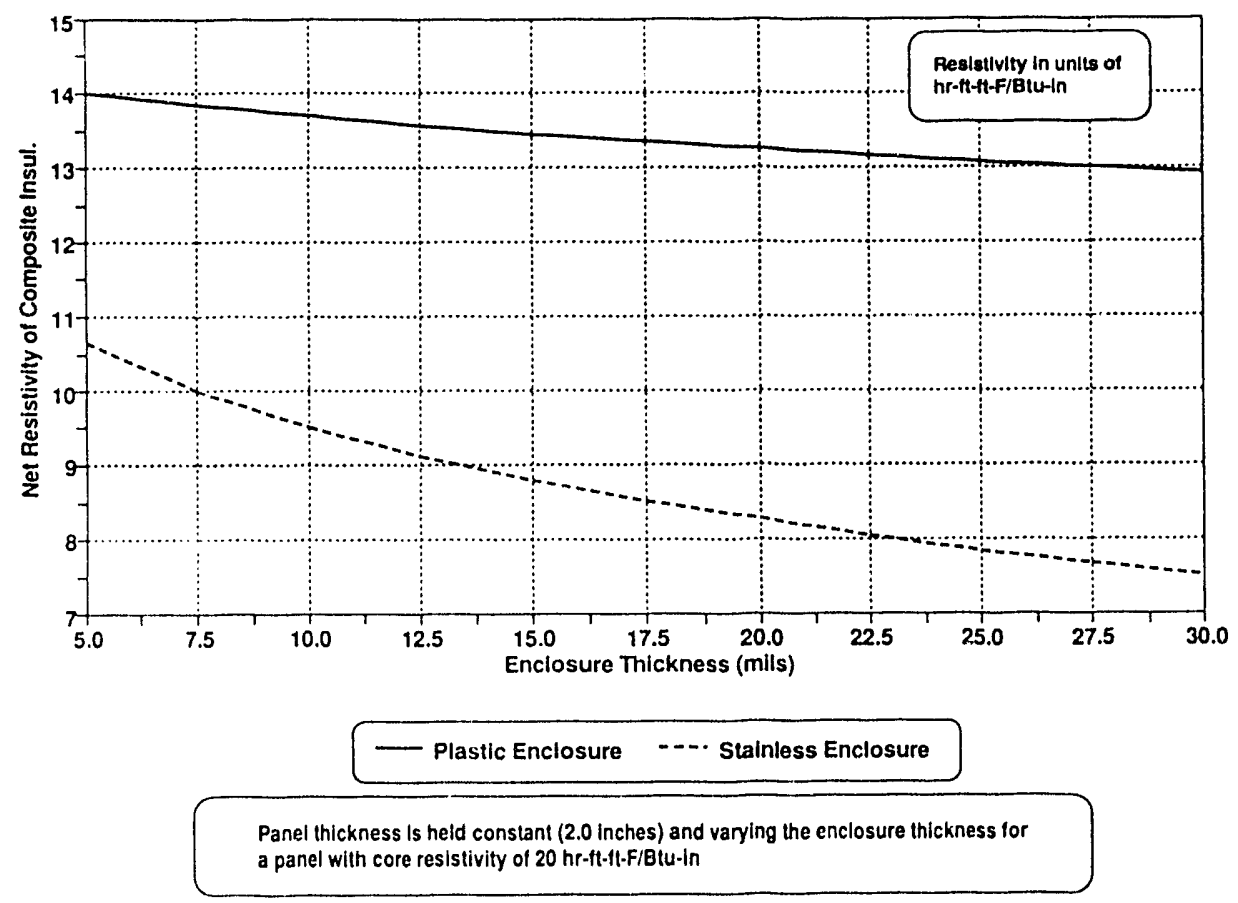

\section{A-4.4.1 Evacuated Foam}

The manufacture of open cell foam boards which have small cell sizes is a developed product. The practice of placing these boards in evacuated spaces for the purpose of increasing the R-value per inch to 18.0 to 20.0 in a vacuum of 0.01 to 0.1 torr has been demonstrated by R\&D but has not been used in full production [94]. Enclosure permeability is more demanding than with powder filled evacuated panels because a lower pressures must be maintained. The upper limit of $\mathrm{R}$-value per inch is limited to radiative plus solid conduction in conventional foams. Outgassing from foams may be a severe problem to overcome. Typically, the use of polymeric enclosures is proposed. Other enclosure materials include glass and metallic materials. Polymers as enclosures would provide a lightweight, low thermal conductivity enclosure which could sustain a vacuum for a limited number of years. 
The advantages of evacuated foam board include:

- Able to produce a board with small cell dimensions which reduces radiation heat transfer. For the demonstrated evacuated foam, cell sizes in the 100 to 350 micrometer range were achieved [94]. Typically foams in the 300 to 1000 micrometer range are formed.

- Low density insulation, on the order of 2.0 to $3.0 \mathrm{lbm} / \mathrm{cu}$. ft.

- Inexpensive fill material, on the order of $\$ 0.20$ per board foot.

Typical problems encountered with evacuated foam include:

- The outgassing of the foam in the required vacuum would affect the system in two fashions: i) increase the gas pressure within the enclosure substantially increasing gas conductivity, and ii) reduce the amount of foam material which would open up the cells.

- Due to lower required pressure, the envelope must have lower permeability which may make this type of insulation unattractive except where weight is an overriding concern. In cases where long duration insulation is not required this type of system may be plausible.

- Encapsulated open cell foam does not provide the required rigidity for supporting appliances and would, therefore, require additional structure, possibly a blown foam.

The evacuated foam insulation has a potential advantage over powder filled evacuated panels when the weight is of prime importance. The use of evacuated foam panels would be suitable for appliances (refrigerator/freezer, vending machines), transportation, retail refrigeration. The common factors in these applications are:

- Insulation requires high $\mathrm{R}$-value in a limited space.

- Insulation is primarily in flat sections which allows open cell board stock to be used. Possibility of foaming cylinders could provide a means of including water heaters in the list of applications.

- Lightweight insulation is advantageous either for saving transportation costs or for providing a lighter insulation system. A lighter insulation would allow the consumer to readily install the insulation or, in the case of use in an appliance, allow the consumer to more readily move the unit.

Evacuated foam panels would not likely be used in building applications since a single puncture would effectively reduce the R-value by five, i.e. a wall with 2 inches of evacuated foam would have a R-value of 40 while intact and an R-value of approximately 8 when punctured. The cost required to protect the insulation would be prohibitive. Also, the life of an evacuated panel would be less than is required for permanent home or commercial building insulation. 


\section{A-4.4.2 Evacuated Powder/Fiberglass Panels \\ Loose fill panels which include powders (precipitated silica, fumed silica, perlite, diatomaceous earth, fly-ash) or fiberglass are made by placing the fill into an enclosure which can sustain a vacuum level of lower than 10 Torr. The fill is compacted to the desired density thereby reducing the interstitial dimensions. As the interstitial spacing increases, a better vacuum (lower pressure) is required to maintain the high $\mathrm{R}$-values. The fill carries the compressive load set up by the atmospheric pressure. The entire system is then evacuated to the range of 0.01 to 0.001 Torr which allows for some degradation of the vacuum while still maintaining a $R$-value per inch in the range of 20 .}

Various organizations have developed panels and full housing systems which use powders and have R-values per inch in the range of 18 to 30 . The final R-value per inch depends on the enclosure system, internal pressure, interstitial dimensions, solid thermal conduction, solid to solid thermal conduction, and radiation heat transfer. One method to improve the $\mathrm{R}$-value per inch and reduce the vacuum requirement is to selectively mix fills so a smaller interstitial gap is formed. Finer fill materials result in a higher transition pressure allowing a more permeable and possibly less expensive barrier material. Also, the use of opacifiers is an option to further improve the thermal characteristics. Typically all of the fills are of low thermal conductivity and are selected so that line or point contacts exist between the various particles. This reduces the solid conduction.

The evacuated fiberglass systems can achieve resistivities of over 80 [73, 92]. The fiberglass tested consisted of board (pressed fibers with and without binders) and batts of fiberglass. The range of resistivities was 4 to 100 over a vacuum level of 0.025 Torr to 100 Torr. Typically at a vacuum of 0.02 Torr the evacuated fiberglass insulation began to level-off below 30. At this pressure the range of resistivities was 31 to 62.5 . The large range which exists is due to the different types of fiberglass which were tested (fiberglass diameter, bat board forming method), and compression prior to evacuation.

Since these types of insulation panels are significantly heavier, Table A-25 lists their densities, the structure has added requirements. The structural supports must be able to sustain the added mass including drop tests, vibration requirements, etc. An added problem, for appliances, of providing for consumer ease in safely moving the unit is present. For transportation, the increased weight translates to increased cost. In some new refrigerator designs with deeper doors, the increased wall mass may be useful to stabilize the refrigerator when the door is open.

The primary application for these systems would be in appliances (refrigerator/freezer, freezers, vending machines, water heaters), retail refrigeration and transportation systems. These applications can also benefit from the higher R-value per inch provided by evacuated panels. Substituting the vacuum panels for foam in refrigerators may require increased mechanical supports between the inside and outside walls for rigidity. 
Building applications would be possible if multiple panels were used. This could increase the reliability to the required level. Some protection for the insulation in building applications is required to avoid excessive damage. Also, the required life of the insulation is longer which requires extremely low permeation encapsulation material. The use of metal or glass encapsulated panels which do not cover large areas is possible but the edge losses may be too high for metal envelopes.

The use of evacuated loose fill insulation in transportation would increase the fuel requirements. The density of this type of insulation is typically in the 10.0 to $28.0 \mathrm{lbm} /$ cu. ft. range. The benefit of increased $R$-value per inch may not be offset sufficiently for refrigerated transport application but this needs to be evaluated.

\section{A-4.4.3 Evacuated Aerogel}

Aerogel panels can be made up of granular or monolithic fills. Both are formed by drying a gel at supercritical temperature and pressure. By following this procedure the remaining solid structure does not contract with the receding liquid meniscus tension. The final structure is then left with small pores with an overall shape of the mold. The most common material for aerogels is silica although other substances have been used. Due to the high porosity $(98 \%)$, the density is approximately $6 \mathrm{lbm} / \mathrm{ft}^{3}$ or less.

Evacuated aerogels require encapsulations but due to the smaller pore sizes, vacuum levels of 80 Torr are required to achieve a thermal resistivity of 20 . This is one order of magnitude higher than other evacuated systems which means that a similar enclosure system can be used.

$R$-value per inch of 20 have been achieved in small panels (does not include the effects of edge losses) and $R$-value per inch of up to 36 have been estimated when opacifiers were used. Typical opacifiers are carbon soot or titanium oxide. In a non-evacuated system aerogels still maintain a relatively high $\mathrm{R}$-value per inch, on the order of 7 to 15 [79].

The current panel sizes available from Thermalux, 14 inch by $14 \mathrm{inch}$, are limited by the available autoclaves. The shapes of the aerogels is limited by the mold which must be made.

Aerogels, due to the higher allowable pressure, has less of a issue with permeation. Evacuated aerogel's problem areas include:

- Water will dissolve the aerogels which could be a problem during the manufacturing of the panels. Thermalux claims to have an aerogel which provides the same thermal characteristics while not dissolving in water.

- Aerogels have limited strength and would require foam as support or other additional structure. The external pressure on the aerogel increases its rigidity. This does not eliminate the need for additional support structure. 
The use of evacuated aerogels (once the manufacturing and integration issues are resolved) would be suitable for appliances (refrigerator/freezer, water heaters, vending machines), transportation, retail refrigeration. The common factors in these applications
are:

- Insulation requires high $\mathrm{R}$-value in a limited space.

- Light weight insulation is advantageous either for saving transportation costs, increase consumer ease of handling.

Evacuated aerogels would not likely be used in building applications since a single puncture would effectively reduce the R-value, i.e. a wall with 2 inches of evacuated foam would have a $R$-value of 40 while intact and an R-value of approximately 14 when punctured. The cost required to protect the insulation would be prohibitively too high. Also, the life of an evacuated panel would be less than is required for permanent home or commercial building insulation.

\section{A-4.5 High Vacuum Insulation}

High vacuum insulation is similar to a thermos bottle system. The primary mode of heat transfer is radiation and conduction through some spacers. The proposed system used two sheets of stainless steel with low emissivity surfaces separated by glass beads and welded along the edges. A getter is included within the enclosure. The system is evacuated to below 1 microtorr. With the getter a vacuum level of $10^{-12}$ torr is estimated. At this pressure level no/minimal convective heat transport is present. The only modes of heat transfer are radiation, solid conduction through the spacers, and solid conduction through the edges. Table A-26 lists the CVI characteristics.

NERL (formally SERI) has produced panels with R-values of 5 in a 0.2 inch thickness and has a goal of producing panels with $R$-values of 10 to 15 in a 0.1 inch thickness (NOTE: These R-values are for measurements of the core section of the panels). The values reported by NERL are contested by various insulation experts and further testing by independent facilities is required.

High vacuum panels have a different set of problems than the other evacuated panels. These issues arise because of the requirement for metal encapsulation. Only metal will be able to sustain the required vacuum of better than $1 \mu$ torr. The issues with the high
vacuum panels include:

- High edge losses due to the required metal encapsulation. The use of stainless steel helps in reducing the edge losses. The core $\mathrm{R}$-value is not dependent on panel thickness since the dominant heat transfer mode is by radition. Additionally, the design of thicker panels (which would include longer heat transfer paths at the edges) may prove to be better for many applications. By using a thicker panel the edge losses are reduced and thinner material can be used with fewer spacers. Sagging of the enclosure must be controlled with a 0.1 inch panel. The deformation of the panels near the spacers will increase the heat transfer and lower the R-value. This 
Table A-26: Summary of High Vacuum Insulation

\begin{tabular}{|c|c|c|c|c|c|c|}
\hline $\begin{array}{c}\text { Primary } \\
\text { Insulation } \\
\text { System and } \\
\text { References }\end{array}$ & \begin{tabular}{|c|} 
Initial \\
R-value \\
and Thick \\
ness \\
(Edge \\
losses \\
are not \\
included) \\
(hroft' $0^{\circ} \mathrm{Fl}$ \\
Btu-in) \\
\end{tabular} & $\begin{array}{c}\text { Density } \\
\text { in Final } \\
\text { Form } \\
\left(1 \mathrm{bm} / \mathrm{ft}^{3}\right)\end{array}$ & $\begin{array}{l}\text { Required } \\
\text { Vacuum } \\
\text { (Torr) }\end{array}$ & $\begin{array}{c}\text { Encapsulation } \\
\text { or Barrier } \\
\text { Type }\end{array}$ & $\begin{array}{c}\text { Status of } \\
\text { Technology }\end{array}$ & $\begin{array}{c}\text { Flammability/ } \\
\text { Toxicity/ } \\
\text { Safety }\end{array}$ \\
\hline $\begin{array}{l}\text { CVI } \\
{[94,95,96,97,} \\
98]\end{array}$ & $\begin{array}{l}\text { R-value: } 5 \\
\text { thick: } 0.2 \\
\text { inches }\end{array}$ & 48 & $10^{-6}$ & metal & $\begin{array}{l}\text { SERI is building } \\
\text { and testing } R / F \\
\text { size panels in } \\
R / F \text {, edge losses } \\
\text { will have to be } \\
\text { reduced }\end{array}$ & $\begin{array}{l}\text { No toxicity or } \\
\text { flammability } \\
\text { issues. }\end{array}$ \\
\hline
\end{tabular}

may occur due to creep or mishandling. The cost benefits must be examined between thinner insulation and cost to manufacture. Using panels with a lower edge to area ratio also improve the panels overall $\mathrm{R}$-value.

- Requirement for a high vacuum due to the large spacing in the panels. Since the basic spacing is from one side to the other, 0.1 inch, the required vacuum is much higher than in other insulation. With thicker panels, the use of some type of multilayer sheets could be incorporated. Again the cost issues have to be examined.

- Unlikely to be competitive with alternative insulation applications except where volume is of overriding concern. Edge losses and the cost of the panels make them very unattractive in the current form.

Application to small systems (refrigerator/freezer, vending machines) would be difficult due to the edge losses. This type of insulation panel requires that the ratio of edges to area be reduced. Applications such as transportation or cylindrical systems (water heaters) are more likely.

The use of these systems would be possible in buildings if the panels could be protected from puncture. This being unlikely, the use of high vacuum insulation in buildings is small [99]. 


\section{References}

[1] Trane Company, "Alternate Refrigerants - The Safety Factor," CFC Update, Volume 8, July 1991.

[2] Merriam, R.L., and Mathias, S., "Evaluation of Advanced Vapor Compression Cycles for Use with Non-Azeotropic Refrigerant Mixture," report to the Oak Ridge National Laboratory, ORNL/Sub/86-22000C/1, January, 1988.

[3] Jakobs, R., and Kruse, H., "The Use of Non-Azeotropic Refrigerant Mixtures for Energy Saving," Proc, of Meeting of Commission 32, Int. Institute of Refrigeration, Draft, 1987.

[4] Cooper, W.D., "The Use of Mixed Refrigerants in Air-to-Air Heat Pumps," ASHRAE Transactions 1982, Vol. 88, 881.

[5] Vakil, H., "Thermodynamics of Heat Exchange in Refrigeration Cycles with Nonazeotropic Mixtures: Part I: Heat Exchange in Condenser and Evaporator; Part II: Suction Line Heat Exchange and Evaporative Cooling of Capillary," Proc. XVI International Congress of Refrigeration 5, (1963).

[6] Arora, C.P., "Power Savings in Refrigeration Machines Using Mixed Refrigerants," Proceedings XII International Congress Refrigeration, Madrid 2 (1967) 397-409.

[7] Haselden, G.G., and Klimch, K., "An Experimental Study of the Use of Mixed Refrigerants for Non-Isothermal Refrigeration," Proceedings Institute of Refrigeration, 65 (1957-58) 129-154.

[8] Mulroy, W., and Didion, D., "The Performance of a Conventional Residential Sized Heat Pump Operating with a Nonazeotropic Binary Refrigerant Mixture," NBSIR 860-3422, O Italy, 1986.

[9] Stoecker, W.F., "Improving the Energy Effectiveness of Domestic Refrigerators by the Application of Refrigerant Mixtures," report No. ORNL/Sub-78/55463/1, Oak Ridge National Laboratory, September, 1978.

[10] Lorenz, A., and Meutzner, K., "An Application of Nonazeotropic Two-Component Refrigerants in Domestic Refrigeration and Home Freezers," XIV International Congress of Refrigeration, Moscow, 1975.

[11] Pollard, J.H., "A New Household Refrigerator/Freezer Design with Three Major Advantages over Present Units," $42^{\text {nd }}$ IATC Conference, Madison, Wisconsin, 1991.

[12] Pollard, J.H., "A Household refrigerator Which Uses Refrigerant 22: Further Development of the LaBrecque Cycle," report prepared by University of Maine. 
[13] Gus, J.X., Tau, L.C., and Chin, Z.Q., "A New Compression/Injector Hybrid Cycle for Domestic Refrigeration," paper 142, XVIIIth International Congress of Refrigeration, Montreal Canada, August 10-17, 1991.

[14] Biermann, W., "To keep scaling at a reasonable level, only a fraction of the water passed over the evaporator pad is vaporized, typically about $20 \%$. A calculation with the psychometric chart for a system with $300 \mathrm{cfm}$ air flow, outside air at $95^{\circ} \mathrm{F}$ $\mathrm{db}, 70^{\circ} \mathrm{F}$ wb and cooled to $75^{\circ} \mathrm{F}$ db by evaporation of waicr, wiil require 1.5 $\mathrm{lbs} / \mathrm{min}$ water. If four times this much is rejected, i.e., $6 \mathrm{lbs} / \mathrm{minute}$, the water wastage will be 360 \#/hour, or 47 gallons per hour."

[15] Biermann, W., Claimed in sales brochure from Champion Cooler Corp. of El Paso, Texas. The Greenpeace "Survey of Alternatives to Ozone Destroying Technologies," Johnson and Noble (1990), also quotes similar claims by Albers Engineering Co., which offers a desiccant cooling system.

[16] McClellana, C.H., "Estimated Temperature Performance for Evaporative Cooling Systems in Five Locations in the United States," ASHRAE Trans. 94, Pt 2, 1988.

[17] McClellen, loc cit

[18] Kathabar Systems Division, Somerset Technologies, Inc., P.O. Box 791, New Brunswick, NJ 08903. Mr. William Griffiths, Chief Engineer

[19] "Data Collection and Model Development of Liquid Desiccant Integrated HVAC System at the Science Museum of Virginia," Gershon Meckler Associates. DOE Contract No. DE-AC03-84SF15256, 1985.

[20] Some of the programs relevant to liquid dehumidification, which were administered out of the Oakland Office of DOE during the middle 1980s were:

Z. Lavan, Open Cycle Desiccant Cooling materials, components, and systems. At Illinois Institute of Technology.

Byard Wood, Kirk Collier. Solar driven, open cycle, absorption cooling. At Arizona State University.

George Lof, S. Karaki, and many coworkers. Developed a three ton, open cycle, chiller using packed column contactors. Much of the simulation work would be directly applicable to areas of this report.

Argonne National Laboratory - dehumidification materials.

[21] A now expired patent by W.J. Biermann (U.S. 3,793,171) teaches the use of a strong sulfuric acid solution containing an easily regenerable oxidizing material for removing impurities and restoring air quality. This would permit simultaneous 
dehumidification and air quality control, which would further save energy by reducing the need for induced air. The technology was reduced to practice in two commercial installations.

[22] Munters is marketing, with some success, a desiccant wheel for supermarket use, under the name "Cargo Care".

[23] "Open Cycle Lithium Chloride Cooling System," Lenz, T., Lof, G.O., Wenger, J., Iyer, R., Kaushik, V., and Sandell, G., Report SAN-11929-17, Colorado State University, April 1985 for Packed Column regenerator.

[24] Mathematical modelling of liquid desiccant systems was done at the University of Wisconsin under Dr. Sanford Klein. This work was reported as the Ph.D. thesis of Frederick Sick, 1986.

[25] "High COP Rotating Wheel Solid Desiccant System," Macriss, R., and Zawacki, T. 9 Energy Technology Conference, February 1982. Washington D.C.

[26] "Field Development of a Desiccant-Based Space Conditioning System for Supermarket Applications," Cohen, B.M., Levine, A.H., and Arora, R., Thermo Electron Corporation, Waltham, MA, 1983.

[27] "Operational Experience with a Liquid Desiccant Heating and Cooling System," Robison, H., 18 ${ }_{\mathrm{ut}}$ IECEC, 1952.

[28] "The Development of Free Piston Duplex Stirling Heat Pumps," Kawasaki Heavy Industries, Ltd., Japan, Proceedings of International Symposium on the Stirling Engine and Its Application to Heat Pump Systems, Tokyo (1986).

[29] "Duplex Stirling Heating-Only Gas-Fired Heat Pump - Final Report," Sunpower, Athens, Ohio 45701, Gas Research Institute, Contract No. 5081-341-0464.

[30] Fallon, J., "High Temperature Brayton Cycle Heat Pumps," Report DOE-C.S.-40005-T2 (1981)

[31] Mills, J.I., Chappell, R.N., "Advanced Mechanical Heat Pump Technologies for Industrial Applications," Report DE85-014613 (1985)

[32] Gigiel, A.J., AFRC Institute of Food Research, Bristol Laboratory, U.K., per H. Kruse, Private Communication. See also Giguel, A.J., "Is Air a Viable Alternative Refrigerant" ATRAGH Journal 44, 26-32 (1990).

[33] Granryd, E., Kungl. Teknisha, Hogskolen;Mekanisk Varmeteori ock Kylteknik, 100044 Stockholm, Sweden, per H. Kruse, Private Communication.

[34] Henatsch, A., Hochschule fur Verkehrswesen "Freidrick List, Dresden, Germany, per H. Kruse, Private Communication. 
[35] Kruse, H., Institute of Refrigeration, University of Hannover, 3000 Hannover 1, Germany, Private Communication, (H. Kruse is a member of the program expert team).

[36] Brown, G.V. "Magnetic Heat Pumping Near Room Temperature," J. App. Physics 47,8 (1975).

[37] Barclay, J.A., and Steyert, W.A., "Magnetic Refrigerator Development," Final Report prepared by LANL for EPRI (1981).

[38] Kirol, L.D., Mills, J.I., Fullurer, K.S., Zabriske, J.N., "Magnetic Heat Pump Feasibility Assessment," Prepared for DOE by EG\&G Idaho, Contract No. DE-AC07-761D01570 (1984).

[39] Clen, F.C., Hsu, C.T., "Performance of Ejector Heat Pumps," Energy Research, 11,289 (1987)

[40] Hamner, R.M., "An Investigation of an Ejector-Compression Refrigeration Cycle and its Applications to Heating, Cooling, and Energy Conservation," Ph.D. Thesis, University of Alabama (1978)

[41] Swift, G.W., "Thermoacoustic Engines," J. Acoust. Soc. Am., 84 (4), 1145 (1988)

[42] T. Hofler, "Thermoacoustic Refrigerator Design and Development," Ph.D. dissertation, Physics Dept., University of California at San Diego (1986)

[43] Ranque, G.J., United States Patent No. 1,952,281 (1934)

[44] Hilsch, R., Rev. Sci Instr., 18, 18 (1947)

[45] Vortec Corporation, General Catalog (1991)

[46] W.E. Gifford and R.C. Longsworth, "Surface Heat Pumping," Adv. Cryogenic Eng, 11, 171 (1966)

[47] E.I. Mikulin, A.A. Tarasov, and M.P. Shkrebyonock, "Low Temperature Expansion Pulse Tubes," Adv. Cryog. Eng. 29, 629 (1984)

[48] R. Radebaugh, J. Zimmerman, O.R. Smith, and B. Louie, "A Comparison of Three Types of Pulse Tube Refrigerators: New Methods for Reaching 60K," Adv. Cryog. Eng. 31, 779 (1986).

[49] R. Radebaugh, "Pulse Tube Refrigeration - A New Type of Cryocooler," Proc. 18th Int. Conf. on Low Temp. Physics, Kyoto (1987).

[50] Malone, J.F.J., "Heat Engine," U.S. Patent No. 1,487,664 (1924)

[51] Malone, J.F.J., "Heat Engine Operated by the Expansion of Liquids," U.S. Patent No. $1,717,161$ (1929) 
[52] Malone, J.F.J., "A New Prime Mover," Journal of the Royal Society of Astor, London England 79,679 (1931)

[53] Swift, G.W., "A Stirling Engine with a Liquid Working Substance," J. App. Phy. 65, 4157 (1989)

[54] Swift, G.W., "Malone Refrigeration," ASHRAE Journal 32, 28 (1990)

[55] "A Survey of Alternatives to Ozone Destroying Technologies," Greenpeace International, 1990.

[56] Bristol Compressor Co., Bristol, VA

[57] Melcor Catalog, Trenton, N.J.

[58] Woods, G., "The ICI Polyurethanes Book," John Wiley \& Sons, New York, 1990.

[59] The UNEP Foam Technical Options Committee, "Technical Progress on Protecting the Ozone Layer, Flexible and Rigid Foams Technical Options Report," June 30, 1989.

[60] Lawrence, W.T. and Ruccia F.E., "Development of Advanced Insulation for Appliances: Task 1," ORNL/Sub-81/13800/1, Oak Ridge National Laboratory, Oak Ridge, TN, June 1981.

[61] Fine, J.A., "Advanced Evacuated Thermal Insultations: The State of the Art," Journal of Thermal Insulation Volume 12, January 1989.

[62] Fricke, J., et.al., "Opaque Silica Acrogel Insulation as Substitutes for Polyurethane (PU) Foams," $21^{\text {st }}$ International Thermal Conduction Conference, Lexington, Kentucky, October 1989.

[63] McElroy, D.L., and Scofield, M.P., "Chlorofluorocarbon (CFC) Technologies Review of Foamed-Board Insulation for Buildings," ORNL/TM-11291, March 1990.

[64] Fischer, S.K., and Creswick, F.A., "Energy Use Impact of Chlorofluorocarbon Alternatives," ORNL/CON-273, prepared for the U.S. Department of Energy under Contract No. DE-AC05-84OR21400, February 1989.

[65] Dietrich, K.W., and Doerge, H.P., "Performance of Alternative Chlorofluorocarbons in Rigid Urethane Appliance Foams," Proceedings of the SPI 31st Annual Technical/Marketing Conference, March 7, 1989.

[66] Correspondence from Dr. Richard M. Minday of 3M to David McElroy of ORNL, March 11, 1991.

[67] Ingwalson, J., Manville, personal communication with J. Aguilar, Arthur D. Little, Inc., March 1990. 
[68] Dishart, K.T., and Ascough, M.R., "The duPont Program on Fluorocarbon Alternative Blowing Agents for Polyurethane Foams," Polyurethanes World Congress 1987, September 29 - October 2, 1987.

[69] Parsons, Roberi, A., Ed., "1989 ASHRAE Handbook Fundamentals, I-P Edition, American Society of Heating, Refrigeration, and Air Conditioning Engineers, Inc., 1989.

[70] Montreal Conference, Insulation Review Meeting, August 12-13, 1991.

[71] Department of Energy (DOE), Insulation Fact Sheet, DOE/CE-0180, January 1988.

[72] Rennex, Brian, and Somers, T., ".Apparent-Thermal Conductivity Characterization of Low Density, Glass-Fiber Insulation Material," Journal of Thermal Insulation Volume 8, January 1985.

[73] Young, J.R., and Schreck, R.M., "Vacuum Thermal Insulation Panel," U.S. Patent 4,444,821, April 24, 1984.

[74] Dodd, R.A., "The Key Issues in Reducing CFC-11 in Polyurethane Foam Insulation for Household Refrigerator/Freezers," Submitted for ASHRAE Transactions 1990, Volume 96, pt. 1, 1990.

[75] Mitchell, B.S., ar:: Koutsky, J.A., "Binder Droplet-Fiber Interactions in the Production of Thermal Insulations," Journal of Thermal Insulation, Volume 15, July 1991.

[76] Thermalux, "Silica Aerogel: Physical Properties," Literature provided to J. Aguilar, Arthur D. Little, Inc. in 1989

[77] Thermalux, "The.malux Fact Sheet," Literature provided to J. Aguilar, Arthur D. Little, Inc. in 1984, August 15, 1989.

[78] Ramamurthi, S., Battelle, private communication with Aguilar, J.L., Arthur D. Little, Inc., May 1991.

[79] Lu, X., et.al., "Thermal Transport in Opacified Monolithic Silica Aerogels," Report E21-0790-6, September 1990, ECTP Vienna.

[80] Buttner, D., Hummer, E., and Fricke, J., "Thermal Conductivity of Granular $\mathrm{iO}_{2}$ Aerogels," Aerogels, Proceedings of the First International Symposium, Wurzburg, Fed. Rep. of Germany, September 23-25, 1985.

[81] "Inorganic and Organic Aerogels," Materials Research Society Bulletin, Volume XV, Number 12, pp. 3i-37, December 1990. 
[82] '"Frozen Smoke" and Other Insubstantials: The Development of Aerogels at LLNL,' Energy \& Technology Review, Published by Lawrence Livermore National Laboratory, January 1991.

[83] Correspondence between D. McElroy of ORNL and B. Griffith and D. Aresteh of Lawrence Berkeley Laboratory which included test results of High-R gas panels, January 10, 1991.

[84] Arasteh, Dariush, et.al., "Super-Insulating Gas-Fired Panels" (draft version), Lawrence Berkeley Laboratory, LBL-29401, August 1990.

[85] Kruck, R.W. and Cur, O.N., "Heavy Gas-Filled Multilayer Insulation Panels," U.S. Patent 4,808,457, February 28, 1989.

[86] Phillip, B.L., "Innovative Thermal Superińsulation for Refrigerators," DOE SBIR Solicitation 15793, Enhanced Insulations, Inc., March 1991.

[87] Barito, R.W. and Downs, K.L., "Precipitated Silica Insulation," U.S. Patent 4,636,415, January 13, 1987.

[88] Barito, R.W. and Downs, K.L., "Insulation Formed of Precipitated Silica and Fly Ash," U.S. Patent 4,681,788, July 21, 1987.

[89] Yoneno, H., "Powder-Filled Evaculated Thermal Insulation Panel," New Materials and New Processes, Volume 3, 1985.

[90] Schilf, L., "Thermal Insulation of Vessels and Method of Fabrication," U.S. Patent 4,349,051, September 14, 1982.

[91] Schilf, L., "Method of Thermally Insulating Vessels," U.S. Patent 4,417,382, November 29, 1983.

[92] Fay, R.M., "Fibrer Glass for Use in Evacuated Thermal Insulations," Journal of Thermal Insulation, Volume 14, January 1991, pp. 195-210.

[93] Uekado, K. and Odada, K., "Heat Insulating Body," U.S. Patent 4,668,555, May 26, 1987.

[94] "Compact Vacuum Insulation," Solar Energy Rescarch Institute Highlight, Thermal Sciences, 1989.

[95] Correspondence between Potter, T.F. of SERI and Statt, T. of the U.S. Department of Energy, May 1, 1989.

[96] Progress report from T. Potter which includes a "Summary Report on the June Meeting of SERI's CVI Industry Review Panel," (meeting held on June 15, 1989), August 17, 1989. 
[97] "Summary of the January 1990 Meeting of SERI's Compact Vacuum Insulation (CVI) Industry Review Panel for Refrigerator/Freezer Applications," Held at SERI, Golden, Colorado, March 30, 1990.

[98] "Summary of the June 1990 Meeting of SERI's Compact Vacuum Insulation (CVI) Industry Review Parel for Refrigerator/Freezer Applications," Held at SERI, Golden, Colorado, August 2, 1990.

[99] Montreal Protocol 1991 Assessment, "Technical Progress on Protecting the Ozone Layer, Refrigeration, Air Conditioning, and Heat Pumps," Technical Option Committee, RWR-570-LK-91423-al, December 1991. 
Appendix B

Domestic Refrigeration 
Table of Contents

Appendix B Domestic Refrigeration

B-1

B-1 State-of-the-Art

B-1

B-2 Substitute Options

B-3

B-2.1 Energy Usage in Current Refrigerators

B-3

B-2.2 Vapor Compression Cycle Losses

B-4

B-3 Recent and Current Research and Development

B-8 


\section{B-1 State-of-the-Art}

A refrigerator/freezer is an essential household appliance which serves to preserve both fresh and frozen food and to provide conveniences such as ice. Typical construction consists of a sheet metal outer enclosure with a thermoformed plastic inner liner. The space between the two is filled with insulation, typically a rigid polyurethane foam. The foam is critical to two aspects of product design--efficiency and strength.

The refrigerator cycle consists of four major elements: the compressor, condenser, expansion device, and evaporator(s). Many cabinet-cycle configurations are available, including: top-mount refrigerator (freezer section on the top), bottom-mount refrigerator/freezer, side-by-side refrigerator/freezer, single door refrigerator with freezer box, chest freezer, and upright freezer. Additional configurations refer to the method of defrost and to the presence of other convenience features such as through-the-door cold water and/or ice.

The typical American refrigerator/freezer has about $18 \mathrm{cu}-\mathrm{ft}$. total storage, and uses a fan-forced single evaporator in the freezer compartment with a baffle arrangement to direct some of the refirigerated air to the fresh food section. Typical European and Asian designs have a smaller total food storage volumes and use two evaporators, in natural convection heat exchange with the air in each cabinet section.

CFCs are currently used in virtually all refrigerators, in both the insulation foam and the refrigeration loop. CFC- 11 is used as a blowing agent to create the polyurethane foam. The foam is poured, into the space between the inner and outer liners, in liquid form where it expands due to chemical reaction and fills all the space, after which it cures to form a rigid multi-celled matrix containing CFC-11 gas entrapped in the cells and having a very low heat conductivity. Replacement of fiberglass insulation by polyurethane foam has been a major contributing factor in a substantial reduction in annual energy consumption over the past decade of refrigerator/freezer design development. Further discussion of alternatives to CFC foam is given in Appendix F of this report.

CFC-12 is normally used in the refrigeration loop. Until the advent of concern over the ozone depletion processes contributed to by CFCs, CFC- 12 was considered an ideal refrigerant from nearly all points of view. In particular, it is non-flammable, non-toxic, has a boiling point slightly below normal freezer conditions allowing above atmospheric pressures in the evaporator, is compatible with most plastics and is suitable for use with mineral oils. Replacement of this refrigerant with another will have impacts in all these areas, including efficiency, which may require cycle modification. 
Efficiency improvements have been made continuously over the past several decades (see Figure B-1) [1]. A 1990 typical $18 \mathrm{cu}$-ft. top mount unit uses about $900 \mathrm{kWh}$ /year, a drop of almost $50 \%$ from the 1972 design. Current legislation requires a maximum consumption of about $690 \mathrm{kWh}$ year starting in 1993. Consideration is underway to further reduce the consumption to the $400-500 \mathrm{kWh} /$ year range in 1998.

Figure B-1: Annual Average Energy Use for Refrigerator/Freezers

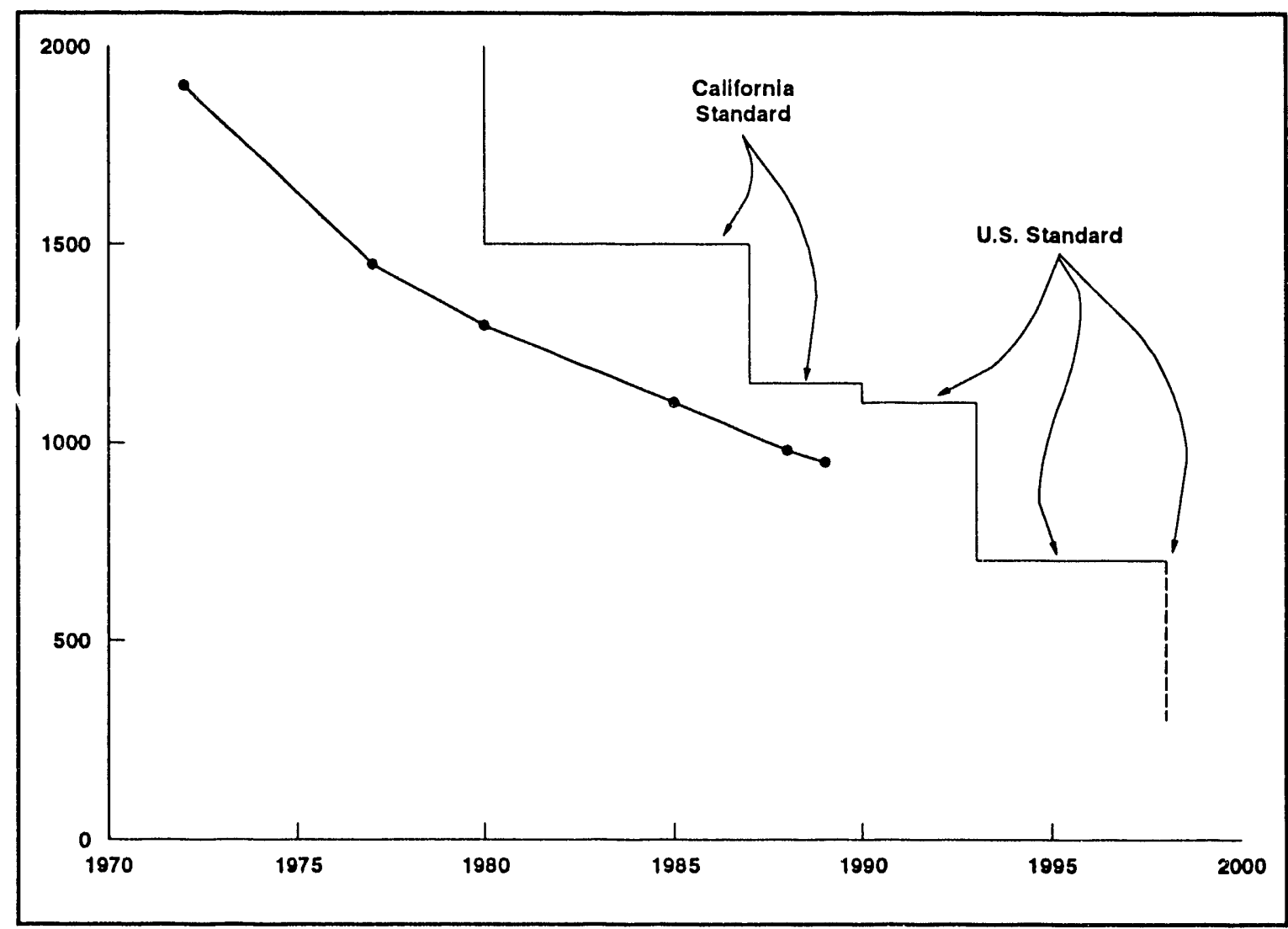

Source: Reference 1.

The 1993 model American refrigerators will probably all continue to use CFC-11 blown foam in the insulation and CFC-12 as the refrigerant. However, starting around 1995, CFCs will be phased out of refrigeraiors, with total phase out completed by 1998 . The required use of alternative fluids for the insulation blowing agent and the refrigeration loop will lead to slight degradation in overall energy efficiency, which must be compensated by improvements in component efficiency, and/or by cycle modification. European manufacturers appear headed toward use of HFC-134a as the refrigerant. Decisions have not yet been made in the U.S. and Asia, but HFC-134a is probably the leading near-term refrigerant replacement candidate. Acceptable replacements for CFC-11 as an insulation blowing agent are less clear. 
The American market is currently dominated by five organizations: General Electric, Whirlpool, Electrolux (WCI), Admiral, and Amana, with an annual production near 8 million units. Within this cost-sensitive, very competitive market, much of the research takes place internally, with some industry-wide shared research funded through an industry consortium (AHAM).

Up to this point in time, the research has focussed on incremental changes in components required to meet the energy standards at the minimum cost. Significant advances have taken place in compressor efficiency, fan energy reduction, minimization or elimination of electrical resistance anti-sweat heaters, and improvements in heat exchanger design. It is likely that additional energy reductions are available through use of more costly "off-the-shelf" components or through further incremental improvements in component design. Development and adoption of these component technologies will take place by private industry, both here and abroad, with or without government research. Cost and reliability will remain a dominant factor in the adoption of all future technology. Other factors that will be retained to the extent possible are user-convenience attributes, such as a large food storage area, automatic defrost, quiet operation, rapid pulldown, moisture control, and good temperature control.

\section{B-2 Substitute Options}

\section{B-2.1 Energy Usage in Current Refrigerators}

A very simple way to address the issue of overall energy usage in a refrigerator/freezer is to consider it as determined by four factors: 1) cabinet loads, 2) internal heat loads, 3 ) refrigeration cycle efficiency, and 4) auxiliary energy.

$$
\mathrm{E}=\frac{\text { Cabinet }+ \text { Internal }}{\mathrm{COP}}+\text { Auxiliary }
$$

To a first order, these factors are independent of one another. However, some subtle relationships may hold, such as:

- Fans are used to improve heat exchanger performance, thereby increasing the cycle efficiency. The fan energy is both an internal load, which must be removed by the refrigeration system, and an auxiliary electric power.

- Superheated gas from the compressor can be used to replace electric anti-sweat heat. A portion of this heat could enter the cabinet, the degree depending on how the tubing is routed and on details relating to the structure holding the foam in place near the door. This heat is an internal load.

- Defrost energy, which consumes auxiliary electrical power and is an internal load. Adaptive defrost techniques seek to minimize the load by activating defrost only when necessary. 
It is noted that under the DOE $90^{\circ} \mathrm{F}$ closed door test conditions defrost activation is normally on a timer basis, whereas in actual use in a residence, the refrigerator doors will normally be opened many times over the course of a day, thereby introducing moisture into the cabinet. Testing at $90^{\circ} \mathrm{F}$, rather than at normal room temperature, is intended to account for the additional energy use associated with moisture input. However, some cycles inherently will require less defrost energy use in normal operation; this difference in defrost will not be recognized by the current closed door test protocol.

Reduction in cabinet loads through increased insulation or better gasket designs is discussed in Appendix F. Reduction of internal loads is primarily the subject of near-term $R \& D$ and/or component selection, rather than longer-term $R \& D$ which is the object of this study. For example, more efficient fans are available now (at a higher cost) or will become available from industry research. Hence, the focus will be on components and cycles that will maximize the COP term appearing in Equation B-1.

\section{B-2.2 Vapor Compression Cycle Losses}

Table B-1 summarizes the major loss mechanisms in a typical vapor compression cycle refrigerator/freezer. Research aimed at improving the vapor compression cycle focuses on reducing these loss mechanisms; research into alternate cycles aims at avoiding some of the losses by use of a different cycle strategy.

For each loss mechanism identified in Table B-1, potential means of reducing the loss are listed along with a judgement concerning whether the technology can be available in the near term or whether it requires long-term $R \& D$, the focus of this report.

Efficiency losses in the evaporator and condenser are associated with finite temperature differences between the refrigerant and the air, with pressure drop, and with reduction in heat transfer due to oil circulating with the refrigerant. Maximization of heat transfer along with minimization of pressure drop is largely a matter of performance - cost tradeoffs where the technology is well understood and with probably little role for DOE sponsored long-term R\&D.

An attribute of the Lorenz cycle is the potential for reducing the heat exchanger irreversibilities by counter-flow heat exchange with an attempted matching of the temperature glides of the two fluids in heat exchange. Here, the Lorenz cycle is considered as a variation of the vapor compression cycle, rather than an "alternate" cycle. A judgement is made that Lorenz cycle technology is near-term R\&D since much has already been done by government (EPA/DOE) and in private industry. The main issues for the cycle are: achieving cost effective, efficient means of control of the cycle (matching the individual evaporator capacities to the cabinet loads), use of efficient components, proper selection of the fluids, approximation to counter-flow heat exchange, and integration into the cabinet. Selection of the refrigerant mixture will probably be impacted by the results of long-term $R \& D$ into alternate refrigerants. 
Table B-1: Loss Mechanisms in Refrigerator/Freezer Vapor Compression Cycle

\begin{tabular}{|c|c|c|c|c|}
\hline \multirow{2}{*}{ Component } & \multicolumn{2}{|c|}{ 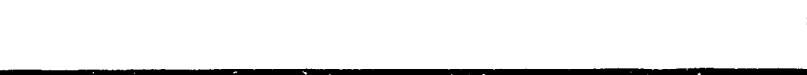 } & \multicolumn{2}{|c|}{ Primary R\&D Time Frame } \\
\hline & Loss Mechanisms & $\begin{array}{c}\text { Potential Approaches to } \\
\text { Reduce Loss }\end{array}$ & Short-Term & Long-Term \\
\hline \multirow[t]{3}{*}{$\begin{array}{l}\text { Evaporator and } \\
\text { Compressor }\end{array}$} & $\begin{array}{l}\text { Temperature difference } \\
\text { between refrigerant and air }\end{array}$ & $\begin{array}{l}\text { Improved HX design } \\
\text { Counter-flow design } \\
\text { Lorenz cycle }\end{array}$ & : & \\
\hline & Pressure Drops & $\mathrm{HX}$ design optimization & $\cdot$ & \\
\hline & Heat transfer resistance & Oil-free compressor & & - \\
\hline Expansion Loss & $\begin{array}{l}\text { "Work of Expansion" } \\
\text { unused }\end{array}$ & Method to extract work & No & $\begin{array}{l}\text { Unlikely to } \\
\text { implement }\end{array}$ \\
\hline \multirow[t]{4}{*}{ Compressor } & Large pressure ratio & $\begin{array}{l}\text { Two separate loops } \\
\text { Dual evaporator with } \\
\text { switching valve } \\
\text { LaBrecque cycle } \\
\text { Two-stage cornpressors } \\
\text { Hybrid } \\
\text { compression/injector }\end{array}$ & $\begin{array}{l}\text { Industry } \\
\text { Industry }\end{array}$ & Industry \\
\hline & Internal losses & $\begin{array}{l}\text { High efficiency motors } \\
\text { Improved lubricants } \\
\text { Reduced suction gas heat } \\
\text { Oil-free compressors } \\
\text { New compression concept } \\
\end{array}$ & $\begin{array}{l}\text { Industry } \\
\text { Industry } \\
\text { Industry }\end{array}$ & $\begin{array}{l}\text { Industry } \\
\text { Industry } \\
\text { Industry } \\
\end{array}$ \\
\hline & Dimensional changes & Low expansion materials & & $\cdot$ \\
\hline & $\begin{array}{l}\text { Internal pressure drops and } \\
\text { refrigerant leakage past } \\
\text { displacer }\end{array}$ & New compressor concept & & • \\
\hline System & Cycling losses & $\begin{array}{l}\text { Shut-off valve to restrict } \\
\text { refrigerant migration } \\
\text { Thermal storage heat } \\
\text { exchangers } \\
\text { Variable speed electronics }\end{array}$ & Industry & Industry \\
\hline \multirow[t]{2}{*}{ Refrigerant } & $\begin{array}{l}\text { Incompatibility with } \\
\text { materials (e.g., } \mathrm{NH}_{3} \text { ) }\end{array}$ & $\begin{array}{l}\text { Alternate materials (e.g., } \\
\text { motor with aluminium } \\
\text { windings) }\end{array}$ & & • \\
\hline & Poor compressor behavior & $\begin{array}{l}\text { Optimize compressor } \\
\text { design for refrigerant } \\
\text { Improved lubricant }\end{array}$ & $\begin{array}{l}\text { Industry } \\
\text { Industry }\end{array}$ & $\begin{array}{l}\text { Industry } \\
\text { Industry }\end{array}$ \\
\hline Cycle & $\begin{array}{l}\text { Departure from Carnot } \\
\text { cycle }\end{array}$ & $\begin{array}{l}\text { Alternate vapor } \\
\text { compression cycles } \\
\text { Stirling Engine } \\
\text { Liquid absorption } \\
\text { Metal hydride } \\
\text { Thermal acoustic } \\
\end{array}$ & : & $\begin{array}{l}\bullet \\
\bullet \\
\bullet\end{array}$ \\
\hline
\end{tabular}

Heat exchanger heat transfer resistance is affected by mass-transfer effects associated with differences in the compositions in the liquid and gas phases of a mixture, and by the presence of oil in the refrigerant. Enhancement of heat transfer in the presence of refrigerant blends is judged a near-term $R \& D$ agenda; elimination of oil in the circulating refrigerant by use of an oil-free compressor is a long-term R\&D agenda item (there are other reasons as well for R\&D into oil-free compressors). 
The refrigerant expansion in a capillary tube involves a non-reversible process, with an attendant potential work loss (approximately 10\%). To recover this loss would require a mechanism such as a miniature turbine or staged expansion with vapor extraction. Most industry personnel and other researchers consider it unlikely that such a mechanism would ever be implemented in a domestic refrigerator, and for this application, this is not a candidate for long-term R\&D.

The compressor is the heart of the refrigeration system. Losses here directly affect the overall efficiency of the refrigerator. Mechanisms for compression inefficiency include: motor losses, suction gas heating, bearing losses, suction port and discharge port pressure drops, gas blow-by, and non-isothermal compression. The magnitudes of most of these losses are related to the pressure ratio across the compressor.

One means of reducing the effects of compression inefficiency is by altering the cycle to reduce the pressure ratio, such as by using two separate refrigerant circulation loops, a dual evaporator cycle with a switching valve to alternately connect the compressor and condenser to one evaporator (e.g., freezer), and then to the other (e.g., fresh food) as required to meet the cabinet loads, a two-stage compressor, or the hybrid compression/injection cycle discussion in Appendix F. Most of these will be undertiken by industry in either the near-term or long-term, with little need for involvement by DOE. The two cycles that are likely not be undertaken very seriously by industry are the LaBrecque cycle and the hybrid compression/ejector cycle, because of added cycle complexity and the availability of alternate means of accomplishing a similar purpose at a low cost.

A direct means of reducing compressor losses is offered by use of higher efficiency electric motors, improved lubricants and reduced suction gas heating. Each of these is being undertaken by industry, not requiring long-term DOE R\&D involvement.

Development of an oil-free compressor could provide a means of eliminating the effects of lubricants on compressor behavior with different refrigerants. This is a high technical risk undertaking. Another long-term R\&D project would be developmen expansion materials for use in the compressor to ensure controlled tight clearances and reduced friction losses over the operating temperature range of the compressor.

According to Arthur D. Little estimates for a reciprocating compressor (based on work performed for the U.S. EPA), friction losses correspond to about $8-10 \%$ of the compressor inefficiency while gas leakage corresponds to about $1 \%$ to $2 \%$ of the inefficiency; in a rotary compressor gas leakage losses are about $5 \%$. Thermally dimensional stable materials could help reduce these losses.

The long-term options for compressors in domestic refrigeration applications seem restricted to the reciprocating and rotary (rolling piston) type designs. It is unlikely that scroll compressor technology could be successfully applied in the overall capacity range associated with current refrigerators, and even less likely with future designs, employing advanced cabinets, that will require even smaller compressor. A potential long-term $\mathrm{R} \& \mathrm{D}$ agenda item is a new compressor concept that does not require the tight tolerances of the scroll concept. 
Cycling losses can contribute to approximately $2-5 \%$ of the energy input $[2,3]$. These losses arise during the off-cycle from: (1) refrigerant liquid migration from the high pressure condenser to the low pressure evaporator; (2) heat exchanger temperature cycling; and (3) refrigerant flashing at the condenser exit at the initiation of the off cycle. This flashing can actually lower the refrigerant temperature at the condenser exit below the ambient, thereby contributing to the cooling of the condenser.

At least three methods can be employed to reduce cycling losses: (1) use of a shut-off valve to isolate the low and high pressure regions during off-cycle; (2) employment of thermally massive heat exchangers; and (3) use of variable speed compressor (and fan) operation to minimize the incidence of cycling. Implementation of any of these measures can lead to very substantial energy savings, $15-20 \%[2,4]$.

Incorporation of a shut-off valve is current practice in some Japanese refrigerators using a rotary compressor. To gain the full thermodynamic benefit the controls should be set to cause frequent cycling of the compressor [3]. The technology has been demonstrated, therefore, not requiring long-term $R \& D$ inputs from DOE.

Thermally massive heat exchangers should provide a similar thermodynamic advantage as variable speed control--limitation of the pressure ratio across the compressor to a level intermediate between the minimum and maximum pressure ratios experienced during compression cycle in a standard design. At least one researcher has built a prototype with a more massive evaporator and condenser [5]. However, to facilitate wide-spread introduction into American model refrigerators, long-term R\&D could fruitfully be carried out in this area. That is, it is not clear whether this technology, or the compressor variable speed electronics technology, would be the most cost effective approach. At present, there appears to be a lower level of interest in the use of more massive heat exchangers.

The third approach to reduce cycle losses is offered by variable speed electronics. Successful implementation will require significant first cost reduction and use of very efficient fans (DC motors). This work is currently being undertaken by industry, providing little opportunity for impact of long-term DOE sponsored research.

The choice of refrigerants will affect the thermodynamic operating parameters, issues relating to thammability, compatibility with commonly used electronics and motor winding, and lubricity in the compressor. Table B-1 (shown earlier) lists some potential loss related issues.

Materials incompatibility may affect ti ange of refrigerants that can be used in the design. Most of these issues are now being addressed by industry (e.g., seals, filters, driers, etc.). One potential research area identified for a long-term DOE role is the development of hermetic compressors for ammonia heat transfer loop application. This would involve replacement of currently used motor windings with a material compatible with the ammonia refrigerant, such as aluminum, without a substantial loss in motor efficiency. 
A number of efforts are currently underway to study the behavior of compressors with alternate refrigerants. This work is largely being carried out by industry and universities and requires little long-term involvement by DOE. Design of improved compressors optimized for specific refrigerants is an industry function, as is the development of improved lubricants.

As listed in Table B-1, alternate cycles include advanced vapor compression designs (Lorenz, dual loop, multiple evaporators), Stirling cycle, liquid absorption, metal hydride solid absorption cycles, and thermal acoustic. Each of these technology areas has been described in Appendix A.

Long-term DOE R\&D role in alternative vapor compression cycles is needed. For example, although the technology of the Lorenz cycle is by now well understood, the impact of new fluids developed in the long-term would require additional cycle optimization and testing.

Stirling cycle development is being undertaken at various research laboratories throughout the world. Laboratory testing and analyses have shown some potential for energy efficient applications in domestic refrigeration $[6,7]$. Areas requiring long-term R\&D include improved small heat exchangers, regenerators, gas bearings, and improved drive mechanisms. According to computer model analyses [5], compression COP values in the range of 1.5 to 2.0 are feasible targets. This compares with current refrigerator vapor compression COPs near 1 to 1.4; advanced vapor compression cycle COP values could be in the range of 1.6 to 2.().

Liquid absorption refrigerators are widely used in Europe. They are typically of small storage volume, and are used in hotels or in mobile homes. The primary energy source is fuel (gas or propane). Most of the patents are held by Electrolux, Sweden. The technology is well defined. There appears little if any role for long-term DOE sponsored R\&D in this technology for domestic refrigeration applications.

Solid absorption heat pump technology is being developed under current DOE funding. A brief analysis of the application to domestic refrigerators suggests a potential thermal COP of 0.65 assuming use of a double effect generator-absorber heat exchanger, with liquid ammonia as the active working fluid and a solid absorbent [8]. It is unlikely that development work will be undertaken for applications in refrigerator/freezers in private industry. Development of a viable product would require long-term R\&D.

The principles of ihermal acoustic refrigeration have been described in Appendix A. Initial feasibility analyses and experiments for domestic refrigeration show a COP ratio of about 10-20\% of Carnot in small units [9]. Development of this concept into a viable domestic refrigerator would require long-term $R \& D$. Its ability to compete against more highly developed vapor compression refrigerators is questionable.

\section{B-3 Recent and Current Research and Development}

Table B-2 provides a partial summary of recent and current research in the following areas: (1) refrigerant fluid testing in compressor calorimeters and refrigerators, 
(2) evaluation of materials compatibility and lubrication compatibility with alternate refrigerants; (3) development, testing, and evaluation of advanced vapor compression cycles; (4) development of new ("synthesized") refrigerants; (5) flammability risk assessment and testing; and (6) alternate non-vapor compression cycles.

Table B-2: Recent and Current R\&D: Domestic Refrigeration

\begin{tabular}{|c|c|c|c|c|}
\hline R\&D Organization & Sponsor & Technology & Research Description & Potentlal Impact \\
\hline \multirow[t]{6}{*}{$\begin{array}{l}\text { Oak Ridge National } \\
\text { Laboratory }\end{array}$} & $\mathrm{DOE}$ & $\begin{array}{l}\text { CFC Alternatives } \\
\text { Screening }\end{array}$ & $\begin{array}{l}\text { Characterize fluids applicable } \\
\text { to refrigerator, commercial } \\
\text { refrigeration, chiller, heat } \\
\text { pump }\end{array}$ & $\begin{array}{l}\text { Identify available fluids } \\
\text { Define attributes }\end{array}$ \\
\hline & ASHAAE & Compressor Testing & $\begin{array}{l}\text { Compressor Calorimeter } \\
\text { Testing }\end{array}$ & $\begin{array}{l}\text { Characterize effect of } \\
\text { refrigerant on compressor } \\
\text { behavior }\end{array}$ \\
\hline & $\begin{array}{l}\text { AHAM } \\
\text { ORNL }\end{array}$ & Advanced Cycles & $\begin{array}{l}\text { Develup a technology base for } \\
\text { turn-of-the-century products. } \\
\text { Construct breadboard and } \\
\text { perform testing. }\end{array}$ & $\begin{array}{l}\text { Experiment results for } \\
\text { alternative designs. Looking } \\
\text { for } 25 \%-40 \% \text { efficiency gain. }\end{array}$ \\
\hline & DOE & Lorenz Cycle & $\begin{array}{l}\text { Test performance for various } \\
\text { refrigerant pairs }\end{array}$ & $\begin{array}{l}\text { Performance potential and } \\
\text { limiting factors }\end{array}$ \\
\hline & EPA & Dual Loop & Test dual-loop design & $\begin{array}{l}\text { Establish promise and } \\
\text { limitations of the dual loop } \\
\text { approach }\end{array}$ \\
\hline & ARI & Materials Compatibility & $\begin{array}{l}\text { Test material and lubricant } \\
\text { compatibility with new } \\
\text { refrigerants }\end{array}$ & $\begin{array}{l}\text { Database on practical design } \\
\text { Issues associated with } \\
\text { alternative refrigerants }\end{array}$ \\
\hline \multirow{3}{*}{$\begin{array}{l}\text { Beijing Household } \\
\text { Electric Appliance } \\
\text { Research Institute } \\
\text { (BHEARI) }\end{array}$} & EPA & Compressor Testing & $\begin{array}{l}\text { Compressor calorimeter } \\
\text { testing }\end{array}$ & $\begin{array}{l}\text { Characterize effect of } \\
\text { refrigerant on compressor } \\
\text { behavior }\end{array}$ \\
\hline & EPA & CFC Alternate Fluids & $\begin{array}{l}\text { Refrigerator testing with } \\
\text { alternate fluids }\end{array}$ & $\begin{array}{l}\text { Energy efficiency in Chinese } \\
\text { refrigerators with alternate } \\
\text { fluids }\end{array}$ \\
\hline & EPA & Lorenz Cycle & Develop and test Lorenz cycle & $\begin{array}{l}\text { Performance potential in } \\
\text { Chinese refrigerators }\end{array}$ \\
\hline \multirow[t]{2}{*}{ University of Maryland } & EPA & Alternative Refrigerants & "Drop-in" substitutes research & $\begin{array}{l}\text { Database - goal is to match } \\
\text { CFC- } 12 \text { performance at a } \\
\text { minimum, and improve } \\
\text { efficiency if possible. } \\
\text { Flammability may be an issue. }\end{array}$ \\
\hline & EPA & Lorenz uycle & $\begin{array}{l}\text { Develop Lorenz cycle } \\
\text { breadboard and test }\end{array}$ & $\begin{array}{l}\text { Improve performance of } \\
\text { Lorenz cycle. Look for } \\
15-20 \% \text { efficiency advantage. }\end{array}$ \\
\hline \multirow[t]{2}{*}{ University of Illinois } & EPA & $\begin{array}{l}\text { Lorenz Cycle } \\
\text { Component }\end{array}$ & $\begin{array}{l}\text { Evaporator module } \\
\text { optimization (include lower } \\
\text { temp interchanger) }\end{array}$ & $\begin{array}{l}\text { Component design for } \\
\text { reduced cost. }\end{array}$ \\
\hline & Industry & $\begin{array}{l}\text { Refrigerant and Oil } \\
\text { Evaluation }\end{array}$ & $\begin{array}{l}\text { Condensation Heat Transfer } \\
\text { and Pressure Drop }\end{array}$ & $\begin{array}{l}\text { Improved heat exchanger } \\
\text { design. }\end{array}$ \\
\hline University of Hannover & EPA & Lorenz Cycle & $\begin{array}{l}\text { Development of a computer } \\
\text { model. Test performance for } \\
\text { various refrigerant pairs and } \\
\text { for a ternary mix. }\end{array}$ & $\begin{array}{l}\text { Performance potential and } \\
\text { limiting factors. }\end{array}$ \\
\hline
\end{tabular}

Much of this work is focussed on the near-term options for CFC replacement, especially calorimeter and system testing of available alternate religerants including blends (NARMs). This work focuses on finding acceptable replacements for CFC-12 that can provide reliable operation at close to current efficiency or at an improved energy efficiency. 
Table B-2: Recent and Current R\&D: Domestic Refrigeration (Continued)

\begin{tabular}{|c|c|c|c|c|}
\hline R\&D Organization & Sponsor & Technology & Research Description & Potential Impact \\
\hline lowa State & EPA & $\begin{array}{l}\text { Refrigerant and Oil } \\
\text { Evaluation }\end{array}$ & $\begin{array}{l}\text { Heat transfer with HCFC-123 } \\
\text { and HFC-134a }\end{array}$ & Heat exchanger design \\
\hline $\begin{array}{l}\text { Ecoles des Mines } \\
\text { (Paris) }\end{array}$ & & Alternate Refrigerants & $\begin{array}{l}\text { Experimental studies of } \\
\text { refrigerator/freezer } \\
\text { performance with propane, } \\
\text { HFC-134a }\end{array}$ & Database \\
\hline $\begin{array}{l}\text { University of } \\
\text { Tennessee } \\
\end{array}$ & EPRI & $\begin{array}{l}\text { Fluorinated Ethers } \\
\text { Synthesis }\end{array}$ & $\begin{array}{l}\text { Thermodynamic properties, } \\
\text { toxicity, flammability }\end{array}$ & Alternate refrigerant \\
\hline Clemson University & EPA & $\begin{array}{l}\text { 3-4 Carbon Atom Fluid } \\
\text { Synthesis }\end{array}$ & Thermodynamic properties & Alternate refrigerant \\
\hline $\begin{array}{l}\text { EPA Research Triangle } \\
\text { Park }\end{array}$ & EPA & $\begin{array}{l}\text { Compressor } \\
\text { Calorimeter Tests }\end{array}$ & $\begin{array}{l}\text { Using oil-free compressor, test } \\
\text { replacements for CFC-11, } \\
\text { CFC-12, CFC-114 }\end{array}$ & $\begin{array}{l}\text { Inherent properties of } \\
\text { refrigerant free of oil }\end{array}$ \\
\hline ULArthur D. Little & EPA & $\begin{array}{l}\text { Use of Flammable } \\
\text { Refrigerant }\end{array}$ & $\begin{array}{l}\text { Risk assessment of } \\
\text { HFC.152a, tests }\end{array}$ & $\begin{array}{l}\text { Allow use of flarnmable } \\
\text { refrigerant }\end{array}$ \\
\hline Wanbao (China) & & $\begin{array}{l}\text { Use of Flammable } \\
\text { Refrigerants }\end{array}$ & $\begin{array}{l}\text { Tests for flammability in } \\
\text { retrigerators }\end{array}$ & $\begin{array}{l}\text { Allow use of flammable } \\
\text { refrigerant }\end{array}$ \\
\hline $\begin{array}{l}\text { Institute per la Tecnico } \\
\text { del Freddo, Padova } \\
\text { Italy }\end{array}$ & & $\begin{array}{l}\text { Use of Flammatle } \\
\text { Refrigerants }\end{array}$ & $\begin{array}{l}\text { Test results for flammable } \\
\text { refrigerants }\end{array}$ & $\begin{array}{l}\text { Database on performance } \\
\text { with alternate refrigerants }\end{array}$ \\
\hline University of Maine & & LaBrecque Cycle & $\begin{array}{l}\text { Cycle development and test } \\
\text { with HCFC-22 }\end{array}$ & $\begin{array}{l}\text { Two pressure level } \\
\text { evaporating use of HCFC-22 }\end{array}$ \\
\hline Naval Research Lab & DOE & $\begin{array}{l}\text { Thermal Acoustic } \\
\text { Refrigerator }\end{array}$ & Feasibility test and analysis & Alternate cycle, uses $\mathrm{H}_{e}$ or $\mathrm{H}_{2}$ \\
\hline Rocky Research & DOE & Metal Hydrides & $\begin{array}{l}\text { Characterize cycles using } \\
\text { solid absortents }\end{array}$ & Thermal cycle alternative \\
\hline $\begin{array}{l}\text { Oak Ridge National } \\
\text { Laboratory }\end{array}$ & DOE & $\begin{array}{l}\text { Stirling Cycle } \\
\text { Refrigerator/Freezer } \\
\text { Application }\end{array}$ & Investigate feasibility & $\begin{array}{l}\text { Non-CFC refrigerant. } \\
\text { Target high efficiencies }\end{array}$ \\
\hline Sunpower and $\mathrm{MTI}$ & DOE & $\begin{array}{l}\text { Free-Piston Stirling } \\
\text { Cycle }\end{array}$ & $\begin{array}{l}\text { Feasibility test and analysis of } \\
\text { Stirling cycle refrigerator }\end{array}$ & Efficiency potential \\
\hline
\end{tabular}

Some currently available refrigerants offer potential for significant energy reduction. These tend to be flammable pure refirigerants, such as CFC-152a or cyclopropane, or include mixtures containing a flammable component, such as R-22/R-142b. Research to determine the risks associated with flammable fluids is being undertaken in the U.S. (U.L., Arthur D. Little, EPA) and in China (Wanbao). While this focuses on near-term applications, flammability analysis may be needed in the long-term as well, as new fluids are identified or synthesized.

Development and testing of Lorenz cycle refrigeration loops is being carried out at a number of organizations throughout the world, including ORNL, University of Maryland, Hannover University, the Beijing Household Electric Appliance Research Institute, and various refrigerator manufacturers. The University of Illinois has carried out design development of a compact evaporator-interchanger component for a Lorenz cycle.

Attempts are underway at the University of Tennessee and Clemson University to develop entirely new refrigerants based on fluorinated ethers and 3-4 carbon systems. Properties of these refrigerants are being determined, and some preliminary calorimetic testing of the fluorinated ether components is being carried out by the EPA. Searches 
for "ideal" refrigerants will likely be a concinuing activity in the long-term. Properties of ideal refrigerants include low-ioxicity and low-tlammability, as well as potential for low-cost production.

Current research efforts into the LaBrecque cycle (two-stage compression) and into metal hydrides as a solid absorbent for an absorption-type refrigeration cycle are at a relatively low funding level. Neither technology appears a likely candidate to replace advanced vapor compression technology.

Stirling cycle research related to refrigerator/freezer applications is taking place at least three organizations: Sunpower, MTI, and IST Engineering Ltd (Israel). IST has demonstrated "feasibility" of application to refrigerators, but little performance data is available. As noted earlier, only preliminary laboratory tests have been carried out at conditions similar to a domestic refrigerator. For example, compression COP near 1 has been achieved at a cold end temperature of $-28^{\circ} \mathrm{F}$ and a hot end temperature of $62^{\circ} \mathrm{F}$ (too low for refrigerator applications)[6]. Considerable development work relating to the linear actuator, bearing system, regenerator efficiency, and low $\Delta \mathrm{T}$ heat exchanger is required to achieve a system competitive with current vapor compression technology. In addition, a focus needs to be placed on long-term reliability for a practical refrigerator. 


\section{References}

[1] Potter, T.F., and Benson, D.K., "Non-CFC Vacuum Alternatives for Energy-Efficient Insulation of Household Refrigerators: Design and Use," Proc. 42nd International Appliance Technology Conference, Madison Wisconsin, May $21-22,1991$.

[2] Janssen, M.J.P., Kuijpers, L.J.M., and deWit, J.A., "Theoretical and Experimental Investigation of a Dynamic Model for Small Refrigeration Systems, "Proc IIR Meeting at Purdue, 1988, West Lafeyette, pp.245-257

[3] Janssen, M.J.P., deWit, J.A., and Kuijpers, L.J.M., "Cycling Losses in Domestic Appliances: An Experimental and Theoretical Analysis," Proc IIR Meeting at Purdue, 1990, West Lafayette, pp.90-98

[4] Results of Arthur D. Little analysis carried out for U.S. EPA, 1991

[5] Pedersen, et.al, "Design and Construction of an Efficient U.S.-Type Combined Refrigerator/Freezer," Proceedings: 17th International Congress of Refrigeration, 1987, Volume B

[6] Fabien, M.J., "Evaluation of the Free Piston Stirling Cycle for Domestic Cooling Application," paper 141, XVIIIth International Congress of Refrigeration, Montreal Canada, August 1()-17, 1991.

[7] Berchowitz, D.M., and Unger, R., "Experimental Performance of a Free-Piston Stirling Cycle Cooler for Non-CFC Domestic Refrigerator Applications," paper 144, XVIIIth International Congress of Refrigeration, Montreal Canada, August $10-17,1991$.

[8] Communication from Dr. Wendell Biermann, August 15, 1991.

[9] Hofler, T.J., "Concepts for Thermoacoustic Refrigeration and a Practical Device," Naval Post Graduate School, Monterey California 
Appendix C

Chiller Systems 
C-1 State-of-the-Art

C- 1

C-1.1 Description and Applications ............................................. C-1

C-1.2 Refrigerants/Lubricants ..................................................... C-2

C-1.3 Energy Efficiency Levels ..................................................... C-3

C-1.4 Industry Characteristics ..................................................... C-3

C-1.5 Progress in Use of "Newer" Refrigerants/Technologies ................ C-4

C-2 Substitute Options ....................................................................... C-4

C-2.1 Substitute Refrigerants for Building Chillers ............................ C-5

C-2.1.1 HCFC-123 ....................................................... C-5

C-2.1.2 HFC-134a .............................................................. C-5

C-2.1.3 HFC-152a ............................................................. C-6

C-2.1.4 Ammonia ............................................................ C-6

C-2.1.5 HCFC-124 Ternary Blend ............................................ C-7

C-2.1.6 HCFC-22 …......................................................... C-8

C-2.1.7 Propane ............................................................. C-8

C-2.1.8 Cyclopropane ........................................................ C. 8

C-2.1.9 NARMS ............................................................ C-9

C-2.1.10 Newly Synthesized Fluids ........................................... C-9

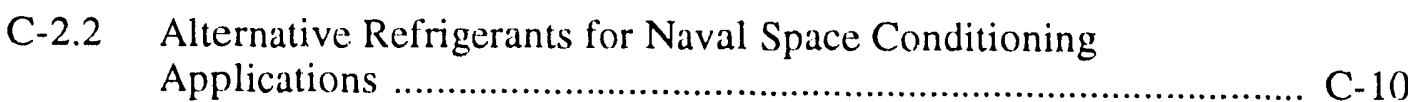

C-2.2.1 HCFC-124 ....................................................... C- 10

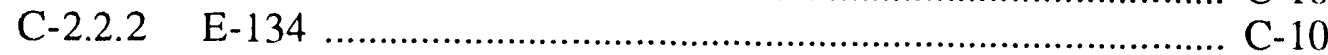

C-2.2.3 Refrigerant Mixtures .............................................. C- 10

C-2.2.4 Newly Synthesized Fluids .......................................... C-11

C-2.3 Substitute Technologies ....................................................... C-11

C-2.3.1 Absorption and Adsorption ........................................ C-11

C-2.3.2 Stirling Cycle .............................................................. C- 12

C-2.3.3 Vuilleumier Cycle ................................................... C- 13

C-2.3.4 Brayton Cycle ........................................................... C- 13

C-2.3.5 Magnetic Refrigeration .............................................. C- 13

C-2.3.6 Ejector Heat Pump ..................................................... C- 13

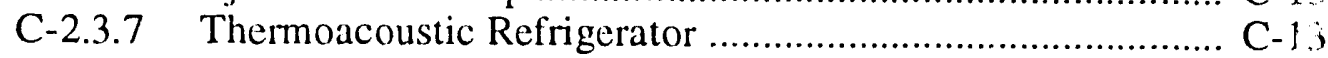

C-2.3.8 Vortex Tube ............................................................ C- 14

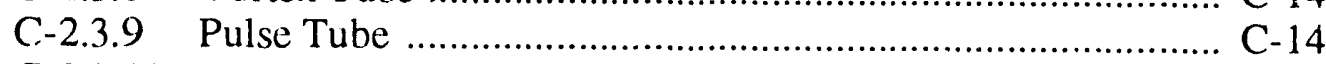

C-2.3.10 Malone Refrigeration ............................................... C-14

C-2.3.11 Thermoelectric Refrigeration ...................................... C- 14 


\section{Appendix C Chiller Systems}

\section{C-1 State-of-the-Art}

\section{C-1.1 Description and Applications}

Chillers cool water or a water/glycol mixture which is pumped throughout buildings, factories or processes. The cooled liquid passes through heat exchangers located within the facilities. Fans move the air through heat exchangers which are contained in air handlers thereby cooling and dehumidifying it. These systems have capacities from less than 10 tons to greater than $8(0)(0)$ tons and are broadly used for commercial applications. System life ranges from 10 to more than 4() years, and efficiency has significantly improved over the past decade.

Chillers are divided into two main classifications, depending upon the technology employed: vapor compression and absorption. Selection is based on fuel source availability and economics. Vapor compression systems are typically electrically operated, while absorption systems are thermal energy activated. Vapor compression systems utilize CFC or HCFC refrigerants, while absorption systems use water as a refrigerant, with lithium bromide or ammonia as an absorbent. Lower first cost and higher efficiency favor vapor compression systems and they are the dominant installed type.

Vapor compression chillers are further classified depending on the type of compressor employed: positive displacement or eentrifugal. Electric motors are the most common drivers for the compressors, although steam turbines and internal combustion engines have seen limited application. Additional components of these systems are the evaporator, where the refrigerant evaporates at a low pressure, thereby cooling the liquid, and the condenser, where the high pressure vapor is condensed and heat rejected. An expansion device is located between the condenser and the evaporator to control the now of the high pressure liquid refrigerant to the lower pressure evaporator. Expansion devices range from a simple orifice in centrifugal chiller systerns using CFC-11 or HCFC-123 to sophisticated thermal expansion valves (some electronically controlled) in positive displacement chillers. System controls vary the output of the chiller and its operation.

Cycle efficiencies for very ellicient chillers have a power consumption of ().6 kW/ton, which is ahout 7()\% of Carnot hased on evaporator and condenser temperatures of 40$)^{\circ} \mathrm{F}$ and 100$)^{\prime F}$. This efliciency does not include energy associated with the atmospheric cooling tower for heat rejection.

Positive displacement water chillers use reciprocating, scroll, or screw compressors and have capacities ranging from 10) to higher than $1(0)()$ tons, although the vast majority have capacities less than 2(0) tons. A distinction is made based on the heat rejection medium; systems are either air or water cooled. Air cooled systems are generally 
limited to chillers of less than 200 tons capacity. In water cooled systems, in the condenser, the refrigerant is on the shell side of a shell and tube heat exchanger. The water is typically cooled in an atmospheric cooling tower.

Centrifugal water chillers range from about 100 to more than 8000 tons and are the prevalent method of air conditioning buildings of more than 40000 square feet. Heat rejection is almost exclusively through atmospheric cooling towers, although some air cooled and ground or river water cooled units have been produced.

Absorption chillers range from less than 100 to 1600 tons. They are operated by thermal energy, in the form of hot water, steam, or the direct combustion of natural gas. System components include an evaporator; an absorber, a generator, and a condenser. The refrigerant (water) evaporates below atmospheric pressure to produce the cooling effect. An absorbent fluid (a concentrated lithium bromide or ammonia solution) absorbs the water vapor in the absorber. The solution pump raises the solution to the higher pressure generator where the refrigerant is driven from the diluted absorbent solution. Heat of condensation is rejected to an atmospheric cooling tower. Due to the large specific volume of the refrigerant and the four heat exchangers, absorption chillers are larger than vapor compression chillers for the same capacity. Cooling towers are also larger due to the lower thermal efficiency of the absorption cycle.

In order to improve thermal efficiency, additional stages of generation car be added to absorption systems. Dual effect systems operate at higher overall temperature differences and are more thermally efficient. Direct-fired systems and some steam activated systems use dual effect cycles.

Both vapor compression and absorption technology are considered to be mature. The competitive nature of the air conditioning industry has led to a continuous refinement of these systems, from both the cost and energy standpoints.

\section{C-1.2 Refrigerants/Lubricants}

Vapor compression chillers use CFC or HCFC refrigerants, including HCFC-22, CFC-11, CFC-12, CFC-114, and R-50). Positive displacement chillers use almost exclusively $\mathrm{HCFC}-22$, although a few use CFC-12. Centrifugal chillers primarily use CFC-11, with some use of CFC-12, CFC-114, R-5()(), and HCFC-22.

Absorption chillers primarily use lithium bromide - water or ammonia - water as working fluids. The ODP and GWP for these fluids is negligible. Ammonia is not desirable in many applications due to its toxicity.

The commonly used refrigerants and compatible lubricants have been well established and in use for many decades. 


\section{C-1.3 Energy Efficiency Levels}

Efficiency levels for vapor compression equipment tend to improve as the capacity of the equipment increases. Water cooled equipment is more efficient than air cooled equipment due to closer approach temperatures in the condenser and the lower lift requirements of the compressor. Centrifugal compressors are generally more efficient than positive displacement compressors because of lower friction and the lack of valve throttling losses. Also, lower heat transfer losses occur in the generally larger capacity centrifugal compressors.

Efficiency improvements since the oil embargo of 1974 have been considerable, especially in the case of centrifugal chillers, where a $25 \%$ efficiency improvement has been obtained, primarily as a result of the use of larger and more efficient heat exchangers and more efficient electrical motors. Development of nucleate boiling evaporator tubes represented a breakthrough in heat exchanger design, which substantially reduced evaporator temperature drops across the heat exchanger surface, thereby raising the evaporator temperature.

Absorption equipment is thermally less elficient than vapor compression equipment. COPs for diect-fired absorption chillers approach 1.1 , considerably below the COP of 5.3 for a typical centrifugal chiller. If an allowance is made for a powerplant efficiency of $30 \%$, the overall primary energy source COP for centrifugal chillers is $1.6($ ). Triple effect cycles, approximately 2 years in development, have a performance target of 1.6 to 1.8. Achieving this target would overcome the current performance deficiency of absorption chillers, but would somewhat increase the currently unfavorable first cost differential.

\section{C-1.4 Industry Characteristics}

The largest market for chillers is the U.S. and the majority of the manufacturers are domestic corporations. The industry is in a mature phase after having gone through a rapid growth cycle in the 1950s and 1960s. Manufaciurers have left the market and the remainder have gone through considerable change as a result of new ownership and leveraged buyout activity. The principal manufacturers are Carrier (a division of United Technology), Trane, York International, and Snyder General Corporation. The industry has an effective trade organization, the Air Conditioning and Refrigeration Institute (ARI), and is governed by standards covering the certification of equipment performance and efficiency.

Hot water and steam activated absorption chillers lost favor in the U.S. with growing energy awareness in the 1960s. Japanese manufacturers, such as Hitachi, Ebara, Sanyo, and Mitsubishi-York, developed direct-fired versions to meet a need for natural gas-fired equipment in Japan. Favorable supplies of natural gas in the U.S., coupled with concern over the long term viability of CFCs, has led to the introduction of this newer equipment in the U.S., where the technology has seen limited but growing application. 
Forty to fifty percent of new chillers are purchased for retrofit applications. Many existing chillers have substantial remaining useful ives. Thus, retrofit of existing chillers to non-CFC refirigerants is an important consideration. It is estimated that 80,000 centrifugal chillers are currently installed w: th useful lives of 25 to 40 years.

\section{C-1.5 Progress in Use of "Newer" Refrigerants/Technologies}

Domestic manufacturers have reacted very rapidly to supply non-CFC equipment. HCFC-123 is being offered as an alternative to CFC- 11 by several manufacturers and one (York) claims to have received its 100 th order since it began shipping HCFC-123 centrifugal chillers one year ago. HCFC-22 positive displacement, screw compressor chillers have been developed and are being offered by several manufacturers (Trane and York) as alternatives to CFC-11 centrifugals in the 10() to 450) tonnage capacity range. HCFC-134a has been successfully tested in a CFC-12 centrifugal chiller. One manufacturer (Carrier) recently announced the availability of eentrifugal chillers in the 300 to 500 ton range, which use HCFC-22 or HFC-134a refrigerants. York offers HCFC-22 centrifugal chillers from $8(0)$ to 2()()() tons.

For existing CFC-11 installations, several manufacturers are retrofitting chillers to use HCFC-123. Retrofits vary from simple replacement of refrigerants and lubricants and recalibration of controls to more complex replacements of hermetic motors and refrigerant seals. Due to the lower allowable concentration limits of the new refrigerants in equipment rooms, refrigerant concentration monitors are installed.

Four domestic manulacturers are now distributing direct-fired absorption chillers as an alternative to vapor compression equipment. This has occurred through "teaming" with Japancse manufacturers.

$\begin{array}{ll}\text { Company } & \text { Partner } \\ \text { Trane } & \text { Kawasiaki } \\ \text { Carrier } & \text { Ebara } \\ \text { York } & \text { Hitachi } \\ \text { Snyder General } & \text { Sanyo }\end{array}$

\section{C-2 Substitute Options}

The vapor compression cycle as applied to commercial space conditioning applications (chillers) will be the major, if not dominant, technology into the foresecable future. The reasons are proven reliability, already high efficiency, and a potential for additional efficiency improvements of $10-15 \%$.

Present cycle efficiencies are about $70 \%$ of Carnot based on evaporator and condenser temperatures of $40^{\circ} \mathrm{F}$ and $100^{\circ} \mathrm{F}$ respectively. Typical electric compressor power consumption is about $0.6 \mathrm{~kW} / \mathrm{ton}$. Parasitic losses (pumps, fans, and blowers) during full load can reach $50 \%$ of the compressor power input. 
The major issue associated with current technology vapor compression cycle chillers appears to be the selection of refrigerants with long-term acceptability. Concerns include materials compatibility, flammability, toxicity, ozone depletion potential, and perhaps most important, the effect on system efficiency. A discussion of the current and near-term options is given below. Needs for additional fluid options and for other component R\&D are summarized in Section 1.

\section{C-2.1 Substitute Refrigerants for Building Chillers}

\section{C-2.1.1 HCFC-123.}

HCFC-123 represents an attractive short-term replacement working lluid option for existing CFC- 11 chillers. The ODP and GWP of HCFC- 123 are each about $2 \%$ of those of CFC-11. However, long term viahility is in question because HCFC-123 contains chlorine and, therefore, does not eliminate entirely the threat to the ozone layer. The results of the PAFT testing reported recently suggests that HCFC-123 may have a higher degree of toxicity than desired. It is felt that additional toxicity testing is needed to make definite conclusions about HCFC- 123 berause the HCFC-123 used in the recent testing program contained 7\% HCFC-123a. However, this may not be an issue because production HCFC-123 also contains ahout 7\% HCFC-123a. Although the toxicity of HCFC-123 is far less than that of ammonia, the odor of ammonia allows simple detection at about 20 PPM whereas HCFC-123 requires a more sophisticated form of detection. Sensors to detect HCFC-123 levels as low as I PPM have been developed. A well-positioned monitoring unit in the equipment room can be sufficient to detect HCFC-123 leaks.

\section{C-2.1.2 HFC 134a.}

It is expected that HFC-134a will be the near term choice as a replacement working fluid for CFC-12/50)() chiller systems. The application includes screw compressors from 50 tons to $1,2()()$ tons capacity in addition to centrifugal compressors. HFC-134a has a zero ODP, since it does not eontain any chlorine, and has a GWP of about $10 \%$ of that of CFC-12. Theoretical cycle efficiencies for conditions typical of chillers are about $2 \%$ lower than for CFC-12. It is expected that efficiency levels for systems optimized for HFC-134a will have efficiencies comparable to those of CFC-12.

Safety is probably not an issue regarding the use of HFC-134a. It is non-flammable and, although toxicity testing is as yet incomplete, it appears that it is also non-toxic.

HFC-134a is compatible with most materials used in the construction of chiller systems. It can therefore be viewed as a retrofit fluid over the entire capacity range and compressor types in which CFC-12 is employed. Use of HFC-134a in systems with positive displacement compressors requires a change from mineral to synthetic oils while a relatively small (1()\%) compressor speed increase is required to use HFC-134a in centrifugal chillers. System pressure levels for HFC-134a would be comparable to those of CFC-12, therefore system structural changes are not required. McQuay is offering HFC-1.34a retrofit systems for its CFC-12 and R-50) centrifugal systems with 
minor hardware changes (gearset changes) with little or no loss of performance. Long term acceptance of HFC-134a may depend on the achieved levels of compressor reliability.

\section{C-2.1.3 HFC-152a.}

HFC-152a is an excellent refrigerant but it will not be used as a working fluid in chiller systems as a replacement for CFC-12/500 unless and until the issues related to its flammability can be resolved.

Theoretical efficiencies of HFC-152a are several percent greater than for CFC-12. It has a zero ODP and a GWP of about $1 \%$ compared to that of CFC-12, and is also non-toxic. It is available now in small quantities, as HFC-152a used with CFC-12 in $\mathrm{R}-500$ and in aerosol blends. HFC-152a is compatible with all materials used to fabricate chiller systems and since it has a vapor pressure-temperature relationship very similar to that of CFC-12, no structural changes to the system are necessary. Use of HFC-152a may require a change from inineral oil. From a refrigeration point of view, HFC-152a can be viewed as a near "drop-in" for CFC-12, thus retrofit of CFC-12 positive displacement compressor systems is possible. On the other hand, use of HFC- $152 \mathrm{a}$ in centrifugal systems requires considerable $(>25 \%)$ compressor rotational speed increase, which may necessitate redesign of the compressor.

If the issues associated with the llammability of HFC-152a are resolved, then HrC-152a can be viewed as an attractive replacement for CFC-12 available in the near term.

Additional study is needed on the impact of moderate flammability.

\section{C-2.1.4 Ammonia.}

Ammonia is an excellent refrigerant with a high latent heat, low required suction flow rate, and superior heat transfer properties. It represents an attractive substitute to replace CFC-11, CFC-12/500, and R-502 in new chiller systems but would require substantial redesign. Issues related to its toxicity and mild tlammability and heat exchanger designs need to be addressed and resolved. Ammonia has often been considered unsuitable for comfort cooling applications because of its toxicity. Another issue is the high cost and size of current systems.

The implementation of ammonia chiller systems requires designs specific for ammonia. A large knowledge base exists surrounding ammonia refrigeration technology since it is used as the working fluid in many industrial refrigeration installations.

Ammonia research is needed with specific developments aimed toward hermetic compressors, heat exchanger development including materials and enhanced surfaces, spray evaporators, and expansion valve improvements.

Ammonia will attack the copper materials used in the motors of hermetic compressors. The hermetic compressor investigation must include the use of materials compatible with ammonia. 
Present heat exchangers for ammonia service are constructed from steel. Improvements in ammonia chillers can be made by selection of other materials compatible with ammonia and by the development of enhanced heat exchange surfaces, particularly on the ammonia side of the heat exchanger. There have been problems with water chiller applications due to utilization of steel heat exchangers in contact with water.

As noted above, ammonia has superior heat transfer properties - on the ammonia side of the heat exchanger. Steel heat exchange surfaces (tubes) are used with ammonia. These have increased thermal resistance and are subject to water side fouling. Heat transfer augmentation is not as easily applied as it is with copper tubes. The result is that overall heat transfer using ammonia is generally not as good as is the case with CFCs, HCFC, and HFCs.

Spray evaporators offer the potential of achieving superior evaporator refrigerant side heat transfer effectiveness while reducing the inventoiy of refrigerant in the evaporator.

In summary, ammonia has better heat transfer characteristics than any known refrigerant except CFC-11. However, if the benefit/use of ammonia is to be expanded, the issues of flammability, toxicity, and material compatibility need additional research.

\section{C-2.1.5 HCFC-124 Ternary Blend.}

The DuPont HCFC- 124 ternary blend represents an attractive short term replacement for CFC-12 chillers from a refrigeration point of view. It is unlikely that it will be a long term solution because it has an ODP greater than zero and thus it does not eliminate entirely the refrigerant threat to the ozone layer.

The components of the HCFC-124 ternary blend are HCFC-22/HCFC-152a/HCFC-124 mixed in proportions of $36 / 24 / 40 \%$, respectively. It is in the class of mixtures called near-azeotropes, in which the change in saturation temperature relative to vapor quality (for constant pressure) is small. This mixture has a vapor pressure-temperature curve almost identical to that of CFC- 12 while required suction flow rates are about $5-10 \%$ less. The mixture is non-toxic, and for the composition described above, it is non-flammable. It has an ODP of 0.03 compared to 1 for CFC- 12 and a GWP only about $5 \%$ that of CFC- 12 .

Because the HCFC-124 ternary blend is not an azeotrope, the effect of system leakage on flammability is a question because of the HFC-152a. Based on experiental work at DuPont, the composion does change during vapor leakage. However, the mixture has been formulated such that it remains nonflammable during all leakage scenarios.

The DuPont ternary blend represents an attractive working fluid alternative to CFC-12 on a temporary basis. Use of blends in positive displacement machines may require a change from mineral to an alternative oil, while a $10 \%$ compressor speed increase may be required in a centrifugal compressor due to the slightly lower molecular weight. Also, reclamation when the blend is removed from the system is a consideration. HCFC-124 is difficult to process in reclamation. 
A program of investigating near azeotropes with regard to leakage characteristics and multicomponent/two phase heat exchanger phenomena is needed if the HCFC-124 ternary blend use is to be expanded.

\section{C-2.1.6 HCFC-22.}

HCFC-22 represents an attractive interim replacement working fluid to reduce substantially the ODP and GWP for new installations that would otherwise use CFC-11, CFC-12, or R-5()2.

HCFC-22 systems can also be used to replace axisting chillers that use CFC-11 or CFC-12 for all capacities. This would involve the insiallation of new systems, as HCFC-22 cannot be used to retrofit existing systems.

HCFC-22 screw compressor systems are available up to about 1250 tons. High speed centrifugal systems are available up to 200() tons.

\section{C-2.1.7 Propane.}

Propane is an excellent refrigerant and can be viewed as an alternative replacement working fluid for CFC-11 and CFC-12 in new systems. However, issues related to its flammability must be addressed and resolved. The lise quantities of refrigerant in these systems may preclude the use of hydrocarbons in comfort cooling installations.

Propane has been used successfully as a refrigerant in the past. Applications include industrial refrigeration with multis age centrifugal compressors. Systems that use propane will have to be designed to cope with the higher system pressures. The relatively low molecular weight and required suction tlow rates compared to CFC-11 and CFC-12 require the use of screw compressors for applications where centrifugal compressors with CFC-11 and CFC-12 systems have normally been used. Propane is compatible with all materials used in the fabrication of chillers, eliminating the need for extensive materials research. It has a "ero ODP and a GWP about $2 \%$ of CFC-12, and is non-toxic.

As with HFC-152a, use of propane requires assessment of the risks associated with its flammability and the implementation of design modifications for risk minimization.

\section{C-2.1.8 Cyclopropane.}

Cyclopropane is theoretically an excellent refrigerant and can be viewed as an alternative working fluid for CFC-11 and CFC-12. However, issues related to its flammability must also be addressed and resolved.

Theoretical calculations indicate that cyclopropane is inherently about $5 \%$ more efficient than CFC-12 for conditions typical to those found in most chiller applications. Cyclopropane has a zero ODP and a GWP about $2 \%$ compared to the GWP of CFC-12. It has excellent transport properties, is non-toxic although it is an anesthetic. Issues associated with the use of cyclopropane are essentially the same as those for propane. 
C-2.1.9 NARMS.

Nonazeotropic Refrigerant Mixtures (NARMS) represent attractive working fluid options for replacement of CFCs for chiller applications while offering comparable efficiencies.

NARMS are mixtures that show changes in temperature (or glide) versus vapor quality at con.ant pressure. NARM research is at the fundamental level, focusing on choice of refrigerant mixtures and determination of heat transfer properties. As in the case with the DuPont ternary blend, it is not known if a distillation effect will occur in a flooded evaporator. Research is needed in the very broad areas of:

- refrigerant identitication

- system design

- performance prediction

- thermophysical properties

- heat exchanger performance

- compressor performance and suitahle lubricants

- composition delection

- servicing techniques

- reclamation techniques

\section{C-2.1.10 Newly Synthesized Fluids.}

The synthesis of new fluids which have zero ODPs and very low or zero GWPs represents a long term research strategy that may lead to a replacement for CFC working fluids for chiller applications. The optimum fluid for use as a substitute for ozone depleting fluids in chillers may not be presently known. A program to logically and rationally investigate new fluids may lead to more efficient, environmentally acceptable substitutes.

Long term research into the synthesis of new substances which are tailored to possess favorable characteristics as a refrigerant without the adverse affects on the environment should be a priority. For a substance to be considered as a refrigerant for a particular application, it generally should have at least a boiling point and suction flow rate comparable to the refrigerant it replaces, be non-toxic and non-tlammable, and be compatible with most materials used in system fabrication. Also, it must pose no threat to the ozone layer and contribute a minimum to the global warming phenomenon.

The search for substances which satisfy the above mentioned criteria is ongoing, with the University of Tennessee focusing on fluorinated ethers and Clemson University, focusing on molecules that contain three and four carbon atoms. The University of Tennessee has reported the synthesis of 37 fluorinated ether compounds and has identified some potential replacements for the current CFC compounds; e.g., E-125 for CFC-115.

Long term research will necessarily involve the further identification of new substances and determination of their properties, toxicity and flammability testing, materials compatibility testing, and testing of these substances as refrigerants. 


\section{C-2.2 Alternative Refrigerants for Naval Space Conditioning Applications}

It is expected that for substances to be considered as potential CFC-114 replacements for Naval shipboard chillers, they would be those that most closely match CFC-114 in molecular weight, boiling point, and suction flow rate to allow the continued use of relatively quiet compact centrifugal compressors. A key issue is refrigerant toxicity in the enclosed space of submarines and ships. Another issue is that the pressure of the refrigerant in the system should always be above atmospheric pressure to prevent inward leakage of air and moisture.

In addition, the chemical stability of CFC-114 makes it compatible with submarine atmospheric control systems. Thus, consideration of overall chemical stability of a potential substitute should be taken into account when attempting to minimize redesign of such systems.

\section{C-2.2.1 HCFC-124.}

HCFC-124 is an attractive choice to replace CFC-114 in Naval shipboard chillers available in the near term. It has a theoretical efficiency almost identical to that of CFC-114, and a ODP and GWP each about $2 \%$ of those for CFC-114. However implementing HCFC-124 may require major redesign of the entire chiller system. Suction flow rates are about half those of CFC-114 while working pressures are approximately doubled.

In 1991, testing was done on a 125 ton CFC-114 centrifugal chiller modified for HCFC-124 to determine effects of the substitution on system performance. Initial results indicate that HCFC-124 heat transfier coefficients are comparable to those of CFC-114 and also verify existing HCFC-124 thermodynamic data. Prototype HCFC-124 impellers were fabricated and tested by the U.S. Navy in a modified 125 ton chiller in 1991 .

\section{C-2.2.2 E-134.}

The fluorinated ether E-134 $\left(\mathrm{CF}_{2}-\mathrm{CF}_{2} \mathrm{H}\right)$ represents an attractive working fluid replacement for CFC-114 Naval shiphoard applications possibly available in the near term. All things being equal, E-134 represents a more attractive alternative than HCFC -123 because of its zero ODP.

There is no indication that this will ever become important in terms of national energy use.

This substance was patented as an aerosol propellant in the 1970's. Based on preliminary thermodynamic analyses, it appears that E-134 will be an excellent replacement for CFC-114 from a performance point of view. It has a normal boiling point of about $41^{\circ} \mathrm{F}$ compared to $39^{\circ} \mathrm{F}$ for CFC-114. For the Navy, NIST is now in the process of generating comprehensive thermodynamic property tables, heat transfer coefficients, speed of sound data, and transport property measurements. This data will be used to assess E-134 performance as a retrofit fluid in existing CFC-114 designs. 


\section{C-2.2.3 Refrigerant Mixtures.}

Refrigerant mixtures represent attractive near term and possible long term alternative working fluids for Naval shipboard applications.

The consideration of refrigerant mixtures expands the list of possible CFC-114 alternatives and allows the possibility of tailoring the mixture to provide a closer match of properties to CFC-114 such as average molecular weight, suction flow rate, and evaporator and condenser temperatures and pressures. The prime concern is the effect that a substitute refrigerant has on component design issues. Suction flow rate, working pressures, and heat transfer and pressure drop characteristics must be considered.

An example of a mixture from a performance viewpoint is a $50 \% / 50 \%$ mixture of HCFC-124/HCFC-123. Compared to CFC-114, theoretical efficiencies are 3\% greater, required suction flow rates are only $3 \%$ greater, and working pressures are practically identical. Although the average molecular weight is lower, CFC-114 compressors could possibly be adapted to use this mixture by increasing the compressor speed by about $10 \%$.

\section{C-2.2.4 Newly Synthesized Fluids.}

The synthesis of new fluids which have zero ODPs and very low or zero GWPs represents a long term research strategy that may lead to a replacement for CFC working fluids for Naval chiller applications.

The search for substances which satisfy the above mentioned criteria is ongoing, with the University of Tennessee focusing on fluorinated ethers and Clemson University, focusing on molecules that contain three and four carbon atoms. The University of Tennessee has reported the synthesis of 37 lluorinated ether compounds.

Long term research will necessarily involve the further identification of new substances and determination of their properties, toxicity and flammability testing, materials compatibility testing, and testing of these substances as refrigerants.

\section{C-2.3 Substitute Technologies}

Failing identification of long-term acceptable substitute refrigerants from either a compatibility standpoint or with respect to achieving acceptable system efficiency, alternative cycles may be employed. A brief discussion is given below of the applicability to building chillers of a variety of alternative cycles.

\section{C-2.3.1 Absorption and Adsorption.}

C-2.3.1.1 Liquid Absorption. Single effect absorption chillers have COPs of about 0.7. Double effect machines have COPs of about 1.1. These are not generally competitive with vapor compression chillers which achieve a primary energy source COP in the range of $1.6-1.8$. 
Triple effect chillers have the potential of achieving primary energy COPs of about 1.8 , which is very competitive with vapor compression. The capital cost will be on the order of 2 to 3 times that of a vapor compression system; however, there are situations where the overall lifetime cost may be competitive. One of these areas is district cooling. Here the energy used for the absorption system is steam from a central steam generating station or from waste heat.

C-2.3.1.2 Solid Abso.ption. As discussed in Appendix A, the solid absorption COP is expected to be about 1.(1)3. The system can also be used in the heating mode. The cost and size may be comparable to a mid range electric air conditioner plus a furnace.

Additional basic research will be needed if solid absorption is to be available as a manufactured product. This includes adding to the selection of sorbent materials so that greater design flexibility will result, additional work on life expectancy, heat exchanger optimization, process control, and materials specification.

Given that the COP is not competitive with vapor compression, the energy consumption will likely increase if solid absorption is used--even with eycle improvements.

C-2.3.1.3 Solid Adsorption. As discussed in Appendix A, the COP is expected to be somewhat in excess of unity - not really competitive with vapor compression in the larger sizes used in chillers. An additional concern is cost and size which appear to be appreciably higher. For example, materials and assembled component costs for a three ton unit are probably going to be in the ballpark of $\$ 25())(\$ 833 /$ ton), to which must be added labor and overhead. It does not appear to be competitive with other methods.

\section{C-2.3.2 Stirling Cycle.}

The Stirling eycle offers the highest possible efficiency potential - that of the Carnot cycle. Presently, hardware limitations have imposed efficiencies that are far less. Recent developments have experimentally shown that Stirling heat pumps can achieve efficiencies approaching 5()\% of Carnot (based on heat exchanger temperatures) even with low temperature lifts, compared to $70 \%$ for vapor compression in chillers.

Technical issues to be addressed include system life, reliability, and the impact of Stirling cycle equipment on overall system design, performance and cost, high pressure operation, high heat transfer density, restricted void volume, and the associated parasitic power requirements. Although these are problems that have historically limited the application of Stirling cycle equipment, the Stirling cycle olfers the best alternative shaft power driven eycle to vapor compression for chillers. The potential of maximum cycle efliciency, if the elusive hardware limitations in heat exchange, piston motion and leakage discussed in Appendix A can be solved, provide a strong incentive to develop Stirling technology. The use of lluids such as helium which have \%ero ODP and GWP also provides a strong incentive considering the purposes of the present program.

There is also a practical side to consider. It may not be realistic to think of 500 to 2000 ton capacity Stirling systems competing with centrifugal chillers. The hardware may be large and complex. 


\section{C-2.3.3 Vuilleumier Cycle.}

The VM cycle can be designed into hardware with high reliability. However, the efficiency is too low to be competitive with the Stirling cycle or vapor compression. Efficiency improvements of the magnitude to promote effective competition do not appear promising. The only favorable application opportunities would oceur in instances whose low-cost, or free, heat is available to dive the unit.

\section{C-2.3.4 Brayton Cycle.}

Brayton cycle efficiencies are $10 \%$ 10 $20 \%$ of Carnot in the temperature range of 40$)^{\circ} \mathrm{F}$ used in chillers. This is less than half the efficiency of current vapor compression technology. Indications are that efficiency improvements in essential components compressors, expanders, and heat exchangers - will be very marginal because of the intense development that has already taken place in the aircraft industry.

While a Brayton cycle chiller would not contribute to ozone depletion by the use of air, helium, or other fluid with zero ODP, the cycle has low efficiency.

The Brayton cycle still has the advantages of high reliability and installation convenience in Naval turbine drive systems discussed in Appendix A. Even with the lower system efficiency, the Brayton cycle has possible potential in Naval chiller applications. However, hecause the Brayton cycle does not meet the efficiency goals of this program, further development programs will not be suggested at this time.

\section{C-2.3.5 Magnetic Refrigeration.}

The problems with magnetic refrigeration (Appendix A.2.7) are the energy eost of refrigerating the superconducting magnets; material cost for the superconducting magnets, working material, magnet refrigerator, and regencrator; and the parasitic power associated with secondary heat transfer loops. Without significant hreakthroughs in high temperature superconductor lechnology and in magnetic working media, the requirement for a large regenerator capacity and the extremely high magnetic fields that are only available with superconducting magnets cooled to cryogenic temperatures creates an essentially insurmountable barrier to the development of a low cost technically viable magnetic chiller system.

\section{C-2.3.6 Ejector Heat Pump.}

The low efficiency of the ejector heat pump makes it non competitive with vapor compression in the vast majority of chiller applications. While reliahility of the ejector heat pump may increase with development, it would have to become very high to compete with vapor compression. Ejeckor heal pumps may have polential in low cost energy applications. However, the technology does not ofler a potential for widespread, cost effective alternatives to vapur compression chilling

\section{C-2.3.7 Thermoacoustic Refrigerator.}

While the thermoacoustic refrigurator may likely have potential for high reliability requirement applications such as spacecralt (sec Appendix A.2.9), its efficiency is too low to be considered for chillers. 


\section{C-2.3.8 Vortex Tube.}

The vortex tube technology is not applicable for chillers.

\section{C-2.3.9 Pulse Tube.}

The relative simplicity of the (orifice) pulse tube offers potential for high reliability and low cost compared to Stirling systems. However, the efficiency is at least a factor of 2 , and more likely a factor of 4 lower than vapor compression. Because of the high energy penalty, the pulse tube is not competitive for chillers.

\section{C-2.3.10 Malone Refrigeration.}

Malone refrigeration is described and evaluated in Appendix A.2.12. Current efficiencies are $20 \%$ of Carnot with the potential of reaching close to $50 \%$ of Carnot. The inherent COP is no greater than that of vapor compression.

Operational pressures are high since the cycle operates between $70 \%$ and $100 \%$ of the critical pressure of the working fluid. Even though the liquid working fluid stores less elastic energy that gases, the danger of explosion is still present. Also, the relatively heavy construction to contain the high pressures must be traded off against the smaller heat exchangers.

It is difficult to recommend a new technology that does not have the potential to reduce the energy consumption below that of vapor compression.

\section{C-2.3.11 Thermoelectric Refrigeration.}

Thermoelectric refrigeration, with a COP of about $5 \%$ of Carnot, is totally out of range regarding energy consumption. High cost is also another problem. There is no basis or indication that additional research would significantly improve the deficiencies of thermoelectric refrigeration for this application. 


\section{Appendix D}

Commercial Refrigeration 
D-1 Commercial Refrigeration-Central Refrigeration Systems for Supermarkets - State of the Art

D-1.1 Refrigerants/Lubricants D-6

D-1.2 Energy Efficiency Levels D-7

D-1.2.1 Performance at Design Conditions and Load ..................... D -8

D-1.2.2 Part Load Performance .................................................... D-8

D-1.2.3 Summary of Losses .................................................... D-9

D-1.3 Progress in the Use of "Newer" Refrigerants and Technology ....... D-12

D-1.3.1 Single Stage R22 Compressor with Liquid Injection ........... D-13

D-1.3.2 HCFC-22 Based Blends for Existing CFC-502 Systems ..... D-14

D-2 Commercial Refrigeration-Substitute Options-Supermarket Central Refrigeration Systems

D-2.1 Vapor Cycle Options - Refrigerants D-15

D-2.2 Vapor Cycle Options - Cycle and Configuration Modifications D-16

D-2.2.1 Secondary Low Side Heat Transport Loops

D-2.2.2 Secondary High Side Heat Transport Loops

D-2.2.3 Open Drive Compressors with Water Cooled Cylinder Heads D-17

D-2.2.4 Reduced Refrigerant Inventory D-17

D-2.3 Alternative Cycles D-18

D-2.3.1 Reverse Stirling D-18

D-2.3.2 Advanced Adsorption Cycle D-18 
This category includes refrigeration systems used for retail food display, cold beverage vending machines, refrigeration equipment in restaurants, bars, and commercial and institutional food service, and commercial ice machines. This diverse range of systems can be subdivided into two basic categories--supermarket central refrigeration systems and unitary equipment.

As indicated by the category name, supermarket central refrigeration systems are large capacity systems having a central condensing unit (compressor unit with oil separators, receiver, and controls; and condenser) providing for multiple frozen or refrigerated display cases, walk in cold storage, and a meat cutting area. These systems are direct expansion types, with liquid refrigerant distributed to the evaporator coils in individual display cases and the vapor from these evaporators returned to the compressor unit via suction piping. Semi-hermetic compressors are generally used in this category of equipment.

The remainder of commercial refrigeration equipment can be classified as unitary equipment; the equipment is generally self contained, with the cold storage space, evaporator, compressor, and condenser packaged into a single unit. Welded hermetic compressors are usually used. In most respects the technology in this category parallels, and is similar to the technology used in domestic refrigeration, i.e. household refrigerators and freezers. While there are exceptions to the preceding characterization of this category, in terms of component technologies, refrigerants used, and factors influencing energy efficiency, it is adequate for the purposes of this study.

A significant difference between the factors driving the design and performance of domestic refrigeration equipment and those that drive commercial refrigeration is energy efficiency standards. Federal standards mandating very clearly spelled out, and, beginning in 1993, very stringent minimum efficiency levels apply to domestic refrigerators, no such standards currently apply to commercial equipment.

As a result, the level of efficiency and performance that is offered by the different segments of the commercial refrigeration equipment industry, and demanded by their customers, is determined by tradeoffs between equipment purchase costs (capital costs) and operating costs. While operators of various commercial establishments are subject to electric rate structures that are, in part, driven by regulatory processes, the net effect of this is to alter the capital costoperating cost trade-off.

For the two categories of commercial refrigeration equipment, the outcome of this equipment cost/efficiency tradeoff is significantly different, because the financial and operating circumstances of the respective customer base is significantly different. Supermarkets are generally operated by well capitalized organizations, operating at large sales volumes and very thin net profit margins (as a percentage of sales). Control of operating costs is paramount and efficient refrigeration equipment is important. As a result, manufacturers and users are generally receptive to change and innovation, and 
there has been widespread adoption of innovations that have resulted in significantly increased energy efficiency. In contrast, the users of the unitary types of equipment tend to be smaller, undercapitalized operations. There is little customer demand for energy efficiency. Customer requirements are low first cost, compact design (maximum storage volume per unit of floor space), and reliable operation. This market is highly fragmented with numerous manufacturers, many of whom have a strong regional presence. The manufacturers of this equipment are generally resistant to innovation and change.

Only supermarket central systems have been treated in the material that follows because the total level of both energy and refrigerant consumption of these systems is considerably greater than that of unitary systems. Much of the material presented in Appendix B on domestic refrigeration is generally applicable to commercial unitary refrigeration equipment.

\section{D-1 Commercial Refrigeration-Central Refrigeration Systems for Supermarkets - State of the Art}

The vapor-compression refrigeration cycle has been the dominant technology for use in supermarket refrigeration. Beyond the current process in the industry of adapting HCFC-22 as the interim non-CFC replacement for CFC-502, considerable research and development remains to be performed before one or more choices for the long term, chlorine free technology or refrigerant becomes solidly established. Supermarket systems are complex due to their large scale, multiplicity of parallel evaporators and compressors, and the need to continuously match a load. Maintaining high reliability is critical due to the value of the extensive inventory at risk. Each substitute refrigerant must be evaluated for its effect on energy consumption, reliability, and safety.

Supermarket central refrigeration systems provide cooling for large numbers of refrigerated ("medium temperature") and frozen ("low temperature") food display cases. The usual arrangement is for large numbers (20 to 40) of display case evaporators to be connected in parallel to a remotely located condensing unit. The condensing units for low temperature evaporators most commonly consist of rack mounted semi-hermetic, parallel, one-or-two-stage compressors (up to five compressors in parallel, typical capacities range from 30,000 - 180,000 Btu/hr in one "rack" of parallel compressors), a liquid receiver, and a remote air cooled or evaporatively cooled condenser. The complex design of this equipment requires highly trained service personnel.

Supermarkets may have a variety of system types. Virtually all are remotely installed. They have the compressors or compressor systems in an equipment room. The condensers may be on the roof or inside with an evaporative condenser, or evaporative condenser with a secondary "closed circuit" water loop for condenser cooling. Some systems may have the condenser directly on the unit base and with a ventilated room to provide $100 \%$ fresh air to each condenser. Most systems have a diverting valve to route discharge gas through a secondary condenser in the air path of the store's air handler. With appropriate controls this "heat recovery" can supply all or a portion of the 
refrigeration system heat rejection to the store interior space heating requirements, replacing the heat removed from the sales area by the refrigerated display cases and meeting other cold weather heat loads. Figures D-1 and D-2 illustrate typical supermarket refrigeration system configurations, with the latter being more typical of the large supermarket. Because of their remote nature factory built units are connected in the store by a contractor. The contractor buys tubing, fittings, refrigerant and supporting components from a local wholesaler. There are many disciplines involved in making suck refrigeration system $s_{s}$ functional.

Figure D-1: Conventional Refrigeration System (Single Compressor) Used in Supermarkets

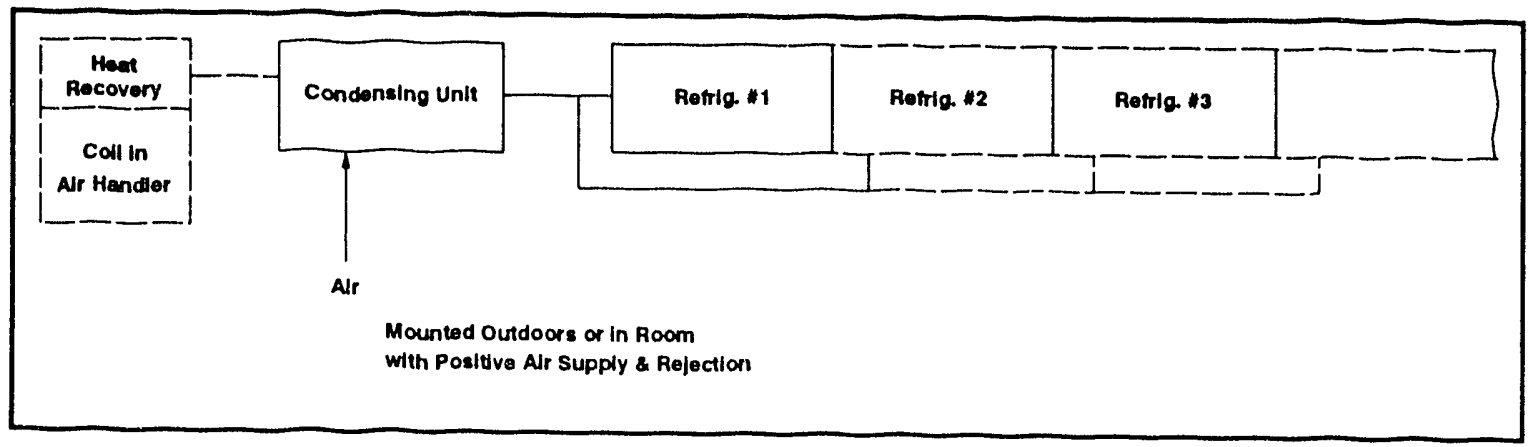

Figure D-2: Conventional Refrigeration System (Rack Mounted Parallel Compressors) Used in Supermarkets

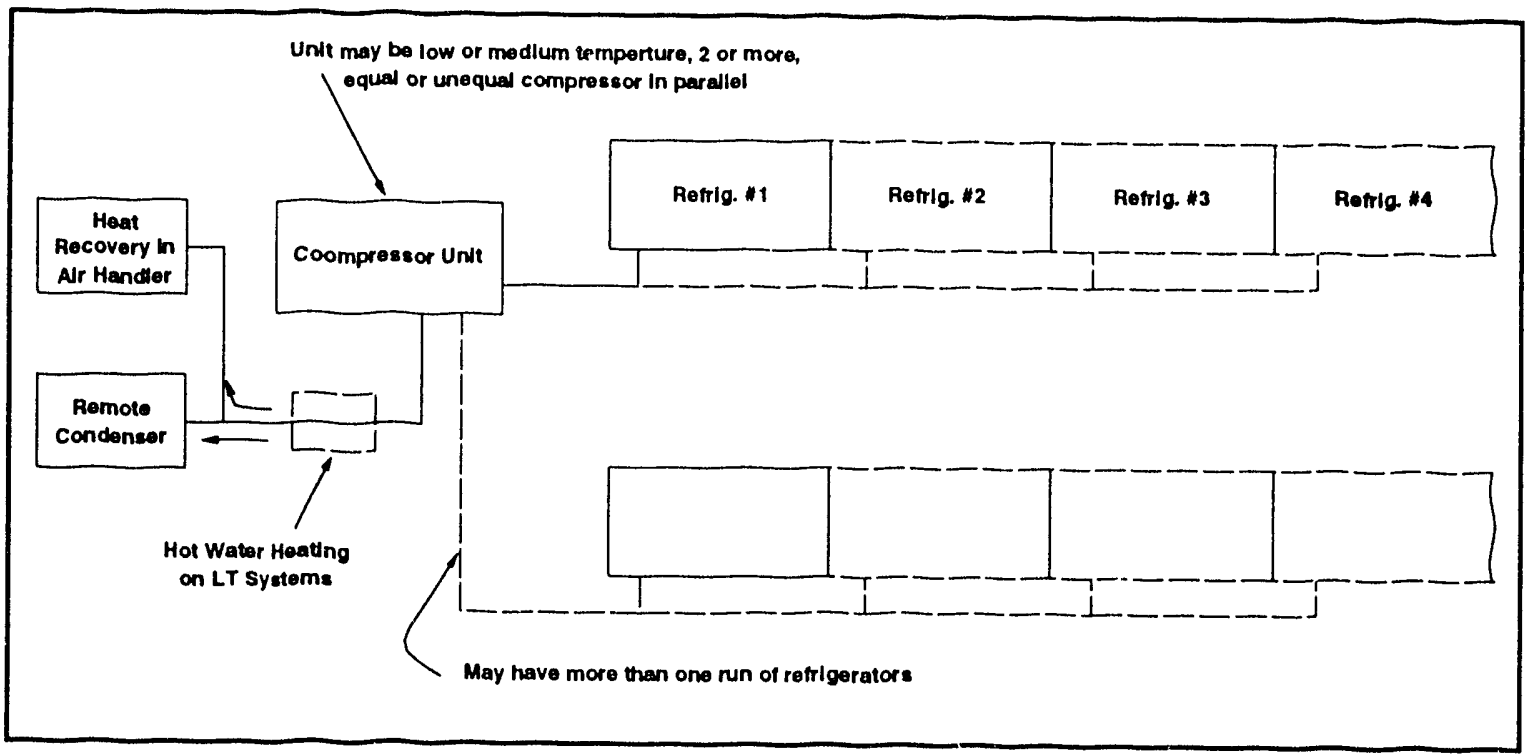

As a general rule, supermarket refrigeration systems fall into two categories, low temperature (for frozen food cases) and medium temperature (for refrigerated fresh food cases). Table D-1 presents a representative sample of typical operating temperatures for low and medium temperature refrigerated display cases. $20^{\circ} \mathrm{F}$ and $-25^{\circ} \mathrm{F}$ is representative of the saturated suction temperature for medium temperature and low temperature compressors, respectively. In addition, most supermarkets have a meat 
cutting area, which is maintained at approximately $50^{\circ} \mathrm{F}$. Refrigeration for this area is provided sometimes by a separate "high temperature" refrigeration system having an evaporator temperature of $30^{\circ}$ to $35^{\circ} \mathrm{F}$, otherwise by the medium temperature system.

Table D-1: Typical Operating Temperatures of a Sample of Various Types of Supermarket Refrigerated Display Cases (Reference Only)

\begin{tabular}{|c|c|c|c|c|}
\hline & & \multirow{3}{*}{$\frac{T_{\text {evap }}}{-19}$} & \multicolumn{2}{|c|}{ Air Side } \\
\hline \multicolumn{2}{|c|}{ Low Temperature } & & \multirow{2}{*}{$\begin{array}{c}T_{\text {out }} \\
-12 \\
\end{array}$} & \multirow{2}{*}{$\frac{T_{\ln }}{-7,-9}$} \\
\hline$\cdot$ & Ice cream or frozen juice door type & & & \\
\hline$\cdot$ & Open type other frozen food & -30 & -20 & $-5 \max$ \\
\hline$\cdot$ & Door type frozen food & -11 & -5 & 0 \\
\hline$\cdot$ & Open multi-deck frozen & -18 & -8 & --2 \\
\hline \multicolumn{5}{|c|}{ Medium Temperature } \\
\hline$\cdot$ & Produce (non-critical) & 21 & 37 & 45 varies \\
\hline & Deli Department & $\begin{array}{l}21 \\
23 \\
\end{array}$ & $\begin{array}{l}25 \\
27 \\
\end{array}$ & $\begin{array}{r}-32 \\
-32 \\
\end{array}$ \\
\hline$\cdot$ & $\begin{array}{l}\text { Multi-deck - open smoked meat case } \\
\text { (also dairy) }\end{array}$ & 18 & 32 & $\sim 36-38$ \\
\hline$\cdot$ & Single deck - meat open & 9 & 22 & $32-34$ \\
\hline$\cdot$ & Multi-deck - meat open & 11 & 22 & $32 \cdot 34$ \\
\hline - & Dairy reach-in & 18 & 28 & -34 \\
\hline
\end{tabular}

Although multiplexed systems described above are used in the majority of new installations, a large amount of supermarket refrigeration equipment uses single compressors with attached air-cooled condensers. Single-compressor systems are less efficient than properly installed and maintained multiplexed systems. However, the initial equipment cost is less and maintenance is simpler.

Several basic configurations of frozen food display cases are common: so called "reach in" units, that have large glass doors to reduce infiltration of store interior air and various open top and open deck configurations. Similar configurations are used for medium temperature, fresh food display cases. Merchandising considerations, i.e. attractive, readily accessible display of the frozen product, play a major role in the design of these cases.

A basic overview of the supermarket refrigerating system industry structure follows. As indicated in Table D-2, display cases and compressor systems for supermarkets are supplied, $80 \%$ plus, by four manufacturers. The balance of the equipment is made or assembled by smaller producers making more limited lines. As a general rule, the full line system manufacturers build the refrigerated display cases in house, starting with raw stock, i.e., stainless steel or steel sheet, glass, etc. Purchased components, i.e., fans and motors, tube fittings, lighting, etc. accounts for a relatively modest portion of the total value. Coils for refrigerated cases (evaporators) or for condensers may be fabricated in house or purchased from outside vendors. Compressors, primarily semi-hermetics, are purchased from outside vendors, primarily Copeland and Carlyle, 
and packaged into "racks" which are built up of multiple compressors, one or more refrigerant receivers, piping, and operating controls, much of which is fabricated in house.

Table D-2: Industry Structure Overview - Commercial Refrigeration - Supermarket Central Systems

\begin{tabular}{|l|c|}
\hline \multicolumn{1}{|c|}{ Manufacturer } & Approximate Market Share (1990) \\
\hline \hline Hussman & 32 \\
\hline- Hill & 12 \\
\hline- Tyler & 16 \\
\hline- Warren & 16 \\
\hline- Other & 24 \\
\hline$-\quad$ Copeland (compressors) & 87 \\
\hline $\begin{array}{l}\text { Carlyle (Carrier) } \\
\text { (compressors) }\end{array}$ & 12 \\
\hline
\end{tabular}

Table D-3 summarizes the installed capacity and the annual production of supermarket refrigeration equipment, broken down by refrigerant. There has been a trend to increase the use of HCFC-22 in new medium temperature equipment, driven in part by favorable economics, in part by the anticipated phase out of the CFC's. Total annual shipments are approximately 60,000 tons with $\mathrm{HCFC}-22$ being the major working fluid, although some CFC-502 based equipment is still being purchased. The average useful life of supermarket refrigeration systems appears to be approximately 15 years. The refrigeration systems survive longer. However, their, as originally installed, life is mostly controlled by the continued commercial viability of the store. Real market growth is nonexistent, i.e, unit sales have been steady for at least the past 10 years and the industry has added little, if any, new capacity over that time period.

Table D-3: Installed Cooling Capacity and Annual Production of Commercial Refrigeration Equipment - Supermarket Central Systems

\begin{tabular}{|l|c|c|}
\hline Working Fluid & $\begin{array}{c}\text { Installed Capacity } \\
\text { in tons }\end{array}$ & $\begin{array}{c}\text { Annual Production, } \\
\text { in tons capacity }\end{array}$ \\
\hline \hline HCFC-22 & 130,000 & 60,000 \\
\hline CFC-12 & 300,000 & Negligible \\
\hline CFC-502 & 425,000 & $<5,000$ and falling \\
\hline
\end{tabular}

The installed cost of supermarket type commercial refrigeration systems is approximately $\$ 10,000 /$ ton of cooling capacity, for the typical mix. Table D-4 presents an approximate cost breakdown by major element of the complete system. Custom design and engineering costs and installation costs together account for approximately one third of the total installed system cost. The cost per ton of low temperature capacity is higher than the cost per ton of medium temperature, given the larger compressor horsepower required for low temperature. 
Table D-4: System Cosi Structure - Commercial Refrigeration - Supermarket Central System

\begin{tabular}{|l|c|}
\hline Compressor Units & \$/ton of cooling capacity \\
\hline Condensers and Heat Reclaim Coil & 1,500 \\
\hline Walk-ins and Coils & 340 \\
\hline Controls, Valves, Piping w/installation & 1,300 \\
\hline Display Cases or Cabinets & 2,000 \\
\hline Total Equipment, installed & 4,860 \\
\hline
\end{tabular}

\section{D-1.1 Refrigerants/Lubricants.}

CFC-12, CFC-502, and HCFC-22 are the three refrigerants that are used in virtually all commercial refrigeration equipment. The use of CFC-12 has been steadily declining for many years, beginning with its displacement from low temperature equipment by the lower boiling CFC-502. By the 1980's, virtually all low temperature systems used CFC-502 as the refrigerant (this has been the case through 1990). Capacity per suction gas flow is reasonably high, compared to CFC-12, and the amount of superheat developed in the compression process is sufficiently low that a single stage compressor can be utilized. In response to the CFC phase out, as is described in Appendix D.1.3, HCFC-22 is being increasingly applied at low evaporator temperatures by electronicaliy controlled liquid injection into the suction gas of a single stage compressor, two stage compressors with intercooling, or two-stage compression with medium temperature evaporators iied into the interstage line.

CFC-12 continued to be utilized for medium temperature equipment, gradually being displaced by HCFC-22 and to a lesser extent, CFC-502. By the late 1980's, the vast majority of new medium temperature equipment used HCFC-22, which in comparison with CFC-12, results in compact, low cost compressors and refrigerant piping.

However, CFC-12 is still widely used in older equipment that is still in service, and to a negligible extent in new eq!:ipment.

With the current reirigerants (CFC-12, CFC-502 and HCFC-22) conventional lubricants are used, both mineral oils and alkylbenzene oils. Oil management is an important design consideraiion for supermarket systems, with respect to both maintaining the correct oil level in each compressor sump (in parallel compressors) and insuring oil return from the evaporators via the often long runs of suction lines. The common approach to oil management uses an oil separator and reservoir between the compressor discharge and the condenser, and individual compressor oil level controls. The oil separator minimizes the amount of oil circulating to the condenser and the low side of the system, and supplies the oil reservoir which in turn supplies the individual compressor oil level contro!s. Oil is returned from the evaporators by sufficient suction line velocity to entrain the oil, facilitated by the hot gas defrost cycle, which also heats the oil in the evaporator and suction line, reducing its viscosity. 
Table D-3 in the preceding section shows the approximate distribution of refrigerants in the current inventory of supermarket refrigeration systems. The substantial inventory of CFC based equipment is being phased out as store remodeling occurs, and as older equipment is retired. A substantial amount of CFC- 502 based low temperature equipment is likely to be still in place at the end of 1995 when the CFC phase out is complete.

Table D-5 summarizes the current usage of refrigerants in supermarket refrigeration systems. The working refrigerant charge accounts for essentially all of the refrigerant used in new equipment. Refrigerant usage for servicing (including leakage replacement) is a relatively modest proportion of usage in new equipment, with some modest CFC-12 usage to service existing equipment. As indicated in the table, CFC-12 has been essentially completely displaced by HCFC-22 and lesser amounts of CFC-502 in new medium temperature systems, while in low temperature systems CFC-502 is used exclusively.

Table D-5: Use of CFC Working Fluids in Commercial Reirigeration in the U.S. (Millions of Pounds Per Year)

\begin{tabular}{|c|c|c|c|}
\hline Supermarket Systems & & \\
\hline Working Fluid & New Equipment & Servicing $^{*}$ & Total \\
\hline HCFC-22 & 2.0 & 1.7 & 3.7 \\
\hline CFC-12 & Negligible & 4.0 & 4.0 \\
\hline CFC-502 & 1.6 & 6.3 & 7.9 \\
\hline
\end{tabular}

- Including leakage replacement.

The working fluid inventory of individual systems is quite large often amounting to 40 to 60 pounds per ton of capicity. These large inventories result from the extensive lengths of piping in such systems, as well as the overall system complexity. On average, annual refrigerant consumption in supermarket systems is on the order of one third of the total charge.

\section{D-1.2 Energy Efficiency Levels.}

About half of the electrical energy costs for a typical supermarket is for refrigeration, and is roughly comparable to the net profit for the entire store. As a result, reduced energy consumption is an impirtant factor in equipment selection.

Supermarket refrigeration cycle COP levels can be viewed in terms of the performance as design load and design conditions and in terms of the performance at part load and lower ambients.

While the design of the refrigerated display cases directly affects the energy consumption via the effect on the thermal loads, the primary emphasis of this study is on the refrigeration cycle and the effect of the CFC phase out thereon. Several basic configurations of frozen food display cases are common: so called "reach in" units, that 
have large glass doors to reduce infiltration of store interior air and various open top and open deck configurations. Similar configurations are used for medium temperature, fresh food display cases. In general, the more closed configurations have lower thermal loads, especially during periods of light traffic within the store. Merchandising considerations, i.e. attractive, readily accessible display of the frozen product, play a major role in the design of these cases.

\section{D-1.2.1 Performance at Design Conditions and Load.}

Typical COP's range from 1.0 to 1.2 for frozen food to 1.9 for meat or dairy to 2.5 for produce. Controls are employed to subcool refrigerant when the ambient temperature is below the design temperature, thereby improving efficiency. Figure D-3 examines the refrigeration cycle losses (for a low temperature system) by comparing the Carnot COP levels with actual levels. For design conditions of $95^{\circ} \mathrm{F}$ ambient temperature and a frozen display case interior temperature of $-5^{\circ} \mathrm{F}$, the Carnot COP is somewhat higher than 4.5, indicated in bar number 1. Bar 2 indicates the Carnot COP level of approximately 3 , for high and low reservoir temperatures at the typical condensing and evaporating temperatures that normally occur at these design conditions. The difference between the bar 1 and bar 2 temperatures is used to transfer heat from the evaporator or condenser coil to the air passing through the coil and to transport the heat from the coil to either ambient or the refrigerated display space via a finite flow rate of air. The third bar is the theoretical vapor compression cycle COP, for HCFC-22, with and without mechanical subcooling of the liquid to $40^{\circ} \mathrm{F}$ before expansion. The major losses involved are expansion losses and compressor discharge superheat raising the heat rejection temperature above the condensing temperature for a portion of the heat rejection. The fourth bar gives the COP of the best commercially available motor/compressor, with the difference between 3 and 4 being motor losses and compressor thermal, fluid, and mechanical losses. Finally, bar 5 gives the COP when parasitics -- primarily fans and defrost -- are taken into account.

\section{D-1.2.2 Part Load Performance.}

Relative to a basic air cooled system having fixed head pressure control and a fixed capacity compressor, part load energy savings can be obtained through wider use of available technology:

- Uneven parallel compressors, which are individually cycled on and off as needed to maintain the suction pressure to the compressor rack at the intended level. A variable speed compressor will accomplish the same result, and some uneven parallel compressor racks now include one variable speed compressor to provide a finer match to instantaneous capacity requirements.

- Floating head pressure controls allow the condensing temperature to follow the ambient temperature down to reasonably low pressures. Compared to fixed head pressure control, somewhat more sophisticated control is needed to meter the refrigerant flow to each individual evaporator, and balanced port expansion valves are required. A disadvantage is that in cold ambients with floating head pressure, the condensing temperature will be well below the level needed for heat reclaim, i.e., to 
Figure D-3: Effect of Equipment Inefficiencies on Low Temperature Supermarket Refrigeration Cycle Efficiency

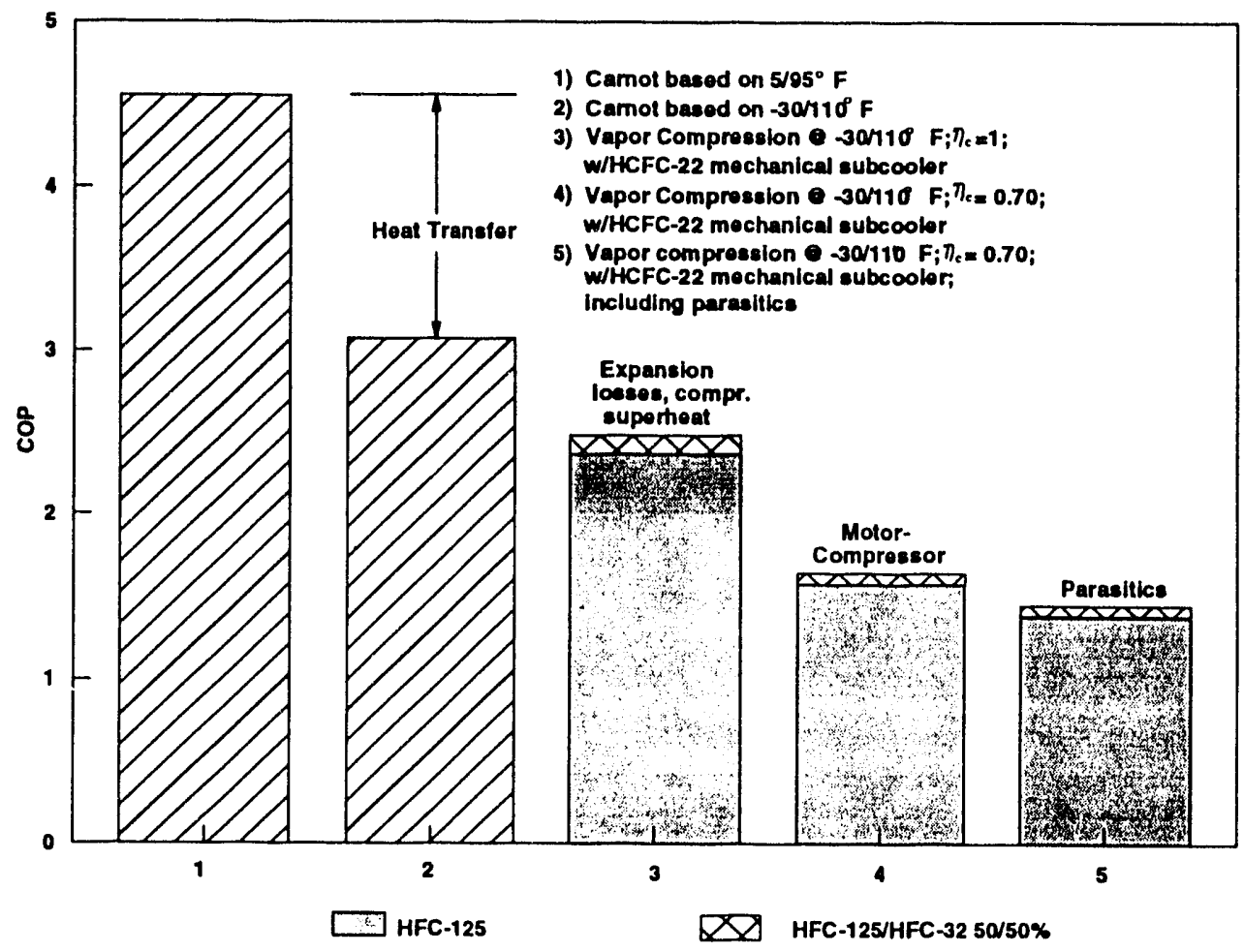

use the heat rejected from the refrigeration system for store heating. (A general consensus is that a store is better off using floating heat pressure to gain efficiency, rather than using heat reclaim.)

- Evaporatively cooled condensers, allowing the condensing temperature to approach the ambient wet bulb temperature, which is usually 10 to $20^{\circ} \mathrm{F}$ below the ambient dry bulb temperature. In dry climates, the difference between wet and dry bulb temperatures can be considerably greater. Energy savings are applicable to both full load and part load operation.

Uneven parallels and floating head pressure control are currently included in about $50 \%$ of new equipment. Together, they generally reduce energy consumption by 15 to $30 \%$. Use of space conditioning equipment that reduces relative humidity can reduce the latent load on the cases, also reducing defrost requirements for display cases.

\section{D-1.2.3 Summary of Losses.}

Table D-6 summarizes the losses discussed above, the measures that could be applied to reduce these losses, and the technical/commercial status and needed R\&D to apply the design measure. While the distribution of losses will range somewhat with the refrigerant, this is generally applicable to all vapor cycle based supermarket 


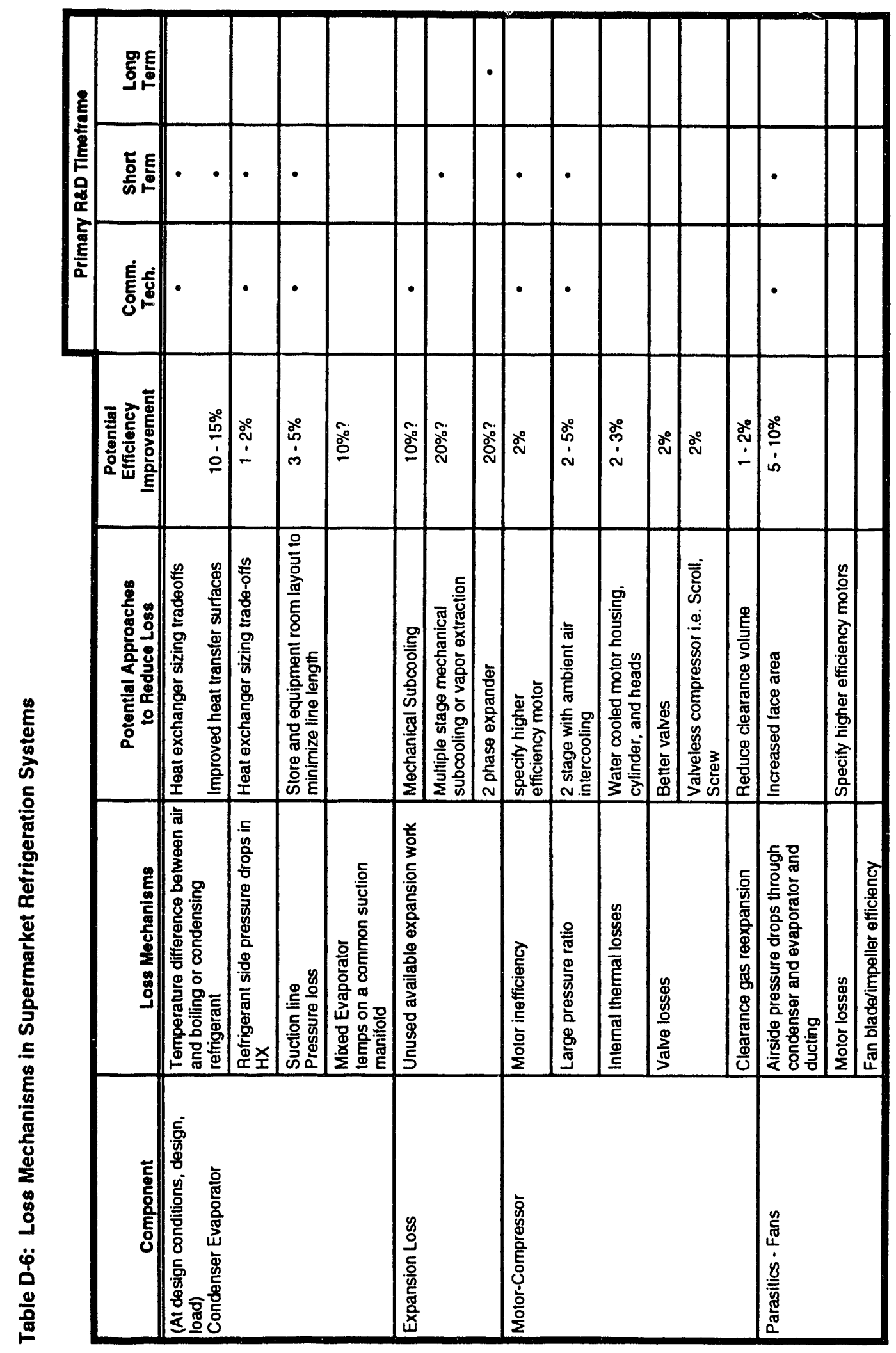

우ํ 


$$
\text { th }
$$


refrigeration systems. As indicated in the Table, most of the options to reduce losses and improve efficiency use commercially available technology. Indeed, many options, such as uneven parallel compressors, floating head pressure controls, and mechanical or ambient subcooling are in widespread use in existing stores, and account for a higher proportion of new equipment sales, reflecting the importance to the protitability of supermarkets of controlling energy costs.

A few of the areas listed in Table D-6 that are not currently used are:

- Implementation of design options that could reduce the difference between the case temperature and the saturated suction temperature at the compressor by 5 to $10^{\circ} \mathrm{F}$.

- Integration of defrost and liquid subcooling.

While the Table indicates numerous incremental losses in compressors that could be reduced, the potential gain, relative to the best compressors is fairly small. The best integral horsepower compressors have performance factors (EER's) that are about $70 \%$ of the EER associated with isentropic compression. With the efficiency of a good, 5 horsepower, 4 pole, 3 phase induction motor being approximately $90 \%$, the shaft power basis compressor isentropic efficiency is close to $80 \%$, a level that is comparable to the best compressor available in this power range for any application. Further, small incremental efficiency improvements can be expected over time, but compared to validating designs to use the new refrigerants, compressor efficiency improvement will have a decidedly lower priority in the industry over the next several years.

\section{D-1.3 Progress in the Use of "Newer" Refrigerants and Technology.}

The transition from CFC-12 and CFC-502 based supermarket refrigerations systems will occur in two stages. In the first, or interim stage, HCFC- 22 based vapor cycle technology is replacing CFC based vapor cycle technology. This stage is well under way in both commercially implemented systems and ongoing equipment and refrigerant blend development efforts.

Depending on the ultimate timing of the HCFC-22 phase out, a second stage technology that does not utilize a chlorine containing working fluid will be needed. No second stage technology has reached commercial status. The longer term substitute options for the second stage are discussed in Appendix D.2.1.

Significant progress has been made with respect to the interim, HCFC-22 based technologies. As of 1991, virtually no new CFC based low or medium temperature refrigeration systems have been purchased for supermarket installations. As described in the preceding section, HCFC-22 based medium temperature systems have been commonplace for many years. For low temperature systems, three arrangements are in production, each of which provides a means of limiting compressor discharge temperatures to levels that are consistent with reliable long term operation. These three arrangements are briefly described below. 
When the CFC phase out is completed in 2000 (under the current Montreal protocol and the Clean Air Act Amendments of 1990) or in 1995 (the likely outcome of the ongoing scientific reassessment), a significant number of CFC-502 based, single stage compressor low temperature systems will still be in service. Several HCFC-22 based refrigerant mixtures that can be used as "drop-in" substitutes for CFC-502 in these systems are being investigated, with some field tests in progress. These blends are described below.

The interim, HCFC-22 based technologies, for low temperature systems, for new equipment and for retrofitting existing CFC-502 systems, are described briefly below.

\section{D-1.3.1 Single Stage R22 Compressor.}

HCFC-22 is the only commonly available refirigerant to replace the superbly performing CFC-502. CFC-502 has an excellent history, usable for temperatures down to -40 degrees even with relatively high condensing temperatures with the simplest of refrigeration systems, single stage. HCFC-22 on the other hand, is preceded by its poor performance history in such applications, due to the high levels of superheat that are developed in the HCFC-22 compression process. It is generally accepted by the compressor manufacturers that the high limit of gas temperature, and therefore compressor component temperature in the head of the compressor is $275^{\circ} \mathrm{F}$. This is an experience factor having to do with the stability of the refrigerant and oil mixture. It is stated as a useful constraint given the available technology.

In low temperature applications much below $-10^{\circ} \mathrm{F}$ and particularly when the compressor design required the gas to do significant motor cooling and with commonly found summertime condensing temperatures, the gas temperature quickly reaches the $275^{\circ} \mathrm{F}$ level. The potential for failure caused by chemical breakdown for the oil and/or refrigerant is great. When this failure occurs the motor winding insulation is attacked by the resultant acid which is a product of the decomposition. The internal passages of the entire system become contaminated. It is a serious failure. This refrigerant may be used for low temperature applications but only if speciïic designs are applied to limit discharge gas temperatures.

\section{D-1.3.1.1 Single Stage R-22 Liquid Injection.}

Single stage compressors, with liquid injection at the suction port, have the quantity of liquid injected controlled to that needed to limit the discharge gas temperature to an acceptable level. At design conditions the vaporization of the injected liquid adds to the refrigerant vapor load to be compressed, reducing system efficiency by approximately $10 \%$ in comparison with a single stage CFC-5(2) system. At lower ambients, with a correspondingly reduced condensing temperature, liquid injection is unnecessary and there is little, if any, impact on efficiency. The additional hardware cost for implementing liquid injection should be modest. If this solution becomes common it may significantly increase the summertime electricity demand for establishments that use it. 


\section{D-1.3.1.2 Two Stage R-22 Compression - Externally Compounded.}

In this arrangement, a rack of low temperature compressors is tied to a rack of medium temperature. The vapor discharging from the low temperature compressors is combined with the vapor returning to the medium temperature compressors, which compress the combined vapor to the condensing pressure. The combining of the low stage compressor discharge and medium temperature evaporator vapor streams results in a sufficiently low suction temperature to the medium temperature compressor that excessive discharge temperatures do not occur.

\section{D-1.3.1.3 Internally Compounded R-22 Compressor.}

In this arrangement, a multicylinder compressor is manifolded so that the discharge from several first stage cylinders flows to the inlet of the remaining, second stage cylinders. As with single stage compressors with controlled, on demand liquid injection, a temperature sensor in the high pressure stage cylinder head senses high temperatures. In response, liquid is injected into the interstage manifold to the extent needed to moderate the discharge gas and cylinder head temperatures. There is an efficiency penalty associated with this use of the liquid.

Two stage compressors with interstage cooling so that the discharge of the second stage may not reach $275^{\prime \prime} \mathrm{F}$. Water cooling, liquid head cooling or other application devices may be used to accomplish this. One of the strategies being considered in accomplishing the above is liquid injection into the suction of the high stage compressor. Such injection might be controlled by a valve with a sensor at the discharge of the compressor but preferably mounted at a point closest to that which reaches the highest temperature within the head of the compressor. Efficiencies with currently available 2 stage HCFC-22 equipment are comparable to single stage CFC-502, but there is a potentially significant increase in efficiency as compared to single stage CFC-502 equipment.

\section{D-1.3.2 HCFC-22 Based Blends for Existing CFC-502 Systems.}

CFC-502 is an azeotropic mixture of HCFC-22 and CFC- 115 (approximately 50)\% by weight of each). The effect of adding the CFC- 115 portion is to reduce the compression temperature rise significantly (compared to $\mathrm{HCFC}-22$ ) and to modestly increase the capacity. An advantage of CFC-115 is that it forms an azeotropic mixture with HCFC-22. Fluids other than CFC-115 can be added to HCFC-22 to moderate the increase in discharge temperature. Four "near azeotropic mixtures" that are being developed and field tested are the duPont HP-80 and 81 blends and the Rhone-Poulenc R-69S and R-69L mixtures. Several technical papers reporting on field testing of low temperature refrigeration systems with these blends were presented at the International CFC and Halons Alternatives Conference in December 1991. 


\section{D-2 Commercial Refrigeration-Substitute Options-Supermarket Central Refrigeration Systems}

\section{D-2.1 Vapor Cycle Options - Refrigerants.}

This section addresses long range options. Vapor cycle working fluids that contain chlorine, primarily the HCFC's, are not considered here. "Interim" options based on HCFC-22 are described briefly in D.1.3.

As discussed in Appendix D.1, HCFC-22 and HCFC-22 based blends will be replacing CFC-502 for low temperature applications; HCFC-22 will also be used in most mediun temperature systems as well. An industry consensus has yet to develop on the long term, non-HCFC refrigerants for either low or medium temperature equipment. Table D-7 lists the fluid options, indicating whether they are applicable to low or medium temperature systems, and whether they are flammable or toxic. They are grouped into five categories, medium pressure HFC's, high pressure HFC's, ammonia, hydrocarbons and fluoroethers. None of these groups contains the "ideal" replacement refrigerant, at least in comparison with the characteristics of CFC-5()2 and HCFC-22.

The medium pressure HFCs are both low capacity refrigerants, in comparison with either CFC-12 or, particularly, HCFC-22. Suction line pressure losses would adversely impact the efficiency. In addition, in most applications where HFC-134a has been substituted for CFC-12, on the order of 5\% efficiency degradation has resulted. HFC-152a is flammable. Special lubricants are required.

The high pressure HFCs have the common problem of a high GWP (close to half of the GWP of CFC-12). HFC-32 and 143a are flammable. HFC-32 develops an extremely high level of superheat in the compressor discharge. HFC-32/HFC- 125 forms a very nearly azeotropic blend, superficially analogous to CFC-5(1)2, but the operating pressures are much higher than with CFC-5()2 and the compression superheat is roughly comparable to HCFC-22. Other blends (e.g., DuPont HP-62), which more nearly approximate $\mathrm{CFC}-5(2)$, are being actively pursued. Special lubricants are required. HFC-23 could be used for low temperature refrigeration in a cascade arrangement, rejecting heat to medium temperature evaporators, but the operating pressures are high and the condensing temperature is close to the critical temperature.

Institutional barriers (e.g., ASHRAE Std. 15, "Salety Code for Mechanical Refrigeration") bar the use of ammonia in direct expansion systems and the hydrocarbons in commercial occupancies, but they are excellent refrigerants, with well established thermodynamic and transport property data and stability and lubricant compatibility characteristics. They are environmentally benign and their properties generally lead to equal or higher energy efficiency than with the CFCs. ASHRAE Std. 15 does allow ammonia to be used in commercial buildings provided that a secondary loop is used to the cold cases and the ammonia equipment is installed in a suitable equipment room.

The fluoroethers are not well characterized but may provide useful characteristics. 


\section{D-2.2 Vapor Cycle Options - Cycle and Configuration Modifications.}

The technology options discussed below are modifications to the vapor cycle to facilitate the use of hazardous refrigerants, e.g. ammonia or hydrocarbons, to accommodate refrigerants that develop high suction gas superheat, or to provide for improved efficiency.

Table D-7: Vapor Cycle - Fluid Options for Commercial Refrigeration

\begin{tabular}{|c|c|c|c|c|c|c|}
\hline & & Applic & bility & & & \\
\hline Category & Fluid & Medium & Low & Flammable & Tox & $\begin{array}{c}\text { Major } \\
\text { Problem } \\
\end{array}$ \\
\hline $\begin{array}{l}\text { Medium Pressure } \\
\text { HFC }\end{array}$ & $\begin{array}{l}134 a \\
152 a\end{array}$ & $\dot{\square}$ & & $\begin{array}{l}N \\
F\end{array}$ & $\begin{array}{l}N \\
N\end{array}$ & $\begin{array}{l}\text { Suction vapor } \\
\text { pressure and density } \\
\text { too low. Need } \\
\text { synthetic lubricant. }\end{array}$ \\
\hline $\begin{array}{l}\text { High Pressure } \\
\text { HFC }\end{array}$ & $\begin{array}{c}32 \\
125 \\
143 a \\
32 / 125 \\
23 \text { (cascade) }\end{array}$ & : & : & $\begin{array}{l}\mathrm{F} \\
\mathrm{N} \\
\mathrm{MF} \\
\mathrm{N} ? \\
\mathrm{~N}\end{array}$ & $\begin{array}{l}N \\
N \\
? \\
N \\
N\end{array}$ & $\begin{array}{l}\text { High GWP. Need } \\
\text { synthetic lubricants. }\end{array}$ \\
\hline Ammonia & Ammonia & • & - & $M F$ & Y & $\begin{array}{l}\text { Toxicity, need } \\
\text { secondary heat } \\
\text { transport loop. }\end{array}$ \\
\hline Hydrocarbons & $\begin{array}{c}\text { Propane } \\
\text { Propylene } \\
\text { Cyclopropane } \\
\end{array}$ & : & • & $\begin{array}{l}F \\
F \\
F\end{array}$ & $\begin{array}{l}N \\
N\end{array}$ & Flammability \\
\hline Fluoroethers & $\begin{array}{l}\text { HFC-143a } \\
\text { HFE-125 } \\
\text { E-116 } \\
\text { CE-216 }\end{array}$ & $?$ & $\begin{array}{l}? \\
? \\
?\end{array}$ & $\begin{array}{l}? \\
N \\
N \\
N\end{array}$ & $\begin{array}{l}? \\
? \\
? \\
?\end{array}$ & $?$ \\
\hline
\end{tabular}

\section{D-2.2.1 Secondary Low Side Heat Transport Loops.}

Many of the alternatives to existing CFC based commercial refrigeration equipment require a secondary low temperature heat transport loop between the display cases and the central refrigeration equipment. The need for a secondary loop arises from either the hazardous nature of the working fluid, precluding the use of direct expansion evaporators, or the inherent characteristics of the alternative cycle. In either low or medium temperature applications, the secondary low side loop will operate below freezing, so pure water cannot be used as the heat transport medium. The basic loop can be configured as a pumped liquid loop or a pumped two phase loop.

For a pumped liquid loop, the desirable fluid characteristics are high thermal conductivity, high specific heat, and low viscosity. Fluid options include:

- Water-glycol solutions

- Water-alcohol 
In a pumped two phase loop, the heat transport fluid is pumped in the liquid phase to the cooling coils in the display cases. Heat absorbed in the coil vaporizes a portion of the fluid. Liquid and vapor return to the central refrigeration equipment where the vapor is condensed to liquid, and is again circulated to the display cases. Fluid options are many of the same candidate refrigerant fluids, but used where lubricant compatibility, other materials compatibility, and compressor discharge temperature are not considerations. For both types of secondary heat transport loop, the key technical issues are:

- The need to minimize the additional heat transfer temperature differentials introduced by the loop.

- The need to minimize the parasitic, i.e., pumping, power required to operate the loop.

- Heat gain to the cold lines (direct expansion refrigerant systems are subject to similar losses in this area).

The impact of the latter two of these considerations can be minimized through a store and central equipment layout that minimizes the length of the heat transport loop piping.

\section{D-2.2.2 Secondary High Side Heat Transport Loops.}

A high side heat transport loop, i.e., a cooling water loop, would provide condenser cooling for display cases that included a self contained refrigeration system. From the viewpoint of the store interior conditions, the interaction with the refrigerated cases would be identical: the refrigerated cases gain heat from the interior air, and this heat ultimately would be rejected to the outdoor ambient unless intentionally reintroduced to meet comfort heating needs. The potential advantages of this arrangement include:

- Low cost, plastic piping could he used. With the circulating water temperature being near room temperature, no insulation would be required, nor would heat loss or gain have a significant impact on the efficiency.

- Welded hermetic refrigeration systems having essentially no refrigerant leakage could be used. If the best hermetic compressor technology is utilized, very good energy efficiency can potentially be obtained.

\section{D-2.2.3 Open Drive Compressors with Water Cooled Cylinder Heads.}

This option, in place of the semi-hermetic compressors that are most commonly used in commercial refrigeration, provides maximum flexibility in the choice of working fluids. Locating the drive motor outside the compressor minimizes suction gas superheating and water cooling, when needed, facilitates the use of fluids that develop high levels of superheat in the compressor discharge. Working fluid change can be more readily accommodated, because there are fewer material compatibility issues and capacities can be adjusted by changing belt drive ratios between the motor and compressor.

\section{D-2.2.4 Reduced Refrigerant Inventory.}

Due to either the high cost, or potential hazards of some alternative refrigerants, system designs having significantly less refrigerant inventory would be desirable. 


\section{D-2.3 Alternative Cycles.}

Two of the alternative cycles should be considered for commercial refrigeration application -- reverse Stirling for low temperature systems and advanced absorption/or adsorption for both low and medium temperature applications.

\section{D-2.3.1 Reverse Stirling.}

For a detailed description of the basic characteristics of this technology refer to Appendix A.2.4. For low temperature commercial refrigeration, the primary incentive to evaluate reverse Stirling equipment is the high percentage of Carnot COP obtained at high lifts by this type of equipment. A key technical issue for commercial refrigeration is thermal coupling of the high and low temperature heat exchangers of the Stirling machine with ambient and the cold case. The heat exchangers of the Stirling machine need to have minimum internal volume, leading to compact configurations that do not match directly with the extended surface area needed for an external air side (except in very small capacity machines). This suggests a need for liquid coupling or using small capacity individual Stirling machines. The liquid coupled machine would probably be a remotely located central unit, coupled to refrigerated display cases via a secondary fluid loop. Small individual Stirling machines would be located in individual cold cases and reject heat to a common liquid loop.

\section{D-2.3.2 Advanced Adsorption Cycle.}

Multiple effect, solid sorbent based cycles have the potential to have highest primary energy COP of any of these alternatives.

\section{D-3 Recent and Current R\&D}

Table D-8 lists recent and current R\&D projects in commercial refrigeration. These projects represent a wide cross section of private sector participants (supermarkets, refrigerant suppliers, and compressor system manufacturers), trade associations, government agencies, academics, contract R\&D firms, and consultants. Technologies addressed range from HCFC-22 based interim technologies to HFC's, ammonia, and alternative cycles. The GAX water-cooled, ammonia absorption cycle under development by Phillips Engineering Company also has potential for scale up to commercial refrigeration systems. 
Table D-8: Recent and Current R\&D: Commerclal Refrigeration

\begin{tabular}{|c|c|c|c|c|}
\hline $\begin{array}{l}R \& D \\
\text { Organization }\end{array}$ & Sponsor & Technology & $\begin{array}{l}\text { Research } \\
\text { Description }\end{array}$ & $\begin{array}{l}\text { Efficlency } \\
\text { Improvements to be } \\
\text { Obtained through this } \\
\text { Research }\end{array}$ \\
\hline EPA - ATD & EPA & $\begin{array}{l}\text { HFCs for low } \\
\text { temperature }\end{array}$ & $\begin{array}{l}\text { Pure HCFs are blends, tested } \\
\text { in a unitary frozen case }(-1 \\
\text { HP) }\end{array}$ & \\
\hline EPA & & $\begin{array}{l}\text { Vapor cycle } \\
\text { refrigeration }\end{array}$ & $\begin{array}{l}\text { Systematic comparison of } \\
\text { alternative vapor cycles }\end{array}$ & \\
\hline Radian & $\begin{array}{l}\text { ASHRAE } \\
\text { EPA }\end{array}$ & \begin{tabular}{|l|} 
Assess refrigerant \\
issues and emissions \\
in retail food \\
refrigeration
\end{tabular} & & \\
\hline Germany & Fed. Gov. & $\begin{array}{l}\text { Ammonia vapor } \\
\text { cycle, }\end{array}$ & $\begin{array}{l}\text { Developmeni of hermetic } \\
\text { ammonia compressor/system }\end{array}$ & \\
\hline & & & & \\
\hline & $\begin{array}{l}\text { Ontario } \\
\text { Hydro }\end{array}$ & $\begin{array}{l}\text { Vapor cycle } \\
\text { refrigeration }\end{array}$ & $\begin{array}{l}\text { Demonstrate of all HCFC-22 } \\
\text { based, high efficiency } \\
\text { commercial refrigeration } \\
\text { equipment }\end{array}$ & \\
\hline & & & & \\
\hline $\begin{array}{l}30-40 \text { store chain of } \\
\text { Florida convenience stores }\end{array}$ & Same & $\begin{array}{l}\text { Ammonia based } \\
\text { vapor cycle }\end{array}$ & & \\
\hline $\begin{array}{l}\text { Ammonia } \\
\text { institute }\end{array}$ & $\begin{array}{l}7-11 \\
\text { Stores }\end{array}$ & $\begin{array}{l}\text { Packaged ammonia } \\
\text { and secondary loop }\end{array}$ & & \\
\hline Hanifer Brothers & & $\begin{array}{l}\text { Alternative fluids for } \\
\text { vapor cycle } \\
\text { refrigeration }\end{array}$ & Test of $134 \mathrm{a}$ in a store?? & \\
\hline $\begin{array}{l}\text { Pacific Gas } \\
\text { and Electric }\end{array}$ & & $\begin{array}{l}\text { Refrigeration systems } \\
\text { for warehous } \in \mathbf{S}\end{array}$ & Modeling/Optimization & \\
\hline Copeland Corporation & Copeland & \begin{tabular}{|l|}
$\begin{array}{l}\text { Vapor cycle - medium } \\
\text { temperature } \\
\text { compressors }\end{array}$ \\
\end{tabular} & $\begin{array}{l}\text { Tests to evaluate duPont MP } \\
\text { blend in existing medium } \\
\text { temperature CFC-12 } \\
\text { compressor }\end{array}$ & \\
\hline Copeland Corporation & Copeland & $\begin{array}{l}\text { Vapor cycle - low } \\
\text { temperature } \\
\text { compressors }\end{array}$ & $\begin{array}{l}\text { Tests to evaluate duPont } \\
\text { HP81 and HP80 blend in } \\
\text { existing low temperature } \\
\text { CFC-502 compressor }\end{array}$ & \\
\hline Copeland & Copeland & $\begin{array}{l}\text { Vapor cycle - low } \\
\text { temperature } \\
\text { application }\end{array}$ & $\begin{array}{l}\text { Qualification of DuPont } \\
\text { HP-62 HFC blend for low } \\
\text { temperature }\end{array}$ & \\
\hline Hussmann & Hussmann & Vapor cycle & $\begin{array}{l}\text { Evaluate HFC-134a in } \\
\text { supermarket refrigeration } \\
\text { systems }\end{array}$ & \\
\hline Shaw's Supermarket & Shaw's & $\begin{array}{l}\text { Vapor cycle - low } \\
\text { temperature } \\
\text { refrigeration }\end{array}$ & $\begin{array}{l}\text { Field test of Rhone - Poulenc } \\
\mathrm{R}-69 \mathrm{~S} \text { blend }\end{array}$ & \\
\hline $\begin{array}{l}\text { Continental } \\
\text { Refrigerator }\end{array}$ & & Vapor cycle & $\begin{array}{l}\text { Test of R-69S in a self } \\
\text { contained refrigerator }\end{array}$ & \\
\hline Grant Foods & & $\begin{array}{l}\text { Vapor cycle-medium } \\
\text { temperature } \\
\text { refrigeration }\end{array}$ & $\begin{array}{l}\text { Test of HFC-134a in standard } \\
\text { supermarket medium } \\
\text { temperature system. }\end{array}$ & \\
\hline
\end{tabular}


Table D-8: Recent and Current R\&D: Commercial Refrigeration (continued)

\begin{tabular}{|c|c|c|c|c|}
\hline $\begin{array}{l}\text { R \& D } \\
\text { Organization }\end{array}$ & Sponsor & Tochnology & $\begin{array}{l}\text { Research } \\
\text { Description }\end{array}$ & $\begin{array}{l}\text { Efficiency } \\
\text { Improvements to be } \\
\text { Obtained through this } \\
\text { Research }\end{array}$ \\
\hline Sunpower & DOE & \begin{tabular}{|l}
$\begin{array}{l}\text { Reverse Striling } \\
\text { Cycle }\end{array}$ \\
\end{tabular} & $\begin{array}{l}\text { Assess application to HVAC } \\
\text { and refrigeration }\end{array}$ & Promising for high lift \\
\hline MTI & DOE & $\begin{array}{l}\text { Reverse Stirling } \\
\text { Cycle }\end{array}$ & $\begin{array}{l}\text { Assess application to HVAC } \\
\text { and refrigeration }\end{array}$ & Promising for high lift \\
\hline Thermatek/Bassett & - & $\begin{array}{l}\text { Ammonia based } \\
\text { vapor cycle }\end{array}$ & $\begin{array}{l}\text { Development of packaged, } \\
\text { air cooled ammonia chiller for } \\
\text { secondary fi inds }\end{array}$ & \\
\hline $\begin{array}{l}\text { Refrigeration } \\
\text { Research Foundatic. }\end{array}$ & $\begin{array}{l}\text { International } \\
\text { Association of } \\
\text { Refrigerated } \\
\text { Warehouses }\end{array}$ & $\begin{array}{l}\text { Ammoria vapor } \\
\text { sensor }\end{array}$ & $\begin{array}{l}\text { Ammonia vapor sensors - } \\
\text { reliability, maintainability, } \\
\text { sensitivity }\end{array}$ & \\
\hline
\end{tabular}


Appendix E

Industrial Refrigeration 
Appendix E Industrial Refrigeration

E-1

E-1 Industrial Refrigeration - State of the Art

E-1

E-2 Industrial Refrigeration - Substitute Options .................................. E-5

E-2.1 Vapor Cycle Options - Refrigerants

E-5

E-2.2 Substitute Options - Alternative Technologies

E-7

E-2.2.1 Reverse Stirling E-7

E-2.2.2 Advanced Absorption Cycle

E-7

E-2.2.3 Reverse Brayton Cycle E-7 


\section{Appendix E Industrial Refrigeration}

This category includes the systems used to provide refrigeration for food and beverage processing; chemical, oil and gas processing; ice rinks, cold storage warehousing, and other specialty cooling requirements associated with industrial processes. This range of applications encompasses a diversity of capacities, operating temperatures, equipment types, and working fluids. This section does not address the large scale refrigeration systems associated with chemical, oil, and gas processing - these systems do not commonly use CFC and other halocarbon working fluids, often using the hydrocarbons being processed as the refrigeration cycle working fluid, the refrigeration cycle is often integrated with other process steps, and the systems are extensively custom engineered. Despite the diversity of the remaining applications, there is considerable similarity among the equipment that is currently used.

The systems typically are large, often up to thousands of horsepower. However, many industrial systems may be small, 5-30 hp. Therefore, some of the records of the sales of these systems are captured under the category of commercial refrigeration.

Industrial refrigeration systems generally are custom-designed, field erected systems utilizing some standard components and some custom designed components, especially heat exchangers. The compressors typically are open drive, and increasingly screw type. Hermetic compressors in the 15-50 hp range are $20-30 \%$ of the units, (but less than $5 \%$ in total connected horsepower).

Industrial refrigeration is one of the few applications where ammonia is extensively utilized as a working fluids. The reasons for this include the very large inventories of working fluid in some of the large systems (i.e., working fluid costs can be significant) and the attention the equipment receives on a continuous basis from skilled O\&M staff in an industrial setting.

The temperatures of application range from water cooling at $+40^{\circ} \mathrm{F}$ down to process requirements as low as $-120^{\circ} \mathrm{F}$.

An important characteristic of industrial refrigeration is the much lower level of institutional barriers to the use of "hazardous" working fluids, most notably ammonia. Ammonia is the refrigerant used in well over half (approaching 80\%) of the installed industrial refrigeration capacity, and much of the remaining capacity could be converted, or is already in the process of being converted to ammonia. Much of this technology base could be adapted to other areas, notably commercial refrigeration and HVAC chillers, given some modification of institutional restraints.

\section{E-1 Industrial Refrigeration - State of the Art}

The basic technology of industrial refrigeration is vapor-compression refrigerating systems that are either field erected from standard or slightly modified components, or are factory pre-packaged unit systems. The factory pre-packaged unit systems may be 
standard off-the-shelf or standard catalog built-to-order items, or custom designed one-of-a-kind packages built for a specific application, but fabricated from standard or slightly modified components. The key equipment components are:

- Compressors

- open-drive - reciprocating and screw, single and two stage, all refrigerants

- semi-hermetic-reciprocating, halocarbon refrigerants only

- Liquid feed control devices

- thermostatic expansion valves

- level control valves

- injectors

- Liquid chilling heat exchangers

- Air cooling heat exchangers

- Specialized cold processing equipment

- scraped surface heat exchangers

- jacketed tanks

- plate heat exchangers and freezers

Systems based on semi-hermetic compressors use halocarbon refrigerants, CFC-12, CFC-502, HCFC-22. These are generally packaged systems, and the technology, and the refrigerant substitution issues, are generally similar to commercial refrigeration technology, because the same compressors are used, and the operating conditions are similar.

Large central systems typically use open drive compressors, with halocarbons, ammonia, and hydrocarbons used as refrigerants. Ammonia is the refrigerant in a large proportion of the installed horsepower of industrial refrigeration systems, because it is low cost, has a high theoretical COP, and has excellent heat transfer properties. The typical central refrigeration plant has a centralized compressor and heat rejection plant that services multiple process cooling loads throughout the facility. Refrigerant is distributed to the evaporators at the individual process. The two common arrangements are liquid recirculation and direct expansion. In direct expansion systems, liquid refrigerant from the condenser is distributed to the individual evaporators, where it is metered by a thermostatic expansion valve. The refrigerant vapor returns to the compressor via a network of branch and main suction lines. In liquid recirculation systems, a large, low temperature accumulator is operated with a large liquid refrigerant inventory. Liquid is either pumped, or gravity fed, to the individual evaporators, and liquid and vapor return to the low temperature accumulator. The compressor suction draws vapor from the vapor space of the accumulator. The advantages of this arrangement include the ability to absorb rapid fluctuations in the process cooling loads due to the thermal flywheel effect of the large, low side accumulator. The vapor temperature at the compressor inlet is low, resulting in lower temperature compressor 
operation. In this arrangement, a large refrigerant inventory is used, and the cost of the refrigerant is an important factor, partially accounting for the widespread use of ammonia in these types of systems.

Open-drive reciprocating compressors are perceived to be more maintenance intensive than semi-hermetic compressors. This is due more to the marketing practices of the hermetic compressor manufacturers than to major differences in the maintenance requirements of the machines. From an operational standpoint, no difference ought exist, as the typical periodic maintenance required for open-drive compressors ought also be applied to semi-hermetic compressors and, in fact, they are constructed to allow for such accessibility for maintenance. The difference is strictly perceptual because of the internal motor construction of the semi-hermetic compressor (vs. the shaft seal of the open drive compressor). However, damage to machines from periodic mild liquid carryover can be a more acute potential problem with open-drive compressors than with semi-hermetics due to some protection afforded the semi-hermetic compressors by the pre-heating of the suction vapor from the motor.

Typically for those systems where air-cooled/semi-hermetic compression is selected, the primary objective is mechanical/operational simplicity. Thus, single-stage compression is the choice for hardware and the specific operating temperature requirements and the compressor size and operating power at those temperature, dictate the choice of refrigerant.

Overall, the technology is mature and the problems are lew. One chronic problem area is strictly mechanical, economically driven and easily solvable by method changes; that is, the joining methods typically employed for small tuhing tend to be sensitive to vibration and physical abuse and thus extremely vulnerable to breakage and ultimate leakage of refrigerant. Surer joining methods already commercially available at higher costs can solve this problem.

Where operational simplicity is not a primary requirement, i.e., where operations and/or maintenance personnel are in attendance, typically operational economy is also a concern and more efficient open-drive compressors and water cooling are also chosen. Such systems may be factory-packaged or field-erected. Again, operating temperatures will partially dictate the choice of refrigerant, but single-stage operation for low temperature applications is not a limitation so that, where halocarbon refrigerants are the preferred choice (where codes restrict the use of refrigerant or where halocarbon(s) is more readily available), $\mathrm{R}-22$ predominates.

For large field-erected systems in all phases of the food industry, ammonia predominates.

There are numerous plants in the 15 - 25 year age group that were built to utilize available machinery technology at the time that either use solely R-12 or R-22 or use hybrid R-12/NH, cascade. Many of the owners of these plants are either currently engaged in converting the facilities to ammonia, or are developing strategies and designs to convert them to ammonia at a later date. 
Table E-1 indicates the major companies in the industrial refrigeration field. The largest manufacturers of large industrial compressors in the U.S. are Vilter and Frick, having combined sales of roughly $\$ 85$ million. The overall size of the industry is about $\$ 500$ million annually, divided among the equipment manufacturers and the system integrators, such as RECO. Most industrial refrigeration facilities are custom-designed and fewer than 5,000 of the larger systems are installed annually, over a broad range of applications. Major components, such as compressors, are made in relatively small quantities on an as-ordered basis. Modern machine tooling is utilized. However, there is no opportunity for mass production economies due to the small number of any given compressor made on an annual basis. This structure does, however, allow the industry to change compressor mix or design details with little disruption.

Table E-1: Industry Structure Overview-Industrial Refrigeration

\begin{tabular}{|l|l|}
\hline \multicolumn{1}{|c|}{ Company } & \multicolumn{1}{c|}{ Products } \\
\hline \hline Frick (owned by York International) & - Screw compressor plus other components \\
\hline Vilter & $\begin{array}{l}\text { Reciprocating compressors and components } \\
\text { (import screw compressors) }\end{array}$ \\
\hline Dunham-Bush & - System packages \\
\hline Sullair & - Screw compressors and components \\
\hline FES (subsidiary of Carrier) & - Screw compressor supplier \\
\hline RECO (owned by York International) & - System packages \\
\hline LEWIS & - Manufacturers HX \\
\hline Bohn & - Manufacturers HX and freezers \\
\hline Hussmann & - System packager \\
\hline
\end{tabular}

Table E-2 indicates the annual shipments of industrial refrigeration compressors by working fluid and compressor type. The total shipments are about 440 thousand tons with HCFC-22 and ammonia being the major working fluids. The useful life of most industrial refrigeration systems is about 20 years. Sales of systems have been more or less level for many years. The estimated installed capacity of equipment is roughly 18 million tons representing about 20 years of production.

Table E-2: Shipments of Refrigeration Compressors

a. Annual Shipments (tons/yr)

\begin{tabular}{|l|c|c|c|c|}
\hline Compressor Type & CFC-12 & HCFC-22 & CFC-502 & NH $_{\mathbf{3}}$ \\
\hline Screws & - & 68,000 & - & 170,000 \\
\hline Open Drive Reciprocating & 13,000 & 20,000 & 15,000 & 100,000 \\
\hline Hermetic Recip 15 hp \& up & 7,000 & 30,000 & 10,000 & \\
\hline
\end{tabular}

b. Installed capacity is approximately 18 million tons assuming inventory equals 20 years at current shipments. 
Table E-3 provides an estimate of the current use of working fluids in this sector. The use of CFC-12 and CFC-502 are seen to be quite modest being only about 4 million pounds annually. This reflects the relatively small size of this industry and the predominant use of HCFC-22 and ammonia.

Table E-3: Overview-Use of CFC Working Fluids in Industrial Refrigeration (U.S., 1989)

\begin{tabular}{|l|c|c|c|}
\hline \multicolumn{1}{|c|}{ Working Fluid } & $\begin{array}{c}\text { New Equipment } \\
\text { (mm lb/yr) }\end{array}$ & $\begin{array}{c}\text { Servicing* } \\
\text { (mm lb/yr) }\end{array}$ & $\begin{array}{c}\text { Total } \\
\text { (mm lb/yr) }\end{array}$ \\
\hline \hline HCFC-22 & 6.66 & 13.3 & 20 \\
\hline CFC-12 & 0.3 & 2 & 2.3 \\
\hline CFC-502 & 0.4 & 0.8 & 1.2 \\
\hline Ammonia & 12 & 11 & 23 \\
\hline
\end{tabular}

Servicing based on $10 \%$ annual loss of inventory equal to 20 years current for HCFC-22 CFC-502

CFC-12 losses estimated @ $30 \%$ of current shipment levels to account for many large central plants built 1950-1970

* $\mathrm{NH}_{3}$ losses estimated @ $3 \%$ for 30 years

As indicated by Table E-4, the working fluid inventories of individual systems is quite large, often amounting to 9 to 30 pounds per ton of capacity. These large inventories result from the extensive lengths of piping in such systems and from designs employing large storage volumes of cold refrigerant as part of the overall control strategy. The large working fluid inventories can result in the cost of working fluid being an important consideration.

The cost of industrial refrigeration systems range from $\$ 2800$ per ton for site built units to about $\$ 1500$ per ton for unitary equipment. The major subsystems impacting on cost are the heavy duty compressors ( $\$ 200$ to $\$ 400$ per ton) and the heat exchangers (roughly $\$ 500$ to $\$ 800$ per ton). Equipment typically represents about $60 \%$ of the system installed costs.

\section{E-2 Industrial Refrigeration - Substitute Options \\ E-2.1 Vapor Cycle Options - Refrigerants}

The same substitute refrigerants that are potentially applicable to commercial refrigeration (listed in Table D-8 in the Appendix D) are potentially applicable to industrial refrigeration systems that are currently using CFC-12, CFC-502, or HCFC-22. In contrast to commercial refrigeration, both institutional and technical factors will allow substitutes to be more readily adopted.

- As noted above, ASHRAE Std. 15, Safety Code for Mechanical Refrigeration [1] places no prohibitions on refrigerant choice in industrial occupancies, facilitating the use of ammonia and hydrocarbons. 
Table E-4: Refrigerant Charges (Industrial Refrigeration)

\begin{tabular}{|c|c|c|c|c|}
\hline System Type & $\begin{array}{c}\text { Temperature } \\
\text { Range } \\
\end{array}$ & Refrigerant & Refrigerant Feed & $\begin{array}{c}\text { Refrigerant Charge } \\
\text { (lb/ton) }\end{array}$ \\
\hline \multirow[t]{3}{*}{ Unitary } & \multirow{2}{*}{$\begin{array}{c}\text { High } \\
\& \\
\text { Med } \\
\end{array}$} & CFC-12 & $\begin{array}{c}\text { Thermal Expansion } \\
\text { Valve } \\
\text { (TXV) }\end{array}$ & $8.5-10$ \\
\hline & & HCFC,-22 & TXV & $8-9$ \\
\hline & Low & CFC-502 & TXV & 10 \\
\hline \multirow{6}{*}{$\begin{array}{l}\text { Central } \\
\text { Plant }\end{array}$} & \multirow{4}{*}{$\begin{array}{c}\text { Med } \\
\text { (Air Cooled) }\end{array}$} & CFC. 12 & TXV & $15-25$ \\
\hline & & CFC-12 & $\begin{array}{l}\text { Liquid Recirculation } \\
\text { (LR) }\end{array}$ & $50-60$ \\
\hline & & HCFC-22 & TXV & $12 \cdot 22$ \\
\hline & & & LR & $45-55$ \\
\hline & \multirow{2}{*}{$\begin{array}{c}\text { Low } \\
\text { (2-Stage) }\end{array}$} & HCFC-22 & LR & $45 \cdot 55$ \\
\hline & & Ammonia & LR & $22-27$ \\
\hline
\end{tabular}

- The open drive compressors used in industrial refrigeration systems are often suitable for a range of refrigerants. With the motor located outside the compressor, refrigerant compatibility considerations are simplified and heat dissipated within the motor does not heat the refrigerant. The latter point, combined with the availability of water cooled cylinders and heads allows the use of high compression superheat refrigerants (e.g., ammonia, HFC-32, HCFC-22) whose use in hermetic and semi-hermetic systems is restricted to moderate single stage lifts.

Where codes allow and prudence and logical consideration for safety concerns dictate, ammonia is a direct substitute for R-22 and R-12 but not necessarily a drop-in. The constraints on substitution are hased on materials of construction, compressor size and type, and motor size. There are some R-22 systems wherein ammonia could be a drop-in substitute with only a few changes required in controls.

Development of unitary air-cooled ammonia systems has already hegun. One manufacturer has a line of units catalogued, has sold one and has indicated a high level of interest for additional potential sales. Where codes limit the application of ammonia to secondary refrigerant type systems only, a chilled water or antifreeze solution must be used as the secondary coolant. In applications such as these, the preferred heat exchanger is typically a compact plate and frame type. There are several commercially available for any refrigerant and their advantage in size, high heat transfer rates and low refrigerant charge: capacity ratio is what establishes their desirability. Two drawbacks exist in this particular application. One is the added costs associated with the secondary coolant loop. The capital cost will typically be higher than a direct system, if for no other reason than the addition of the liquid pumps and the associated electric gear. The pipe sizes will be different than the refrigerant pipes, but possibly of different material than the refrigerant piping and at lower design pressures, which may mitigate some of the added capital cost. The second drawback is the heat transfer temperature differential 
and the parasitic power associated with the secondary coolant loop, which would also include the operating power of the air or process cooler, which could also be higher or lower than that of the direct refrigerant unit.

\section{E-2.2 Substitute Options - Alternative Technologies}

Three alternative cycles should be considered for commercial refrigeration application-reverse Stirling for low temperature systems and advanced absorption/or adsorption for both low and medium temperature applications, and reverse Brayton cycle.

\section{E-2.2.1 Reverse Stirling}

For a detailed description of the basic characteristics of this technology, refer to Appendix A.2.4. For low temperature refrigeration, the primary incentive to evaluate reverse Stirling equipment is the high percentage of Carnot COP obtained at high lifts by this type of equipment. A key technical issue for industrial refrigeration is thermal coupling of the high and low temperature heat exchangers of the Stirling machine with ambient and with the process cooling load. The heat exchangers of the Stirling machine need to have minimum internal volume, leading to compact configurations that do not match directly with the extended surface area needed for an external air side (except in very small capacity machines). This suggests a need for liquid coupling. The liquid coupled machine would probably be a remotely located central unit, coupled to the process cooling loads via a secondary fluid loop.

\section{E-2.2.2 Advanced Absorption Cycle}

Multiple effect, solid sorbent based cycles have the potential to have highest primary energy COP of any of the alternatives.

\section{E-2.2.3 Reverse Brayton Cycle}

An open recuperated, reverse Brayton Cycle is potentially comparable in efficiency to vapor cycle for blast freezers. While the vapor cycle is inherently higher in efficiency than reverse Brayton, the power consumption of the air blast blowers is a significant parasitic in vapor cycle based system that would be largely absent from a reverse Brayton cycle system. Air is the working fluid, so safety and ozone depletion potential are not issues. 


\section{References}

[1] ASHRAE Standard 15-1989. Safety Code for Mechanical Refrigeration 
Appendix F

Insulation Applications 
Table of Contents

Appendix F Insulation Applications ......................................................... F-1

F-1 Refrigerator/Freezers and Freezers ............................................... F-1

F-1.1 State-of-the-Art ........................................................... F-1

F-1.2 Substitute Options ...................................................... F-1

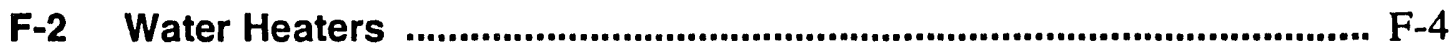

F-2.1 State-of-the-Art ........................................................ F-4

F-2.2 Substitute Options ........................................................ F-4

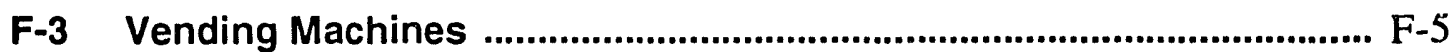

F-3.1 State-of-the-Art ........................................................ F-5

F-3.2 Substitute Options ........................................................ F-5

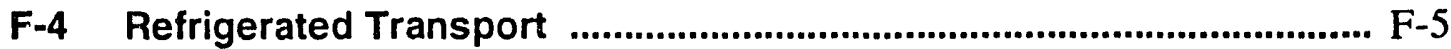

F-4.1 State-of-the-Art .......................................................... F-5

F-4.2 Substitute Options ......................................................... F-6

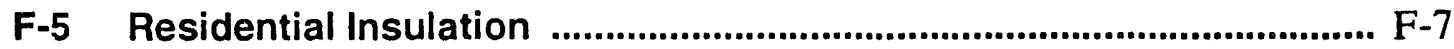

F-5.1 State-of-the-Art .................................................................. F-7

F-5.2 Substitute Options ........................................................ F-7

F-6 Foundation (Inside and Outside) ............................................. F-8

F-6.1 State-of-the-Art ........................................................... F-8

F-6.2 Substitute Options ........................................................ F-9

F-7 Commercial Construction (Walls and Foundations) ......................... F-9

F-7.1 State-of-the-Art ............................................................. F-9

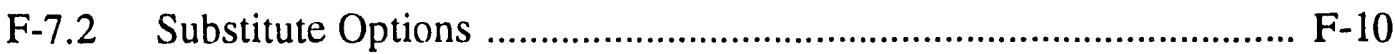

F-8 Low Slope Roofs ......................................................................... F-10

F-8.1 State-of -the-Art .......................................................... F-10

F-8.2 Substitute Options ...................................................... F-11

F-9 Current R\&D Efforts .................................................................. F-11 


\section{Appendix F Insulation Applications}

\section{F-1 Refrigerator/Freezers and Freezers}

\section{F-1.1 State-of-the-Art}

Most currently built domestic refrigerator/freezers use CFC- 11 blown polyurethane (initial R-value/inch of 8.3). The use of fiberglass (R-value/inch of 4 ) in the doors is still in practice in some units while most designs are now using blown polyurethane.

The insulation must be compatible with the liners and acceptable for use in the proximity of food products. The temperature of insulated compartments are typically set at $38.0^{\circ} \mathrm{F}$ for the fresh food compartment and $5.0^{\circ} \mathrm{F}$ for the freezer. The foam insulation used in currently produced units serves as the structural support for the refrigerator/freezers.

A short-term use of substitute blowing agents is likely for this application. One of the main obstacles which has yet to be overcome is the incompatibility of the blowing agent and the refrigerator/freezers liners (blowing agents HCFC-123 and HCFC-141b produce cracking of the liners). Another blowing agent which is possible is water. In this case the gas left in the foam is $\mathrm{CO}_{2}$. However, $\mathrm{CO}_{2}$ has a high diffusion rate through the polyurethane foam which accelerates the aging process and reduces the thermal resistivity. If proper facings are uses the diffusion can be reduced and possibly eliminated.

Additionally, the initial resistivity of foams blown with a alternate agents is typically lower ( 6 to 8 for HCFCs and 5 to 6 for water). With new energy requirements being imposed in the U.S. for refrigerator/freezers, the use of such insulations would require thicker sections. As a consequence, either the interior volume must be decreased or the external dimensions increased.

\section{F-1.2 Substitute Options}

Figure F-1 shows the energy consumption for a typical $18 \mathrm{ft}^{3}$ refrigerator/freezer [1] decreases from $370 \mathrm{Btu} / \mathrm{hr}$ to below $130 \mathrm{Btu} / \mathrm{hr}$ as the thermal resistivity of the insulation increases from 4 to 40 . From this and previous studies [2] it can be seen that insulations that achieve an effective resistivity above about 20 reduce the insulation heat leak to the point that it is no longer the overwhelming factor. The long term options include:

- Use of alternative blowing agents such as water, perfluoroalkanes, HFCs, or new blowing agents. These will typically have a lower resistivity and hence may require thicker insulation sections. The insulation is currently polyurethane but blown 
phenolics may be possible, with the phenolics providing better aging characteristics. Further research is required in the development and characterization of new blowing agents.

Figure F-1: $18 \mathrm{ft}^{3}$ Refrigerator/Freezer Energy Consumption

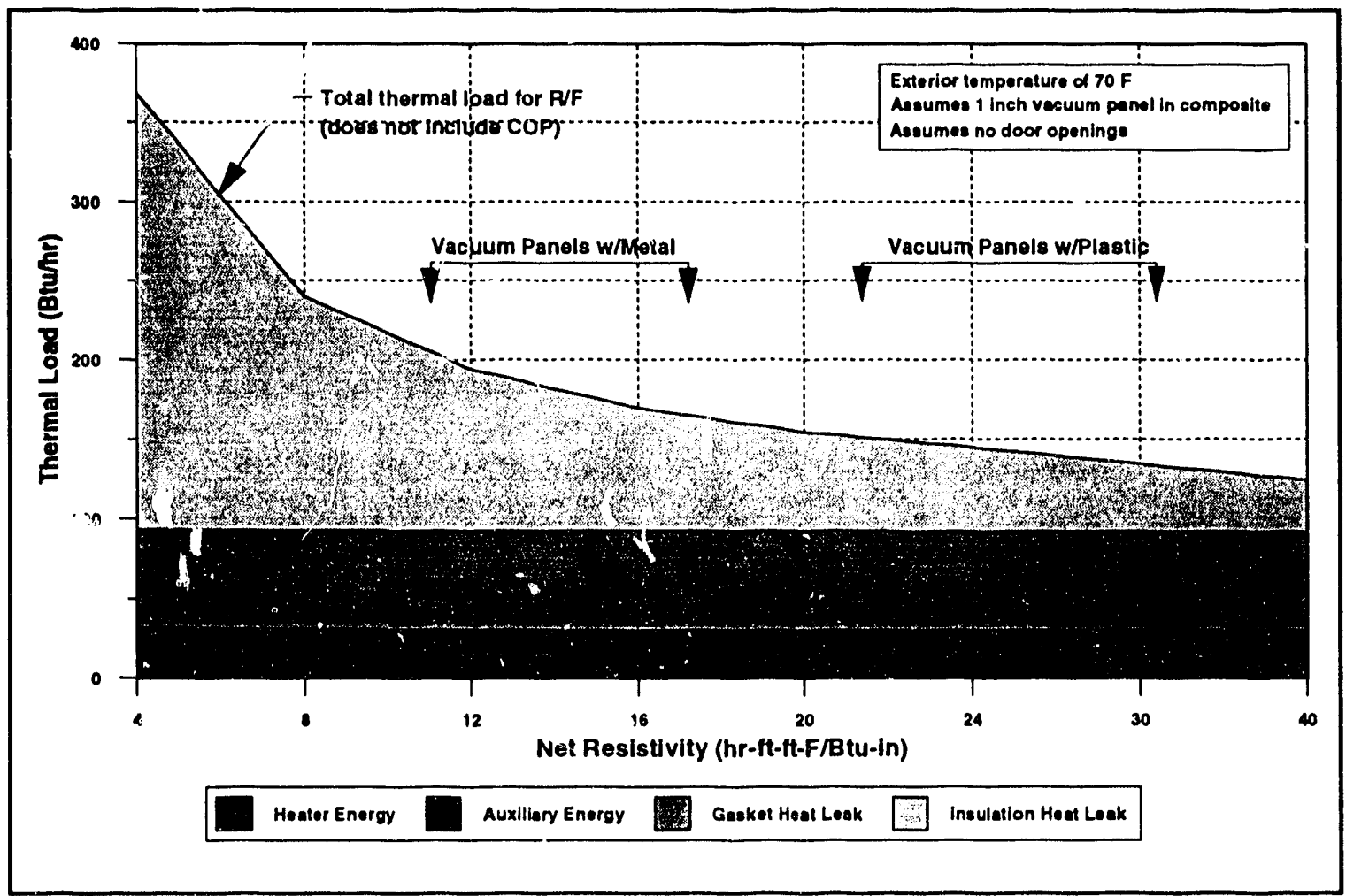

- Use of evacuated insulation panels. These could be combined with foam to reduce the edge losses and to improve the structural characteristics. The entire range of fills which were described in Appendix A could be used. The added weight of the insulation could be a problem, which could double or triple the cabinet weight depending on the type of enclosure. This increased weight not only affects the instaliation and consumer ease of moving, but specific drop tests and storage criteria must be passed. A trade-off could be made in the number of panels used for the insulation system. If single panels are used per each side, a total of 5 fi i the main cabinet, then the chance of destroying a large portion of the insulation is creased; $t^{-}$improve the reliability many smaller panels could be used, but this would increase enire losses and would mean that a thicker insulation would be reqi:ired.

- Use of a single vacuum enclosure which forms the cabinet. This type of system is proposed by $\mathrm{MBB}$ and would use diatomaceous earth as the fill (technically any fill is possible). The reliability of this type of insulation design would be a major concern. Any defect or dam: ge to the insulation would eliminate the vacuum in the 
entire insulation cabinet and thereby reduce the benefits of the insulation. Manufacturing issues must also be resolved to determine the cost competitiveness of this type of insulation.

- Use aerogels for the insulation. For the evacuated aerogels, the issues are similar to the evacuated panels except that the weight penalties are not as great ano the vacuum requirements are one order of magnitude less stringent. The unevacuated aerogels could be used, with a potential doubling of the resistivity over current foams. If the aerogels with resistivities of 15 are developed then the insulation package would be relatively lightweight, environmentally safe, and not require a vacuum system. These types of aerogels could be formed into panels or into full cabinets. The second type of system would eliminate losses through the corners. The last consideration is the exposure to moisture. If this current problem has not been solved, additional barriers or enclosures will be required. The aerogels can be exposed to low levels of moisture but the effects over time must be characterized. Additionally, foam or other support structure must be provided.

- Use of high-R gas panels. The current systems, described in Appendix A, use soft panels and therefore can provide no structural integrity. The aging of these panels must be examined as well as the possibilities for development of better baftles and enclosures.

Any of the advanced insulation techniques will require major changes in refrigerator cabinet design and manufacture which will require substantial investment and lead time. Any evacuated system requires a test technique which assures long life integrity of the envelope system to prevent gas diffusion into the panels. Failures in service will be catastrophic, i.e., refrigeration systems may not be able to maintain proper interior conditions, condensation on the outside of the cabinet with water puddles on the floor may occur, and substantial increase in energy consumption. The likely "fix" would be to replace the unit. The economic consequences of a series of such failures could be fatal to a manufacturer.

Other options for refrigerator/freezers and freezers which are not considered as likely are:

- Fiberglass: due to the low resistivity.

- Extruded polystyrene: due to the low thermal resistivity.

- Evacuated foam: due to the harsher vacuum requirements, if weight is a limiting issue then these panels may become more attractive (density if evacuated foam is 2 $\mathrm{lb} / \mathrm{ft}^{3}$ and evacuate panels in the 6 to $\left.28 \mathrm{lb} / \mathrm{ft}^{3}\right)$.

- CVI: due to the high edge losses in relatively small panels. 


\section{F-2 Water Heaters}

\section{F-2.1 State-of-the-Art}

About half of the water heaters sold use CFC-11 blown polyurethane foam (R-value/inch of 6.9, lower than other foams); the other half uses fiberglass. The typical water heater is cylindrical and requires insulation which can be formed into this type of configuration.

The use of foams with the alternative blowing agents is possible as a near term solution, in addition to the use of fiberglass. In most instances the size constraints are not as great as with refrigerator/freezers, thereby allowing the use of a thicker insulation system. Also, water heaters are stationary items once installed so that increased weight is of lesser concern once installed. Transportation costs increases due to additional weight may be an issue. A critical area to insulate properly is the top of the water heater. Good sealing between the top and the side must be achieved to limit the heat loss.

\section{F-2.2 Substitute Options}

The options which are expected to be long-term include:

- The use of foams with alternative blowing agents. The flammability of the blowing agents must be zero due to the type of application, especially in the use of gas fired water heaters. The use of water blown foams is also very attractive for this type of application since the foam can be placed in an all-metal enclosure. This may reduce the aging problem of the water blown foam. A thicker foam section will still be required to maintain the overall thermal resistance.

- The use of evacuated loose fill systems. In this case the use of a system similar to the MBB refrigerator/freezers design would be favorable since the geometry is a cylinder. It may be possible to fabricate smaller panels using plastic enclosures but the higher temperature would make this more difficult. The plastic would have to be able to survive long periods of time exposed to water temperatures of approximately $140^{\circ} \mathrm{F}$ while maintaining the vacuum. Glass enclosures might be preferred to polymer designs.

- Aerogels can be formed into the proper shape and evacuated, back-filled with a high-R gas, or left as an air filled insulation. Any of these options are possible, especially since an all-metal or glass enclosure is available.

- Use high-R gas panels. These could also take advantage of the all-metal enclosure. The baffles would have to be able to withstand the operating temperatures and may require that metal foils be used.

- The use of CVI as in a dewar type of system. This application is very similar to a common Thermos and could be a likely application. The cost would have to be investigated. 
Options for water heaters which are not likely include:

- Evacuated foam: due to the difficulty in evacuating the foam to the required level.

\section{F-3 Vending Machines}

\section{F-3.1 State-of-the-Art}

Vending machines are similar to domestic refrigerator/freezers in design. They use CFC-11 blown polyurethane foam. ICI is currently providing an all water blown foam for use in vending machines [3]. The typical ageing problem is eliminated in this application by using metal external shell and internal liner if the shell and liner are completely airtight. The space limitations are determined by the location of the vending machine. In certain locations the cost of floor space will be very high and a compact design will be desired. No energy limitations have been imposed on vending machines and they can, therefore, use less efficient insulation systems although in the future, energy conservation considerations will probably demand more stringent insulation standards. In the near term, the use of alternative blowing agents is very likely, especially the use of water blown foams.

\section{F-3.2 Substitute Options}

The alternatives which are possible include:

- Alternative blowing agents such as water, perlluoroalkanes, HFCs, or new blowing agents;

- Evacuated insulation panels;

- Single vacuum enclosure which forms the cabinet;

- Aerogels;

- High-R gas panels; or

- Non-evacuated fumed or percilitated silica panels $(\mathrm{R}$-value/inch $=5.5)$.

The attributes of all these approaches are the same as listed for refrigerator/freezers.

Other options for vending machines which are not considered as likely are:

- Fiberglass: due to the low thermal resistivity.

- Extruded polystyrene: due to the low thermal resistivity.

- Evacuated foam: due to the harsher vacuum requirements, if weight is a limiting issue then these panels may become more attractive.

- CVI: due to the high edge losses in relatively small panels.

\section{F-4 Refrigerated Transport}

\section{F-4.1 State-of-the-Art}

The typical insulation for refrigerated transport vehicles is CFC-11 blown polyurethane. HCFC-22 is used in some cases as the blowing agent, where the thickness of the 
insulation varies anywhere from 0.6 to 5.0 inches [4]. Prior to foam, fiberglass was used in thicknesses up to 6 inches. A separate mechanical structure is provided in some vehicles while others use the foam as the sole structural member. One drawback to using the foam for structure is that it may delaminate over time. The exterior shell is typically aluminum and the internal liner is fiberglass. The cost competitiveness will tend to drive the technology used.

In the short-term, the use of fiberglass (due to low cost) or foams with alternative blowing agents will likely be used. Disadvantages with a fiberglass insulation include the increased weight and the requirement of a full structural system.

\section{F-4.2 Substitute Options}

The likely long term solutions for refrigerated transport are:

- Alternatively blown foams. The use of liberglass and aluminum liners may limit the diffusion sufficiently that it is no longer an issue, but delamination can lead to free standing foam without facers and aging will proceed. Additionally, the low weight of foams is very attractive for this application.

- Expanded polystyrene, although lower in resistivity, has a low weight and may be applicable.

- The use of evacuated loose fill systems and the associated increased weight makes them less attractive for this application. Using evacuated aerogels or foam may be more attractive, although, attempting to develop an insulation which must be able to survive the vibration environment of a moving vehicle may he difficult. The use of polymers as the enclosure may also be more difficult due to the temperature range which will be experienced. For a vehicle traveling through the desert, the ambient temperature could well exceed $100^{\circ} \mathrm{F}$ and in colder climates could drop to below zero (based on anbient tempertures). The polymer would have to be well suited to both these extremes while maintaining the vacuum and experiencing the vibratory environment.

- The use of non-evacuated aerogels is attractive since they are relatively light and should be able to provide sufficient insulating value. The issue of exposure to moisture must still be examined. Since the vehicles can be designed with support systems, the aerogel need not be a structural member.

- The use of panels filled with high-R gases is also attractive for this application due to the low weight. Similar issues with the plastic enclosures must be examined. Also, effects of loss of the gas or air diffusion must be reviewed.

- CVI panels may be applicable to this application due to the larger areas which must be covered. With the lower edge to area ratio the insulation becomes more effective and could provide a vehicle with increased internal volume. 
- Evacuated arrulus space systems similar to cryogenic over the road trailers which include a vacuum pump are quite common.

\section{F-5 Residential Insulation}

\section{F-5.1 State-of-the-Art}

Typical insulating materials for residential applications which use CFCs are:

- CFC-11 blown polyurethane board, blown, and sprayed in place of foams;

- CFC-12 extruded polystyrene board;

- CFC-11 or CFC-113 blown phenolic foam board (no major U.S. supplier currently exists).

Fiberglass insulation, in the form of batts, is the primary insulation used in homes. The use of foams varies depending on the specific application. New and old construction have different requirements. In old construction if the $\mathrm{R}$-value is to be increased in an already existing space with minimal modilication, an insulation with a higher resistivity will be required.

For new construction the use of tiberglass can be used to increase the $R$-value of the insulation section. This would require that thicker walls be built which would likely increase the cost of construction. High density fiberglass batts with thermal resistivities of 4.3 are on the market. Foam boards are typically used as sheathing. This is a very compact and lightweight method of increasing the overall $R$-value of walls and roofs.

In retrofits, where older houses are under renovation or improvement, it would be more costly to increase the wall thickness. The economic value assigned to floor space has not been characterized but would likely vary depending on location, environmental considerations, and energy cost. Blowing foams into existing spaces is a means of quickly and economically adding insulation to existing spaces. Foam use in retrofits would be common. In new housing, the use of foams could generally be eliminated while still providing a high $\mathrm{R}$-value insulation system but potentially with higher costs. The deciding factor would be the value of floor space and building materials cost.

Other near term solutions include HCFC blown foams, water blown foams, and expanded polystyrene. These would not have the same performance of current foams and either energy penalties would be incurred or land/floor space would be lost.

\section{F-5.2 Substitute Options}

The materials which could be used to replace the insulation systems mentioned above include:

- Use of foams with alternative blowing agents. These would require a slight increase in thickness compared to current standards, but this should typically not be 
undesirable. Phenolic, polystyrene, and polyurethanes should all be available in some form. The phenolic foams have been preferred for some applications, due to the better non-flammability characteristics.

- A possible use of unevacuated aerogels if exposure to moisture is not an issue. Aerogel could possibly double the R-value for the same thickness, which makes this very attractive. A likely method would be to encase the aerogel in a foam board which would provide the structure to the aerogel and protect it from handling.

- Other likely options include the use of new building systems concepts such as foam core structural sandwich panels. In this case the supporting rafters or studs could be eliminated improving the R-value or allowing the same overall envelope R-value with lower R-insulations. Also the use of roof systems with ridge beams and oriented strand board ribs and facers allow thicker panels with conventional fiberglass insulation without the cost penalties of deep (i.e., $2 \times 10$ or $2 \times 12$ ) rafters.

Options which are probably not viable candidates are:

- The use of evacuated panels. The added complexity required in protecting these panels makes them less attractive. One concept is to enclose the evacuated panel in a foam board. The primary issue is puncturing the enclosure. These types of systems would most likely be used only where floor space or land is extremely valuable. Similar problems exist with high- $R$ gas panels. In this application the use of smaller panels may be preferred so that in the event of damage only a small area would be affected. The use of evacuated foams will be less likely here since the weight of the insulation should not be of prime importance.

- The use of CVI for residential insulation. Since it is very thin, it has an advantage where floor space is critical. The current designs of CVI would have to be modified so that large panels are used. The main drawback is that if a panel becomes damaged, a large portion of the wall will be affected.

\section{F-6 Foundation (Inside and Outside)}

\section{F-6.1 State-of-the-Art}

Currently extruded polystyrene is the primary insulation for foundations, with fiberglass boards and sprayed polyurethanes comprising the remaining types. Foundation insulation should be able to provide protection from radon and allow for sub drainage. Using exterior foundation insulation can also help protect the concrete from cracking due to thermal cycling. The preferred system is to use exterior boards on the foundations as opposed to interior, floor, or crawl space insulation [5]. A concern with the use of interior insulation is the promotion of damage to the foundation. Extruded polystyrene blowri with HCFC-142b is commercially available as the replacement for polystyrene boards foamed with CFC-12. 


\section{F-6.2 Substitute Options}

The possible substitute options are:

- Using fiberglass drainage boards [5]. Fiberglass drainage boards provide adequate moisture protection and insulation performance. Expanded polystyrene is also a possibility but the cost is expected to be higher. The characteristics of CFC-12 and HFC-134a are very similar and the polystyrene foam should be of similar quality, with the exception of lower resistivity.

- The use of high-R gas panels and evacuated systems. Use of these types of insulation for the exterior could be risky due to the potential degradation of the enclosure.

- CVI systems. The cost may be prohibitive and as an external insulation the benefit of a thin panel is not as significant. As an interior panel in a finished basement, CVI may be attractive. Care must be taken to protect the panels from damage and large panels must be used to reduce the edge losses.

Aerogels may not be suitable as exterior or interior insulation due to the exposure to moisture.

\section{F-7 Commercial Construction (Walls and Foundations)}

\section{F-7.1 State-of-the-Art}

Insulations currently used in commercial construction are CFC-11 blown polyurethane, expanded and extruded polystyrene, and fïberglass batts and boards. Reference [6] describes five construction methods for commercial construction. These are:

1. Systems similar to residential construction using wood and steel studs. Typically fiberglass bats are used or a rigid foam board sheath and stuceo are adhered to the exterior. The use of foam boards on the interior is typically not used due to the lost noor space.

2. Concrete-masonary walls which uses foam insulation on either the interior or exterior.

3. A brick and block cavity wall which uses rigid foam or expanded polystyrene in the cavity between the brick and blocks.

4. Metal-skin composite panels which have a polyurethane core.

5. Flat curtain panels, interior insulation. These typically use fiberglass bats or are sprayed in place foam due to the irregular shapes. 
The use of alternative blowing agents in foams is likely only a short-term solution, as is the use of fiberglass batts and boards. The reduced resistivity can be accounted for by having thicker panels. The floor space of buildings, especially commercial, is valuable and its preservation is very important. In this respect the less efficient insulations are not as desirable. If the insulation can be applied to the building exterior then the availability floor space is preserved.

\section{F-7.2 Substitute Options}

The potential substitute options are:

- Foams using alternative blowing agents. The foams should be used as exterior insulation in order to preserve the availability of floor space.

- The use of additional fiberglass is an option but the greater thickness required may be unacceptable, especially for existing buildings. For new buildings the designs could incorporate the required thickness.

- The use of unevacuated aerogels if exposure to moisture is not an issue. Aerogel could possibly double the R-value for the same thickness, which makes this very attractive. A likely method would be to encase the aerogel in a foam board which would provide the structure to the aerogel and protect it from handling.

- Evacuated panels may be considered likely for masonry buildings without cavities where the outside facade of the building is to be preserved. In this case especially for retrofit, evacuated panels on interior surfaces is a likely solution. The vacuum insulation would be used in small sizes and protected against penetrations.

Options which are less attractive, for the same reasons stated for residential applications, include:

- Evacuated panels.

- CVI.

\section{F-8 Low Slope Roofs}

\section{F-8.1 State-of-the-Art}

Low slope roofs are used in a wide variety of applications (commercial, industrial, and residential). The common insulation materials are sprayed and board polyurethane, polyisocyanurate, extruded and expanded polystyrene, and liberglass boards. The insulations which use CFCs constitute approximately 65\% of the total (1989) [6].

Use of fiberglass boards, expanded polystyrene, and alternative blowing agents are expected for the short-term. Using thicker insulation is not always possible; therefore insulations with the same resistivity are desired. The weight of roofs are typically not of concern but a review of the structural characteristics of low slope roofs is required. 


\section{F-8.2 Substitute Options}

The substitute options include:

- Foams or fiberglass boards. These will keep the weight down and will last for long periods. New roof designs, especially in the attachment of insulation boards, may be required to maintain the $R$-value of current roofs.

- Aerogels. They would have to be protected so that they do not get crushed under the weight of equipment. Also, protection from moisture is required.

- High-R gas panels and evacuated panels. These may be prohibited by the requirements on the enclosure and the added weight, (for evacuated panels). The insulation being on the roof will be exposed to hot temperatures in the summer and cold during the winter. A polymer which can maintain a vacuum over this range for extended periods of time may be unlikely. The use of glass encapsulation may be feasible for roofs since they can be protected and will not be moved or damaged. The concern for roof insulations is in the damage which may be caused when a piece of equipment (antenna, HVAC system, etc.) is attached. The CVI panels would have similar concerns for roof systems.

\section{F-9 Current R\&D Efforts}

Table F-1 provides a summary of research which is currently active in the area of advanced insulation. These only list more commonly known activities. The industry is very cautious about releasing information.

The work is primarily focused on developing foams which do not use CFCs but use HCFCs or water. This is typically viewed as the first step in the elimination of CFCs. The alternative blowing agents (non-CFC) and the corresponding foams are being characterized. This includes thermal, structural and life measurements, along with materials compatibility. The work on new foams is typically sponsored by the industry with some guidance by government agencies.

The University of Tennessee and Clemson University are developing new refrigerants which may also be applicable as blowing agents.

The work on the non-foam systems is primarily focused on developing a long life and inexpensive insulation. The performance for the various unaged evacuated and non-evacuated insulations are known. The main issues tend to be cost and life (especially for the evacuated systems). This work is typically sponsored by government agencies within the United States. Outside of the United States there are a variety of companies which have invested funds.

ORNL is conducting studies of the effects of alternative insulation systems on building energy requirements, as well as reviewing and testing of some of the advanced insulation systems (CVI and high-R gas panels). Arthur D. Little is conducting a review of the MBB insulation concept as applied to refrigerator/freezers. 
Table F-1: Recent and Current R\&D for Insulation Technologies

\begin{tabular}{|c|c|c|c|}
\hline Technology & R\&D Organization & Research Description & Potential Impact \\
\hline \multirow[t]{2}{*}{$\begin{array}{l}\text { Alternative Blowing } \\
\text { Agents }\end{array}$} & $\begin{array}{l}\text { Numerous Chemical and } \\
\text { Foam Manufacturers }\end{array}$ & $\begin{array}{l}\text { Investigation of altemative blowing } \\
\text { agents for the various foams. }\end{array}$ & $\begin{array}{l}\text { Reduction/elimination of the use of } \\
\text { CFCs. Improve foam systems to } \\
\text { maintain current resistivity levels. }\end{array}$ \\
\hline & $\begin{array}{l}\text { Clemson University and } \\
\text { University of Tennessee }\end{array}$ & $\begin{array}{l}\text { Development of new chemicals } \\
\text { (possible application as blowing } \\
\text { agents). }\end{array}$ & $\begin{array}{l}\text { Develop blowing agent which have } \\
\text { zero ODP and GWP and can be } \\
\text { used as a direct substitute in } \\
\text { current foam systems. }\end{array}$ \\
\hline \multirow[t]{6}{*}{$\begin{array}{l}\text { Non-Evacuated } \\
\text { Advanced } \\
\text { Insulations }\end{array}$} & $\begin{array}{l}\text { Lawrence Livermore } \\
\text { National Laboratory }\end{array}$ & $\begin{array}{l}\text { Improvement of High- } \mathrm{A} \text { gas } \\
\text { panels. }\end{array}$ & $\begin{array}{l}\text { Will be able to approach the } \\
\text { theoretical resistivities of the } \\
\text { high-R gas panels, typically using } \\
\text { argon and krypton. }\end{array}$ \\
\hline & MIT & $\begin{array}{l}\text { Improved foams, i.e., use of } \\
\text { opacifiers, characterization of the } \\
\text { aging of faced and unfaced foams }\end{array}$ & $\begin{array}{l}\text { More efficient use of foams and } \\
\text { ability to project foam useful life. }\end{array}$ \\
\hline & $\begin{array}{l}\text { Enhanced Insulation, } \\
\text { Inc, }\end{array}$ & Develop new high- $\mathrm{A}$ gas panels. & $\begin{array}{l}\text { Development of new high- } R \text { gas } \\
\text { systems (includes, enclosures, fill } \\
\text { gases, and baffling) could improve } \\
\text { the overall resistivity and life of } \\
\text { panels. }\end{array}$ \\
\hline & $\begin{array}{l}\text { Lawrence Berkeley } \\
\text { Laboratory }\end{array}$ & Development of organic aerogels. & $\begin{array}{l}\text { Organic aerogels are expected to } \\
\text { provide better thermal } \\
\text { characteristics (compared to silica } \\
\text { aerogels) at similar or higher } \\
\text { pressure levels. }\end{array}$ \\
\hline & Thermalıx & $\begin{array}{l}\text { Improvement of manufacturing } \\
\text { techniques for silica aerogels. }\end{array}$ & $\begin{array}{l}\text { More efficient and faster } \\
\text { processing times would make } \\
\text { aerogels more cost competitive. }\end{array}$ \\
\hline & Battelle & $\begin{array}{l}\text { Development of high resistivity } \\
\text { aerogels. }\end{array}$ & $\begin{array}{l}\text { Claims to have aerogels which } \\
\text { have resistivities up to } 15 \text { in a } \\
\text { non-evacuated environment. }\end{array}$ \\
\hline \multirow[t]{5}{*}{$\begin{array}{l}\text { Evacuated } \\
\text { Insulations }\end{array}$} & $\begin{array}{c}\text { DeGussa, } \\
\text { General Electric, } \\
\text { R. Barrito, MBB, and } \\
\text { Manville. }\end{array}$ & $\begin{array}{l}\text { Development of evacuated loose } \\
\text { fill and board filled panels. }\end{array}$ & $\begin{array}{l}\text { Researchers are improving } \\
\text { manufacturing techniques, } \\
\text { enclosure integration, and } \\
\text { optimizing fills. } \\
\end{array}$ \\
\hline & MIT & $\begin{array}{l}\text { Glass encapsulations for } \\
\text { evacuated panels }\end{array}$ & $\begin{array}{l}\text { Would reduce edge losses and } \\
\text { diffusion problems }\end{array}$ \\
\hline & $\begin{array}{l}\text { Lawrence Berkeley } \\
\text { Laboratory }\end{array}$ & Development of organic aerogels. & $\begin{array}{l}\text { Organic aerogels are expected to } \\
\text { provide better thermal } \\
\text { characteristics (compared to silica } \\
\text { aerogels) at similar or higher } \\
\text { pressure levels. }\end{array}$ \\
\hline & Thermalux & $\begin{array}{l}\text { Development of evacuated aerogel } \\
\text { panels. }\end{array}$ & $\begin{array}{l}\text { More efficient and faster } \\
\text { processing times would make } \\
\text { aerogels more cost competitive. }\end{array}$ \\
\hline & NERL & Development of CVI. & $\begin{array}{l}\text { Investigating the application areas } \\
\text { while improving manufacturing } \\
\text { techniques, and improving panel } \\
\text { configurations. }\end{array}$ \\
\hline
\end{tabular}

MIT is working on improved opacifiers for foams, means of characterizing the aging of faced and unfaced foams. MIT is also developing glass encapsulated evacuated particle/fiber filled panels. There is also an ongoing project sponsored by a consortium of industrial sponsors for innovative systems for building envelopes. These are manufactured systems using new materials, lightweight cementious foams in foam core panels, and new concepts, deep OSB rib and facer roof panels for increased $R$-values. 


\section{References}

[1] Aguilar, J. "State of the Art Survey of Advanced Insulation Materials for Refrigerator/Freezer Units and Edge Loss Analysis of Vacuum Insulation Systems," Draft report to U.S. EPA by Arthur D. Little, Inc., June 1991.

[2] Lawrence, W.T., and Ruccia, F.E., "Development of Advanced Insulation for Appliances: Task 1," ORNL/Sub-81/13800/1, Oak Ridge National Laboratory, Oak Ridge, TN, June 1981.

[3] Montreal Conference, Insulation Review Meeting, August 12-13, 1991.

[4] Kovatch, Dr. G., "Advanced Insulation for Refrigerated Shipping Containers," DOT Research No. 9()-MA1, RE/SPEC Inc., April 2, 1991.

[5] Christian, J., "Impact of CFC Restrictions on U.S. Building Foundation Thermal Performance," ORNL/CON-245, DE88 0()6143, Contract DE-AC05-840OR21400, December, 1987.

[6] Fischer, S.K., and Creswick, F.A., "Energy-Use Impact of Chlorolluorocarbon Alternatives," ORNL/CON-273, prepared for the U.S. Department of Energy under Contract No. DE-AC(05-84OR2140), February, 1989. 
Appendix $\mathbf{G}$

List of Attendees 


\section{List of Attendees at Montreal Workshop}

The attendees at the Montreal workshops are listed below by the working groups:

\section{Domestic Refrigeration}

\begin{tabular}{|l|l|}
\hline \multicolumn{1}{|c|}{ Name } & \multicolumn{1}{c|}{ Affiliation } \\
\hline \hline Jeff Anselmino & Whirlpool \\
\hline Jane Bare & U.S. E.P.A. \\
\hline Van Baxter & ORNL \\
\hline Michael Cauffeld & University of Hannover \\
\hline Denis Clodic & Econe des Mines de Paris \\
\hline Roy Crawford & University of Illinois \\
\hline Nolan Van Gaalen & Dordt College \\
\hline Ron Huffman & LDI Manufacturing \\
\hline Horst Kruse & University of Hannover \\
\hline Lambert Kuijpers & Philips Labs, NL \\
\hline Jean Lupinacci & U.S. E.P.A. \\
\hline Vince Mei & ORNL \\
\hline Richard Merriam & Arthur D. Little \\
\hline Matthew Mitchell & Mitchell Stirling \\
\hline Len Swatkowski & AHAM \\
\hline Peter Teagan & Arthur D. Little \\
\hline
\end{tabular}

\section{Chillers}

\begin{tabular}{|l|l|}
\hline Name & Affiliation \\
\hline Frank Biancardi & $\begin{array}{l}\text { United Technologies Research Center } \\
\text { (Carrier) }\end{array}$ \\
\hline Wendell Biermann & Consultant \\
\hline Larry Butz & Trane \\
\hline Robert Doerr & Trane \\
\hline Richard Erth & Consultant \\
\hline Glenn Hourahan & ARI \\
\hline Bill Kopko & U.S. E.P.A. \\
\hline Don Leibowitz & Trenton District Energy Co. \\
\hline Bill Pirtle & Arthur D. Little, Inc. \\
\hline Carl Sgamboti & $\begin{array}{l}\text { United Technologies Research Center } \\
\text { (Carrier) }\end{array}$ \\
\hline Sam Shelton & Georgia Tech. University \\
\hline Bill Wilkinson & Battelle Columbus Laboratories \\
\hline
\end{tabular}




\section{Commercial/Industrial Refriocration}

\begin{tabular}{|l|l|}
\hline Name & Affiliation \\
\hline \hline Nigel Carpenter & ICl America \\
\hline Ron Cole & R. A. Cole and Associates \\
\hline Thomas DeKleva & ICl America \\
\hline Johr. Dieckmann & Arthur D. Little \\
\hline Steve Fisher & ORNL \\
\hline Cynthia Gage & U.S. E.P.A. \\
\hline Shyamol Ghosh & Hill Refrigeration \\
\hline Joseph Humphrey & Tyler Refrigeration \\
\hline Jean Lupinacri & U.S. E.P.A. \\
\hline Art Perez & Consultant \\
\hline Paul Reed & duPont \\
\hline Terry Statt & D.O.E \\
\hline Sonny Sundaresan & Copeland \\
\hline
\end{tabular}

\section{Insulation}

\begin{tabular}{|l|l|}
\hline Name & Affiliation \\
\hline Jerry Aguilar & Arthur D. Little \\
\hline Bob Barito & R. W. Barito and Associates \\
\hline Margaret Barito & R. W. Barito and Associates \\
\hline Mary Barito & R. W. Barito and Associates \\
\hline Robert Hendricks & U.S. E.P.A. \\
\hline Kumar Kumaran & IRC/NRC Canada \\
\hline Marlo Martin & Thermalux \\
\hline David McElroy & ORNL \\
\hline Peter Teagan & Arthur D. Little \\
\hline Arthur Thomas & ICI Polyurethanes \\
\hline
\end{tabular}



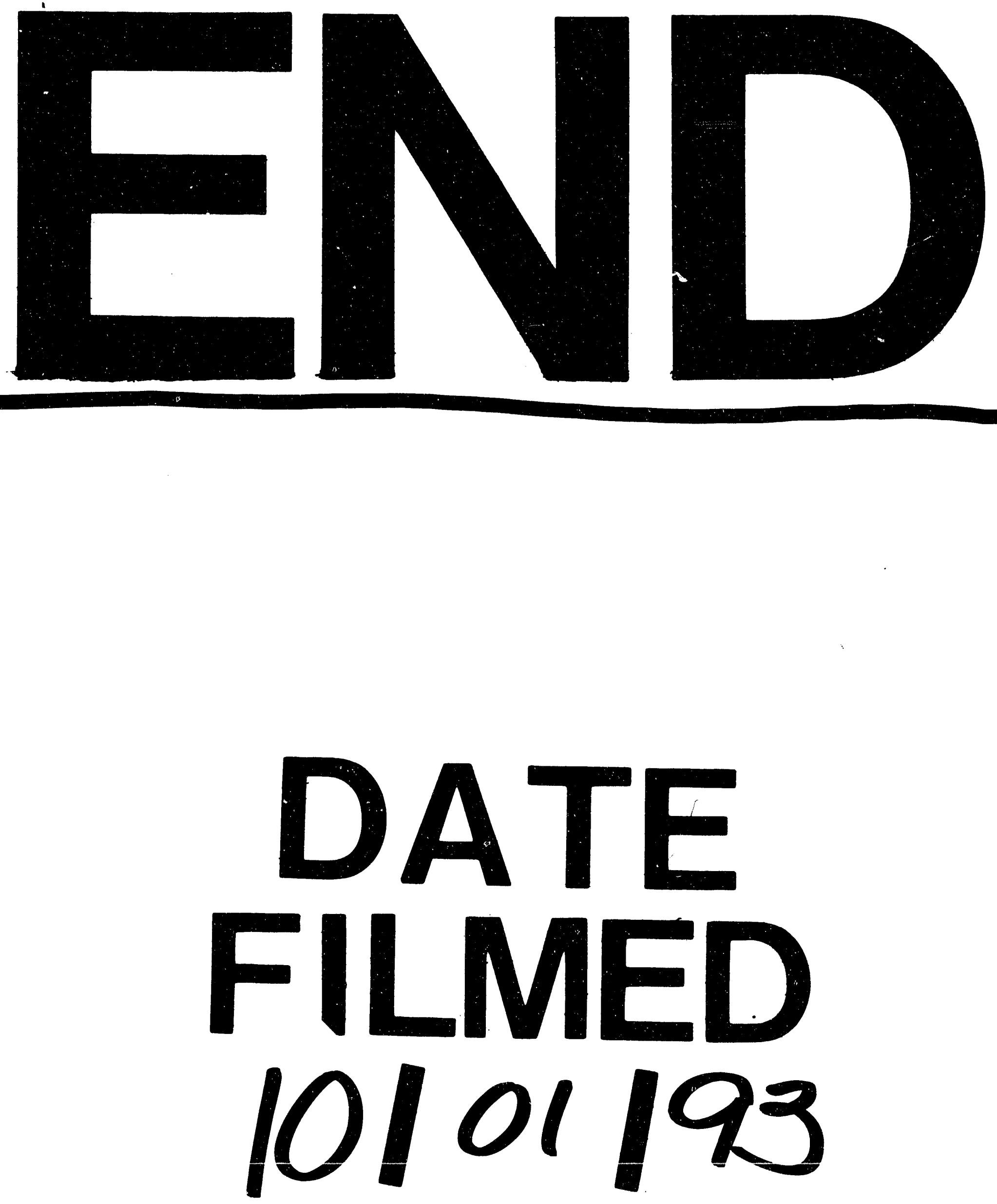
